\title{
Parent-Taught Driver Education in Texas: A Comparative Evaluation
}


This publication is distributed by the U.S. Department of Transportation, National Highway Traffic Safety Administration, in the interest of information exchange. The opinions, findings, and conclusions expressed in this publication are those of the authors and not necessarily those of the Department of Transportation or the National Highway Traffic Safety Administration. The United States Government assumes no liability for its content or use thereof. If trade or manufacturer's names or products are mentioned, it is because they are considered essential to the object of the publication and should not be construed as an endorsement. The United States Government does not endorse products or manufacturers. 
Technical Report Documentation Page

\begin{tabular}{|c|c|c|}
\hline 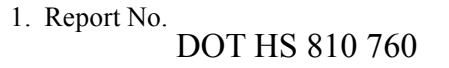 & 2. Government Accession No. & 3. Recipient's Catalog No. \\
\hline \multirow{2}{*}{\multicolumn{2}{|c|}{$\begin{array}{l}\text { 4. Title and Subtitle } \\
\text { Parent-Taught Driver Education in Texas: A Comparative Evaluation }\end{array}$}} & $\begin{array}{l}\text { 5. Report Date } \\
\text { April } 2007\end{array}$ \\
\hline & & 6. Performing Organization Code \\
\hline \multicolumn{2}{|c|}{$\begin{array}{l}\text { 7. Author(s) } \\
\text { V. J. Pezoldt, K. N. Womack, and D. E. Morris }\end{array}$} & 8. Performing Organization Report No. \\
\hline \multirow{2}{*}{\multicolumn{2}{|c|}{$\begin{array}{l}\text { 9. Performing Organization Name and Address } \\
\text { Texas Transportation Institute } \\
\text { The Texas A\&M University System } \\
\text { College Station, Texas } 77843-3135\end{array}$}} & 10. Work Unit No. (TRAIS) \\
\hline & & $\begin{array}{l}\text { 11. Contract or Grant No. } \\
\text { DTNH22-02-D-85121 }\end{array}$ \\
\hline \multirow{2}{*}{\multicolumn{2}{|c|}{$\begin{array}{l}\text { 12. Sponsoring Agency Name and Address } \\
\text { National Highway Traffic Safety Administration } \\
\text { U.S. Department of Transportation } \\
400 \text { Seventh Street SW. } \\
\text { Washington, DC } 20590\end{array}$}} & $\begin{array}{l}\text { 13. Type of Report and Period Covered } \\
\text { Final Research Report }\end{array}$ \\
\hline & & 14. Sponsoring Agency Code \\
\hline
\end{tabular}

16. Abstract

An evaluation of the Parent-Taught Driver Education (PTDE) program in Texas was conducted using three different research techniques: (1) focus groups with driver education instructors, teen drivers, and their parents; (2) a statewide mail survey of young drivers; and (3) an analysis of Texas driver records.

\section{Differences in Age at Licensing}

Prior to implementation of the Texas graduated driver licensing (GDL) program in 2002, the PTDE program does not appear to have encouraged earlier licensing, and may have delayed obtaining an instructional permit for a portion of the PT students. Since implementation of the GDL, PT students obtain their instruction permits earlier than commercial/ public school driver education students, suggesting that PT novice drivers are subject to the opportunity for increased exposure to the risks of driving.

\section{Differences in Attitudes, Knowledge, and Skills of Novice Drivers}

Driver education (DE) students and their parents generally agree that the PTDE program offers advantages over commercial and public school modes of DE delivery in terms of cost, comfort, and individualized personal attention to the student. Professional DE instructors believe the negative aspects of the PTDE program outweigh any perceived benefits, due largely to a lack of training, knowledge, and teaching skills on the part of parent-teachers. As measured by stateadministered tests, PT students demonstrate poorer driving knowledge early in the training and licensing process and poorer driving skills at the end of formal driver education. Although only a small proportion of DE students fail to pass either the test required to obtain an instructional permit or the optional in-vehicle road test on the first attempt, significantly more PT drivers require multiple attempts to pass either test.

\section{Differences in Driving Errors, Traffic Offenses and Crash Involvement}

Self-reports by young drivers reveal no, or at most very small, differences related to type of DE with regard to driving knowledge and skills, driver errors, traffic convictions, and crashes among drivers subject to the GDL program. Driver records, however, both before and after implementation of the GDL, indicate PT novice drivers committed more traffic offenses and were in more crashes than were commercial or public school-trained drivers. Since implementation of the GDL, traffic convictions and crashes are substantially fewer for all novice drivers. Differences that exist are smaller and favor PT drivers during the period of most supervision (i.e., instructional permit phase of licensing). However, during the period when requirements for adult supervision are reduced (provisional license), and after supervisory and other GDL restrictions are removed (full licensure), PT drivers again experience proportionally more total traffic convictions and more, and more serious, crashes than drivers trained under commercial/public school DE programs.

17. Key Words

Novice drivers, driver education, parent-taught driver education, evaluation
18. Distribution Statement

No restrictions. This document is available to the public through NTIS:

National Technical Information Service

5285 Port Royal Road

Springfield, Virginia 22161

\begin{tabular}{l|l}
$\begin{array}{l}\text { 19. Security Classif.(of this report) } \\
\text { Unclassified }\end{array}$ & $\begin{array}{l}\text { 20. Security Classif.(of this page) } \\
\text { Unclassified }\end{array}$ \\
\hline
\end{tabular}

Form DOT F 1700.7 (8-72)
Reproduction of completed page authorized 


\section{Acknowledgements}

The authors gratefully acknowledge the people and organizations who provided important contributions to the project, either as members of the project staff or as interested professionals who freely gave of their expertise in young driver education, safety, and licensing.

The authors wish to acknowledge the contributions of:

- The Texas Education Agency (TEA), including Mike Peebles, Jim Crenshaw, and Victor Alegria of the Driver Training Division and, especially Lauralea Bauer, of TEA's In-School Driver Education and Traffic Safety Unit for providing essential background information about driver education in Texas and the role of TEA.

- The Texas Department of Public Safety Driver License Division, for providing more than two million Texas driver records. Thanks to Chief Judy Brown, Driver License Division; Debbie Cartwright, manager, License Issuance Bureau; and Marylisa Garcia-Lopez of the License Issuance Bureau.

- Texas Driver and Traffic Safety Education Association for allowing us to solicit their membership for participation in the driver educators focus groups and providing a venue for those groups.

- Dr Maurice Dennis, coordinator and professor, Safety Education Program, Department of Health and Kinesiology, Texas A\&M University, and David Willis, senior research scientist in the Texas Transportation Institute's (TTI) Center for Transportation Safety, both of whose many years of experience in driver education and driver and traffic safety provided invaluable advice and assistance to the principal investigator throughout the project.

- Larry Lonero, principal of Northport Associates, Ontario, Canada, for providing pre-publication information regarding his work on the evaluation of novice driver education in Canada that was especially useful in development of the young driver survey.

- Sandra Schoeneman and Carol Mendez Coker of TTI's Center for Transportation Safety for making most of the arrangements for the focus groups, supervising the audio taping, and transcribing those tapes.

- Thanks also to NHTSA's technical manager for the project, Dr. Patricia Ellison-Potter, for her careful reading of the manuscript and her many cogent editorial and organizational suggestions. Her support throughout the project and her patience and assistance in helping us weather initial contractual storms and the senior author's procrastination are much appreciated.

- The Highway Safety Research Center of the University of North Carolina through whose "Behavioral Research for Traffic Safety" contract with NHTSA this project was funded as a Task Order.

- Finally, and most of all, thanks to the novice drivers, parents, and driver education instructors who provided us with their knowledge, insights and opinions .

Val Pezoldt 


\section{TABLE OF CONTENTS}

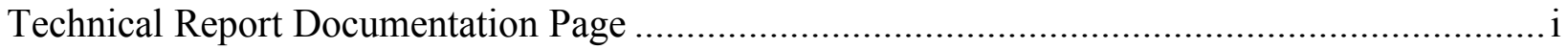

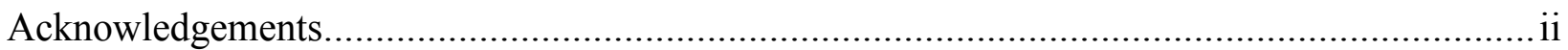

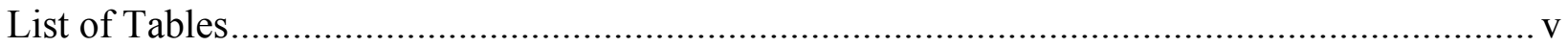

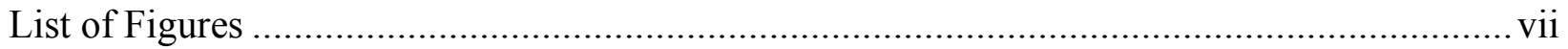

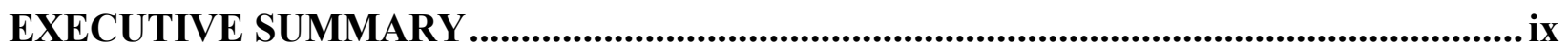

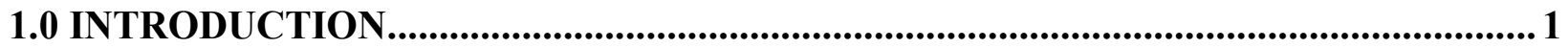

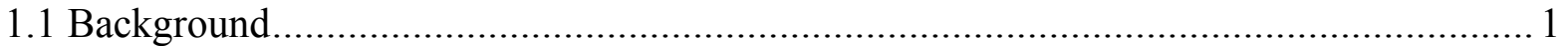

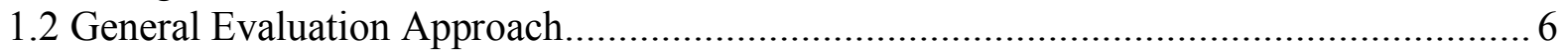

2.0 OVERVIEW OF TEXAS NOVICE DRIVER LICENSING AND DRIVER

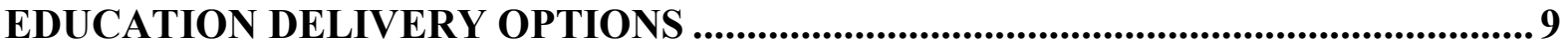

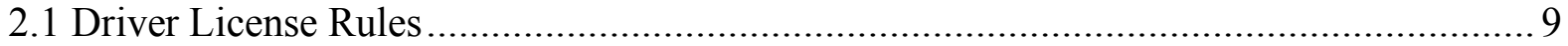

2.2 Driver Education Program, Course and Instructor Requirements ............................. 10

2.2.1 Commercial and Public School Driver Education..................................... 10

2.2.2 Rules for Participation in the Parent-Taught Program.................................. 13

3.0 DETAILED EVALUATION APPROACH AND RESULTS........................................ 17

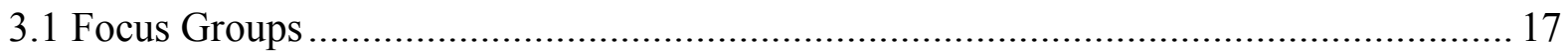

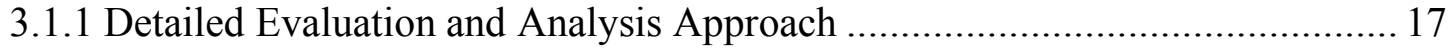

3.1.2 Findings from the Focus Groups ......................................................... 20

Public and Commercial School Driver Education Instructors ..................... 20

Parents of Driver Education Students..................................................... 32

Current and Recent Driver Education Students ..................................... 39

Summary of Focus Group Findings................................................. 54

3.2 Survey of Young Drivers................................................................................... 56

3.2.1 Detailed Evaluation and Analysis Approach .......................................... 56

Survey Development.............................................................. 56

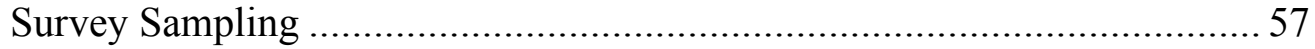

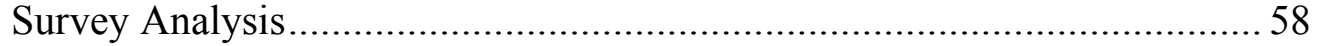

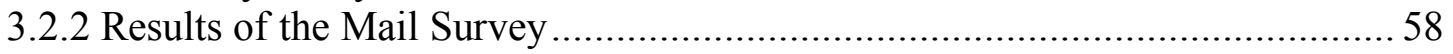

Survey Response Rates ................................................................. 58

Survey Responses and Discussion................................................ 59

Summary of Survey Results............................................................ 83

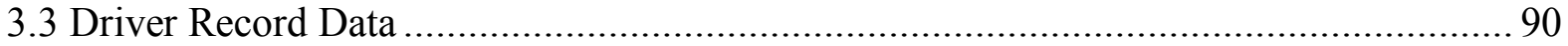

3.3.1 Detailed Evaluation and Analysis Approach ........................................ 90

Source Data for Analysis ............................................................... 90

3.3.2 Results of the Driver Record Analysis ................................................. 100 
Age, Crash and Traffic Conviction Data ........................................... 100

Age at Origination of Driver Records........................................... 100

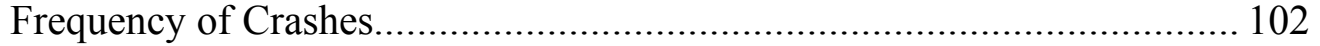

Relative Likelihood of Crashes ....................................................... 103

Graphical Presentation of Crash Analysis Results ................................ 108

Summary of Driver Record Crash Analysis........................................... 115

Frequency and Relative Likelihood of Traffic Offense Convictions .......... 118

Graphical Presentation of Conviction Analysis Results .......................... 118

Summary of Driver Record Conviction Analysis .............................. 138

4.0 CONCLUSIONS AND RECOMMENDATIONS FROM THE EVALUATION......... 141

4.1 Conclusions from the Analyses ..................................................................... 141

4.1.1 Differences in Age at Licensing .............................................................. 141

4.1.2 Differences in Attitudes, Knowledge, and Skills of Novice Drivers.............. 143

4.1.3 Differences in Driving Errors, Traffic Offenses, and Crash Involvement....... 145

4.2 Recommendations for Texas Driver Education.................................................. 149

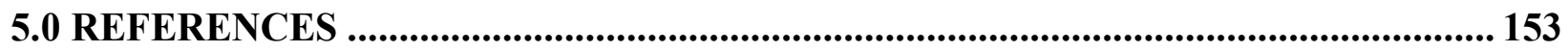

6.0 APPENDICES ................................................................................... Appendices 1

Appendix A: Guidance Provided by the Texas Department of Public Safety to

Participants in the Parent-Taught Driver Education Program...... Appendices 3

Appendix B: Texas Education Agency Guidance for Model Course 101 .......... Appendices 11

Appendix C: Focus Group Discussion Guides ........................................ Appendices 17

Appendix D: Mail Survey Forms .......................................................... Appendices 27 


\section{List of Tables}

$\underline{\text { Page }}$

Table 1. Number and percent of driver education certificates issued by school year................ 4

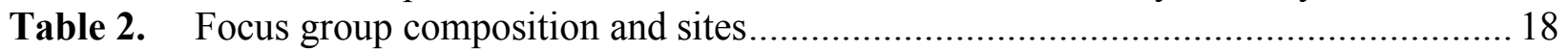

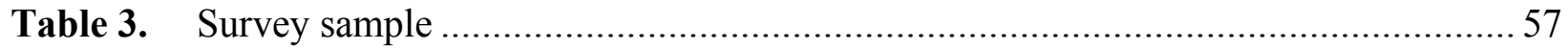

Table 4. Percent of sample as drawn compared with percent of sampling frame, by age and

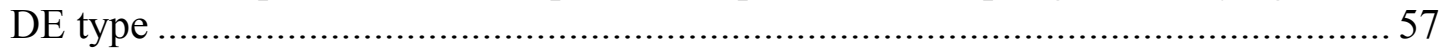

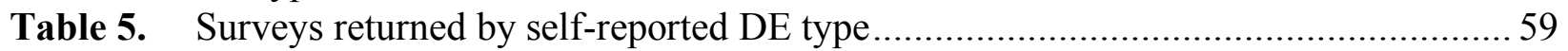

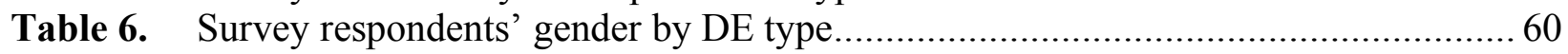

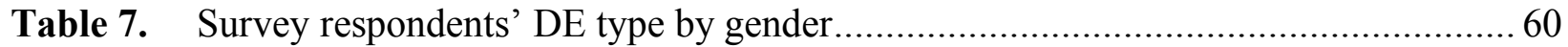

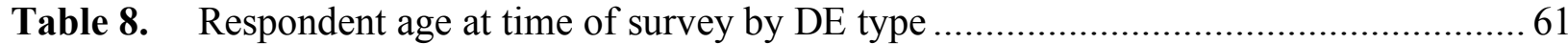

Table 9. Highest educational attainment of parents by DE type of respondents - Number..... 61

Table 10. Highest educational attainment of parents by DE type of respondents - Percent...... 62

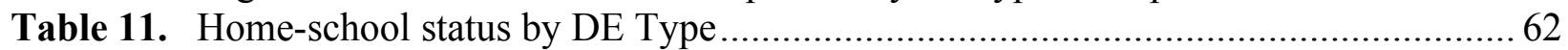

Table 12. DE type of home-schooled and non-home-schooled respondents ............................62 62

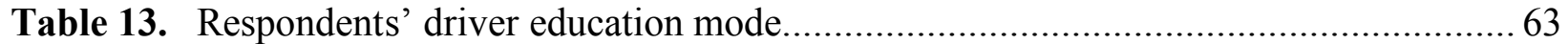

Table 14. Reasons for choosing DE course taken by DE type - Number.................................63

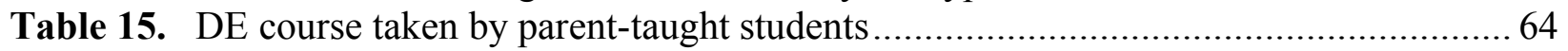

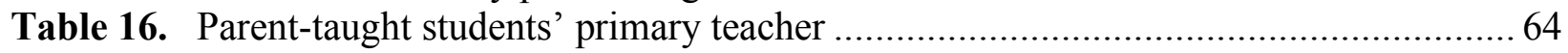

Table 17. Performance on "traffic law and signs test" by DE type ……….............................65

Table 18. Respondents opting to take DPS in-vehicle driving test by DE type ........................66

Table 19. Performance on DPS in-vehicle driving test by DE type ........................................6 66

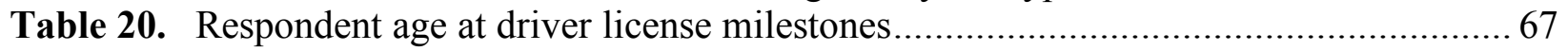

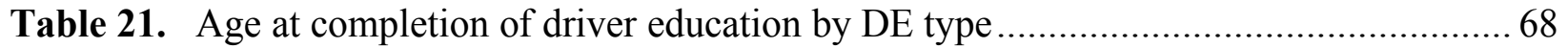

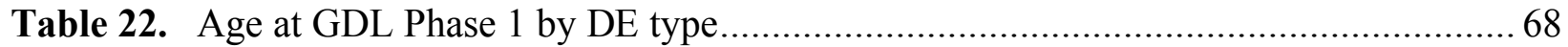

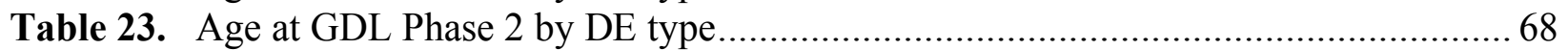

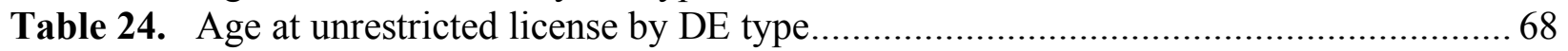

Table 25. Extent of agreement with course evaluation statements ......................................... 70

Table 26. Self-reported frequency of driving in selected environments during past year ......... 74

Table 27. Self-reported rating of overall driving skill and safety .......................................... 74

Table 28. Self-reported comparison of driving knowledge, skills and attitudes with others .... 75

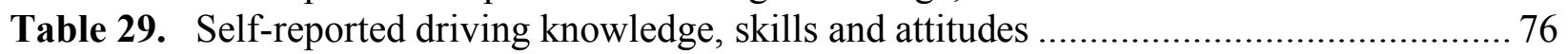

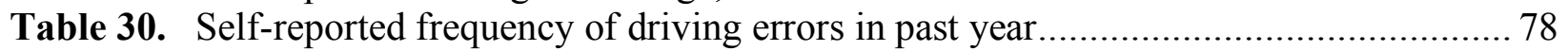

Table 31. Self-reported traffic violations by DE type ……............................................... 79

Table 32. Number of drivers stopped for speeding by DE type ........................................... 79

Table 33. Self-reported crash involvement while driving by DE type .................................... 80

Table 34. Self-reported crash involvement while driving by DE type - categories

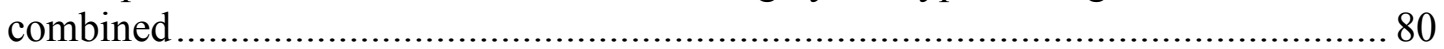

Table 35. Licensure status at time of first self-reported crash by DE type ................................ 81

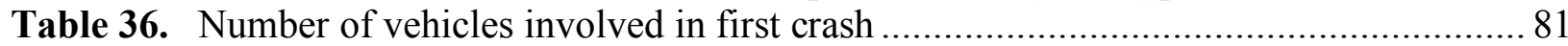

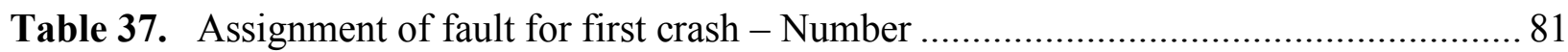

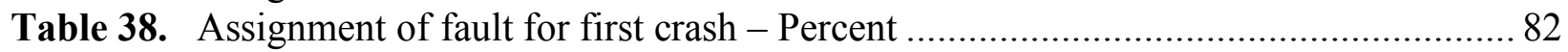

Table 39. Assignment of fault for most recent crash - Combined fault categories.................... 82

Table 40. Severity of first self-reported crash by DE type - Number ....................................8 83

Table 41. Severity of first self-reported crash by DE type - Percent ..................................... 83 


\section{List of Tables (cont'd)}

$\underline{\text { Page }}$

Table 42. Driver record history file fields (variables) ............................................................ 93

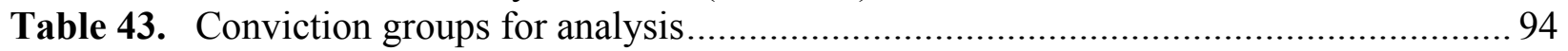

Table 44. Offenses included in conviction groups for analysis.............................................. 94

Table 45. Crashes per 10,000 drivers not subject to GDL, by driver education mode............. 103

Table 46. Crashes per 10,000 drivers subject to GDL, by driver education mode................... 103

Table 47. Likelihood of crashes involving parent-taught relative to commercial/public

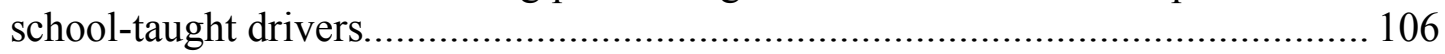

Table 48. Incidence of motor vehicle crashes as a function of DE type - Summary .............. 116

Table 49. Convictions per 10,000 drivers not subject to GDL, by driver education mode...... 119

Table 50. Convictions per 10,000 drivers subject to GDL, by driver education mode ............ 120

Table 51. Likelihood of convictions of parent-taught relative to commercial/public-school-

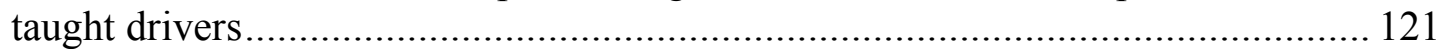

Table 52. Incidence of traffic offense convictions as a function of DE type - Summary ....... 139 


\section{List of Figures}

$\underline{\text { Page }}$

Figure 1. Section added to Texas Transportation Code by Senate Bill $964,74^{\text {th }}$ Texas Legislature to provide parent-taught driver education...................................... 3

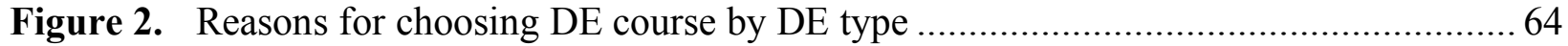

Figure 3. Self-reported performance on instructional permit and DPS road tests ................. 65

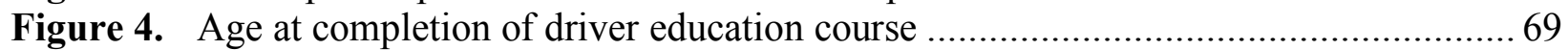

Figure 5. Age at obtaining GDL Phase 1 instructional permit..........................................6 69

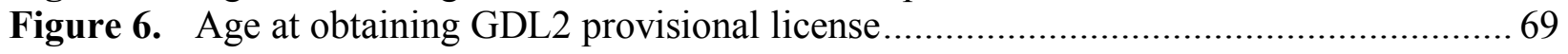

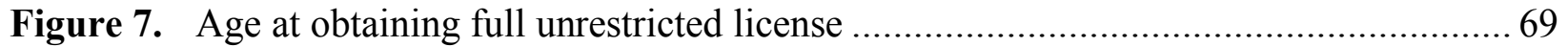

Figure 8. Pre-GDL distribution of driver ages at driver record origination ....................... 101

Figure 9. Post-GDL distribution of driver ages at driver record origination....................... 101

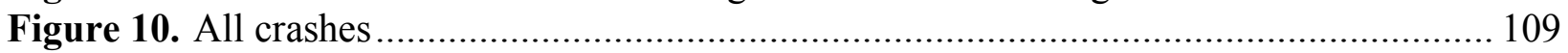

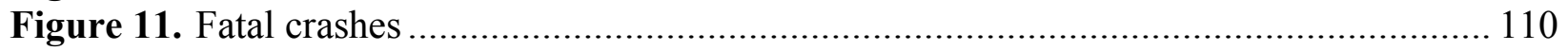

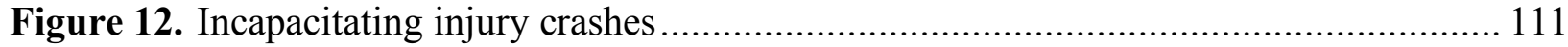

Figure 13. Non-incapacitating injury crashes .......................................................... 112

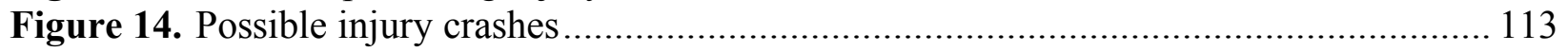

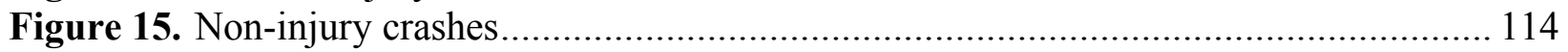

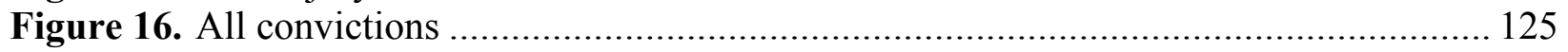

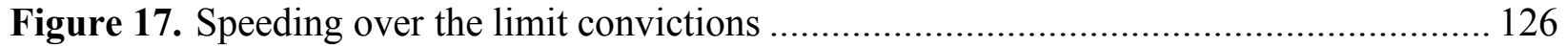

Figure 18. Racing/excessive acceleration convictions................................................. 127

Figure 19. Other speed-related convictions .............................................................. 128

Figure 20. Red light/stop sign convictions ........................................................ 129

Figure 21. Disregard/fail to obey traffic signs, signals or markings (other than red lights

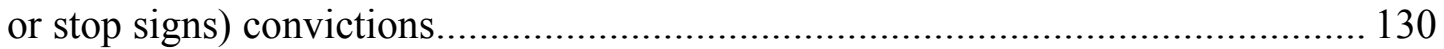

Figure 22. Failure to yield right-of-way convictions ................................................ 131

Figure 23. Improper signal or failure-to-signal convictions ....................................... 132

Figure 24. Other moving violation convictions (excludes moving violations illustrated in

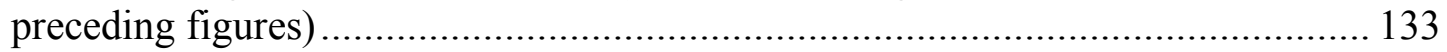

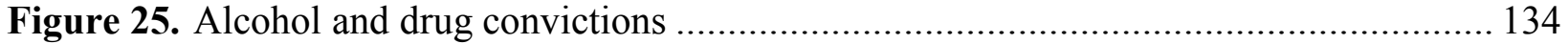

Figure 26. Negligent or "antisocial" violation convictions .......................................... 135

Figure 27. Driver license violations/driving without a license convictions ......................... 136

Figure 28. Driving safety course/program mandated in lieu of other conviction placed on driving record 
This page intentionally left blank. 


\section{EXECUTIVE SUMMARY}

\section{Background}

The important role and responsibility of parents in the education and training of young novice drivers has long been recognized. With the rise of graduated driver license programs and the decline of public school-based driver education in recent years, parents' roles have become even more essential. This report documents an assessment of one approach to involving parents directly in the education and training of new teenaged drivers, with particular emphasis on how it compares on outcome measures with traditional models of driver education.

Since 1967, teenagers in Texas have been permitted to obtain a driver's license at age 16 (or even younger if they could demonstrate a "hardship" need) only if they successfully complete an approved public school or commercial driver's school education course. Prior to 1997 this training requirement could be met solely if it was provided by schools and instructors certified by the Texas Education Agency (TEA).

In April 1997 the Texas Department of Public Safety (DPS) implemented rules, based on legislation passed in 1995, that provided for parent or guardian-taught novice driver training that meets all of the driver training requirements necessary for licensing between age 16 and 18 . As currently constituted, the parent-taught driver education program in Texas essentially grants to parents the same role, rights, privileges, and responsibilities as were formerly granted only to State-licensed and approved novice driver instructors and driver education programs.

\section{Goal and Approach}

The primary goal of the present evaluation is determination of the impact, if any, of the Texas Parent-Taught Driver Education (PTDE) program on the education and training of young novice drivers and on the safety of novice drivers on Texas streets and highways. Information and data pertinent to these issues has been developed through focus groups conducted with driver education (DE) instructors, students and parents of DE students; a statewide mail survey of young drivers; and analysis of Texas driver records. Analysis of the information generated by this approach attempts to answer two basic questions about the parent-taught program relative to commercial driving school and public school based DE:

- Are there discernible differences in the attitudes, knowledge, and skills of novice drivers exposed to the three core driving instruction options available in Texas?

- Do parent-taught teenage drivers in Texas differ from those who complete either schoolbased or commercial driving school training as measured by post-licensing crash involvement and traffic offense convictions?

Although various DE stakeholder groups (e.g., educators, researchers, parents of novice drivers and young drivers themselves) often disagree about what the overriding objective of novice driver education is or should be, debate continues about the appropriate measures for assessing DE's success. The two most frequently cited goals for DE are: 
- To impart knowledge of the rules of the road, the basic skills involved in vehicle operation, and instill and reinforce attitudes consistent with safe driving.

- To produce safe drivers, e.g., drivers with measurably lower crash rates.

This evaluation is comparative in nature and does not purport to asses the absolute extent to which the three modes of DE delivery in Texas meet either of the two goals above. Nor does it attempt to evaluate specific DE courses, course providers or instructors/teachers. Rather, the evaluation was conducted at a more global, macro level to determine if the parent-taught program, as a State policy, has contributed in any negative way to the training and licensing of young, novice drivers in Texas. In short, this study investigated whether the PTDE program performs less well than either of the two more traditional DE delivery options.

\section{Results}

Based on the analysis of information derived from nine focus groups, the responses of approximately 500 young drivers to a statewide survey, and analysis of more than 1.4 million Texas driver records, there is evidence to suggest that the parent-taught driver education program has a negative influence on the overall safety of novice drivers in Texas, especially in terms of young driver crash involvement.

Undoubtedly, many parents who serve as their teens' sole driving instructor under the program are highly motivated to do well and succeed in producing novice drivers who are at least as prepared to drive as many teens who take a traditional driver education course and who have a novice driving record at least the equal of graduates of commercial or public school DE courses. Many other parents are highly motivated to be their child's primary driving instructor, have the best interests of their children at heart, but simply are not equipped with the requisite aptitudes, attitudes, and experience to do so successfully. Still other parents who opt to participate in the program are neither appropriately equipped nor motivated.

\section{Specific Conclusions}

Differences between the parent-taught program and Texas Education Agency-approved public and commercial driving school courses led to eleven conclusions in three general areas: (1) differences in age at licensing, (2) differences in attitudes, knowledge and skills of novice drivers, and (3) differences in driving errors, traffic offenses and crash involvement.

\section{Differences in age at licensing}

- Taken as a whole, the data suggests that prior to the Texas GDL program, the parenttaught program does not appear to have encouraged earlier licensing and, indeed, may have delayed obtaining an instructional permit for a portion of parent-taught (PT) students.

- Since the implementation of the GDL, PT students are obtaining at least their first licenses (instructional permits) somewhat younger than commercial/public school DE students do, suggesting that parent-taught novice drivers are subject to the opportunity for increased exposure to the risks of driving, albeit during the period of most supervision. As indicated in the figure below, this is evidenced by the significantly younger average age at which PT novice drivers establish a driver record and the larger proportion of PT novice drivers establishing a driver record as 15.5-15.9 year-olds relative to commercial and public school trained drivers. 
Establishment of a driver record typically coincides with the issuance of an instructional permit. Confirmation of greater exposure would require data not available to the present evaluation, that is, differences in actual miles driven as a function of DE type.

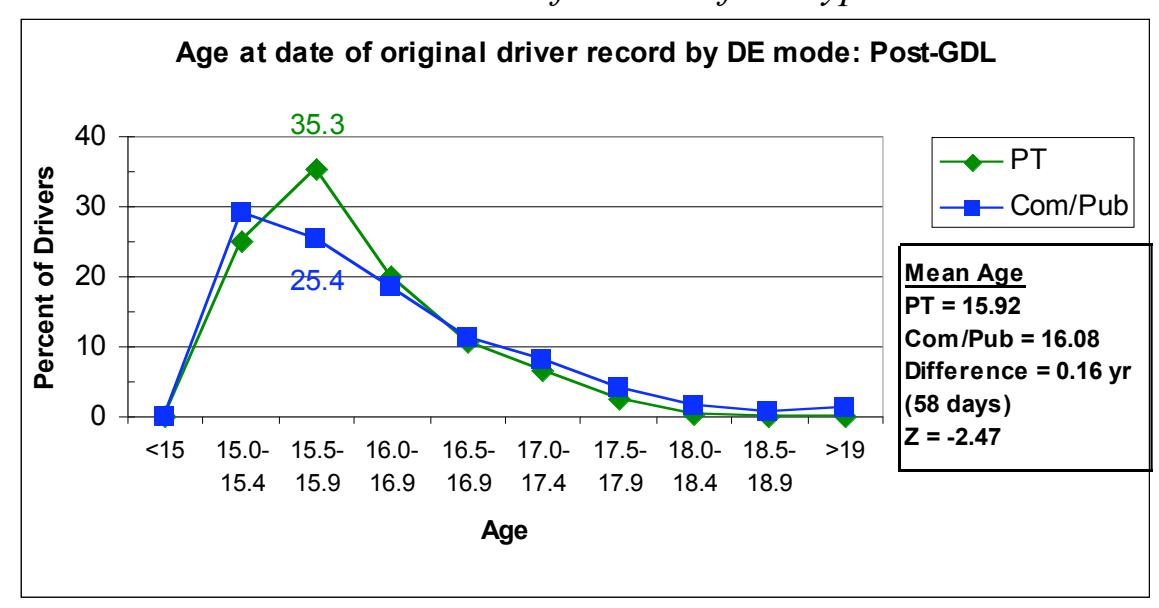

\section{Differences in attitudes, knowledge and skills of novice drivers}

- Driver education students and their parents agree that the parent-taught DE program offers advantages over commercial and public school modes of DE delivery in terms of cost, comfort and individualized personal attention to the student. Professional DE instructors believe the negative aspects of the parent-taught program outweigh any perceived benefits, due largely to a lack of training, knowledge and teaching skills on the part of parent-teachers.

- $\quad$ Very few differences in driving knowledge and skills among the three DE course delivery modes are discernible from self-reports of specific driving-related knowledge and skills.

- $\quad$ As measured by State-administered tests (see figure below), however, parent-taught students demonstrate poorer driving knowledge early in the training and licensing process and poorer driving skills at the end of formal driver education. Although only a small proportion of DE students fail to pass either the test required to obtain an instructional

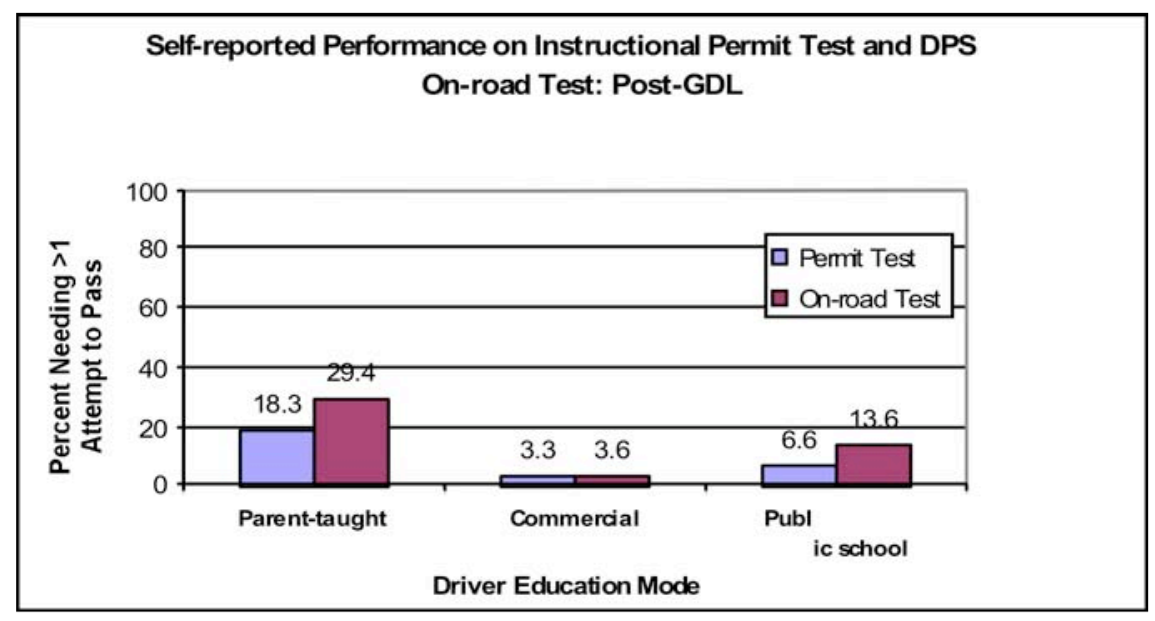


permit or the optional in-vehicle road test on the first attempt, significantly more PT drivers require multiple attempts to pass.

\section{Differences in driving errors, traffic offenses and crash involvement}

- Based on self-reports, the incidence of driving errors among young drivers subject to the $G D L$ does not differ as a function of type of $D E$.

- Based on driver records, PT novice drivers were convicted of more traffic offenses than commercial or public school-trained drivers before implementation of the GDL program, especially in the first year of driving.

- $\quad$ Since implementation of the GDL, convictions for traffic offenses are substantially fewer for all novice drivers. Differences that do exist are generally smaller and favor PT drivers during the period of most supervision, i.e., the instructional permit phase of licensing. During the period when, for most young drivers, requirements for adult supervision are reduced (provisional license) and after supervisory and other GDL restrictions are removed (full licensure), PT drivers again experience proportionally more total traffic convictions than drivers trained under commercial/public school DE programs. The figures below show all convictions and speeding convictions per ten thousand drivers by DE type.
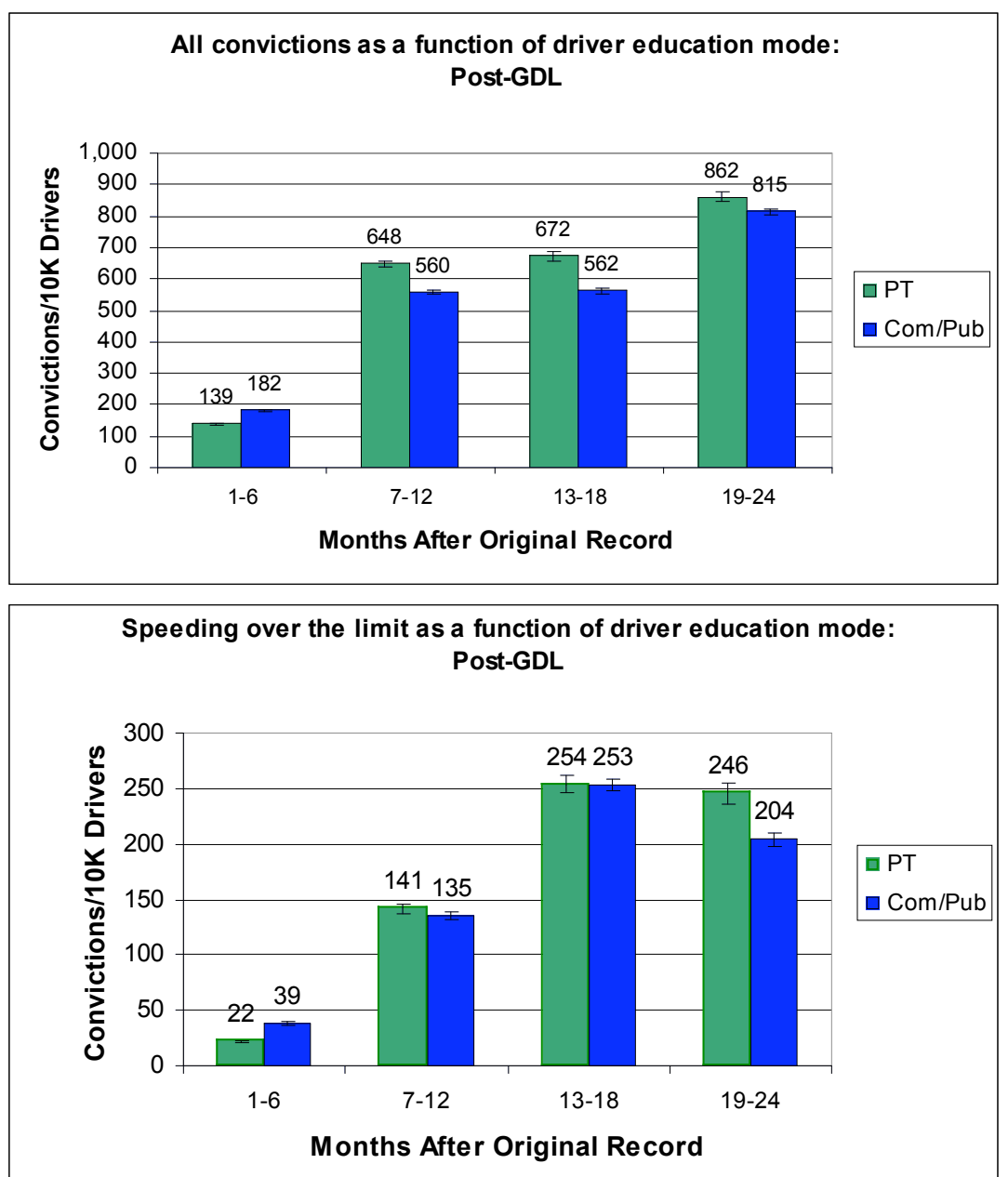
- Based on self-reports of novice drivers subject to the GDL, the incidence of crashes involving parent-taught drivers is not greater than that reported by commercial or publicschool-trained novice drivers.

- $\quad$ Based on crashes reported in Texas driver records, before implementation of the Texas GDL proportionally more and more serious crashes were experienced by parent-taught novice drivers over the first 18 months of driving experience. Through the next 18 months of driving most differences disappeared. However, possible injury crashes occurred with greater frequency among commercial or public-school-trained drivers and fatal crashes occurred significantly more often among PT drivers in the first half of the third year of driving experience.

- $\quad$ Since implementation of the GDL, crashes are substantially fewer for all novice drivers. Differences that do exist generally are small and favor PT drivers during the period of most supervision, the instructional permit phase of licensing. During the period when requirements for adult supervision are reduced (provisional license) and after supervisory and other GDL restrictions are removed (full licensure), PT drivers experience proportionally more crashes and more serious crashes than drivers trained under commercial/public school DE programs. All crashes and fatal crashes per10,000 drivers by DE type are illustrated below.
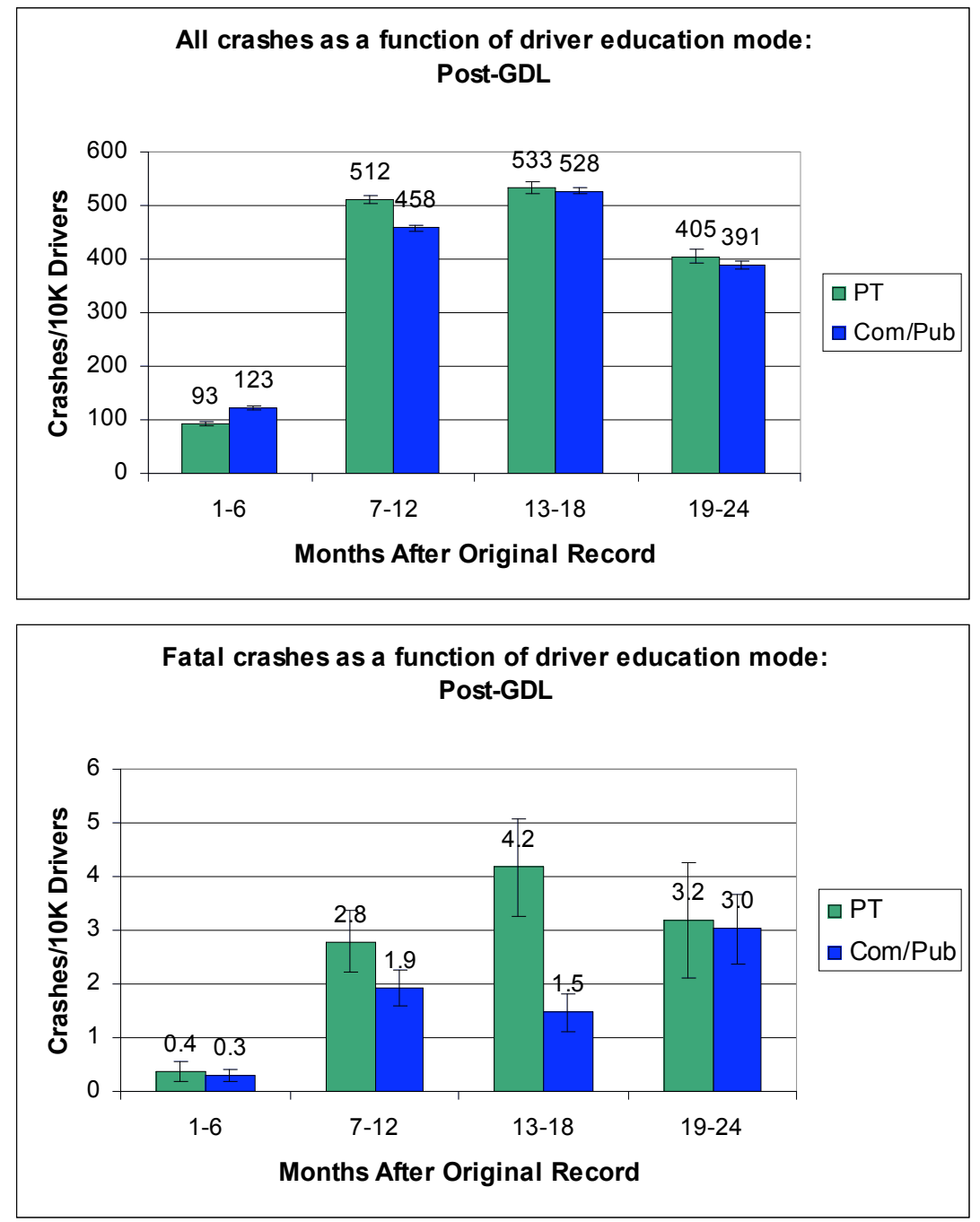


\section{Recommendations for Texas Driver Education}

Four recommendations are offered that may at least incrementally improve the parent-taught program if Texas continues the program in its current form.

- Improve the criteria for parental participation in the parent-taught driver education program.

A more demanding parental driver record may be appropriate with regard to traffic convictions and crash involvement in order to qualify for the parent-teacher position. As a minimum, consideration should be given to disqualifying parents from participating in the PT program if sufficient points have been assessed and recorded on their driving record under the Texas Driver Responsibility Program to subject them to driver license surcharges.

- $\quad$ Require at least some minimum training and/or testing for parents who want to teach their children to drive under the program.

The addition of a qualifying examination and/or a short training program developed specifically for the parent-taught program could help assure at least a minimum degree of mastery of the necessary subject matter for teaching teens to drive. Even a requirement for the parent-teacher to pass the current instructional permit test and successfully complete an approved defensive driving course could motivate parents to upgrade their knowledge of current laws, increase their awareness of traffic issues and raise their level of consciousness with regard to driving safety.

- Improve DPS monitoring of and accountability for the activities of the PT program. Currently, parents are required to complete a Parental Driver Education Affidavit (DL-90A) and may be required to present a Classroom Instruction Record (DL-91A) and a Behind the Wheel Record Log (DL-91B). While it is not obvious precisely how improvements might be implemented, it is apparent that the current procedures for assuring parents are in fact meeting their responsibilities under the parent-taught program are not sufficient.

- $\quad$ Reinstitute a requirement for an on-road driving assessment before granting a provisional and/or unrestricted license to novices under 18.

Over the past several Texas legislative sessions, various bills have been introduced that would reinstitute the requirement for a road test for drivers licensed before they are 18 years old. Some would have required a road test only for young license applicants who completed a PTDE course, while others required all applicants to pass a road test without regard to the type of driver education completed. To date, all such bills have failed. While requiring all applicants to pass a road test has the obvious advantage of appearing to be more equitable, there is a rational counterargument to the proposition that requiring only parent-taught students to take a road test would be discriminatory. The original purpose of a road test as a prerequisite to licensure was to provide "a demonstration of the applicant's ability to exercise ordinary and reasonable control in the operation of a motor vehicle of the type that the applicant will be licensed to operate." Driving instructors certified or licensed by the State by virtue of their education, training, and experience clearly can be characterized as acting as agents of the State when they certify that their students have demonstrated the ability to exercise ordinary and reasonable control in the operation of a motor vehicle. It is

\footnotetext{
${ }^{1}$ Chapter 521, Section 161 of the Texas Transportation Code
} 
reasonable to posit that among the knowledge and skills obtained through training is the ability to determine an applicant's ability to control a motor vehicle to a degree acceptable for licensing. Delegating this responsibility to parents without any training or other demonstration that they are capable of making that determination is neither reasonable nor prudent.

Neither the conclusions indicating a negative impact of the parent-taught program on young driver crash involvement nor the recommendations above diminish the desirability, indeed critical importance, of extensive and intensive parental involvement in the learning process for young novice drivers, especially in providing structured, supervised driving practice. The conclusions and recommendations here are directed specifically to the condition under which parents often become the only source of novice driver education and training. 
This page intentionally left blank. 


\section{Parent-Taught Driver Education in Texas: A Comparative Evaluation}

Primum non nocere

\subsection{INTRODUCTION}

\subsection{Background}

In a 1994 report to Congress, the National Highway Traffic Safety Administration noted the importance of parental involvement in driver education:

Parents, guardians, or other adults must play a greater role in the education and licensing of novice drivers. There will never be enough time or money to fully train a novice driver through public institutions. There will always be the need for additional supervised oversight during initial training. Research has shown that parents and other guardians have great potential to influence youngsters. At a minimum, adults through their own driving behaviors provide models (positive and negative) to novice drivers. Research also has documented that there are multiple problems in using parents and guardians to enhance the training and learning of young drivers. For example, there are households where available adults work and report that they do not have the time nor inclination to provide guided supervised driver training. However, because the potential positive benefits far outweigh the negative, educators are attempting to include parents and guardians in all aspects of educating young students. (Smith, 1994)

This report documents an assessment of one approach to involving parents directly in the education and training of young novice drivers, with particular emphasis on how it compares on outcome measures with more traditional models of driver education.

Throughout much of the United States obtaining a license to drive has long been an important rite of passage for teenagers. Regardless of what, if any, formal driver education or training novice drivers receive, parents typically play an important role in young drivers' preparation for driving. Since 1967, teenagers in Texas have been permitted to obtain a driver's license at 16 (or even younger if they could demonstrate a "hardship" need) only if they successfully complete an approved public school or commercial driver's school education course. Prior to 1997 this training requirement could be met solely if it was provided by schools and instructors certified by the Texas Education Agency (TEA). The requirements for licensing minors were specified in Chapter 521, Section 204 of the Texas Transportation Code, as follows:

\section{TEXAS TRANSPORTATION CODE CHAPTER 521. DRIVER'S LICENSES AND CERTIFICATES}

\subsection{Restrictions on Minor}

The department may issue a Class $\mathrm{C}$ driver's license to an applicant under 18 years of age only if the applicant:

(1) is 16 years of age or older; 
(2) has submitted to the department a driver education certificate issued under Section 9A, Texas Driver and Traffic Safety Education Act (Article 4413(29c), Vernon's Texas Civil Statutes), that states that the person has completed and passed a driver education course approved by the Central Education Agency. ${ }^{2,3}$

(3) has obtained a high school diploma or its equivalent or is a student:

(A) enrolled in a public school, home school, or private school who attended school for at least 80 days in the fall or spring semester preceding the date of the driver's license application; or

(B) who has been enrolled for at least 45 days, and is enrolled as of the date of the application, in a program to prepare persons to pass the high school equivalency exam; and

(4) has passed the examination required by Section 521.161 .

In April 1997 the Texas Department of Public Safety (DPS) implemented rules, based on legislation passed in 1995, that provided for parent or guardian-taught novice driver training that meets all of the driver training requirements necessary for licensing drivers 16 to 18 years old. That legislation amended the statutes requiring driver education by adding to 521.204 above, “...person has completed and passed a driver education course approved by the department $\mathbf{t}^{4}$ under Section 521.205 or by the Texas Education Agency" and by adding Section 205. Chapter 521, Section 205 is quoted in its entirety in Figure 1.

Despite attempts during the 1997 Texas legislative session to rescind the Parent-Taught Driver Education Program, it was implemented in April of that year and has since become a popular alternative to the more traditional modes of novice driver education delivery. The program's popularity among young prospective licensees and their parents can be seen in its rapid and generally sustained growth in both absolute number of participants and its share of the driver education market. The number and percent of driver education certificates issued under the parent-taught program has increased in all but three years since the program was introduced, as shown in Table 1. These certificates are issued by TEA and are required in order for students to obtain instruction permits and driver's licenses from DPS. In the first year of the parent-taught driver education program (1996-97 school year) 35,000 certificates were sold. In 2004-05, close to 85,000 certificates were issued; down from its peak of 94,500 the preceding year. During this same period, certificates issued through commercial driver training schools have remained fairly constant; fluctuating from about 101,000 - 113,00 annually, while those issued through public schools have decreased dramatically; from more than 90,000 in 1996-97 to 27,300 in 2004-05 (Texas Education Agency, 2006). Note that this data is based on gross distribution of certificates that may include duplicates, unused and voided certificates and does not, therefore, provide an accurate indication of the absolute number of students in each training option. It does suggest, however, the relative extent of participation in the three delivery options for approved novice driver education.

\footnotetext{
${ }^{2}$ Emphasis added

${ }^{3}$ Now known as the Texas Education Agency (TEA)

4 "the department" refers to the Texas Department of Public Safety (DPS).
} 


\section{TEXAS TRANSPORTATION CODE CHAPTER 521. DRIVER'S LICENSES AND CERTIFICATES}

\subsection{Department-Approved Courses}

(a) The department by rule shall provide for approval of a driver education course conducted by the parent, stepparent, legal guardian, step-grandparent, or grandparent of a person who is required to complete a driver education course to obtain a Class $C$ license. The rules must provide that:

(1) the person conducting the course be a licensed driver;

(2) the student driver spend a minimum number of hours in:

(A) classroom instruction; and

(B) behind-the-wheel instruction;

(3) the person conducting the course not be convicted of:

(A) criminally negligent homicide; or

(B) driving while intoxicated; and

(4) the person conducting the course not be disabled because of mental illness.

(b) The department may not approve a course unless it determines that the course materials are at least equal to those required in a course approved by the Texas Education Agency, except that the department may not require that:

(1) the classroom instruction be provided in a room with particular characteristics or equipment; or

(2) the vehicle used for the behind-the-wheel instruction have equipment other than the equipment otherwise required by law for operation of the vehicle on a highway while the vehicle is not being used for driver training.

(c) The rules must provide a method by which:

(1) approval of a course is obtained; and

(2) an applicant submits proof of completion of the course; and

(3) approval for delivering course materials by an alternative method, including electronic means, is obtained.

(d) Completion of a driver education course approved under this section has the same effect under this chapter as completion of a driver education course approved by the Texas Education Agency.

Added by Acts 1997, 75th Leg., ch. 165, § 30.79(a), eff. Sept. 1, 1997.

Amended by Acts 1999, 76th Leg., ch. 721, § 1, eff. Sept. 1, 1999; Acts 2003, 78th Leg., ch. 1196, § 1, eff. Sept. 1, 2003.

Figure 1. Section added to Texas Transportation Code by Senate Bill 964, $74^{\text {th }}$ Texas Legislature to provide parent-taught driver education 
Table 1. Number and (percent) of driver education certificates issued by school year*

\begin{tabular}{|l|c|c|c|c|c|c|c|c|c|c|}
\hline DE Mode & $95-96$ & $96-97$ & $97-98$ & $98-99$ & $99-00$ & $00-01$ & $01-02$ & $02-03$ & $03-04$ & $04-05$ \\
\hline Public & 130,822 & 92,164 & 84,520 & 70,074 & 57,259 & 54,170 & 44,556 & 38,715 & 34,675 & 27,309 \\
school & $(52.9)$ & $(38.8)$ & $(32.9)$ & $(27.7)$ & $(24.8)$ & $(24.9)$ & $(18.3)$ & $(18.0)$ & $(14.9)$ & $(12.5)$ \\
\hline Commercial & 116,651 & 110,498 & 112,161 & 113,059 & 112,801 & 102,912 & 111,042 & 101,291 & 104,180 & 105,995 \\
& $(47.1)$ & $(46.5)$ & $(43.7)$ & $(44.7)$ & $(48.8)$ & $(47.3)$ & $(45.6)$ & $(47.2)$ & $(44.6)$ & $(48.6)$ \\
\hline Parent- & 0 & 35,000 & 60,000 & 70,000 & 61,000 & 60,500 & 87,750 & 74,750 & 94,500 & 84,750 \\
taught & $(0.0)$ & $(14.7)$ & $(23.4)$ & $(27.7)$ & $(26.4)$ & $(27.8)$ & $(36.1)$ & $(34.8)$ & $(40.5)$ & $(38.9)$ \\
\hline Total & 247,473 & 237,662 & 256,681 & 253,133 & 231,060 & 217,582 & 243,348 & 214,756 & 233,355 & 218,054 \\
$(100)$ & $(100)$ & $(100)$ & $(100)$ & $(100)$ & $(100)$ & $(100)$ & $(100)$ & $(100)$ & $(100)$ \\
\hline
\end{tabular}

To date, no formal evaluation of the Texas provisions that have elevated parent-taught driver training to the same "approved" status as formal training by certified and licensed public or commercial schools has been undertaken.

It must be noted at the outset, of course, that the value of novice-driver training and education has long been a subject of debate among researchers, educators and others in the transportation and traffic safety community. A significant case in point is the landmark "DeKalb County" study (Stock, et al, 1983), the results of which have been debated, reanalyzed and reinterpreted for more than 20 years.

Mayhew and Simpson (1996) summarize the debate over "DeKalb" and the reanalysis of the original data as follows:

Despite the different methods and statistical procedures that have been applied to the data, however, the findings have been extremely consistent. Taken together, the original Stock et al study and subsequent analysis of the data show that the improved driver education program was not associated with reliable or significant decreases in crash involvement. Any differences that were found could be attributed to differences in exposure to the likelihood of a collision. The increased collision rates found in the re-analyses of the DeKalb data occur largely because students taking driver education become licensed sooner than those who do not. This finding is consistent with earlier research that showed the availability of driver education encouraged young people to become licensed, and consequently, crash at an earlier age than they would have in the absence of training. For example, Robertson (1980) investigated the effect of the elimination of high school driver education on the overall licensing of 16-17 year olds and their fatal crashes in several communities in Connecticut. The study found that "the elimination of high school driver education in some Connecticut communities following the withdrawal of State funding for the course led to a substantial reduction in early licensure of 16-17 year olds to drive and concurrent substantial net reductions in serious crashes of drivers per population of that age relative to changes in communities that retained the courses". Robertson concluded that: driver education in high school is a major contributing factor to 
the early licensure of teenagers to drive and, as a result of this earlier exposure, their increased involvement as drivers in serious crashes.

Mayhew and Simpson do recognize, however, that others draw very different conclusions, citing, for example, McKnight (1985) who suggests:

...it is clearly something of a distortion to attribute accidents to driver education just because it leads to driving. Any group of people that drive will have accidents. By agreeing to license them, society accepts that risk. Driver education is simply a means of achieving a socially accepted goal.

Many of the disagreements about the value of formal driver education can be traced to a lack of consensus about the proper goal of novice driver training and, subsequently, to disputes about appropriate measures for assessing its worth. Though an oversimplification, the debate is often confounded by different and incompatible responses to the underlying question of whether driver instruction should be evaluated on the basis of its capability to produce safer drivers, e.g., drivers with measurably lower crash rates, or in terms of its success in imparting knowledge of the rules of the road, the basic skills involved in vehicle operation, and in instilling and reinforcing attitudes consistent with safe driving.

In several respects the present evaluation approaches this issue from both perspectives, though with somewhat greater emphasis on the former. The evaluation questions include:

- Are teenage drivers exposed to the parent-taught driver education program in Texas demonstrably different from either those who complete school-based or commercial driving school training as measured by post-licensing crash involvement and driving record measures (e.g., citation experience)?

- Are there demonstrable differences in the attitudes, knowledge and skills of novice drivers exposed to the various driving instruction options available in Texas?

State recognition of parent-taught driving instruction does not represent the only change to the Texas Transportation Code and the rules governing the licensing of teenage drivers in recent years. Two other developments interact with the potential impact of the parent-taught provisions and significantly influence the interpretation of evaluation information developed here.

First, as of 1995, the DPS no longer required 16- and 17-year-olds to take and pass a driving test with a DPS trooper in the vehicle as a prerequisite for obtaining a driver's license. Although DPS in-vehicle tests are still provided when requested, a waiver from such tests is available and is the norm. Successful completion of an approved driver education course, since 1997 including a parent-taught course, effectively removes the requirement for an in-vehicle test. Legislation was introduced, but not enacted, in the 2003 Texas legislative session that would have reinstated requirements for an in-vehicle driving test to be administrated by DPS for license applicants who are parent-taught (Senate Bill 946). In the 2005 legislative session a similar bill (SB 696) that required in-vehicle testing for all license applicants under 18 without regard to mode of driver education was introduced and, ultimately, also failed. A related bill in 2005, SB 1005, did pass, was signed by the Governor, and became effective September 1, 2005. Among other provisions, this legislation amended Article 45.051, Code of Criminal Procedure concerning people younger 
than 25 who commit a moving traffic violation. During the deferral period, a judge shall require the defendant to complete an approved driving safety course and if the defendant holds a provisional driver license, to complete a DPS road test prior to obtaining a driver license (emphasis added).

Second, and more importantly, on January 1, 2002, the Texas Graduated Driver License (GDL) Program was implemented. Although the basic requirements for obtaining a license did not change, there is now a two-phase procedure for license applicants under age 18. Under Phase One, applicants must hold an instruction permit for a minimum of six months prior to issuance of a provisional Class $\mathrm{A}, \mathrm{B}$, or $\mathrm{C}$ driver license. The minimum age of the person who must accompany any instruction permit holder during the operation of the vehicle is 21 . Under Phase Two (provisional license), people may not, during the six-month period following issuance of the provisional license:

- operate a motor vehicle with more than one passenger in the vehicle under age 21 who is not a family member

- operate a motor vehicle between midnight and 5 a.m. unless it is necessary for the operator to attend or participate in employment or a school-related activity or because of a medical emergency.

- operate a motor vehicle while using a wireless communications device (note that this restriction was not in effect until September 1, 2005 and, therefore, had no influence on the current evaluation).

The present evaluation did not have the benefit of implementing a true experimental design in which students would have been randomly assigned to one of the three driver education instructional options. Such designs provide for the strongest comparisons, greatly increasing confidence that the groups are truly comparable and that any differences observed in outcomes are the result of treatment differences (i.e., differences among the driver education programs) and not due to extraneous factors or pre-existing differences. Analyses of safety outcomes related to the novice driver training alternatives in this evaluation are based on what at best may be considered a quasi-experimental design relying on analyses of self-selected, pre-existing groups, with all the attendant difficulties associated with such designs. It must also be recognized that this study is restricted to a global, macro-level evaluation of the three types of driver education delivery. No attempt has been made to evaluate specific driver education courses or driver education instructors within any of the delivery modalities. The evaluation is mute on the merits of particular courses offered by specific providers, be they public school systems, commercial driver education businesses or parents using one of the eight specific parent-taught courses currently accepted in the Texas parent-taught program.

\subsection{General Evaluation Approach}

The evaluation described here is characterized as a "comparative evaluation" because it does not attempt to asses the value, benefits, or lack thereof of the parent-taught program in any absolute sense. Rather, it is limited to evaluation of the parent-taught program in relation to what has for many years been the de facto, if not the officially recognized, norm for novice driver education in Texas, namely the driver education and training delivered through the public schools and 
licensed commercial driving schools. Hence, the Latin dictum below this document's title: Primum non nocere - First do no harm. In large part this evaluation endeavors to answer the question: Has the introduction of the parent-taught driver education as a public policy had a demonstrable negative effect on either the education and training of young novice drivers or on the safety of novice or other drivers on Texas streets and highways?

Comparative information and data for the evaluation was obtained from three primary sources:

- Focus groups conducted with driver education instructors, students and parents (both parent-teachers and non-teaching parents)

- A statewide mail survey of young drivers

- Analysis of Texas driver records.

In addition to the formal data sources, numerous formal and informal meetings, phone calls and other communications were held with staff of the two State agencies most directly associated with driver education and licensing in Texas, the Texas Education Agency and the Texas Department of Public Safety. Of special assistance was the staff of the Driver Training Division and the In-School Driver Education and Traffic Safety Unit of TEA and the License Issuance Bureau of the Driver License Division of DPS.

Following an overview of driver licensing requirements and the three driver education delivery modes in Texas in Section 2, the evaluation methodology is discussed in detail and the results of the primary components of the evaluation are provided in Section 3. Section 4 provides the conclusions and recommendations developed from the evaluation. 
This page intentionally left blank. 


\subsection{OVERVIEW OF TEXAS NOVICE DRIVER LICENSING and DRIVER EDUCATION DELIVERY OPTIONS}

State-approved driver education is required for all novice drivers who apply for a driver's license before age 18. From 1967 through April, 1997, approved novice driver education and training courses were offered only through public and private schools that had driver education programs, courses and instructors approved by the "central education agency" (now the Texas Education Agency) or by commercial driving schools licensed by the TEA. In April 1997, the ParentTaught Driver Education Program was instituted, providing a third method of driver education instruction that meets the requirements for licensing before 18. Commercial and public school DE continues to be regulated by TEA. The parent-taught program is administered and overseen by the DPS.

\subsection{Driver License Rules}

The basic licensing rules and regulations are identical for all young novice drivers without regard to the mode of delivery of the required driver education. The regulations are included in multiple sections of the Texas Transportation Code, most particularly in Chapter 521, Driver's Licenses and Certificates. Licensing requirements and, especially, restrictions were modified significantly with the introduction of the Texas graduated driver license program for drivers under 18 years old. The GDL program was implemented on January 1, 2002.

The basic requirements for licensing of teenagers younger than 18 since the GDL has been in effect are summarized below.

- An approved driver education course can be started at age 14.

- All approved DE courses consist of a minimum of:

- 32 hours of classroom instruction

- 7 hours of behind-the-wheel instruction

- 7 hours of in-vehicle observation.

Commercial and public school programs typically conduct DE under the "Core Program Plan" with the hours of instruction as described above. Other public school driver education plans are available that include:

- In-car only program consisting of at least 7 hours of behind-the-wheel instruction and 7 hours of in-car observation.

- Classroom only program consisting of at least 32 hours of classroom instruction.

- School-day credit program. This program consists of at least one class period per scheduled day of school, for a semester, covering the driver education classroom and in-car program of organized instruction or only the classroom program of organized instruction. This class traditionally consists of at least 56 hours of driver education classroom instruction and, if in-car instruction is provided, must include 7 hours of behind-the-wheel instruction and 7 hours of in-car observation. Under this plan, a student may receive one-half unit of State credit toward graduation.

- Non-school-day credit program. This program consists of at least 56 hours of driver education classroom instruction, and, if in-car instruction is provided, must include 7 
hours of behind-the-wheel instruction and 7 hours of in-car observation. Under this plan, a student may receive one-half unit of State credit toward graduation.

- Multi-phase school-day or non-school-day credit program. This program consists of at least 40 hours of driver education classroom instruction, 4 hours of behind-thewheel instruction, 8 hours of in-car observation, and 12 hours of simulator instruction. Under this plan, a student may receive one-half unit of State credit toward graduation.

- The classroom and in-vehicle components of approved courses may be taken either consecutively (Block method), in which case all classroom instruction is completed before the behind-the-wheel phase, or concurrently (Concurrent method), with the requirement that at least 6 hours of the classroom instruction be completed before invehicle instruction begins. In both methods, the student must obtain an Instruction Permit before beginning the in-vehicle phases of instruction.

- Instruction Permit License (GDL Phase 1). Minimum age for obtaining an instructional permit is 15 . The applicant must be enrolled in an approved course and have completed at least the 6 hours of classroom instruction comprising Module One: Texas Driver Responsibilities - Knowing Texas Traffic Laws. Application for an instruction permit requires the student to pass a vision test and a two-part written examination administered by the DPS consisting of a rules (traffic law) test and a highway signs test. The instruction permit allows the student driver to practice when accompanied by a licensed driver who is at least 21 years old, has had at least one year of driving experience, and occupies the seat beside the student driver. An instructional permit must be held for a minimum of six months before a provisional license can be issued.

- Provisional License (GDL Phase 2). Students may "graduate" to a provisional driver license if they are at least 16 and have held an instruction permit for at least six months. Holders of a provisional license may not operate a motor vehicle with more than one passenger under 21 who is not a family member. Driving is not allowed between midnight and 5 a.m., unless operation of a vehicle is necessary for attendance/participation in employment or a school-related activity or because of a medical emergency. A provisional license must be held for a minimum of six months.

- Unrestricted License. Having held a provisional license for at least six months and reached at least age $161 / 2$, the driver is eligible for a full, unrestricted driver license.

\subsection{Driver Education Program, Course and Instructor Requirements}

\subsubsection{Commercial and Public School Driver Education}

The Texas Education Agency's Driver Training Division and In-School Driver Education and Traffic Safety Unit, assists, licenses and regulates commercial and public school driver education, respectively. As of February 2006, 193 commercial driving schools at 252 locations in 124 cities and towns in Texas are licensed to provide novice driver education. As of September 2004, more than 360 public schools in 348 Independent School Districts and other entities located in 323 cities and towns have been approved to offer a driver education program. ${ }^{5}$

\footnotetext{
${ }^{5}$ Approval to offer DE does not imply that DE courses are currently being offered. Other entities that provide DE programs include regional Education Service Centers, universities, and the DPS.
} 
Rules and regulations for commercial and public school novice DE programs, courses and instructors are included in the Texas Education Code, Title 5, Chapter 1001 and the Texas Administrative Code, Title 19, Part II, Chapter 176.

Licensing of Schools and Course Providers

Among other requirements, licensing of a driver education school is based on evidence, including on-site inspections, that the school:

- has courses, curricula, and instruction of a quality, content, and length that reasonably and adequately achieve the stated objective for which the courses, curricula, and instruction are offered;

- $\quad$ has adequate space, equipment, instructional material, and instructors to provide training of good quality in the classroom and behind the wheel;

- $\quad$ has directors, instructors, and administrators who have adequate educational qualifications and experience;

- maintains adequate records as prescribed by TEA to show attendance and progress or grades and enforces satisfactory standards relating to attendance, progress, and conduct;

- $\quad$ on completion of training, issues each student a certificate indicating the course name and satisfactory completion;

- complies with all county, municipal, State, and Federal regulations, including fire, building, and sanitation codes, and assumed name registration;

- $\quad$ is financially sound and capable of fulfilling its commitments for training;

- has administrators, directors, owners, and instructors who are of good reputation and character;

- $\quad$ submits to the TEA for approval the applicable course hour lengths and curriculum content for each course offered by the school; and

- $\quad$ meets any additional criteria required by the TEA.

Schools must use a curriculum based on the instructional objectives in the TEA's approved "Program of Instruction for Driver Education and Traffic Safety" dated October 2000 or, alternatively, a school may use the instructional objectives and topics within a proposed revision to that document. Pre-approved Texas Driver and Traffic Safety Education Master Curriculum Guide Modules were developed by TEA and distributed in 2001. These instructional objectives plus the 10 sample program modules are currently under revision. There will be 12 sample program modules in the future.

Schools must meet the instructional objectives in the "Program of Instruction for Driver Education and Traffic Safety." They may do so by using whatever resources are appropriate, i.e., the current 10 sample modules, the proposed 12 sample modules, or the previously approved driver education textbooks. Of primary importance is that instructors comply with the instructional objectives listed in the "Program of Instruction for Driver Education and Traffic Safety." 


\section{Training and Licensing of Instructors}

A driver education instructor license issued by the TEA is required for a person to teach driver education, either as an individual ${ }^{6}$ or in a driver education school, or conduct any phase of driver education. Obtaining and maintaining a DE instructor license is contingent upon meeting the standards for certification of professional and paraprofessional personnel established by the TEA.

A driver education instructor license authorizing a person to teach or provide behind-the-wheel training may be issued only if, among other requirements:

- The person has successfully completed 6 semester hours of driver and traffic safety education or a program of study in driver education approved by the commissioner from an approved driver education school.

- A person who holds a driver education instructor license authorizing behind-the-wheel training may be approved to assist a classroom instructor in the classroom phase of driver education only if the person has successfully completed 3 additional semester hours of training required for a classroom instructor or a program of study in driver education approved by the commissioner.

A driver education instructor license authorizing a person to teach DE may be issued only if the person:

- has completed 9 semester hours of driver and traffic safety education or a program of study in driver education approved by the commissioner from an approved driver education school; and

- holds a teaching certificate and any additional certification required to teach driver education.

A driver education instructor who has completed the educational requirements prescribed above may teach instructor training classes only if the instructor has successfully completed a supervising instructor development program consisting of at least six additional semester hours or a program of study in driver education approved by the TEA that includes administering driver education programs and supervising and administering traffic safety education.

Maintaining and renewing a DE instructor license also requires the licensee to participate in and provide evidence of completion of continuing education activities specified by the TEA.

In addition to the educational and training requirements, applicants for and holders of a $\mathrm{DE}$ instructor license:

- Must have held a valid class A, B, C, or CDL driver's license, other than a learner's permit, for the preceding five years, and which has not been suspended, revoked, or forfeited in that period,

- May not have been convicted of any felony, an offense involving moral turpitude, involuntary or intoxication manslaughter, criminally negligent homicide committed as a result of the person's operation of a motor vehicle, driving while intoxicated or driving under the influence of drugs, or an offense involving tampering with a governmental record,

\footnotetext{
${ }^{6}$ These license requirements do not pertain to parents teaching under the Parent-Taught Driver Education Program.
} 
- May not be addicted to the use of alcoholic beverages or drugs or become incompetent to safely operate a motor vehicle or conduct classroom or in-car instruction properly, and

- May not have a personal driving record showing that the person has accumulated 10 or more penalty points in the past three-year period. The standards for assessing penalty points for convictions of traffic law violations and accident involvements appearing on the instructor's current driving record are established by the Texas Department of Public Safety and are the same as those used for Texas school bus drivers. ${ }^{7}$

\subsubsection{Rules for Participation in the Parent-Taught Program ${ }^{8}$}

The Texas Department of Public Safety is responsible for the parent-taught driver education program. The Parent-Taught Driver Education Program requires students to "acquire the essential knowledge, skills and experience to perform reduced-risk practices in the total traffic environment." To achieve that goal, students are required to master applicable Texas traffic laws, rules, and procedures for operating and owning an automobile, including:

- Benefits of occupant protection devices (e.g., safety belts, airbags),

- Use of a space management system (i.e., strategies, techniques and procedures that enable the driver to adjust vehicle speed and position to maintain appropriate space for existing and projected conditions),

- Factors and behaviors that effect driver performance including alcohol and other drugs, and

- $\quad$ Protection of Texas natural resources, including litter prevention.

Before an instructor (parent, stepparent, grandparent, step-grandparent, foster parent, or legal guardian) may begin teaching the instructor must have a valid Texas driver license for the preceding three years (active U.S. military personnel and their spouses may participate as instructors if they hold valid licenses from their State of permanent residence or last duty station for the preceding three years).

A Parent-taught DE instructors:

- Cannot have a conviction (including a probated sentence) of criminally negligent homicide or driving while intoxicated;

- Driver's licenses may not have been suspended, revoked, or forfeited in the past three years for traffic-related violations;

- May not be disabled due to mental illness; and

- Must check both their criminal and driver records prior to requesting parent-taught DE packets. (DPS does not check the instructor's record until issuance of the instruction permit or provisional driver license to the student. If the instructor has a prohibited conviction, the instruction permit or provisional driver license will be denied and any prior classroom or behind-the-wheel/in-car instruction credit is invalid.)

\footnotetext{
${ }_{8}^{7}$ Penalty point assessments are available at $\mathrm{http}: / \mathrm{www} . t e a . s t a t e . t x . u s /$ safedriver/busdriverpenalty.html

${ }^{8}$ For additional information and the guidance provided by DPS, see Appendix A: Guidance Provided by the Texas Department of Public Safety to Participants in the Parent-Taught Driver Education Program.
} 
In order to apply for the Parent-Taught Driver Education Program, a parent must complete and submit a DL-92 Request Form to the Texas Department of Public Safety, License Issuance Bureau. A \$20.00 nonrefundable fee is required for each student participating in the ParentTaught Driver Education Program.

Upon receipt of the Request Form a DE-964 Certificate is assigned to the student and forwarded to the designated DPS Driver License Office, where the student will apply for the license and take the required tests. The DE-964 Certificate is maintained and available at the designated Driver License office for the instructor to complete.

When the PTDE Program was originally instituted, specific State-adopted textbooks were required. That is no longer the case. There are currently eight approved courses that may be used within the parent-taught program. The DPS has determined that the curriculum and material for these courses are at least equivalent to that provided by TEA-approved novice driver education courses.

The eight approved parent-taught DE courses are:

- Model Program Course - 101. The Model Program Course is the State-approved curriculum for driver education programs in public and licensed schools developed by the TEA. It replaces the State-adopted driver education textbook, which is no longer required. The Model Program Course package entitled the Texas Driver and Traffic Safety Education Master Curriculum Guide includes 10 modules with over 1,600 pages of sample classroom and behind-the-wheel lesson plans, support materials, worksheets, exams, instructor activities, fact sheets, student worksheets, transparency masters, in-car lessons, resources, evaluations, and parental involvement support. The Model Program Course is available free for use by parent-taught instructors and approved and licensed schools and teachers. It is available online at www.tea.state.tx.us/safedriver/parent101.html or by contacting the TEA. Instructors choosing to use this course are responsible for developing the curriculum and lesson plan, including obtaining course material. Course material is available on-line without charge or may be ordered in hard copy or CD format from the TEA at www.tea.state.tx.us/safedriver/forms/CurriculumOrderForm.doc. ${ }^{9}$

- $\quad$ Program Course - 102 is offered by the National Driver Training Institute. In order to instruct from this course, an application for the Texas Parent-Taught Driver Education Program is required. It has received approval from the DPS for the use of an interactive CD-ROM or NDTI's textbook Help for the Teenager Who Wants to Drive. Parents must contact the National Driver Training Institute. There may be additional costs associated with the program. Additional information about this program is available online at: http://www.GraduatedDriverLicensing.com.

- $\quad$ Program Course - 103 is offered by Driver Ed in a Box. In order to instruct from this course, an application for the Texas Parent-Taught Driver Education Program is required. Course - 103 has received approval from the Department for the use of an

\footnotetext{
${ }^{9}$ See Appendix B for TEA's instructions to parents on how to teach Course 101. The document in this appendix includes links to the curriculum and teaching material for Course 101.
} 
interactive CD-ROM or Driver Ed in a Box's textbook, Driver Ed in a Box: The Textbook. Parents must contact Driver Education Supplies and Training. There may be additional costs associated with the program. Additional information about this program is available online at: www.driveredinabox.com.

- Program Course - 104 is offered by Curb Buster. In order to instruct from this course, an application for the Texas Parent-Taught Driver Education Program is required. Course 104 has received approval from DPS for the use of an interactive CD-ROM or Curb Buster's textbook Drive Right. Parents must contact Curb Busters. There may be additional costs associated with the program. Additional information about this program is available on-line at: http://curbbuster.com.

- $\quad$ Program Course - 105 is offered by Driver Ed at Home. In order to instruct from this course, an application for the Texas Parent-Taught Driver Education Program is required. Course - 105 has received approval from DPS for the use of its textbook Responsible Driving. Parents must contact Driver Ed at Home. There may be additional costs associated with the program. Additional information about this program is available on- line at: http://www.driverslicensetraining.com.

- $\quad$ Program Course - 106 is offered by the Texas Driver and Traffic Safety Education Association. In order to instruct from this course, an application for the Texas ParentTaught Driver Education Program is required. Course - 106 has received approval from DPS for the use of TDTSEA's textbook Texas Traffic Safety Education Student Manual. Parents must contact the Texas Driver and Traffic Safety Education Association. There may be additional costs associated with this program. For additional information about this program send an email to tgilbert@esc6.net.

- $\quad$ Program Course - 107 is offered by Virtual Drive of Texas. In order to instruct from this course, an application for the Texas Parent-Taught Driver Education Program is required. Course - 107 has received approval from DPS for the use of computer-based training version provided on CD-ROM Virtual Drive of Texas. Parents must contact Virtual Drive of Texas. There may be additional costs associated with this program. Additional information about this program is available online at: www.virtualdriveoftexas.com.

- $\quad$ Program Course - 108 is offered by DriversEd.com. In order to instruct from this course, an application for the Texas Parent-Taught Driver Education Program is required. Course - 108 has received approval from DPS for the use of an online computer-based training version DriversEd.com. Parents must contact DriversEd.com. There may be additional costs associated with this program. Additional information about this program is available online at: www.driversed.com. 
This page intentionally left blank 


\subsection{DETAILED EVALUATION APPROACH AND RESULTS}

As noted in the introduction, information and data used to compare the three approved modes of driver education were obtained from three sources: focus groups, a mail survey of driver education students, and analysis of Texas driver records. The specific approach undertaken to develop and analyze information from each of these sources and the results of each of these endeavors are provided in the following Sections.

\subsection{Focus Groups}

\subsubsection{Detailed Evaluation and Analysis Approach}

Nine focus groups were conducted with three key driver education stakeholder groups:

- Public and commercial school teachers of novice driver education courses,

- Parents of novice driver education students - including parents who served as DE instructors under the parent-taught program, and

- Current and recent students in each of the three novice driver education modes in Texas.

The goal of these groups was to ascertain from those with first-hand experience with each of the delivery modes of Texas DE their expectations of the programs; opinions related to the subject matter and instructors, opinions as to the effectiveness of the DE courses in preparing teens to drive, and other relevant issues, including, parents' role in DE, problems teens face in driving, the best and worst aspects of the DE experience, etc.

Focus groups provide a means to gather qualitative data regarding the interpretations, opinions, experiences and preferences of the groups of interest. The groups are usually small enough (typically 6 to 12 people) so a group dynamic can occur and still provide an opportunity for individual expression. This type of group interview allows for discussion during which participants often feel freer to divulge their perspectives and the discussion itself can generate more thought and interaction than a one-on-one interview. Some of the attributes common among teenagers (e.g., their reliance on peer support and their detachment from adult authority) make the discussion group approach particularly advantageous. The results of focus groups can be used as a basis for more in-depth understanding of a topic or issue and/or as a starting point to study a larger population. This report presents the focus group findings as shared perceptions and opinions of groups of ostensibly typical teenage students, parents, and driver educators, while also attempting to identify areas of consensus within and across groups. In this regard, the skill and experience of the moderator (and the analyst) is crucial. The goal is to reveal the extent to which there is consensus, not to build consensus. In the absence of general agreement, the goal is to determine the range of differences in opinions, attitudes and beliefs, etc. As employed here, it is not appropriate to generalize findings from the focus groups to the entire populations since the extent to which participants in the groups are in fact representative of all members of the populations to which they belong is not discernible. Despite efforts to be as inclusive as possible in recruiting and selecting participants, participation was strictly voluntary and subject to self-selection biases. 
Focus groups for this study were carried out throughout the project with the first group conducted in March 2004 and the final group completed in August 2005. Two groups were comprised of instructors involved in the provision of driver education; one with commercial driving school instructors and one with DE teachers in public school programs. Two groups were held with parents of current or recent DE students. One of these comprised parents who participated as teachers in the parent-taught program and the other included both teaching parents and parents whose teenagers who took commercial or public school DE courses. Five groups were made up of DE students who were currently taking or had recently completed one of the three novice DE course types; parent-taught, commercial or public school DE. The groups were conducted in several areas in Texas. A summary of the group locations and compositions are indicated in Table 2.

Table 2. Focus group composition and sites

\begin{tabular}{|c|c|l|l|c|}
\hline \multicolumn{2}{|c|}{ No. of Participants } & \multicolumn{1}{|c|}{ Group Composition } & \multicolumn{1}{c|}{ Location } & Date \\
\hline Male & Female & \multicolumn{1}{|c|}{} & \\
\hline 8 & 3 & Commercial School DE Instructors & San Antonio & Mar 2004 \\
\hline 7 & 4 & Public School DE Instructors & San Antonio & Mar 2004 \\
\hline 0 & 7 & Parents & College Station/Bryan & Nov 2004 \\
\hline 3 & 5 & Parents & Waco & May 2005 \\
\hline 4 & 0 & Students (1 Pub, 2 Com, 1 PT) & Wichita Falls & Dec 2004 \\
\hline 0 & 8 & Students (5 Com, 3 PT) & Wichita Falls & Dec 2004 \\
\hline 8 & 2 & Students (1 Pub, 4 Com, 5 PT) & Wichita Falls & Dec 2004 \\
\hline 4 & 0 & Students (2 Pub, 2 Com) & San Antonio & Aug 2005 \\
\hline 3 & 0 & Students (1 Pub, 2 PT) & San Antonio & Aug 2005 \\
\hline \multicolumn{7}{|l|}{ Pub Public school DE, Com = Commercial driving school DE, PT = Parent-taught DE } \\
\hline
\end{tabular}

Instructors for both the commercial and public school DE groups were recruited at the 2004 annual meeting of the Texas Driver and Traffic Safety Education Association held in San Antonio, thereby providing participants from throughout the State at a common time and location. Both DE instructor groups were held in a meeting room in the conference hotel later on the same day they were recruited.

Participants in the parent groups, convened in Waco and College Station, Texas, and student groups, held in Wichita Falls and San Antonio, were recruited by local contacts in those cities with material and briefings provided by project staff. The Waco and Wichita Falls groups were conducted in public library meeting rooms and the College Station/Bryan and San Antonio groups were held in conference room facilities of the Texas Transportation Institute in those cities.

All participants received $\$ 20$ for their involvement and agreed, as a condition of participation, to join fully in the discussion and to be audiotaped. All groups were conducted in compliance with the requirements of the Texas A\&M University Institutional Review Board - Human Subjects in Research with regard to provisions of informed consent, confidentiality, and compensation. Parents of participants under 18 signed an Informed Consent document for their child, who gave written assent to participate. 
In preparation for the focus groups, guidelines were developed for each target group that detailed the mechanics and logistics of the focus groups and defined the specific topic areas to be addressed with each group of participants. All focus groups were conducted according to the guidelines. Two project staff conducted each group: an experienced group moderator and a project staff member who coordinated session logistics (room availability, set-up, etc.), assured proper audio recording of the sessions, and took detailed notes during the session to supplement the transcribed audio recordings.

Separate moderator discussion guides were developed and targeted for each series of focus groups (teens, parents, instructors). The moderator guide provided an outline of the group discussion but was subject to change as dictated by the course of discussion and the dynamics of each group. Each of the discussion guides is provided in Appendix C. In each of the groups, an introductory section was designed to familiarize participants with the focus group process and the purpose of the research. During this section the importance of candor, participation, and the assurance of confidentiality were each emphasized. A low key, general discussion followed which was designed to allow members of the group an opportunity to become comfortable talking in the group setting. The content of the remainder of the session for teenagers and parents was centered around revelations of experiences with driver education; expectations of the program prior to the experience; opinions related to the subject matter, the instructor, and other relevant issues; suggestions for improvements; and advice for others based on personal experience. The groups for DE professionals focused in the major portion of the discussion on strengths and weaknesses of the curriculum, their teaching, and ideas for improvements and the appropriate role of parents in their children's driver education.

Analysis of focus group results was performed by reviewing verbatim transcripts and detailed notes of the sessions taken by the research associate present at each group. The findings, presented in Section 3.1.2, are organized by specific issues explored in the groups. Because of the similarity in issues covered in all of the groups, findings are presented for each group type within the common issue areas. Areas of discussion encouraged in all of the groups include:

- Goals of driver education;

- $\quad$ Success of DE in meeting goals;

- Specific things it is important to teach/learn in DE;

- Assessment of DE curriculum and material used;

- Assessment of how well DE prepares novice drivers for the driving environment after completion of DE; and

- Parents' role in DE.

Additional emphases in the driver educator groups was placed on:

- Assessment of the three delivery options of DE; and

- Specific assessment of the parent-taught program in Texas.

In addition to the common area of discussion, parent group participants were asked to discuss:

- $\quad$ Problems teens face as new drivers;

- Why parents chose the mode of DE in which they participated;

- The best and worst aspects of their DE experience; 
- How well they followed prescribed procedures; and

- Self-assessment of their teaching.

Student groups focused primarily on:

- $\quad$ Evaluations of the materials used in DE;

- Evaluation of their DE instructor;

- Amount and type of in-vehicle instruction and practice received;

- Why they chose the mode of DE in which they participated and whether it was a good choice;

- Self-evaluation of their own driving; and

- Overall impressions of their DE experience.

\subsubsection{Findings From the Focus Groups}

The sections below provide summaries of the focus groups conducted with public and commercial driver education instructors, parents of DE Students and current/recent students in DE programs.

\section{Public and Commercial Driver School Education Instructors}

The perceptions, opinions, and attitudes articulated by the 22 instructors in public school (11) and commercial (11) driver education programs who participated in two focus groups were, with some exception, very similar in nearly all areas of discussion. Clearly, there is significant commonality among DE teachers without regard to the type of program they teach. Many of the instructors participating in these groups have had experience in both modes of DE delivery. This is especially true among the instructors currently teaching in commercial schools. The range of opinions was fairly narrow both within the two groups and between the groups. Not surprisingly, the area in which the greatest divergence of opinions between public and commercial school DE instructors' is evident is the instructors' assessments of the two modes of school-based DE, that is, commercial versus public school DE programs. Near unanimity, again both within and between instructor groups, was observed in the views expressed about the parent-taught program in Texas.

The findings from the instructor groups, along with illustrative verbatim comments by participants, are summarized below for each of the principal areas of discussion. The issues and questions addressed comprised:

- What are the goals of driver education?

- How successful is DE in meeting its goals?

- What specific things are important to teach/learn in DE?

- Assessment of DE curriculum and material;

- $\quad$ Does DE prepare novice drivers for the driving environment after completion of DE?

- Instructor assessment of different modes of DE;

- What is/should be parents' role in DE? and

- $\quad$ Specific assessment of the Parent-Taught Program in Texas. 
What are the goals of Driver Education?

Public and commercial school driver education instructors approached unanimity on the goals of driver education. In addition to providing the basic skills and knowledge required for driving and getting students on the road safely, the clear consensus is that the goal of driver education is to develop in novice drivers the basis for a lifetime activity (driving), with a very strong emphasis on responsibility, good decision making and development of appropriate attitudes about driving. While DE instructors clearly see themselves as providers of necessary skills and knowledge for safe driving, they appear to place at least equal importance on being role models for their students.

Public school DE instructors suggested, for example:

"What I try to instill in them are good driving practices that they can use for their life. ....and then I break it down, attitude, responsibility, maturity, and before you even get into the other parts of the driving, I set a precedent. This is what I expect from you, driving as a privilege, and I make each one of them write a paragraph about attitude...."

"I see us as a role model, as an experience when they get in there, especially my kids, you know, some of them have never been behind the wheel and you give them an opportunity to get in and you talk with them and sometimes you start at square one, mostly as a role model...."

Among typical commercial school instructor comments:

"It is developing a base for something they may do for most of their life. Most of us drive everyday and take it for granted."

"We are preparing them for the rest of their life; we are preparing them to face a future out there. We are teaching them how to survive in the future. It's not just taking driver's ed, but it is making sure they survive out there."

When asked what they thought non-DE professionals perceived the goals of DE to be, a very different picture emerged. Group members immediately talked primarily about what they believed to be the overriding views of the parents of their DE students. Some commercial school instructors believed that parents perceived the goal of DE as producing "safe, accident-free drivers." However, the most frequent and vociferously expressed opinion was that parents believe the goal of DE is to make sure their children obtain a license quickly with as little responsibility and burden on the parent as possible:

"To get that license and let them go, so I don't have the responsibility of taking them."

"It [DE] is to alleviate a burden on them, because "I have to take little Johnny to football and then I have to take him over here and then I won't have time to go get my nails done....so will you rush him through so he can get his license?' "

"The parents' goal is to get that license, "so I don't have to cart your butt all over Houston,' or whatever. What you know, what you don't know -- that is irrelevant to most parents, it is really irrelevant. Just hurry up and get that license." 
"...all we want is for Johnny to get his license, how long is it going to take, and how much is it going to cost."

"I think there are so many activities at school that a student does need to get to and mom and dad can't get them there, and that is one reason they want them to come in there and get out as quick as they can."

How successful is DE in meeting its goals?

Both public and commercial DE instructors expressed mixed, and sometimes contradictory, opinions with regard to how well DE meets its goals. For example, several commercial instructors suggested that:

"Commercial schools are doing a good job,"

and

"I think we in drivers' ed are making a big difference. We are opening their eyes out there to reality,"

A public school participant indicated that:

"We make an impression."

Other participants, however, were less optimistic or at least more disposed to qualify their opinions of the success of DE in meeting its goals. Instructors in both groups expressed the view that while the goals of DE appear to be met while the students are in the course, the lasting effect - outside the DE environment - is at best uncertain.

"What we give them is A+, what they get after they leave us, I couldn't tell you."

"...if we're not meeting those goals, I think there are outside forces that contribute to that, because we're teaching 15- and 16-year-olds, teenagers, children or whatever, and their maturity level and their attitudes to being sensible have something to do with that. Whereas if the age was, say, 25, we would have a totally different student and the maturity level would be there. And so I think if we are not meeting them [DE's goals], it is because of those outside forces that we have no control over."

One commercial school instructor made it clear he believed success could be measured in terms of observable outcomes - and was less than optimistic:

"I'm not sure we are meeting the goals that we want and set out. I feel if we were meeting those goals we probably wouldn't be having as many wrecks."

\section{What specific things are important to teach/learn in DE?}

Whether due to different dynamics operating in the two groups of DE instructors or some more fundamental differences, public and commercial-school teachers focused on somewhat different types of information when asked to identify specifically what is important to make sure their students learn. In general, the commercial school instructors tended to emphasize specific driving behaviors and vehicle control skills, for example, proper right and left turns, backing, speed control, always clearing intersections and correct mirror use. The public school group 
focused more on attitudes, fostering responsibility and maturity, and overall defensive driving, as typified by the instructor who stated:

"I try to tell them this is the first step towards reaching adulthood, because this is a very responsible act and with this act, you can actually kill or injure people. And I try to make them understand that there is a lot of decision-making and they need to be aware of what is going on not only with you, but with everyone around you while you are driving. You have to take care of your business."

Both groups stressed the importance of attention, awareness of one's surroundings while driving and space management.

Assessment of DE curriculum and material

Most instructors in both groups were quite positive in their opinions of the curricula they employ in teaching novice drivers.

"I think we cover all the bases; we have a very good curriculum."

"Every chapter has good information for the kids."

“There are a couple of excellent videos. They get the kids' attention."

"...you can always take that curriculum you have and mold it and put your own experiences in it. Because the best thing we got here [is] big experience of teaching over and over."

A commercial school instructor voiced the only negative comment about the curriculum; indicating a lack of information is included addressing road rage. She suggested:

"There is a little bit of mention of it, but not very much. And in our area there is a lot of road rage. We try to emphasize that."

Many participants in the public school instructors group noted on-going problems with material provided by the DPS, specifically the Texas Driver Handbook and the test questions used for the traffic law portion of the test required for obtaining an instruction permit. The unmistakable consensus of this group was that there is too much time between changes in traffic and licensing laws (e.g., restraint laws, per se BAC limits) and having those changes reflected in the handbook and in answers deemed correct in the test. For example:

"The biggest problem I have is with DPS themselves...not getting us up-to-date handbooks."

"I actually had to teach the kids on one of the computer tests to answer the question incorrectly, so they would not miss the question."

"I think that what we need from the DPS is maybe a revised deal that we could handout to the students on a yearly basis every year we taught it. If we got a handout from them saying these are the new laws and these are the changes, supplement this to your handbook; then we would have a direction to go." 
How well does DE prepare novice drivers for the driving environment after completion of DE? Discussion of this issue addressed the confidence of DE instructors that they were turning out teens who were ready to drive independently and what else they needed beyond the course.

Public school instructors also raised the issue in this discussion of problems encountered when parents wanted to limit their child's school instruction to the classroom portion of a DE course, intending to provide the in-vehicle training under the parent-taught program. Different jurisdictions deal with this issue differently, but all in the group expressed that they not were in favor of such mixed mode approaches. As one instructor put it:

"I would have a tough time living with that, because I knew I had taught them in the classroom and I had done the best job that I could. Because after you turn them loose and they do the actual driving behind the wheel, that is where the actual danger zone is."

Said another instructor, who did have experience with mixed-mode students:

"I have some parents that I have confidence in and then I have some parents that I know there is no teaching at all going on."

Yet another instructor expressed a worst-case scenario:

"We may have them ready, but then they get to the parent and they work that parent into putting them in a situation that is not good. Maybe being out on the road really late at night or driving in an area where they shouldn't be in and it is out of our control and I really feel helpless when it comes to that. I won't say the town, but we just got this person a license and they were driving in Galveston, Texas, at 2 in the morning and killed somebody on the Seawall and they had approximately had their license a week."

In general, neither public nor commercial school teachers were willing to say their students were fully prepared for independent driving after completing their courses. Most instructors appeared to agree with the comment of one public school instructor that:

"We have given them all the tools to work with and they can be a very good driver with what we have given them... [but] that doesn't mean that they are an expert."

As put by a commercial instructor:

"They are not ready to drive independently. But they think they are ready. I don't sign their certificate unless I know that I am comfortable and they are confident."

Another suggested that his students are ready to drive when they leave the school, but independent driving is less likely. Others agreed, noting a large disparity among young novice drivers in terms of exhibiting the necessary maturity to drive:

"I have students that are 16 years old that are good. Then I have some that are 18 years old that drove like a 12-year-old." 
Several instructors noted that some of the rules governing DE do not allow sufficient flexibility to provide confidence that DE graduates are sufficiently prepared. Of particular note is the requirement for a fixed number of hours of in-vehicle training. As noted by one teacher:

"...some of these kids can drive real well in 5 hours and some of them need 25 hours. We need to have that variable ability to be able to say, "Yes, this is how many hours you need,' instead of 7 hours no matter what, 7 hours and you're out of here."

Some instructors, particularly in commercial schools, noted that if they believed a student was not ready after meeting the required number of hours, they would talk to parents and recommend - usually successfully - that additional classes were necessary. As another instructor observed:

"I drive some of them much longer than the 7 hours because you can't teach some of them who have never driven before in 7 hours to be a perfect driver."

Yet another suggested:

"We could take them to 12 or what ever it takes. I don't think anyone in this room is going to take them through at 7 hours if they're not ready."

Concern about the readiness of their students to be on the road - without an instructor - was certainly not limited to commercial instructors. As a public school instructor phrased it:

"I don't think we let them out of the course, we don't sign off on it until we feel comfortable or confident that they can handle that."

Discussion of the readiness of students to drive also led to several comments about the adequacy of the DPS road test. ${ }^{10}$ While the opinion was offered that "there are some strict DPS tests," others noted that the test is generally inadequate:

"...because you go out and make a right and left turn and you got a license."

One instructor noted that Illinois has third-party testing.

"People make an appointment and if they pass this 45-minute test, sign the paper and give them their license."

It was suggested that such testing would solve multiple problems, including saving time and resources for DPS and providing a more realistic measure of driving capability. Note that no mention was made of the necessary qualifications of the test administrators or the costs associated with such testing.

Instructor assessment of different modes of DE

Both the public and commercial school instructors groups were asked to discuss what they believe the primary differences between public and commercial driving school programs are and whether they think either one produces better drivers. Whereas instructors in both modes

\footnotetext{
${ }^{10}$ Note that this test is not generally required for students who successfully complete an approved DE course, but parents may request it.
} 
generally expressed very similar opinions on most issues, this topic provided the clearest difference between the groups. Not surprisingly, each group stressed the advantages of their own programs.

Overall, most instructors in both groups seemed to agree that both commercial and public school programs provide very similar content in their courses. Said one public school teacher:

"They [instructors in commercial driving schools] have to give them [students] the same amount of in-car program; they have to give them the same classroom..."

And from a commercial school instructor:

"But in all reality, you can do the same thing if you do it in [public or] private schools."

Both groups generally believed that the qualification and training requirements for public and commercial school instructors are comparable. Nonetheless, at least 4 of the 11 commercial school instructors voiced the belief that the training requirements discriminate against commercial school instructors. For example, one instructor, offering evidence of a double standard with regard to training requirements, stated:

"The years that I taught in public school it [TEA training requirements] was 9 hours; then when I went to private I had to go to 15 hours...."

While not entirely clear, the additional 6 hours of training noted in the comment above appears to be a reference to the additional 6 semester hours of training required for an instructor to teach instructor training classes (see Training and Licensing of Instructors in Section 2, p12). Whatever the case may be, a substantial minority of commercial school group participants agreed with the opinion that commercial schools were:

“...for so many years...on an uneven playing field with the public schools."

Other commercial school instructors echoed the sentiment above, suggesting that while there have been improvements, commercial schools are held to a stricter standard than public school programs with regard to regulatory compliance and are more likely to receive penalties or more severe penalties (license suspensions, monetary fines) than are public school programs for similar infractions.

A large majority of the public school instructors agreed with several comments made by their peers, as typified by:

"My biggest beef with commercial schools is they run it like a factory. They have to be through in 14 days. And I take all semester and I don't get in a big hurry to get my kids a permit, I don't give it to them until midway through the semester."

There was also a significant undercurrent among several public school instructors, both expressed and implied, that although both modes of instruction teach the same thing, there may be different motives that could affect the quality of instruction: 
"[a commercial school] is a business, they are there to make money and that is a business of making money and we are at the [public] school, but, that I don't know, that one produces any better [drivers] or not."

Several public school instructors made the point that unlike their counterparts in commercial schools, their livelihoods do not depend on the number of students that can be "turned out" in the shortest time.

Interestingly, a commercial school instructor agreed, "this is our livelihood." However, she used that fact to support her contention that commercial schools are often superior to public school programs, to wit:

“...this is our livelihood, and if we don't do a good job, we don't get any business. Like I said, I've taught in the [public] schools. When you're teaching in that public school, and I'm not saying that they're all bad, because they're not, but they're there, they put in their time, they make their money and they go home. If the parents aren't satisfied, they don't hear about it. Where in a commercial school, you don't do a good job they tell you, they tell TEA, they tell everybody...so, it's a much harder situation. You have to really be on your toes."

The motivation of at least some public school instructors was impugned by the following comment that received tacit and explicit support from other group members:

"I was with all the public schools people and we were in a car driving; and not once did they talk about drivers ed. All the comments were about coaching, 'cause they were all coaches. I mean I've got one that works for me; fortunately, he is full-time now. But we never talked about drivers ed and what we could do to make this whole thing better, it was about who had the best football or basketball players. And I've never taught in public school drivers ed, but I would guess that goes on a whole lot because most of the coaches do the teaching in the public schools, or somebody that's a teacher and that's what you were saying, I think, it's a secondary job/source of income and it's not a reflection if the student learns or if the teacher taught."

A commercial school participant made one of the few comments that directly addressed a perceived difference in teaching approaches between commercial and public school programs, saying:

"I think the main problem with public schools is that they use simulators too much. They only drive them in simulators. Because they only drive them for four hours and then they [use] simulation for the rest of the time. And we have worked for [specifies a jurisdiction] where one set of our kids drove for the 7 hours and the others had simulation as the driving. The beginning drivers that had all driving did much better."

Several of her peers concurred.

What is/should be parents' role in DE? Public and commercial school instructors were very much in accord that the parents of their 
students need to play a significant role in their children's driver education. As expressed by two public school instructors:

"...we stress to the parents that they are a vital link to the success of them completing the course successfully. On our first day we hand out a parent letter that is addressed to the parent...we are needing their help and we have pinpointed it down in areas; this is what you can do to help, when they get their permit, it's all in writing there and they have to bring that back to us the next class day signed by them and by the parents."

"How do they get that experience that they need? Now, we can give them basics, but we can't give them really what they need. They are going to have to get that practice through their parents."

Both commercial and public school instructors stressed the importance of parents providing supervised driving practice time for their children. Several noted specific amounts of time parents should make available for practice. For example, one commercial instructor noted:

"...we say we want that parent to drive these kids at least 20 hours - which it should be at least 50 hours - during the time that they're with us."

Another noted:

"We tell them that [for] every hour of driving [in class] we expect an hour of practice at home..."

And from a public school teacher:

"I will write a letter [to parents] saying that we require you to be in the car with these students for so many minutes a week..."

While agreeing that parents should provide ample practice opportunities, many of the instructors noted both the difficulty in getting them to do so and the need for practice under conditions compatible with their teen's skill level, as illustrated by the following exchange among three instructors:

'I will say [to DE students], 'Are your parents working with you?' They reply, 'No, my parents won't get in the car with me.' I say, 'Well, they need to get in the car with you and work with you on this'..."

“...And then parents come in asking, 'You want me to take them out all over Laredo?' 'No, just take them around the block. Three or four turns to the right; three or four turns to the left, then put the car away.','

"Parents say that they don't want to take the risk."

"You know they're taking them out on the freeway or hard traffic right off the bat. Start them in a parking lot or some place where they can learn to drive."

Instructors also agreed that many parents do not realize that "getting a license" is not the end of the process and completing DE does not make expert, experienced drivers. Practice needs to continue long after the DE course is over. 
Specific assessment of the Parent-Taught Program in Texas

While all DE instructors agreed that parental involvement is crucial to the successful training and education of young novice drivers, their opinions about the formal Texas Parent-Taught Program are decidedly different. Several instructors expressed disdain for the PT program, for example:

"And all these people have never taken defensive driving and yet they are going to teach their kids? They are going to drive just like the rest; they [the kids] are going to drive just like you [their parents] do. Speeding all the time, doing something illegal, they are going to drive just like you do!"

In response to another group member's comments about parents' difficulties in providing needed forms, etc.:

"What I am saying is that shows you the caliber of parents. Not maybe a bad parent, but the caliber of the person teaching this child...they didn't even read the introduction letter to find out what they even needed to have to complete the first session.... So, what I am thinking is, OK, you are going to put this kid on the road with me and my three-year-old. I have a real problem with that."

Most negative opinions about the parent-taught program conveyed by public and commercial DE instructors, however, pointed to what they considered specific problems with the program. They can be grouped based on the comments' overall themes, as suggested by the sample of remarks epitomizing each of the categories presented below.

- Most parents are unprepared, unknowledgeable and/or untrained to teach their children to drive.

"I don't like the home taught for the fact that I have to have the training, I have to have my teaching degree, I have to have the education in order to do the driver education, I have to have continuing education to keep up on it. I have to have all this to teach and the parent has to do nothing. There is no requirement whatsoever...."

"You [DE instructors] have that training and certification and it is something that you do well. [Parents]...they're not driver ed teachers."

"See, it comes back down to, [parents believe] 'It's just drivers ed.' [They think] anybody can do that, it's not science, you know, anybody can teach us to drive."

"I have them [students who started PT but ended up in public school programs or who came to DE instructors for help] tell me my parents told me to do this. Well, they are wrong; this is not what you do. 'My Dad told me to drive close to that yellow line.' Yes, that's real good! ....'Aim at the headlights coming toward you'."

"A parent does not keep up on the new laws, a parent does not keep up on driving techniques; a parent does not keep up on anything. I mean when things change, parents do not know...."

- Many parents have good intentions but do not or cannot follow through. 
"The parents know what they want the student to learn, but they do not know how to teach them. They can't get across to them."

"Most parents don't have the patience. Kids don't listen. They can't drive with their parents because they are constantly yelling."

“...[I]f we took 100 home schooled people, just for sake of throwing out a number, I would think we would get somewhere between the 10-20 range where a parent did a formal good job. Taught them right."

- Many parents provide bad driving examples for their children.

“...[T]he kids will say, 'Well, Dad, you are telling me how to do this but you don't do it; whenever we drive, you don't do it. I never see you do it'."

- Accountability is lacking in the program - among parents, DPS, and the legislature.

"A lot of the parents don't teach the kids. They just sign papers."

"...[I]f you ever go to a DPS office and you work with those people in there, the stories that you can get from them - where they talk about parents coming in with their child and they have no idea of anything that is in that package. Or they picked it up today and they brought it in the day after. There is no way you could complete that course in that time frame, so they have never looked at anything and they have already signed that this child is ready for a license or to get a permit."

“... [Y] ou know how kids are; they talk amongst themselves and brag about how they think they really got away with something. And I have heard people say, 'Well, I wouldn't be in [DE instructor's name] class; just have your Momma sign off on it.' This is the way it is, I hear them say, 'My Momma didn't do [expletive], just let her sign off on it.' And they come right out and tell each other that."

"I have seen it where the kids were telling the parents where they are supposed to sign, because they didn't understand English that well on the parent-taught program."

"The DPS just takes their signature as gold - and their money."

"They [officials at DPS license stations] should ask them [parents] what textbook they used, but now they don't even do that."

"Most of the time they [parents] haven't even signed it [required forms/affidavits], so they go back to the parking lot and five minutes later they have it all filled out. The DPS officer said if she filed [meaning reported for civil action] everyone that did that, she'd spend eight hours a day, everyday, five days a week in court."

"Where did this all start from? It started from the legislature. And we have to let those people know. Because we can complain, [but] when we get to DPS, they are doing just what they were told by our legislature and it's those people you have to convince. The thing is that Mom and Dad don't want to pay. This is a cheaper way and naturally the politician looks at how many votes are in this room versus how many votes are outside." 
- Consequences of parent-taught program go beyond individual participants.

"But the thing about this is exactly what you are saying, in the sense of that what you are doing in teaching drivers ed affects many people because they are behind that car and which is a weapon."

"Like [another participant] was saying about his concern for the other people on the road. We don't know how that parent teaches and they [the parent-taught students] are going to be in our driving environment. How safe is that for us?"

“I don't have the statistics but I try to keep up on every bad accident that has happened [in my area], really serious accidents, because I try to incorporate that into what really happened and share that with the kids; because this is how we lost one of your peers and this is what happened. And I would say probably in the ones that I have really touched base on and the ones that I know personally, most of those, unfortunately, were taught by their parents."

"If you teach English as a parent and you do a lousy job, who are they going to hurt? So that's the big difference."

- The parent-taught program impacts public and commercial school programs.

"I think it has hurt my program because I don't have the enrollment of students I should have, basically. I am not able to afford to have some of the things I would like to have in my school; for instance, a simulator as an additional learning tool. I can't get the learning tools I would like to have because I can't afford it because I don't have the students that I would have had before parent-taught came in."

"Did it affect the driving and my classes at school; no, not really. When it came out right at the very beginning, the parents would say, 'Oh, you're too high and I'm going to teach them myself.' I said, 'Fine.' Well, then I found out right after that; then I had kids coming back that didn't have to go test, because they already had their [instructional] permit [from starting the parent-taught program], but the parents couldn't handle them in their cars. So I don't think it has affected as far as my enrollment or whatever."

- $\quad$ Participants felt that improvements could be made to the parent-taught program. "If they would have parents go through a workshop, that would be something." "I am writing a parent-taught seminar. It is not controlled or overseen by anybody and I am very excited about it. I will bring parents in and teach them how to teach their child and how to fill out the paper work."

"[Legislation was introduced] to try to get them at least to take a test, do some sort of six hour thing with the State, and I forgot what the other one was, but they all got kicked out."

"The DPS is not allowed to ask them about the curriculum (but they [some DPS license personnel] do it). But that would be good. That's accountability. Let the DPS ask them." 
"I am probably the only one here that I am not against parent-taught - and I am not for it. I just want things to be apples and apples, not apples and oranges. I want good accountability. I still look at it that there is money to be made in parent-taught, too. I believe in parent-taught for one reason: there are some people in Oklahoma that do parent-taught for the simple fact that if there is not a school [within] so far from you, then you can do parent-taught. In Virginia, a person that home-schools can do parenttaught. [In] California, you can do the parent-taught in the classroom, but every one in that State has to do the driving part in a driving school. Oklahoma is the only one who puts the tic mark on the permit if you took parent-taught. In Texas it seems like we threw out the parent-taught and said, 'Go for it baby,' and I think there is a way that you can put more accountability on it."

\section{Parents of Driver Education Students}

Fifteen parents participated in the two groups comprised of parents of teens who were currently taking or had recently completed driver education courses. All three DE modes were represented and several parents, with multiple children/step children, had experienced more than one of the modes. Also participating were two "mixed mode" parents. At least one child of each of these parents completed the classroom portion of DE in a public school program and the in-vehicle driving phase in the parent-taught program. Several parents referred to a "free" classroom portion of DE. Some public schools provide (or formerly provided) the classroom portion of DE to their students at no charge, but charge for the in-vehicle phase of DE. Some public schools have changed their policy; from one that allowed students to take only the classroom phase, to requiring that students who participate in the classroom phase also complete the in-vehicle phase in that program. Among the parents of parent-taught students were both the primary parentteachers and non-teaching spouses of parent-teachers. Most of the discussions with parents can be categorized as addressing the following questions and issues:

- Problems teens face as new drivers;

- What are the goals of driver education?

- How successful is DE in meeting its goals?

- What specific things are important to teach/learn in DE?

- How well does DE prepare novice drivers for the driving environment after completion of $D E$ ?

- Why did you choose the DE program you did?

- Best and worst parts of being a parent-teacher/main strengths and weaknesses;

- $\quad$ Assessment of DE curriculum and materials used;

- How well did parents follow prescribed procedures? and

- How good a teacher were you?

\section{Problems teens face as new drivers}

Several parents noted, with general agreement from others, that cell phones and other in-vehicle distractions were a serious source of difficulty with which new drivers were not prepared to deal. Others mentioned their concern with proper control of speed, situational awareness, adjusting to conditions, and overall lack of experience, as typified by the comments below. 
"I try to remind my son about that. He says, 'Well, it says 60, I can go 60.' Then I say, 'But you don't have to go 60.' That is my concern with him being 17, is that he remembers that you don't have to go that speed."

"I think that most of it is common sense; [for example] knowing whether it's safe to turn down the radio. When you're in a situation and knowing what you can and can't do. No matter what you can do, you have to watch what somebody else is going to do. They just need to realize that it is not all up to them; they can't control everybody. They have to watch out for the other guy too."

"I think the main concern is just the inexperience."

What are the goals of driver education? How successful is DE in meeting its goals? Parents seemed somewhat reticent to express in very specific terms what the goals of DE are or should be. They directed their responses more to what they believed it was important for their child to learn rather than any overall goals of DE (see: What specific things are important to teach/learn in $D E$, below).

Despite being unable or unwilling to enunciate the goals of DE, parents in both groups did express their thoughts about the extent to which DE meets its goals. Variability in opinions in this area was evident. Several parents thought their goals were met:

"Yes, because we used the book. I think, as [another participant] said, as a parent I know that book was read. I know that information was covered. I know those instructions got through to her. They are using the same basic materials, I'm assuming, in the drivers ed courses that are taught commercially or through schools. I think those are getting through. The material is very dry, but I don't see any other way of doing it."

"I feel like as parents we are taking the responsibility that whatever material that needs to be covered, we are doing that. I don't know how they teach it in school, but, like, I don't know that my son is reading all his English or history. We know he is reading his drivers ed book."

A number of parents expressed concern that some parents may not be meeting DE goals because a specific textbook is no longer required in the parent-taught program. Several parents who had previously participated in the program when a specific book was required continued to use it, others did not because it was not required. Though many group members thought they were meeting DE goals, they were less certain about other parents. For instance:

"With the older two there was a prescribed handbook that had to be used. With the younger one, the materials, you no longer had to use it. I wondered, if you don't have that handbook, what are you using to teach? What materials are the parents using that don't use that? I'm using the same one that I used from the older two. I will continue to use it on the others."

"I don't know what they are doing if they are not using a particular handbook. I'm talking about the textbook, not the Driver Handbook. They don't have to use a specific 
book. I don't know. When I got the material for the youngest one, it says in there that the text book is no longer mandatory."

"We didn't have a text book because it was not mandatory."

"We used it [an unspecified textbook] for in-depth reading. By the time we got to the paper packet, by the time it got to us, it was like, we talked about this, and this is the same. We just pretty much went through that paper packet pretty fast, because we had gone in detail with the book. There were a couple of things, a law or two here and there, that had changed."

\section{What specific things are important to teach/learn in DE?}

There was apparent agreement that:

"Rules and regulations are definitely at the top of the list. Learning their reactions in the different situations."

"I believe the rules are good for them to know. But what I also think is that experience is good."

Based on their own positive experiences with the use of simulators when they took DE, several parents expressed that the absence of such training ${ }^{11}$ in the parent-taught program, was a negative aspect of the program:

"One of the things my son is, I think, lacking in is, when I took DE, we had a simulator. In the simulator, you could drive down the road and if a ball came rolling out then you knew a kid was right behind it. It is something I had to verbally teach my son. Driving through neighborhoods, what to be aware of and what to expect, how to watch for cars parked nearby because you don't know what is coming between them. I feel like that is lacking. That is one of the things that you can't teach them in reading. It's like they need to experience it. It is just something that you have to try and teach them."

"I agree. When I went through DE, the simulation thing was... it made you feel like you were right there. My kid has not driven through hail or anything. You don't know when any of those things are going to happen. I think one of the main things is control, learning to deal with it; and the simulation really helps with that. I wonder what could happen with a computer-simulated web site. Because you know how these kids are on the computer 24/7."

Why did you choose the DE program you did?

The most frequently cited reasons for selecting the parent-taught program were cost and convenience. Typical parents' comments included:

"I would say money and convenience, because for me to have to take her to classes, I would have to take her and drop her off and have to go pick her up and we don't live in Waco, we live 20 miles out."

\footnotetext{
${ }^{11}$ Note that some of the commercially available PT courses do include a degree of "simulation" through interactive CDs and/or online activities. See descriptions of approved parent-taught DE courses in Section 2.2.
} 
"I couldn't afford to send them to the driving part even if the classroom part was free. I'm a single parent; I couldn't have afforded to send them to the on-the-road part. It was also a matter of convenience. Our classroom part was offered before school so she had to be there - our school last year started at 7:30 - so she had to be there at 6:30."

"Ours was a time thing. I worked and my husband worked and it was going to be, like, if [child's name] was going to take it, he had to take it after school. So that meant someone was going to have to get him back and forth. It gave us the reason to look at another option. Then when we saw this option, and now that we have lived it, we think it was better. The first reason was how we would get him back and forth. It was really a time thing is what made us look for another option."

"To be honest, when I did it with my [now] 22-year-old she played national softball and volleyball...so we were traveling with her all the time. There was just no other way she could have done it in school and take everything she needed to get into college. That was my reason at the time. Another parent told me about it. I had never heard of it and so we sent for it."

Money and convenience, however, were not the sole reasons parents chose parent-taught DE. The cost of commercial and public school DE programs and accommodating parent's work schedules and their children's academic and extracurricular activities clearly did play an important role in choosing the parent-taught program. For many parents, however, the decision to pursue the parent-taught program was also significantly influenced by their child's preferences and the belief they would get more personal attention than is provided in other DE programs. In addition, some parents, influenced by their own DE experience or that of their older children, believed that they could do a better job than commercial or public school programs or provide a less traumatic, more comfortable experience for their children than they remember from their own.

"My sister, her son went through the parent-taught. So I felt like we should look at that option. So when they didn't offer that in school, the time and financial restraints...I still felt like if he would have went through commercial-taught I was still going to get him in the car and make him do time with me. So why not get the rules in front of me and we go through them together. I just felt like that is so important; that I can't teach him his algebra or calculus, but if I think I have something that he can be on top of I'm going to make him do time with me."

"My daughter preferred we teach her, and she had the option of doing either [commercial or parent-taught] and so it was a mutual decision between us that we would do the teaching."

Prompted to explain why he thought his daughter preferred parent-taught, this parent replied,

"I think it was more of the flexibility of scheduling of doing it and that sort of thing. Plus, all her friends were being self-taught as well. It was kind of a peer thing too, as well. She was kind of apprehensive about the schooling, getting through that, too." 
"When I took it [DE]...we took it at the school, and I thought I could do a better job of teaching it."

“....[M]y oldest daughter took the paid driving school and I wasn't satisfied with the results, so that was one of the strong reasons for me to do the self-taught [for a younger child]."

Parents, particularly in the Waco group, expressed disappointment that the public schools in their area no longer offered DE. Had it been, some of the parents that participated in the parent-taught program indicated they would have opted for school-based DE - especially for the classroom portion of the program.

"I was quite unhappy that the school systems dropped the drivers ed courses, because I feel like they get the book knowledge, they are forced to read, because they are forced to take tests, they have the simulator and they get some experience there, then they get that much more riding with their parents. ... I really didn't want to do it [PT], but I did it anyway. I did a good job, they turned out to be good drivers, but I really wish they could have taken the school-taught, with the high school."

\section{Best and worst parts of being a parent-teacher/main strengths and weaknesses}

In response to an inquiry about the best part of participation in the parent-taught program, numerous comments stressed the interpersonal and relationship qualities of the experience. Typical comments included:

"The best part was that I realized that she could do it."

"That I was able to watch them learn."

"Of course at that age, they are starting to gain a little independence, so it gave us a few hours of quality time together."

Similarly, initial comments about the worst part of parent-taught DE also stressed the emotional components of the experience. A sampling of those comments includes:

"[Realization that]...they are on their own now."

"After 25 years I have no one to take to school and that is going to be hard getting used to."

"I made her nervous."

Several parents indicated the worst part was the short tempers and frustration felt at times during the process.

When prompted by the moderator to focus on specifics regarding the content and/or teaching process itself, several parents indicated the difficulty experienced the first time they drove with their child or the first time they did something new in the car, particularly the first time driving on an interstate highway or in city traffic. A number of specific driving tasks and skills were also mentioned as being particularly difficult, for example: 
"Learning how to know if the next person is going to give you the right-of-way or not, teaching them, hey, now you can go."

"... [W] henever it came to the red lights, she didn't know how to really tell if it was a yellow light and then you would see a red light. That is what scared me the most."

"I guess in terms of skills, the curb thing comes to mind; the judging, teaching her how to judge distances and corners and distance between vehicles ... on the interstate, when to merge or when to move out fast and that sort of thing. So I would say judging distances."

"Judging speeds to know when you can pull out."

Although initially raised as independent issues, parents in both groups discussed aspects of each of the following issues together:

Assessment of DE curriculum and materials used

How well did parents/students follow prescribed procedures?

How good a teacher were you?

Considerable confusion and uncertainty was evident among many of the parents regarding procedures required for the parent-taught program. Many cited the complexity of both the materials and the process, for example: "Who needs to sign what, when?" There were also mixed opinions about the amount of material contained in the PT packets, some thinking there was too much information provided and others believing there was not enough. Because the specific information provided in the PT packages distributed by DPS has evolved since the program was instituted and since the parents in the focus groups received their PT packages at widely different times, it is likely they did not all receive the same information from DPS.

Similarly, acquisition and use of teaching material was also a source of some confusion for many parents. When the parent-taught program was introduced, there was only one approved course under the program and it required parents to use specific State-adopted textbooks. Over the years, additional courses, developed and provided by six commercial driving schools and the Texas Driver and Traffic Safety Association, have been added to the approved list of parenttaught courses. Specific data identifying how many parent-taught program participants used each of the approved courses was not available for the evaluation. Based on discussions with parents and DE students (in the student focus groups) and on responses to the mail survey of young drivers, however, it is apparent that a significant majority of parent-teachers used the Model Program Course 101, available from the Texas Education Association. It is equally clear that not all parents used the entire set of material ${ }^{12}$ provided within the "Curriculum," "In-Car Instruction," "Supplement \& Worksheets," and "Transparencies" files associated with each of the 10 TEA instructional modules of the Model Course. Several parents noted that the primary or only teaching material they used was the "handbook," referring to the Texas Drivers Handbook produced and provided by the DPS. This is despite the notification by DPS that "If an instructor chooses to utilize this course they are responsible for developing the curriculum and lesson plan. This would include obtaining course materials." ${ }^{13}$ Some parents indicated they did

\footnotetext{
${ }^{12}$ TEA material is available online without charge or may be purchased on a CD or as a printed hard copy.

${ }^{13}$ See Appendix A: Guidance provided by the Texas Department of Public Safety to participants in the Parent-taught Driver Education Program.
} 
use a textbook (in addition to the Texas Drivers Handbook). A substantial number, however, relied primarily on the handbook and did not appear to use other materials:

"I didn't have my sons look at any textbook. I know they looked at the handbook, because they had to pass the test. The textbook, I don't know if they read it or not."

"In the packet of information they have, like, a suggested outline of things that the child should do and I mean some of it is like they should get online and research this information on the [statistics of] accidents and then make a report for like each chapter and each topic, they had like three or four large assignments for every topic, and I really don't see that happening."

After the moderator probed about "shortcuts" in terms of the amount of time students drove during the in-vehicle phase or time spent on other teaching/learning activities, parents were approximately evenly split as to whether or not they had cut any corners in the prescribed procedures. All agreed that, whether or not they had done so, "... it would be easy to do." Typical comments included:

"The shortcut thing mine took was she read the handbook and she knew the answers to it, so she really didn't want to read those things in the packet I wanted her to read, I had to really do some threatening for her."

"We may have fudged around with a little bit, because we may have driven to the store or to the mall; I probably accumulated some of those short trips into a 30-minute time slot."

"We made ours log their hours."

"We pretty much stayed with the suggested driving times or required driving times, because I wanted her to have as much driving skills [as possible]."

The classroom portion of teaching DE was daunting for some parents, as noted by one parent whose child completed the classroom phase in a public school program:

"I don't feel like I have all of those qualifications to teach my children as well as I feel as I was taught. I feel like I am a safe, courteous and respectable driver. I feel like I taught my children the same thing [during the in-vehicle phase]."

A discussion of parent's qualifications to teach DE and their teaching skills led to a wide range of self-assessments, for example:

"You do pick up a lot of your skills on how you were raised and your parents' abilities. Both of my parents drive good and I think I drive good, I can attest to that. Both of my boys are decent drivers, knock on wood."

"I try to be a better driver once they started realizing and watching what you are doing, when you are driving. When [child's name] started driving, she would say, 'Did you signal?' and I didn't signal. I would lean over and say, 'How fast are you driving?' and 'I don't want you driving and eating french fries until you're my age and you have been driving as long as I have.'” 
"Average, OK, adequate."

"Got the job done, I don't think I would want to teach anybody else."

"We got through, we are still practicing."

"I am kind of like [names another group member]; I modeled after my parents. They were good drivers. They don't have any accidents. I don't have any accidents in my life. I feel confident I could pass on some of that."

How well does DE prepare novice drivers for the driving environment after completion of DE? Mixed responses were offered with regard to the readiness of their children to drive after DE. Though few thought their children were fully prepared for completely independent driving, most believed they were ready for the next phase of driving [provisional license]:

"I think he will be a good driver. I think he is ready. He is ready to start driving."

"...[N] ow do we feel like he is ready to go on? [Yes], because we are living it with him and the teacher is not."

"I think with parent-taught once you have the 32 hours in and met the requirements, then you can go down and get the license. Then you still have control over your kid, I hope, to know whether or not they are taking that license and going on the road. I know mine won't be ready."

Several parents specifically noted the benefits of the Graduated Driver License restrictions through the first six months of post-instruction permit licensing. Some candidly suggested that they both liked the driving hours and number of young-passenger restrictions, and were happy that the State mandated those rules, absolving them of the responsibility to need to do so. Parents expressed similar sentiments about the in-vehicle driving test. Many would prefer that it were still required. None of those who had completed PTDE requested a DPSconducted road test, even though all the parents appeared to recognize that they could.

"If it were the State [that required a road test], then that wouldn't make me look like the bad person ... I didn't make them do that."

One parent who was still teaching her child under the program was uncertain if she would request DPS to test her son after completing the program:

"I don't know. I am thinking about myself. I went through drivers ed at the school and I don't know how old I was before I went down to get my license because I was petrified to take that test the first thing. I am kind of mixed on that, because if I know my child cannot drive from test anxiety, some kids just don't test well. ... I just don't know."

\section{Current and Recent Driver Education Students}

Ten female and 19 male young drivers participated in focus groups comprised of current and recent DE students. Participants ranged from 15 (4 participants) to 21 (1 participant) years old, with a median age of 17 and a mode of 16 (8 participants). All three modes of DE delivery were 
represented, with 10 parent-taught, 13 commercial school and 6 public school DE students participating.

The preponderance of the student group discussions focused on:

- Why they chose the mode of DE in which they participated;

- Evaluations of the material used in DE;

- Evaluation of their DE instructor;

- Amount, quality and type of in-vehicle instruction and practice received;

- Self-evaluation of student's own driving; and

- Overall impressions of their DE experience, including:

- Did they choose the right DE course?

- Would they recommend it to others?

- How would they improve DE?

The findings from the student groups are summarized below, again illustrated by group members' verbatim comments, and where relevant are segregated by type of driver education.

Why they chose the mode of $D E$ in which they participated

Convenience, competing time demands, cost, peer influence, parental dictates, and specific concerns about non-chosen alternatives were all expressed as reasons for selecting a particular type of DE.

\section{Commercial School DE Students}

In addition to frequently citing convenience issues, DE students who participated in commercial driving school DE programs alluded to other both positive and negative reasons for selecting a commercial DE course.

Several students indicated they would have preferred to take a PT course, but their parents did not give them that option:

"I wanted my parents to teach me so I wouldn't have to pay for it. I had to pay for it, which didn't make any sense. My parents didn't have time to teach me. They have to work. There was no way they could teach me. That was the only choice that I had."

"I wanted my mom to teach me because I hate school. I didn't want to go and sit for two hours in a room. I don't do well with that stuff. My mom never has ridden with me yet, because she tried once. She has a standard, so pretty much my first time to drive with my mom, she was teaching me to drive standard. After that she was, like, 'you're going to driver's ed; I'm not teaching you.',"

Other students also suggested a commercial course was their only option - but without the negative connotations suggested in the previous remarks, e.g.:

"I didn't have room in my schedule to take it during school, so I had to find somewhere else to take it.

“...[M]y sister went to the same [commercial] school, didn't know [my public] school offered it. 
"Parents were busy. [Public] school [DE] conflicted with sports. I was in sports at the time, so I couldn't take it at school."

Still others appear to have been drawn to a commercial program for more positive reasons, for example:

"I just wanted to go to [the commercial] school because my dad makes me uncomfortable. He is always trying to tell me a lot of information at once. I would be more comfortable with a teacher."

"I just felt I would learn more by going to [the commercial] school. I wanted to know what I was doing and not just be out there."

In addition, several students noted that in commercial driving schools, unlike public schools, students get exposure to different types of cars in the in-vehicle phase of instruction.

Public School DE Students

Cost, convenience, and peer influence dominated the reasons given for selecting a public school DE course, as exemplified by the comments of three students:

"[Public school DE is] cheaper [than commercial DE]. I had extra course material, so that's why I took it during school, because I have too much to do after school."

"I took it so I would have time outside of school, because I like to do other things."

"I took it because two of my friends had taken it the year before and they said it was good. That's why I took it."

\section{Parent-Taught DE Students}

Students who chose the PT program echoed many of the same reasons for their choice as those selecting commercial and public school DE.

Cost, convenience, and peer influence certainly played a part in some students' decisions:

“I chose my driver's ed. I didn’t have to pay for driver's ed - it was like \$250. All of my cousins took it [commercial DE] and they really didn't learn anything. I just told my mom I wanted home driver's ed."

"It's convenient, the home thing. You can get it done faster. I would feel more comfortable with my parents doing it. I guess they just kind of knew that is what I wanted to do."

"I live 30 miles away and all my friends were, like, we'll just take it here [at home], so that we didn't have to drive into town every single day."

In addition, however, several students suggested that they thought they would be more comfortable with their parents teaching them to drive, believed they would learn more than in the other options, or saw PTDE as a way to avoid what they considered distasteful aspects of any school environment:

"I just didn't want to go through school. I didn't want to sit through class." 
"My mom said she would teach me. I guess she thought I could learn more if she taught me."

"I don't know if I had a choice or not. I think it was just time to take driver's ed. I was scared at first. It was a big deal and I didn't know if I was a good enough driver or not."

Evaluations of the material used in DE

Very few positive comments about the DE material used in their courses were made by any the student groups participants. Among students in all three DE modes, this appears to stem at least in part from the generally held opinion that that the classroom portions of the courses are "just common sense," combined with the apparently widely held belief that much of the classroom portion of the courses is irrelevant to "real driving."

\section{Commercial School DE Students}

Typically, students noted that commercial schools they attended used both the Texas Driver Handbook and an additional textbook. Generally, students who chose to comment about the books did not believe them to be very useful. Some exception was made for the Texas Driver Handbook, used to assist in preparation for the instructional permit test. A large number (if not a majority) of these students claim to have never read the textbook, to have read it only under duress, or found it largely irrelevant, to wit:

"It didn't help me at all. I didn't read it."

"I only read it when I was forced to sit at the table and read it."

"The book didn't go over things that you would use in real-life situations."

In addition to the handbook and textbooks, several students noted the use of videos in their courses. Again, with some limited exception, the use of videos in the program did not gain the favor of this group of students. For example:

"...[W]atched a lot of movies and videos; they were horrible, like in the 1960s."

“... [We watched] cartoons about driving. Yeah, like Goofy and cops. Like the ones you see on TV."

"...Then they showed videos that went along with the book on, like, people stalled on railroads. It was, like, [there was] a train 250 yards away and they just sit there and yelled. We watched hours and hours of videos. Our class was two hours, three nights a week. Of that week, in the six hours, we watched four hours of videos."

Asked by the moderator if the videos were beneficial, this student replied:

"No, they were ridiculous. It doesn't apply to what you are actually driving. They are a little far-fetched."

\section{Public School DE Students}

Overall, public school DE students were perhaps somewhat less derogatory in the opinions they expressed about the material used in their DE courses. Nonetheless, several students expressed sentiments similar to their commercial school counterparts: 
"Materials seemed like they were outdated and the textbooks were kind of old. They need to be updated. It's all common sense. I could have passed it without the education."

Two of the public school students commented on the use of simulators in their course as part of the driving laboratory:

"Each class period, you did half the class in the simulator and half the class in the car."

Both of these students agreed that the use of the simulator was unrealistic and that:

"It was better in the car."

\section{Parent-Taught DE Students}

The parent-taught students in the focus groups usually mentioned the Texas Driver Handbook and some noted they also had a textbook (one PT student, the only group member among all students regardless of DE type, recalled the name of the text). Among our sample of students, the parent-taught students were somewhat more likely to admit having read at least some of the material provided. Similar to students in the other modes, however, they sometimes acknowledged that it took threats or coercion from their parent-teacher:

"The only time I would read it is when he got mad at me and I would have to go look up what I did wrong; like after I was already driving."

On the other hand, a female student, who participated along with her sister in the PT program, suggested that they were responsible for their teacher reading the material:

"We made my mom read it. We read it together."

One male student, noting that he never looked at the textbook and indicating that his teachingmother didn't care ("look over what you need to"), went on to explain, however, that this approach was of benefit to him and resulted from his mother's knowledge of how he learned. In his words:

"My mom threw me the handbook and I had to learn it from front to back. If it's a normal teaching course, it would be drawn out, which is annoying to me and repetitive. The way I learned it -- and the way I was taught -- was formed just to me."

As with the parent groups, there appeared to be some uncertainty about what material was required for their courses. One student, apparently referring to material from the TEA Model Course 101, though she did not identify it as such, noted with some dismay:

"There was a huge stack of papers that took a long time to get through."

\section{Evaluation of DE instructors}

Considerable diversity of opinion about DE instructors was revealed by the comments of students participating in all three DE modes. 


\section{Commercial School DE Students}

Commercial DE students categorized their instructors as everything from "cool" or "funny" to uninterested (allegedly to the extent of falling asleep) and uncaring:

"My instructor was cool, the one that I had towards the end helped me out a lot, he just made sure and he left me alone, so I really wasn't nervous too much and he would tell me where to turn. Other than that, he really didn't say too much. So that was all right."

"David [the instructor] was really funny. He doesn't make the class boring."

"The only thing I didn't like, was one instructor that I had, she actually made me pump gas for her, because she didn't put gas in the car, so she made me drive to a gas station and pump gas for her. I didn't have any other problems, other than that. Everything else was pretty cool."

"Coach [the instructor] was OK; didn't do much; talked about the football team."

"My instructors really didn't talk to me much. They just kind of let me go. I had one instructor that asked me on signs, what they meant, but that was about it."

"They told you the obvious things, and they didn't put you in a situation where you have this and what would you do. They would do stuff like driving down the road and you see this sign, what would you do? They wouldn't, like put you in a situation like, what do you do when a dog runs out in front of you. They never taught us anything about what you do when your brakes go out, what should you do? I'm sorry; I've been in a few bad wrecks." [This student later related she was in a crash when her brakes failed.]

"She [the in-vehicle instructor] was like everyone else; she really didn't want to be there. So we would have really long breaks. It's only two hours and our breaks were only supposed to be 15 minutes. She would give us 30 minutes. She didn't care."

"I think the women were easier to drive with. They were sisters and they were both the same way. They really didn't care, but at the same time, they were not overly friendly. I always felt a little uncomfortable with them. The guys, they freaked me out more because they were like open and friendly. It wasn't as easy to drive with them."

"It varies. There are three people you can drive with; and one of them was dumb. It was my very first time to drive. I never drove with my parents before, because they were scared. So the first time I was driving, I was on the road and he fell asleep and I was so scared."

\section{Public School DE Students}

Public school DE students were, overall, slightly less critical of their instructors than commercial DE students were. Positive comments, however, got no more expansive than the two below:

"It was OK, the instructor we had was really cool, laid back about everything, told us exactly what to do."

"My teacher was actually an ex-police officer. So we got to hear a lot of stories about people coming up on wrecks and bloody stories about decapitations and cool stuff like that, so that made it interesting." 
Parent-Taught DE Students

In general, PTDE students seemed to find their parents either "boring" in the classroom phase of DE or unskilled in the in-vehicle phase.

"It was boring. My mom taught me."

"My mom, no offense to her, but her driving skill is not as up to par as mine. In that area I think I could have done better in a classroom setting with an actual driver helping me."

"Pretty annoying. My mom is a worse driver than I am."

"She didn't really teach me anything I didn't already know. I already knew how to drive. ... Yeah, she corrects me. It wasn't like bad stuff; I just didn't do it her way."

There were exceptions, however. While some students described the in-vehicle part of the course as "annoying" or "scary" with their parent-teacher, others enjoyed what they perceived as an increased level of comfort driving with a parent. One PT student particularly appreciated his mother's unorthodox, but in his view, effective teaching style:

"My mom, I don't want to say weird, but she is different than a lot of adults. She will just grab the book [referring to the Texas Driver Handbook] every three or four years whenever she has to renew her license. She will update herself on any new laws. That separates her from a lot of other parents that teach."

This is the same student, quoted earlier, who said:

"My mom threw me the handbook and I had to learn it from front to back. If it's a normal teaching course, it would be drawn out, which is annoying to me and repetitive. The way I learned it -- and the way I was taught -- was formed just to me."

\section{Amount, quality and type of in-vehicle instruction and practice received}

Similar to their overall judgments about their DE instructors, students in all types of DE courses expressed a broad range of opinions about their in-vehicle experiences during the DE courses. Despite the commonly expressed notion that "I already knew how to drive," many students at least hinted at initial trepidation during in-vehicle training. Overall opinions - among students in all DE modes - ranged from those students who believed that they did not receive enough time or instruction tailored to their individual needs in the driving phase of DE, to students who suggested that their in-vehicle instructors did a good job of transitioning from easier to more difficult situations and provided a variety of roadway and traffic experience. A sample of comments is offered below. The section addressing how students would improve DE provides additional comments about the in-vehicle phase.

\section{Commercial School DE Students}

"I think if it [the in-vehicle phase of DE] just did a better job of recognizing who was a good driver and who wasn't.... They made everyone drive the same amount of time. Even if the bad drivers drove horrible they still passed." 
"Mine was different. ... [T] he first hour I drove, I did residential, the second hour they had me do access roads, then from there to the freeways and then the outskirts of San Antonio, and then from there they had me do downtown. They had me do different parts at different hours."

"I did my class time in two weeks and once I was finished with that then I had to get in 7 hours of driving. And that is what took longer and that is where I had the problems, because one of the instructors I had was really unreliable."

"My instructor was cool, the one that I had towards the end helped me out a lot, he just made sure and he left me alone, so I really wasn't nervous too much, and he would tell me where to turn. Other than that, he really didn't say too much. So that was all right." "It [in-vehicle instruction] helps. You don't want to get your license and never [have] been behind the wheel before. I was scared."

"Well, I pretty much freaked out the first time when I got behind the wheel and had to go out on the road. But I think I am getting better."

The moderator asked, "Were you immediately put into a stressful situation?" This male student suggested:

"Not really. He told me to back out and whenever the other student pulled in a big long driveway and he told me to back up, and I'd never backed out before."

Referring to pre-DE driving experience, this female student quoted above indicated:

"It is a lot different when you don't have your license and you just go down the road a bit, compared to when you get behind the wheel and someone has to rate you on how you drive."

\section{Public School DE Students}

"[We did] residential and, like, main streets and access roads." [Replying affirmatively when asked if the instructor gradually worked up to freeways.]

"At first I was nervous and he would be like telling all these jokes and I would be like, OK. But it was fine."

"My instructor was kind of relaxed about a lot of things and calmly said things, instead of jumping."

"I didn't think it was that bad, because my Grandpa used to let me drive all the time on his property. He would let me drive down different paths of the road, so I already knew how to drive, before I started the class. I have been driving since I was 12, probably."

"They taught us with what little time there was... and tell you how to take turns and stuff. You really didn't get too far from school because you had to get back in time."

Citing the limited variety of driving experience, the student above remarked:

"As far as turning and how to park, I may be a master at that." 


\section{Parent-Taught DE Students}

"[I'd drive] any chance I could get. I would say a good three months period of time. A lot of times she [parent-instructor] would say, 'We got to go here, you are going to drive to get in some more practice.' It's, like, in addition to that she would go to an empty parking lot near our old house. She would go in the parking lot when it was raining and make the car do donuts. She instructed me on how to control the car. I know with my mom it was helpful, like, she paid attention to every aspect when I was driving. After I got over the new driving thing and with driving with just my mom; it got to the point where it went from usual to not usual. She would be like, 'Make sure you're not driving too fast, make sure you obey the speed limit.' It went to more of the annoying, repetitive stuff."

"Yeah, she did [take me driving often], but she did it on a casual basis. Whenever I was behind the wheel, she would be giving me tips and stuff. It was just where we really needed to go. With my mom, I felt like she was more nervous than I was whenever I was behind the wheel. She would just be overly suggestive with her tips because I think she thought we might crash or something."

"It was pretty easy. They [parent-teachers] let you get comfortable and stuff. They didn't make you drive stiff and stuff."

Self-evaluation of their own driving, including extent to which driving restrictions are (were) followed

As is typical of most drivers, not just young novices, a substantial majority of the DE students in all the focus groups consider themselves to be above average drivers. Many of the groups' participants do appear to recognize that they need to improve both their driving skills and the choices they make with regard to how they drive. At the same time, many do not seem to recognize the obvious contradictions between their self-evaluations and the descriptions of their own driving. This is epitomized by the public school student who declared:

“...overall I think I am a good driver. I don't think I have any weaknesses.”

Nevertheless, in the same discussion, this student said:

"I kind of like to race around people, drive illegally. I just stay on their rear."

While apparently seeing no incongruity in these statements, the same driver then indicated that he does recognize that, in fact, some of his driving practices are clearly unsafe and he does not subject his friends to them:

"I speed when I am by myself [but not when others in the car with me]. I don't want to put my friend's life in danger."

Students participating in all three modes of DE expressed similar inflated opinions about driving skill and driving safety combined with recognition of driving limitations and indications of concern for the safety of other vehicle occupants, sometimes mixed with doubts about their peers' driving capabilities. For example, a male commercial school DE graduate suggested: 
"I am above average. [I] never drove before drivers ed [and it helped]. I have personal safety. I don't know about the other people going crazy on the road." However, the same student also said, "I like big empty roads, so I can go fast."

Another commercial school student who evaluated himself as a "decent" driver who believes he is improving in terms of being a better defensive driver, said:

"I have gotten to the point now where I will start thinking about what other people are going to do before they do it."

He went on to decry the driving of other teens:

"People that I have come close to getting hit by most of the time are teenagers and I blame it most of the time when their cars are full of people and they are all joking around or they have too much bass and they can't hear my horn, and those little rapper dudes that drive around with all that bass."

But, when asked if he ever drove fast, he admitted:

"I do occasionally. Occasionally I have a lead foot, so occasionally I catch myself going too fast. I did this one day. We were on Wurzbach Parkway and there usually isn't anybody on Wurzbach and I ended up doing about 90 and I caught myself, so I slowed down."

Other students recognized that teens might be prone to distraction when driving. Said a female public school DE student:

"I don't pay attention all the time. That's how I had my second accident."

Another commented:

"I just drift off sometimes."

A public school DE student both proudly rated himself as "pretty good" and, perhaps a bit sheepishly, added:

"I like to accelerate."

When asked to share any weaknesses in his driving, a parent-taught student, who also rated himself a good driver, simply replied:

"Street racing."

A few group participants neither considered themselves particularly good drivers nor offered contradictory views as illustrated above. When asked how good a driver he was, one student candidly noted:

"I haven't really driven enough to know. I suck everywhere."

Using the same vernacular, another said:

"I really only suck at turns and keeping my speed on the speed limit. I usually go 5 miles over the speed limit. But I don't notice it." 
When asked specifically about traffic tickets received, a catalog of offenses was recited. Not surprisingly, speeding headed the list; both in terms of the number of participants who had received at least one citation and the frequency of repeated violations. Speeding was also noted by a significant number of these young drivers as the offense they frequently commit without being cited. Several participants noted that the fear of citations, and more particularly, the fear of insurance rate increases if caught, was a deterrent to driving fast - at least in areas where they perceived enforcement might be present.

Other offenses participants readily mentioned included, in descending order of frequency, stop signal and sign violations, driving without a license, inspection violations, failure to maintain control, failure to move left safely and, what the recipient referred to as "a dumb one," operating a motor vehicle in a lake.

In addition to evaluating their driving, participants in all teen focus groups were asked their opinions about licensing rules and requirements, the restrictions placed on young drivers under the graduated driving license program, and the extent to which the restrictions were honored.

Although not a majority opinion, a number of participants were vocal in expressing the view that the minimum age requirements for obtaining a learners permit were too high. For example, a male commercial DE participant was only possibly joking when he suggested 12 years old as a minimum. He also did not believe the six-month minimum for holding the GDL Phase 1 license (instructional permit) was justified, suggesting:

“... most people taking drivers ed, it only takes a month. So they should either lower it or get rid of it, because you are already going to learn how to drive whenever you get your permit."

A female commercial DE student, on the other hand, thought the requirement that an instructional permit be held for six-months helped her because she didn't get many opportunities to drive. However, she also thought six months was too long and suggested that two months would be sufficient.

One parent-taught student thought the age requirements for licensing were good while another suggested age requirements should vary depending on the characteristics of the area in which one lives:

"If you're in the country you should get it (instructional permit) at 14 or 15 . People who live in Dallas or L.A. need it at 16."

A female PT student advanced the idea that the whole licensing process is too long and not needed. A second PT female agreed, suggesting:

"There's a lot that could be cut out or summed up."

A third member of that group, a commercial DE student who was licensed before the current age requirements were instituted, commiserated with those who are under the current age restrictions: 
"With the new ones, I think it's ridiculous. She [another group member] has to wait so long to get her license that everything she learned is going to be in the back of her mind. I don't understand why she has to wait."

A commercial DE student summed up his opinion of the age requirements and all of the driving restrictions imposed under GDL by appealing for skill-based rather than age-based criteria, saying:

"I think they should recognize driving skills. If everybody takes that test and does better than the next person, then I don't think they should have any restrictions. It should be based on your skill, not your age. I know when I was 16, I was not the best, but I wasn't the worst."

Most students expressed dislike for both the nighttime (midnight - 5:00 am) and young passenger (maximum of one passenger under 21) restrictions that apply to drivers throughout the provisional (GDL Phase 2) license phase. Several students, however, while admitting to violating restrictions, thought that they were reasonable and made sense. For example, as recounted by a male commercial school DE student:

"I personally didn't like it whenever I had it, but I knew we had them for a reason, so I really didn't argue with them too much about it. Went with it, with the one passenger for six months, it's really not that long."

The same student, however, did indicate that he has violated the nighttime restriction:

"But it was for a good cause. We weren't out joy riding or anything, we went to see somebody we hadn't seen in a long time...."

Challenged by an acquaintance in the group, he modified his story, acknowledging that, in fact, he went shopping at a 24-hour discount store.

Despite a male PT student's statement that, "The restrictions are good," more typical comments about the restrictions, especially the limit on young passengers, are exemplified by that of a female commercial DE student who rather succinctly said of the passenger restrictions:

"I had it. I didn't abide by it."

Another female participant elaborated:

"I got pulled over two weeks after I got my [provisional] license. I had four other people. He [the police officer] asked if I had just gotten my license. He gave me a warning. He didn't say anything about the people in the car. I don't think the six months/one friend in the car makes sense, because if you're a bad driver one person isn't going to change that."

A PT student agreed, suggesting:

"I don't think it really matters if the police aren't going to enforce it."

And a male public school student offered the opinion that:

"Most of the people don't follow the restrictions anyway." 
Finally, two male students, one public school and the other parent-taught, agreed that though they regularly violated the passenger restriction, they had never been stopped for it. Asked what would happen if they were, the PT student suggested:

"I would get a ticket and I would say they are my cousins."

Overall impressions of $D E$ experience:

Throughout the student focus groups, substantial discussion centered on participants' general impressions of their DE experience. Issues addressed included: Did students choose the right DE course; would they recommend it to others; and how would they improve DE? Students' overall impressions of their DE experience varied both within and between the three DE modes.

\section{Commercial School DE Students}

Commercial driving school students generally agreed that the cost of this option was too high, especially in light of what many considered class sizes that were too large. This was noted with regard both to the classroom and in-vehicle phases of DE.

Although some students indicated that the large class sizes they experienced in the commercial school they attended made it difficult to schedule driving times for the in-vehicle phase of instruction, at least one commercial student believed she got more driving time than she would have had she opted for the parent-taught course.

A female commercial school student appears to have summed up the opinions of many of the commercial DE students when she commented:

"When I took my class there was 30 people in there. They didn't have time to focus on all of them so they gave worksheets or popped in a movie. They are being paid for it. If you fail, you fail. There is nothing they can do. If you had to take it again, they would make another 300 bucks. They are really not focused on you learning. They're focused on getting you in and out."

At the same time, this student believed attending a school would be the preferred method of obtaining the required driver education for most of her peers, but specifically emphasized social rather than educational reasons for this choice, suggesting:

"It's the social aspects of it. They go because their friends are going and that is cool; because it is easier to go with someone you know."

While some other students echoed this view, opinions were also voiced that suggested disappointment in the educational quality of their commercial DE experience. For example, a male commercial school student, who felt he learned very little, indicated that his experience in DE did not meet his expectations, stating:

"I was expecting a real class. Especially when you get all the material, I thought we were going to be talking and sitting down. Like a group discussion. We just sat there." 
Several commercial DE students indicated that they would recommend parent-taught DE to others. Their reasons for this recommendation, however, varied. Some agreed with the female student who remarked:

"[In the commercial school] for many kids, you just start not caring. If it's your parents, you're going to try just a little harder."

Others recommended parent-taught DE not because they believed it to be better, but because they perceived it to be faster and easier, as noted by the student who suggested:

"...[I]f you do it with a parent, they would just blow it off."

Commercial students suggested a few ways they thought DE could be improved. Substantive ideas were offered by two students, one of whom explained:

"I think we should get more downtown time. Personally, I don't like driving downtown, but I think it would have really helped me. Showed us more of the awkward streets. Like, I have been on some streets that are really weird. Like the way that they are set up, there is a lot of confusion, where some of the streets are and I wish they would have spent more time in the driving lessons showing us more of those."

The other suggested:

"I think they should do it more like defensive driving. I took defensive driving right after getting my license to make my insurance go down. I learned more there than I did in class."

\section{Public School DE Students}

Unlike commercial DE students, group participants who met their DE requirement in public school courses did not cite class size as being a problem. Several did agree with the commercial DE students, however, that were they to do it over, they would prefer to take a parent-taught course. Like their commercial DE peers, perceptions of the PT option included both the belief that:

"You're more comfortable with your parents,"

and, that PT would be easier, because:

“...[Y]our parents will just sign off."

Two of the public school DE students suggested that their peers or younger siblings pursue DE in a public school program. One apparently valued the training of the instructors, saying:

"Most of the people there are teachers and they give you relief, I guess. They understand and they are cool teachers."

The other indicated that he would recommend taking a public school course, but also noted:

"You have to learn from your parents anyway." 
There was not a great deal of substantive complaints about the public school DE experience. Negative comments, included:

"The only thing I didn't like was the lack of time. And when you went out driving, you had to be back at school by the next class time. So you never really got to go very far."

Another student agreed, replying to the question of how DE could be improved:

"I think more driving time. We only got, like, 15 minutes to spread it between three people, and you have to divide 45 minutes."

One participant thought the course was "too quick." Noting that:

"I think it is crunching too much into your brain at one time, the rules and tests, and you have to pass the test."

This student, who took DE over winter break, also indicated that a longer course was available:

“...but I didn't want to have to go every Saturday for a month.”

One female public school DE student indicated that she believed the course was too easy, and blamed the two crashes she has experienced on that fact. When asked if she thought she would have worked harder had the course been more difficult, the student replied:

"Yeah, I would have to really try instead of just blowing through it."

\section{Parent-Taught DE Students}

A majority of the PTDE students would recommend that option to their peers and siblings. Different students offered different reasons.

One male student indicated that he would take PTDE again if he had to do it over again, primarily because:

"It is just easier. Easier than school-taught or commercial school."

He held this opinion despite indicating that:

"I felt it was up to my mom to teach me. She didn't really do a good job. She left it up to me. I pretty much taught myself."

Cost was also noted as a reason to recommend PTDE. Said one student, suggesting that his younger sister would likely take PTDE:

"...just because of the financial burden. It almost cost 350 dollars to do it privately or in school. It only cost 20 bucks to do it with your parents. It is just more than likely she [his sister] won't drive until she is 18 . When she does get to 18 , my mom still will have her take [parent-taught] drivers ed."

Other PT students confirmed, in effect, the opinions of some public and commercial DE students that PT is more comfortable than the other options. As one male PT student put it: 
"It is easier to relate to your parents than to some teacher. When you're in the classroom it's hard to relate to the teacher, so you can't really ask them real questions like you would your parents."

Another student indicated the classroom portion of his PT course took "like a week," after which he took the test for an instructional permit. Asked if thought he had learned anything in the course, he replied:

"I drove my parents; that's how I learned. They told me what to do. I just did it. You learn more driving than reading it."

\section{Summary of Focus Group Findings}

Focus groups with instructors, parents, and teens were conducted to collect data regarding firsthand experience with each of the three types of Texas DE delivery modes. The discussions included expectations, opinions of effectiveness, assessments of curricula and instructors, and anecdotal information about the DE experience. While not generalizeable to the population of DE participants, data from these groups provide useful descriptive information to shed light on the similarities and differences between the PTDE and other options in Texas.

The following summary statements can be made from the instructor focus groups consisting of a total of 22 commercial and public school DE instructors:

- A consensus view among DE Instructors is that the goal of DE is to develop in novice drivers the basis for a lifetime of driving, with a strong emphasis on responsibility, good decision making, and development of appropriate attitudes about driving.

- DE instructors consider it important to be good role models as drivers.

- Instructors perceive that parents often have views of the goal of DE that differ from that of the instructors, with parents leaning more toward crash prevention or expediting the licensing process.

- Instructors agree that parents have a significant role to play in the driving education of their children, and that practice should continue after licensure.

- Instructors have generally positive opinions regarding the curricula they use, as well as their ability to achieve the course goal of driver competency, at least in the short term.

- The strengths of the comparable content and instructor requirements were noted among both commercial and public school instructors. However, each group of instructors ascribed varying levels of motivation to their counterparts.

- Professional DE instructors expressed concerns over the parent-taught option, specifically regarding parent qualifications, the lack of program accountability, and the impacts of the program on traffic safety and, to a lesser extent, on the commercial/public school program viability.

Two focus groups were held with parents of teens who had recently or were currently taking DE. These groups revealed some insight into why this option was selected by parents and uncovered several pros and cons of their role as driver educator. 
- Money and convenience were two factors often cited as reasons the parent-taught option was chosen. However, the opportunity for one-on-one individualized attention to the student was another motivation for this choice. Some parents expressed the belief that they were more qualified to teach and/or less intimidating as a teacher for their own child. Finally, another factor was simply the lack of availability of another option.

- The parents in the focus groups generally conveyed that they felt they had done a good job teaching their children. Some parents had doubts, however, primarily because there is no State-mandated textbook. Selecting, acquiring, and using a textbook or curriculum is one of the responsibilities parents as DE instructors find challenging. Various options for curriculum use were reported, from none to the use of the 1,600-page TEA course.

- A positive aspect of parent teaching that came across during the focus groups is the opportunity to pass along values associated with driving held by the parent. Example values included the social and financial responsibilities involved and expectations from the parent regarding safety and security while traveling. Parent-teachers also seemed to feel more qualified to determine when their own child was ready to be licensed and better equipped to pace the instruction to suit individual needs.

Five focus groups of teens were conducted with DE students or teens that had recently completed their DE/licensing experience. The teen point of view was elicited regarding the course, the instructors, their driving/learning experience, and their choice of DE program. The following summarizes some of the key points from these groups.

- $\quad$ The reasons for course choice are varied and no single motivation supersedes others. Reasons cited were cost, convenience, competing time demands, availability, peer influence, and parent preferences.

- Students typically do not view the textbooks, curriculum, or visual material as valuable or beneficial.

- Students in each of the DE program types expressed opinions of instructors that did not convey a sense of professional respect.

- $\quad$ Focus group participants considered themselves above average drivers.

- Violating traffic laws, receiving citations, and having crashes were reported as if they are the norm.

- Teens typically object to restrictions and testing for themselves, but not necessarily for other drivers.

- A significant number of participants from all three DE options (commercial, public, and parent-taught programs) would recommend the parent-taught option to their peers. Reasons included the opinion that: (1) new drivers would be more comfortable with their parents; (2) the course can be tailored to the individual student's needs; and (3) that PTDE is faster and easier to complete. 


\subsection{Survey of Young Drivers}

\subsubsection{Detailed Evaluation and Analysis Approach}

Self-reported information from Texas drivers who recently completed novice driver education courses was obtained from a statewide mail survey. The survey was conducted for several reasons. It was devised, in part, to provide a broader sample of opinion than could be garnered from focus groups with recent driver education students about issues related to their early driving experience. In addition, the survey was the primary means to obtain data that might differentiate young drivers who completed driver education in public school settings from those completing commercial driving school courses. The data available from Texas driver records do not make a distinction between these two traditional modes of driver education delivery. Both are coded as 'Commercial.'

\section{Survey Development}

Development of survey items was based on results of focus groups conducted for this and previous projects, review of driver education and young driver survey literature, previously published and proprietary surveys of young drivers and other driver education evaluation instruments. Principal sources for the survey include the work of Lonero and his associates in Canada (Lonero et al, 2005), Masten and Chapman's evaluation of the effectiveness of homestudy compared to classroom instruction in California (2003), and Oregon's guide for implementing parental involvement in driver education (Oregon Traffic Safety Education Association, 2002). Lonero's work was, in turn, significantly influenced by instruments such as the Driver Behaviour Questionnaire of Manstead and his colleagues (e.g., Parker et al., 1995), and Malfetti's Young Driver Attitude Scale (Malfetti et al, 1989).

The survey includes demographic items, questions about the type of driver education completed, why that type was chosen, opinions about the course and course instructor, including, in the case of parent-taught students, their opinion of their parent as a driving instructor. Also incorporated in the survey are items intended to ascertain recent driving experience, driving-specific and general safety-related and lifestyle attitudes, and self-reported traffic violation and crash history.

The survey was pre-tested informally throughout its development using a small convenience sample comprising college-age student workers at the Texas Transportation Institute. A more formal pilot test was conducted with a 100-survey mailing to a sample of young Texas drivers selected from the same population and using the same sample selection process as the final 5,000-person sample selected. Both substantive and format modifications were made as a result of the pilot testing.

The final survey instrument comprised an 8.5 by 11-inch 12-page booklet that was mailed to the 5,000-person sample in early June 2005 using addresses provided in the Texas driver records. A pre-addressed postage paid business reply envelope was included in the mail-out for returning completed surveys. Approximately 10 days following the initial mailing, a follow-up postcard was mailed to all potential respondents from whom a reply had not yet been received. These are shown in Appendix D. 
The first page of the pilot and final survey booklets was an introductory non-personalized letter signed (facsimile) by the project director. The letter outlined the purpose of the survey, requested cooperation and, in compliance with the requirements of the Institutional Review Board - Human Subjects in Research, incorporated the elements of informed consent and provided survey recipients with contact information to address any research-related problems or questions. In addition, the letter assured recipients of confidentiality and conveyed how the survey information would be used.

\section{Survey Sampling}

A stratified (by DE type) random sample was drawn from Texas driver records of 5,000 of the approximately 187,000 Texas residents who received a GDL Phase 1 license (instructional driver permit) and started participation in an approved Texas Driver Education Program between January 1 and December 31, 2003, and who were 17- to 20-year-olds as of May 1, 2005. The ages and DE types of the resultant sample are summarized in Table 3. Table 4 provides a comparison of the characteristics of the survey sample as drawn with those of the sampling frame. No significant differences (z-tests of proportions) were found for any of the sample versus sampling frame comparisons.

Table 3. Survey sample

\begin{tabular}{|c|c|c|c|c|}
\hline $\mathrm{Age}^{1}$ & Commercial $^{2}$ & Parent-Taught & Undetermined $^{3}$ & Total \\
\hline 17 & 571 & 377 & 533 & 1,481 \\
\hline 18 & 1,117 & 712 & 381 & 2,210 \\
\hline 19 & 555 & 268 & 221 & 1,044 \\
\hline 20 & 157 & 43 & 65 & 265 \\
\hline Total & 2,400 & 1,400 & 1,200 & 5,000 \\
\hline
\end{tabular}

Table 4. Percent of sample as drawn compared with percent of sampling frame, by age and DE type

\begin{tabular}{|c|c|c|c|c|c|c|c|c|}
\hline & \multicolumn{2}{|c|}{ Commercial $^{2}$} & \multicolumn{2}{|c|}{ Parent-Taught } & \multicolumn{2}{|c|}{ Undetermined $^{3}$} & \multicolumn{2}{|c|}{ Total } \\
\hline $\mathrm{Age}^{1}$ & Sample & $\begin{array}{l}\text { Sampling } \\
\text { Frame }\end{array}$ & Sample & $\begin{array}{l}\text { Sampling } \\
\text { Frame }\end{array}$ & Sample & $\begin{array}{c}\text { Sampling } \\
\text { Frame }\end{array}$ & Sample & $\begin{array}{c}\text { Sampling } \\
\text { Frame }\end{array}$ \\
\hline 17 & 11.4 & 12.0 & 7.5 & 7.6 & 10.7 & 10.5 & 29.6 & 30.1 \\
\hline 18 & 22.3 & 22.3 & 14.2 & 14.6 & 7.6 & 7.1 & 44.2 & 44.0 \\
\hline 19 & 11.1 & 10.6 & 5.4 & 5.4 & 4.4 & 4.5 & 20.9 & 20.5 \\
\hline 20 & 3.1 & 3.2 & 0.9 & 0.9 & 1.3 & 1.3 & 5.3 & 5.4 \\
\hline Total & 48.0 & 48.2 & 28.0 & 28.5 & 24 & 23.4 & 100 & 100 \\
\hline
\end{tabular}


It merits reiterating that Texas driver records do not distinguish between commercial and public school DE courses; driver education coded as "commercial" in the driver records includes both. Also, the substantial proportion of the survey sample (24\%) identified as "undetermined" with regard to type of driver education reflects a like proportion of drivers represented in the driver records who had not completed a DE program as of the date of the driver records used and also includes the relatively small number of young drivers who completed some combination of 'commercial' and parent-taught DE.

\section{Survey Analysis}

Analyses of survey responses consist primarily of comparisons among the three driver education delivery modes of interest:

- Parent-taught driver education under the Texas Parent-Taught DE Program,

- Courses provided by private commercial driver education schools, and

- Courses provided by public schools, including private and parochial academic institutions.

Chi-squared $\left(\chi^{2}\right)^{14}$ tests were used to compare the distribution of responses to categorical survey items associated with type of driver education. Additional $\chi^{2}$ tests between pairs of DE types were calculated in those instances in which significant differences among the DE types were revealed. Tables provide both the number (n) of responses in each category on which the $\chi^{2}$ analyses were conducted and percentage data for ease of comparisons among the DE types. In some cases small cell values (including zero) precluded use of $\chi^{2}$ analysis using all response categories. In these cases, contiguous categories were combined to meet $\chi^{2}$ statistical assumptions. The tables reflect these groupings.

One way analyses of variance (ANOVA) and associated Duncan Multiple Range Tests for post hoc comparisons of means were applied to survey responses for a subset of the survey items for which numerical scales were derived from respondent ratings and for analyses of items for which driver age was determined, for example, age at various stages of licensure. ANOVAs were conducted using the General Linear Models Procedure in SAS. ${ }^{15}$

\subsubsection{Results of the Mail Survey}

\section{Survey Response Rates}

A higher than anticipated number of mailings returned as "not deliverable as addressed" or for "insufficient address" was initially traced to an error in the postal software used to confirm address validity in the original mailing list. These errors were corrected and approximately 150 surveys were re-mailed. Even after correcting software-related addressing errors, a substantial number of surveys were returned undeliverable. Among the original sample of 5,000, 244 surveys were returned undelivered. Thus, the effective sample size was reduced to 4,756 young Texas drivers. A total of 496 surveys were returned sufficiently completed to warrant coding and use; an effective response rate of 10.4 percent. Seven of these were ultimately disregarded because respondents failed to indicate the type of DE completed, reducing the useful response rate to 10.3 percent. Although somewhat disappointingly low, this response rate is not entirely

\footnotetext{
${ }^{14}$ Unless otherwise specified, a 5 percent level of significance $(\dot{\alpha}=0.05)$ is employed for all tests.

${ }^{15}$ Statistical Analysis System, version 9.1.3, SAS Institute, Cary, NC
} 
unexpected given the age of the respondents and the length and complexity of the survey instrument. It should be noted that the number of respondents replying to every question is not 489 - some questions were directed to only a subset of survey recipients dependent on answers to previous items and some respondents either inadvertently or intentionally did not answer some questions. The number and percent of surveys returned and coded, categorized by self-reported DE type (survey item Q10 ${ }^{16}$ ) are indicated in Table 5.

Table 5. Surveys returned by self-reported DE type

\begin{tabular}{|l|r|r|r|c|}
\cline { 2 - 3 } \multicolumn{1}{c|}{ Q10 } & Number & Percent & Number & Percent \\
\hline Parent-Taught & 192 & 38.7 & 192 & 38.7 \\
\hline Commercial & 209 & 42.1 & 285 & 57.5 \\
\hline Public School & 76 & 15.3 & & 2.4 \\
\hline Mixed & 12 & 2.4 & 12 & 1.4 \\
\hline Unknown & 7 & 1.4 & 7 & 100 \\
\hline Total & 496 & 100 & 496 & \\
\hline \multicolumn{4}{|l}{}
\end{tabular}

The proportion of respondents who completed parent-taught, commercial, and public school DE course $(39,42$ and 15 percent, respectively) compares reasonably well with the proportions of driver education certificates issued by TEA during school year 2001-2002 (parent-taught $=32 \%$, commercial $=49 \%$, and public school DE $=20 \%$ ). Recall that the certificate data is based on gross distribution of certificates that may include duplicates, unused and voided certificates. Thus, while they do suggest the relative extent of participation in the three options for approved novice driver education, they are not intended to provide an accurate indication of the absolute number of students in each training option.

A small number of surveys (12) were returned from young drivers who indicated they completed DE under some combination of the DE modes -- for example, the classroom portion of DE was completed through a commercial or public school course and the in-vehicle portion was completed under the parent-taught program. Responses from these drivers are not included in the analyses or tables. In all cases, analysis was limited to responses from those young drivers who reported completing one of the three unitary DE types specified.

\section{Survey Responses and Discussion}

Presentation and discussion of survey results are organized in six general categories in the sections that follow:

- Respondent demographics - including gender, age at time of survey, and type of DE course completed,

- Driver education course and licensure milestones,

- Students' evaluation of driver education experience,

\footnotetext{
${ }^{16}$ In Table 5 and subsequent tables summarizing survey responses, the survey item) from which the data is derived are indicated by Qx, indicating the survey question(s). Questions and/or response categories may be abbreviated in the tables. See Appendix D for original wording, item order, and survey layout.
} 
- $\quad$ Recent driving experience - including self-evaluations of driving knowledge, skills and attitudes

- Driving errors or misjudgments, and

- $\quad$ Self-reported traffic violations and crashes.

\section{$\underline{\text { Respondent Demographics }}$}

\section{Gender}

A majority of survey respondents, as shown in Table 6, are female, 64 percent overall. As indicated, this preponderance of female respondents holds for each of the DE types. Within gender, however, the distribution of respondents' reported DE mode is much more equally balanced (see Table 7) and does not differ significantly. Among male respondents, 42 percent report they have completed a parent-taught course; compared to 39 percent of the female respondents. A somewhat larger proportion of female respondents took a commercial DE course than did males and very nearly the same proportion of males and females took public schoolbased courses.

Table 6. Survey respondents' gender by DE type

\begin{tabular}{|c|c|c|c|c|c|c|}
\hline \multirow{2}{*}{ Q10 x Q1 } & \multicolumn{3}{|c|}{ Number } & \multicolumn{3}{|c|}{ Percent } \\
\hline & Male & Female & Total & Male & Female & Total \\
\hline Parent-taught & 73 & 119 & 192 & 38.0 & 62.0 & 100 \\
\hline Commercial & 72 & 137 & 209 & 34.4 & 65.6 & 100 \\
\hline Public school & 28 & 48 & 76 & 36.8 & 63.2 & 100 \\
\hline Total & 173 & 304 & 477 & 36.3 & 63.7 & 100 \\
\hline
\end{tabular}

Table 7. Survey respondents' DE type by gender

\begin{tabular}{|l|c|c|c|c|c|c|c|c|}
\cline { 2 - 9 } \multicolumn{1}{c|}{} & \multicolumn{9}{c|}{ Q1 x Q10 } & PT & Com & Public & Total & PT & Com & Public & Total \\
\cline { 2 - 9 } \multicolumn{1}{c|}{} & 73 & 72 & 28 & 173 & 42.2 & 41.6 & 16.2 & 100 \\
\hline Male & 119 & 137 & 48 & 304 & 39.1 & 45.1 & 15.8 & 100 \\
\hline Female & 192 & 209 & 76 & 477 & 40.3 & 43.8 & 15.9 & 100 \\
\hline Total & \multicolumn{8}{c|}{$\chi^{2}=0.56, \mathrm{df}=2, \mathrm{p}>.05$} \\
\hline \multicolumn{10}{|c|}{}
\end{tabular}

Age

An estimate of each respondent's age when the survey was completed was calculated from reported date of birth and the date the completed survey was returned. The distributions of ages, in half-year increments, are shown in Table 8.

Both the two youngest and two oldest 6-month age groups were combined for analysis due to low cell frequencies in the groups at the upper and lower range of respondent age. The age distributions do not differ significantly as a function of DE type.

Respondent average ages at survey completion were $17.7,17.9$ and 17.8 years old for parenttaught, commercial and public school DE students, respectively. Consistent with the results of 
the $\chi^{2}$ test, a one-way ANOVA revealed no significant differences in age associated with DE type $[\mathrm{F}(2)=0.75, \mathrm{p}>.05]$.

Table 8. Respondent age at time of survey by DE type

\begin{tabular}{|c|c|r|r|r|r|r|r|r|}
\cline { 2 - 10 } \multicolumn{1}{c|}{ Q2 x Q10 } & \multicolumn{9}{c|}{ Number } & \multicolumn{4}{c|}{ Percent } \\
\hline Age & PT & Com & Public & Total & PT & Com & Public & Total \\
\hline $16.0-16.9$ & 20 & 21 & 10 & 51 & 10.4 & 10.1 & 13.3 & 10.8 \\
\hline $17.0-17.4$ & 56 & 54 & 22 & 132 & 29.2 & 26.1 & 29.3 & 27.8 \\
\hline $17.5-17.9$ & 70 & 72 & 23 & 165 & 36.5 & 34.8 & 30.7 & 34.8 \\
\hline $18.0-18.4$ & 19 & 22 & 5 & 46 & 9.9 & 10.6 & 6.7 & 9.7 \\
\hline $18.5-18.9$ & 17 & 21 & 8 & 46 & 8.9 & 10.1 & 10.7 & 9.7 \\
\hline $19.0-19.4$ & 7 & 8 & 3 & 18 & 3.6 & 3.9 & 4.0 & 3.8 \\
\hline $19.5-20.4$ & 3 & 9 & 4 & 16 & 1.6 & 4.3 & 5.3 & 3.4 \\
\hline Total & 192 & 207 & 75 & 474 & 100.0 & 100.0 & 100.0 & 100.0 \\
\hline & \multicolumn{9}{|c|}{$\chi^{2}=5.97, \mathrm{df}=12, \mathrm{p}>.05$} & & & \\
\hline
\end{tabular}

\section{Educational attainment of parents}

As a gross measure of socioeconomic status, respondents were asked to indicate the highest academic level achieved by their parents. As reported in Tables 9 and 10, the overall $\chi^{2}$ indicates a significant difference among the DE type distributions. Additional $\chi^{2}$ tests between all pairs of DE type reveal significant differences between all of the pairs (parent-taught versus commercial: $\chi^{2}=14.38, \mathrm{df}=5, \mathrm{p}<.05$; parent-taught versus public school: $\chi^{2}=12.62, \mathrm{df}=5, \mathrm{p}<.05$; commercial versus public school: $\left.\chi^{2}=17.2, \mathrm{df}=5, \mathrm{p},<.05\right)$. Parents of commercial DE students are reported to have generally higher educational achievement than either parent-taught or public school DE parents, particularly as indicated by the proportion of parents with baccalaureate and advanced college degrees. Public school DE parents appear to exhibit the lowest overall educational attainment as evidenced by the proportion whose highest level is less than graduation from high school and the total proportion of those who graduated with any type of postsecondary degree.

Table 9. Highest educational attainment of parents by DE type of respondents - Number

\begin{tabular}{|l|c|c|c|c|c|c|c|}
\cline { 2 - 8 } \multicolumn{1}{c|}{$\begin{array}{c}\text { Q4 } \\
\text { Q10 }\end{array}$} & $\begin{array}{c}\text { Less than } \\
\text { High School }\end{array}$ & $\begin{array}{c}\text { High School } \\
\text { Grad }\end{array}$ & $\begin{array}{c}\text { Some } \\
\text { College }\end{array}$ & $\begin{array}{c}\text { Community/Junior } \\
\text { College Grad }\end{array}$ & $\begin{array}{c}\text { Baccalaureate } \\
\text { degree }\end{array}$ & $\begin{array}{c}\text { Advanced } \\
\text { Degree }\end{array}$ & Total \\
\hline PT & 10 & 31 & 45 & 19 & 52 & 34 & 191 \\
\hline Com & 12 & 21 & 29 & 17 & 68 & 60 & 207 \\
\hline Public & 13 & 12 & 16 & 5 & 13 & 17 & 76 \\
\hline Total & 35 & 64 & 90 & 41 & 133 & 111 & 474 \\
\hline \multicolumn{8}{|c|}{$\chi^{2}=30.81, \mathrm{df}=10, \mathrm{p}<.05$} \\
\hline
\end{tabular}

\section{Incidence of Home-Schooling}

Table 11 provides the number and percent of survey respondents that are being (or were) homeschooled for high school. Overall, 6.4 percent of respondents indicated home-schooling. Parent- 
Table 10. Highest educational attainment of parents by DE type of respondents - Percent

\begin{tabular}{|l|c|c|c|c|c|c|c|}
\cline { 2 - 8 } \multicolumn{1}{c|}{$\begin{array}{c}\text { Q4 x } \\
\text { Q10 }\end{array}$} & $\begin{array}{c}\text { Less than } \\
\text { High School }\end{array}$ & $\begin{array}{c}\text { High School } \\
\text { Grad }\end{array}$ & $\begin{array}{c}\text { Some } \\
\text { College }\end{array}$ & $\begin{array}{c}\text { Community/ Junior } \\
\text { College Grad }\end{array}$ & $\begin{array}{c}\text { Baccalaureate } \\
\text { degree }\end{array}$ & $\begin{array}{c}\text { Advanced } \\
\text { Degree }\end{array}$ & Total \\
\hline PT & 5.2 & 16.2 & 23.6 & 10.0 & 27.2 & 17.8 & 100 \\
\hline Com & 5.8 & 10.1 & 14.0 & 8.2 & 32.9 & 29.0 & 100 \\
\hline Public & 17.1 & 15.8 & 21.0 & 6.6 & 17.1 & 22.4 & 100 \\
\hline Total & 7.4 & 13.5 & 19.0 & 8.6 & 28.1 & 23.4 & 100 \\
\hline \multicolumn{78}{|c|}{} \\
\hline
\end{tabular}

taught respondents exhibit the highest proportion of home-schooled students ( 9.1 percent), but the distributions by DE type do not differ significantly. As shown in Table 12, more than half $(57 \%)$ of those who were home-schooled participated in parent-taught DE. Overall, 40 percent of all respondents took a parent-taught course. Slightly more respondents (44\%) report participating in a commercial DE program and only 16 percent took a course at their high school. When the observed frequency of home-schooled respondents is compared to a theoretical uniform distribution of expected values (i.e., the observed frequencies are tested against proportionally equal numbers of home-schooled respondents in each of the three DE types), the overall $\chi^{2}$ is significant $\left(\chi^{2}=8.6, \mathrm{df}=1, \mathrm{p}<.05\right)$. Not surprisingly, significantly more homeschooled respondents were parent-taught for driver education than received DE in a public school program $\left(\chi^{2}=8.05, \mathrm{df}=1, \mathrm{p}<.05\right)$. While numerically the same holds for parent-taught versus commercial school DE respondents, that difference is not significant $\left(\chi^{2}=2.46, \mathrm{df}=1, \mathrm{p}\right.$ $>.05)$.

Table 11. Home-school status by DE Type

\begin{tabular}{|l|r|r|r|r|r|c|}
\cline { 2 - 7 } \multicolumn{1}{c|}{$\begin{array}{c}\text { Q10 } \\
\text { Q3 }\end{array}$} & $\begin{array}{c}\text { Home } \\
\text { Schooled }\end{array}$ & $\begin{array}{c}\text { Not Home } \\
\text { Schooled }\end{array}$ & Total & $\begin{array}{c}\text { Home } \\
\text { Schooled }\end{array}$ & $\begin{array}{c}\text { Not Home } \\
\text { Schooled }\end{array}$ & Total \\
\hline PT & 17 & 169 & 186 & 9.1 & 90.9 & 100.0 \\
\hline Com & 9 & 195 & 204 & 4.4 & 95.6 & 100.0 \\
\hline Public & 4 & 72 & 76 & 5.3 & 94.7 & 100.0 \\
\hline Total & 30 & 436 & 466 & 6.4 & 93.6 & 100.0 \\
\hline \multicolumn{6}{|c|}{$\chi^{2}=3.89, \mathrm{df}=2, \mathrm{p}>.05$} \\
\hline
\end{tabular}

Table 12. DE type of home-schooled and non-home-schooled respondents

\begin{tabular}{|c|c|c|c|c|c|c|c|c|}
\hline \multirow{2}{*}{ Q10 x Q3 } & \multicolumn{4}{|c|}{ Number } & \multicolumn{4}{|c|}{ Percent } \\
\hline & PT & Com & Pub & Total & PT & Com & Pub & Total \\
\hline $\begin{array}{l}\text { Home- } \\
\text { schooled }\end{array}$ & 17 & 9 & 4 & 30 & 56.7 & 30.0 & 13.3 & 100 \\
\hline $\begin{array}{l}\text { Not Home - } \\
\text { schooled }\end{array}$ & 169 & 195 & 72 & 436 & 38.8 & 44.7 & 16.5 & 100 \\
\hline Total & 186 & 204 & 76 & 466 & 39.9 & 43.8 & 16.3 & 100 \\
\hline
\end{tabular}




\section{Driver Education and Licensure Milestones}

\section{Driver Education Course Selection}

Table 13 partially repeats Table 5 except that respondents reporting mixed DE modes and those not reporting type DE have been removed and the percentages adjusted accordingly.

Table 13. Respondents' driver education mode

\begin{tabular}{|c|c|c|}
\hline Q10 & Number & Percent \\
\hline Parent-taught & 192 & 40.3 \\
\hline Commercial & 209 & 43.8 \\
\hline Public school & 76 & 15.9 \\
\hline Total & 477 & 100.0 \\
\hline
\end{tabular}

Respondents were asked to provide one to three reasons (from a predetermined list ${ }^{17}$ ) why they elected to take the DE course that they did. Table 14 and Figure 2 summarize the number and percent of responses, respectively. The distribution of responses is significantly different as a function of type of DE course. Additional $\chi^{2}$ analysis compared each DE type with each of the other types individually. All pairs of DE modes differ significantly from each other as follows:

PT vs Com: $\chi^{2}=117.54, \mathrm{df}=6, \mathrm{p}<.0001$

PT versus Public: $\chi^{2}=48.74, \mathrm{df}=6, \mathrm{p}<.0001$

Com vs Public: $\chi^{2}=14.05, \mathrm{df}=6, \mathrm{p}<.03$

Table 14. Reasons for choosing DE course taken by DE type - Number

\begin{tabular}{|c|c|c|c|c|c|c|c|c|}
\hline \multirow[b]{2}{*}{ Q13 x Q10 } & \multicolumn{8}{|c|}{ Number } \\
\hline & Cost & Scheduling & $\begin{array}{l}\text { Parent's } \\
\text { decision }\end{array}$ & $\begin{array}{c}\text { Only option } \\
\text { available }\end{array}$ & $\begin{array}{l}\text { Wanted to be } \\
\text { with friends }\end{array}$ & $\begin{array}{l}\text { Best course } \\
\text { available }\end{array}$ & Other & Total \\
\hline Parent-taught & 103 & 101 & 83 & 9 & 4 & 35 & 16 & 351 \\
\hline Commercial & 22 & 52 & 131 & 25 & 26 & 70 & 28 & 354 \\
\hline Public school & 13 & 32 & 29 & 10 & 12 & 26 & 9 & 131 \\
\hline Total & 138 & 185 & 243 & 44 & 42 & 131 & 53 & 836 \\
\hline \multicolumn{9}{|c|}{$\chi^{2}=133.72, \mathrm{df}=12, \mathrm{p}<.05$} \\
\hline
\end{tabular}

The most striking difference in reasons given for choosing a given DE type is found in the high proportion of parent-taught students who cited "Cost" as a reason for selecting this option. Nearly 30 percent of parent-taught respondents cited cost, compared to only about 6 and 10 percent of commercial and public school DE students, respectively, a more than three-fold difference. Scheduling, which ranked second among reasons given by parent-taught students, was 28.8 percent. While quite comparable to the 24.4 percent of public school students selecting this option, it is offered twice as often by PT students than by young drivers taking commercial DE courses. Overall, the single-most-often cited reason for selecting a DE course is, in the view of the student, attributable to their parents making the decision. This seems especially the case

\footnotetext{
${ }^{17}$ The list of reasons provided, shown verbatim in Table 14, were based primarily on focus group results from this and other investigations and were not further defined.
} 
among commercial school students, 37 percent of whom provide that response. The proportion of parent-taught students who identified the course they selected as the "best course available" is only half that of either commercial or public school courses.

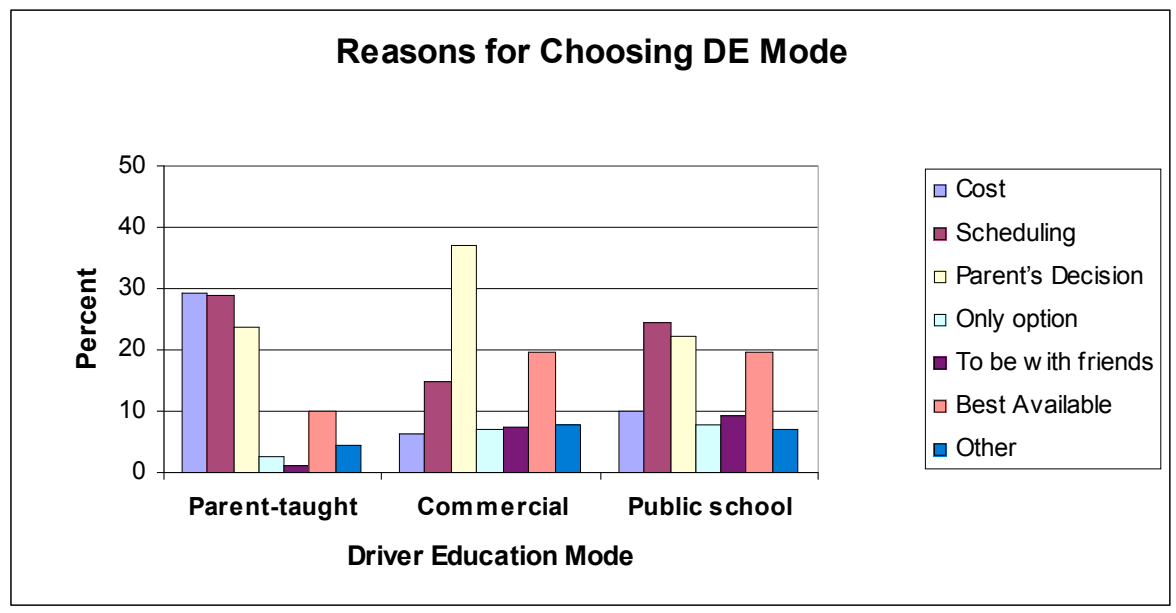

Figure 2. Reasons for choosing DE course taken by DE type

Parent-taught DE respondents were asked a series of questions specific to the parent-taught program. Participation in the parent-taught program requires selection of one of seven ${ }^{18}$ approved course options (see pages 14-15 for brief descriptions of the courses). Asked to identify the specific course they took, nearly half (47.4\%) of those responding to this question could not specify the course by name or course number, both of which were provided in the survey form. Among those who did identify a specific course, Course 101 - the TEA developed "Model Course" - is the most often acknowledged; 28 percent of those responding (Table 15).

Table 15. DE course taken by parent-taught students

\begin{tabular}{|c|c|c|c|c|c|c|c|c|c|c|}
\hline \multirow[b]{2}{*}{ Q12 } & \multicolumn{7}{|c|}{ Course number } & \multicolumn{2}{|c|}{ Unk Course } & \multirow[b]{2}{*}{ Total } \\
\hline & 101 & 102 & 103 & 104 & 105 & 106 & 107 & $\begin{array}{c}\text { Used } \\
\text { computer }\end{array}$ & $\begin{array}{c}\text { No } \\
\text { computer }\end{array}$ & \\
\hline PT Number & 52 & 6 & 13 & 8 & 14 & 6 & 0 & 2 & 87 & 188 \\
\hline PT Percent & 27.7 & 3.2 & 6.9 & 4.3 & 7.4 & 3.2 & 0 & 1.1 & 46.3 & 100 \\
\hline
\end{tabular}

Although both parents may participate in the teaching process, one parent or other eligible adult is typically identified as the primary instructor. Asked to identify the primary teacher, a majority $(60 \%)$ of parent-taught students identified their mothers as the main source of DE instruction (Table 16).

Table 16. Parent-taught students' primary teacher

\begin{tabular}{|c|c|c|c|c|c|c|}
\hline \multirow{2}{*}{\multicolumn{2}{|c|}{ Q11 }} & \multicolumn{5}{|c|}{ Principal instructor } \\
\hline & & Father & Mother & Grandparent & Guardian & Total \\
\hline PT & Number & 69 & 115 & 4 & 4 & 192 \\
\hline $\mathrm{PT}$ & Percent & 35.9 & 59.9 & 2.1 & 2.1 & 100 \\
\hline
\end{tabular}

\footnotetext{
${ }^{18}$ An eighth approved PT course has been added to the program since the survey was administered.
} 


\section{Performance on Driver Education Tests}

Issuance of an instructional driving permit (GDL Phase 1 license) is contingent upon passing a two-part driving knowledge test comprising a "rules" test and a "signs" test. Answers to the questions in both parts, but not the specific set of questions, are provided in the Texas Drivers Handbook. A minimum grade of 70 percent is required to pass each section. Survey respondents were asked how many times they needed to take these tests before they passed. Responses to this question are provided in Table 17.

Table 17. Performance on "traffic law and signs test" by DE type

\begin{tabular}{|l|c|c|c|c|c|c|}
\cline { 2 - 7 } \multicolumn{1}{c|}{} & \multicolumn{6}{c|}{ Number of times test taken before passed } \\
\cline { 2 - 7 } \multicolumn{1}{c|}{} & \multicolumn{3}{c|}{ Number } & \multicolumn{3}{c|}{ Percent } \\
\cline { 2 - 7 } & 1 & $2+$ & Total & 1 & $2+$ & Total \\
\hline Parent-taught & 156 & 35 & 191 & 81.7 & 18.3 & 100.0 \\
\hline Commercial & 202 & 7 & 209 & 96.7 & 3.3 & 100.0 \\
\hline Public school & 71 & 5 & 76 & 93.4 & 6.6 & 100.0 \\
\hline Total & 429 & 47 & 476 & 90.1 & 9.9 & 100.0 \\
\hline \multicolumn{3}{|c|}{$\chi^{2}=26.25, \mathrm{df}=2, \mathrm{p}<.05$} \\
\hline
\end{tabular}

Overall, 90 percent of applicants passed these tests on the first try. Only 82 percent of parenttaught students, however, report passing on the first attempt. Comparison among the three DE types reveals significant differences in reported "times to pass." Pair-wise comparisons indicate the source of these differences is in the performance of parent-taught versus commercial DE students $\left(\chi^{2}=23.82, \mathrm{df}=1, \mathrm{p}<.05\right)$. As indicated in Figure 3, slightly more than 18 percent of parent-taught respondents report taking the test at least twice before passing. Only about 3 percent of commercial DE students required more than one attempt. A smaller proportion of public school DE students also required multiple tries to pass than parent-taught, but the difference does not reach significance. Nor do public and commercial school respondents differ significantly from each other on this measure.

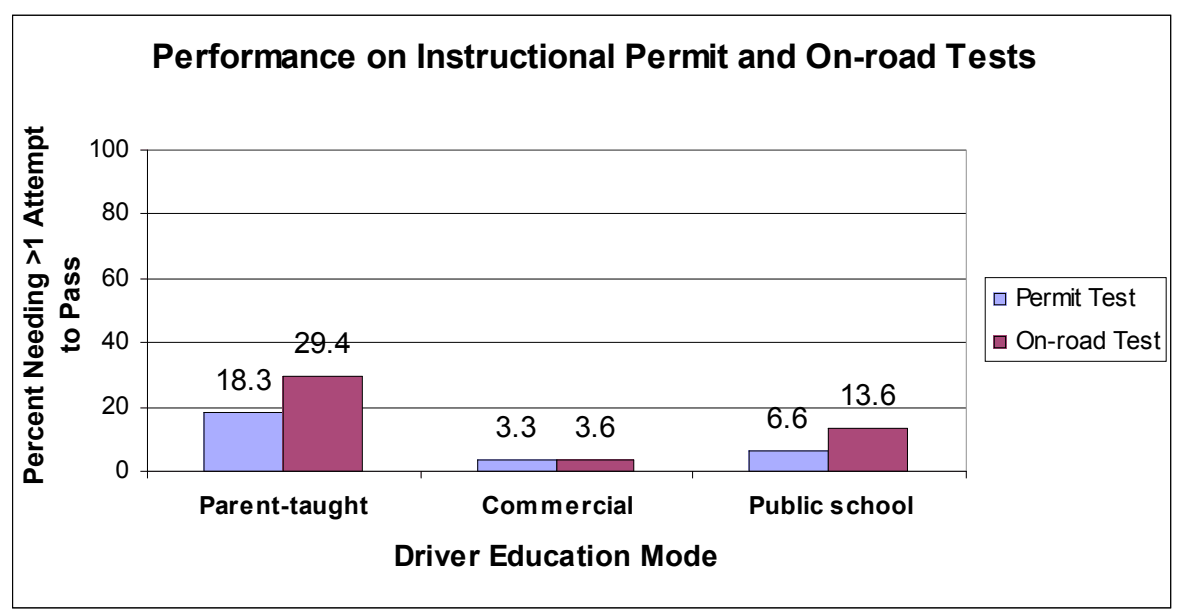

Figure 3. Self-reported performance on instructional permit and DPS road tests

An in-vehicle driving test is not required for a minor to obtain either a GDL Phase 2 (provisional license) or an unrestricted license if they have successfully completed an approved course of 
driver education, including completion of a parent-taught course. However, parents or guardians of any DE student may request that the DPS give a driving test. Overall, only 100 respondents, 21.4 percent, report that they took an in-vehicle DPS driving test. PT students are much less likely to have reported that they took the DPS test. Only 9.4 percent of 191 PT students responding to this question say they took the DPS test, compared to about 30 percent of both commercial and public school DE students (Table 18). Similar to tests required for an instructional permit, a large majority of all DE students, nearly 90 percent, who did take the DPS in-vehicle test, passed on the first try. Again, however, significantly more parent-taught students reported requiring more than one try to pass the test. Only 71 percent of these students report passing on the first attempt, compared to about 96 and 86 percent of commercial and public school DE respondents, respectively (Table 19 and Figure 3).

Table 18. Respondents opting to take DPS in-vehicle driving test by DE type

\begin{tabular}{|c|c|c|c|c|c|c|}
\hline \multirow{2}{*}{ Q7 x 10} & \multicolumn{3}{|c|}{ Number } & \multicolumn{3}{|c|}{ Percent } \\
\hline & Yes & No & Total & Yes & No & Total \\
\hline Parent-taught & 18 & 173 & 191 & 9.4 & 90.6 & 100.0 \\
\hline Commercial & 60 & 145 & 205 & 29.3 & 70.7 & 100.0 \\
\hline Public school & 22 & 50 & 72 & 30.6 & 69.4 & 100.0 \\
\hline Total & 100 & 368 & 468 & 21.4 & 78.6 & 100.0 \\
\hline
\end{tabular}

Table 19. Performance on DPS in-vehicle driving test by DE type

\begin{tabular}{|l|c|c|c|c|c|c|c|c|}
\cline { 2 - 9 } \multicolumn{1}{c|}{} & \multicolumn{8}{c|}{ Q8 $\times 10$} \\
\cline { 2 - 10 } \multicolumn{1}{c|}{} & \multicolumn{8}{c|}{ Number of times test taken before passed } \\
\cline { 2 - 9 } & 1 & 2 & $3+$ & Total & 1 & 2 & $3+$ & Total \\
\hline Parent-taught & 12 & 4 & 1 & 17 & 70.6 & 23.5 & 5.9 & 100.0 \\
\hline Commercial & 55 & 1 & 1 & 57 & 96.5 & 1.8 & 1.8 & 100.0 \\
\hline Public school & 19 & 2 & 1 & 22 & 86.4 & 9.1 & 4.5 & 100.0 \\
\hline Total & 86 & 7 & 3 & 96 & 89.6 & 7.3 & 3.1 & 100.0 \\
\hline \multicolumn{8}{|c|}{ Categories 2 \& 3+ combined for analysis: $\chi^{2}$} & $9.73, \mathrm{df}=2, \mathrm{p}<.05$ \\
\hline
\end{tabular}

Similar to the results for the instructional permit test, comparisons of each of the pairs of DE modes indicate that a significantly larger proportion of parent-taught students required more than one try to pass the in-vehicle test than did commercial DE respondents $\left(\chi^{2}=7.46, \mathrm{df} 1, \mathrm{p}<.01\right.$ with Yates' correction). Despite large percentage differences, neither the parent-taught/public school nor the commercial/public school comparisons reached significance.

Age at Completion of DE and at Graduated Drivers License Phases

In addition to estimates of respondent age at the time of the survey (see Table 8), four other respondent age calculations were made coinciding with four driver education and licensing milestones:

- $\quad$ Age at completion of driver education (Tables $20 \& 21$ );

- $\quad$ Age at GDL Phase 1 - instructional permit (Tables 20 \& 22);

- $\quad$ Age at GDL Phase 2 - provisional license (Tables $20 \& 23$ ); and

- $\quad$ Age at unrestricted license - full license (Tables 20 \& 24). 
Ages were calculated from respondents' reported date of birth and the month and year of achievement of each of the milestone events. The average age of respondents by DE type and the results of one-way ANOVAs to test for differences among the mean ages are shown in Table 20 .

Table 20. Respondent age at driver license milestones

\begin{tabular}{|c|c|c|c|c|c|c|}
\hline \multirow{2}{*}{ Q2\&Q9 xQ10 } & \multicolumn{3}{|c|}{ Means } & \multicolumn{3}{|c|}{ ANOVA } \\
\hline & \multirow{2}{*}{$\begin{array}{l}\text { Parent- } \\
\text { Taught }\end{array}$} & \multirow{2}{*}{$\begin{array}{c}\text { Commercial } \\
\text { School }\end{array}$} & \multirow{2}{*}{$\begin{array}{l}\text { Public } \\
\text { School }\end{array}$} & \multirow{2}{*}{$\mathrm{F}$} & \multirow{2}{*}{ df } & \multirow{2}{*}{$\mathrm{p}$} \\
\hline Age at: & & & & & & \\
\hline Completion of DE & 16.2 & 16.1 & 15.9 & 2.18 & 2 & .114 \\
\hline GDL Phase 1 & 15.7 & 15.9 & 15.8 & 1.03 & 2 & .358 \\
\hline GDL Phase 2 & 16.4 & 16.5 & 16.4 & 0.55 & 2 & .578 \\
\hline Full license & 17.0 & 17.1 & 17.0 & 0.54 & 2 & .585 \\
\hline
\end{tabular}

No significant differences in mean age associated with DE type were observed at any of the licensure milestones. Tables 21 - 24 show the age distributions, in half-year increments, at each of the four events. Inspection of the tables and the accompanying $\chi^{2}$ test results indicates that only the distribution of ages at completion of a driver education course is associated with type of $\mathrm{DE}\left(\chi^{2}=49.03, \mathrm{df}=12, \mathrm{p}<.05\right)$. Comparisons of pairs of the DE modes indicate that parenttaught and commercial DE respondents' age distributions differ significantly $\left(\chi^{2}=30.73, \mathrm{df}=6\right.$, $\mathrm{p}<.05)$ as do the age distributions of parent-taught and public school DE students $\left(\chi^{2}=33.00\right.$, df $=6, \mathrm{p}<.05)$. Commercial $\mathrm{DE}$ and public school $\mathrm{DE}$ age distributions at completion of driver education do not differ from each other $\left(\chi^{2}=7.62, \mathrm{df}=6, \mathrm{p}>.05\right)$. In particular, the proportion of parent-taught respondents completing their DE course before 16 years old is substantially smaller than that for either commercial or public school respondents, but is considerably higher in the 16-16.4 group. Since there are no differences among the distribution of ages at which licenses subsequent to an instructional permit are obtained as a function of DE type, the apparent delay in completion of a DE course by PT novice drivers may simply be an artifact resulting from PT students equating DE completion with application for a GDL Phase 2 provisional license; eligibility for which requires both completion of a DE course and attaining 16 years of age. Students in commercial or public school courses, on the other hand, may be more likely to associate DE completion with the final day of class or in-vehicle training.

This difference, as well as the similarity in the age distributions upon obtaining the sequential licenses under the graduated license program, is illustrated in Figures 4 - 7. 
Table 21. Age at completion of driver education by DE type

\begin{tabular}{|c|r|r|r|r|r|r|r|r|}
\cline { 2 - 10 } \multicolumn{1}{c|}{ Q2 \& Q9 x Q10 } & \multicolumn{5}{c|}{ Number } & \multicolumn{4}{c|}{ Percent } \\
\hline Age & PT & Com & Public & Total & PT & Com & Public & Total \\
\hline $15.0-15.4$ & 17 & 40 & 24 & 81 & 12.2 & 25.3 & 35.8 & 22.3 \\
\hline $15.5-15.9$ & 28 & 48 & 22 & 98 & 20.1 & 30.4 & 32.8 & 26.9 \\
\hline $16.0-16.4$ & 54 & 30 & 6 & 90 & 38.8 & 19.0 & 9.0 & 24.7 \\
\hline $16.4-16.9$ & 20 & 16 & 5 & 41 & 14.4 & 10.1 & 7.5 & 11.3 \\
\hline $17.0-17.4$ & 14 & 8 & 6 & 28 & 10.1 & 5.1 & 9.0 & 7.7 \\
\hline $17.5-17.9$ & 5 & 5 & 2 & 12 & 3.6 & 3.2 & 3.0 & 3.3 \\
\hline $18.0-19.4$ & 1 & 11 & 2 & 14 & 0.7 & 7.0 & 3.0 & 3.8 \\
\hline Total & 139 & 158 & 67 & 364 & 100.0 & 100.0 & 100.0 & 100.0 \\
\hline \multicolumn{9}{|c|}{$\chi^{2}=49.03, \mathrm{df}=12, \mathrm{p}<.05$} \\
\hline
\end{tabular}

Table 22. Age at GDL Phase $1 *$ by DE type

\begin{tabular}{|c|c|r|r|r|r|r|r|r|}
\cline { 2 - 10 } \multicolumn{1}{c|}{ Q2 \& Q5 x Q10 } & \multicolumn{7}{c|}{ Number } & \multicolumn{4}{c|}{ Percent } \\
\hline Age & PT & Com & Public & Total & PT & Com & Public & Total \\
\hline $15.0-15.4$ & 71 & 63 & 30 & 164 & 44.1 & 35.6 & 44.1 & 40.4 \\
\hline $15.5-15.9$ & 31 & 43 & 11 & 85 & 19.3 & 24.3 & 16.2 & 20.9 \\
\hline $16.0-16.4$ & 35 & 38 & 15 & 88 & 21.7 & 21.5 & 22.1 & 21.7 \\
\hline $16.5-16.9$ & 11 & 15 & 3 & 29 & 6.8 & 8.5 & 4.4 & 7.1 \\
\hline $17.0-17.4$ & 8 & 7 & 7 & 22 & 5.0 & 4.0 & 10.3 & 5.4 \\
\hline $17.5-19.4$ & 5 & 11 & 2 & 18 & 3.1 & 6.2 & 2.9 & 4.4 \\
\hline Total & 161 & 177 & 68 & 406 & 100.0 & 100.0 & 100.0 & 100.0 \\
\hline *GDL Phase 1 is the instructional or learners permit & $\chi^{2}=10.87, \mathrm{df}=10, \mathrm{p}>.05 \mathrm{~ns}$ \\
\hline
\end{tabular}

Table 23. Age at GDL Phase $2 *$ by DE type

\begin{tabular}{|c|c|r|r|r|r|r|r|r|}
\cline { 2 - 10 } \multicolumn{1}{c|}{ Q2 \& Q5 x Q10 } & \multicolumn{6}{c|}{ Number } & \multicolumn{4}{c|}{ Percent } \\
\hline Age & PT & Com & Public & Total & PT & Com & Public & Total \\
\hline $16.0-16.4$ & 95 & 95 & 37 & 227 & 59.4 & 57.6 & 61.7 & 59.0 \\
\hline $16.5-16.9$ & 26 & 24 & 7 & 57 & 16.2 & 14.5 & 11.7 & 14.8 \\
\hline $17.0-17.4$ & 33 & 35 & 11 & 79 & 20.6 & 21.2 & 18.3 & 20.5 \\
\hline $17.5-19.4$ & 6 & 11 & 5 & 22 & 3.8 & 6.7 & 8.3 & 5.7 \\
\hline Total & 160 & 165 & 60 & 385 & 100 & 100 & 100 & 100 \\
\hline *GDL Phase 2 is the provisional driving license & \multicolumn{10}{c}{$\chi^{2}=3.00, \mathrm{df}=6, \mathrm{p}>.05$} \\
\end{tabular}

Table 24. Age at unrestricted* license by DE type

\begin{tabular}{|c|r|r|r|r|r|r|r|r|}
\cline { 2 - 10 } \multicolumn{1}{c|}{ Q2 \& Q5 x Q10 } & \multicolumn{1}{c|}{ Number } & \multicolumn{1}{c|}{ Percent } \\
\hline Age & PT & Com & Public & Total & PT & Com & Public & Total \\
\hline $16.0-16.4$ & 35 & 29 & 10 & 74 & 33.7 & 25.9 & 27.0 & 29.2 \\
\hline $16.5-16.9$ & 39 & 49 & 16 & 104 & 37.5 & 43.8 & 43.2 & 41.1 \\
\hline $17.0-17.4$ & 7 & 7 & 1 & 15 & 6.7 & 6.3 & 2.7 & 5.9 \\
\hline $17.5-19.4$ & 23 & 27 & 10 & 60 & 22.1 & 24.1 & 27.0 & 23.7 \\
\hline Total & 104 & 112 & 37 & 253 & 100.0 & 100.0 & 100.0 & 100.0 \\
\hline *A full unrestricted drivers license & \multicolumn{1}{c|}{$\chi^{2}=2.82, \mathrm{df}=6, \mathrm{p}>.05$} \\
\hline
\end{tabular}



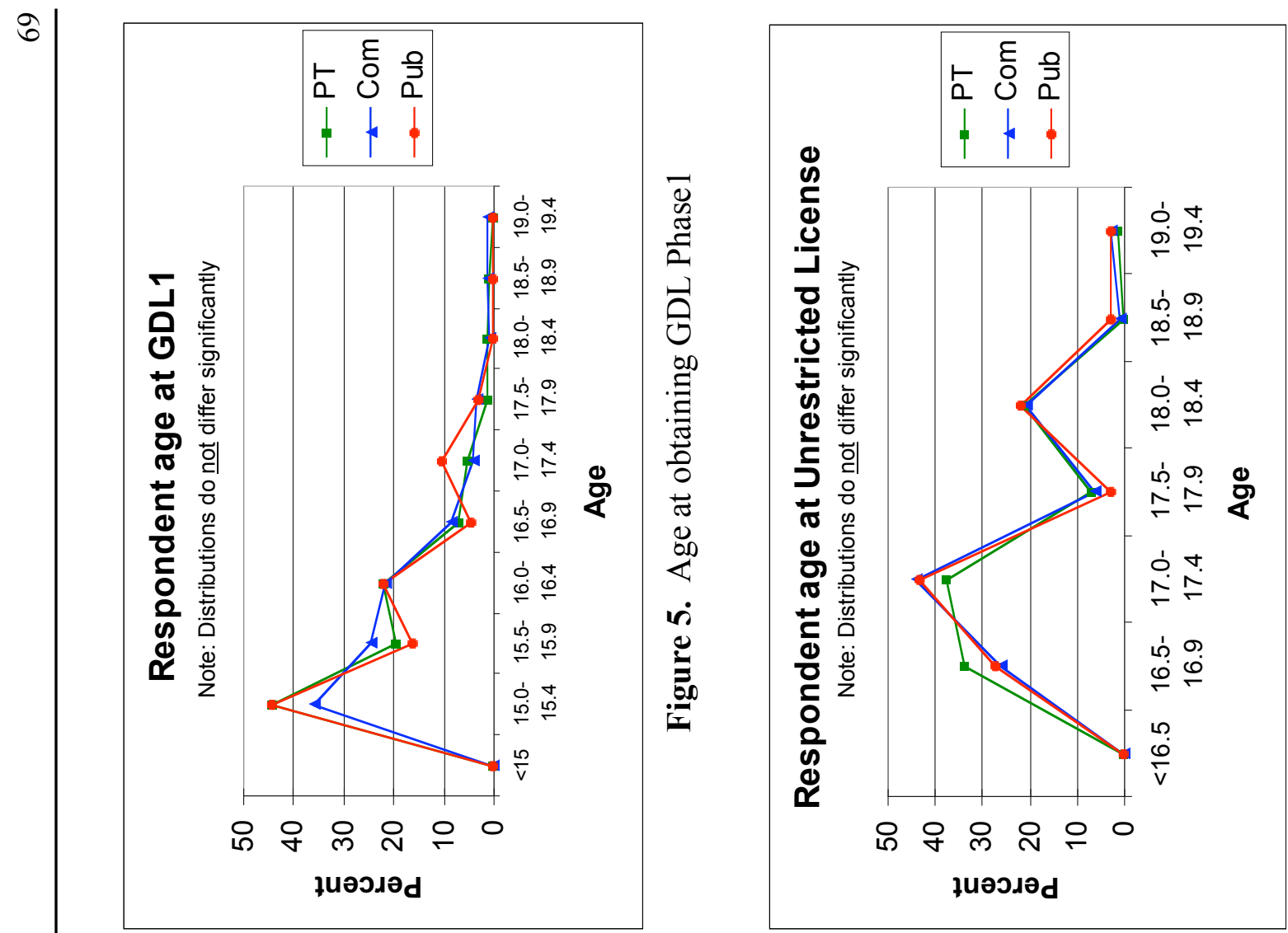

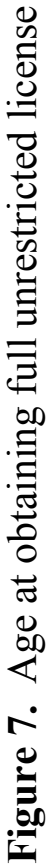
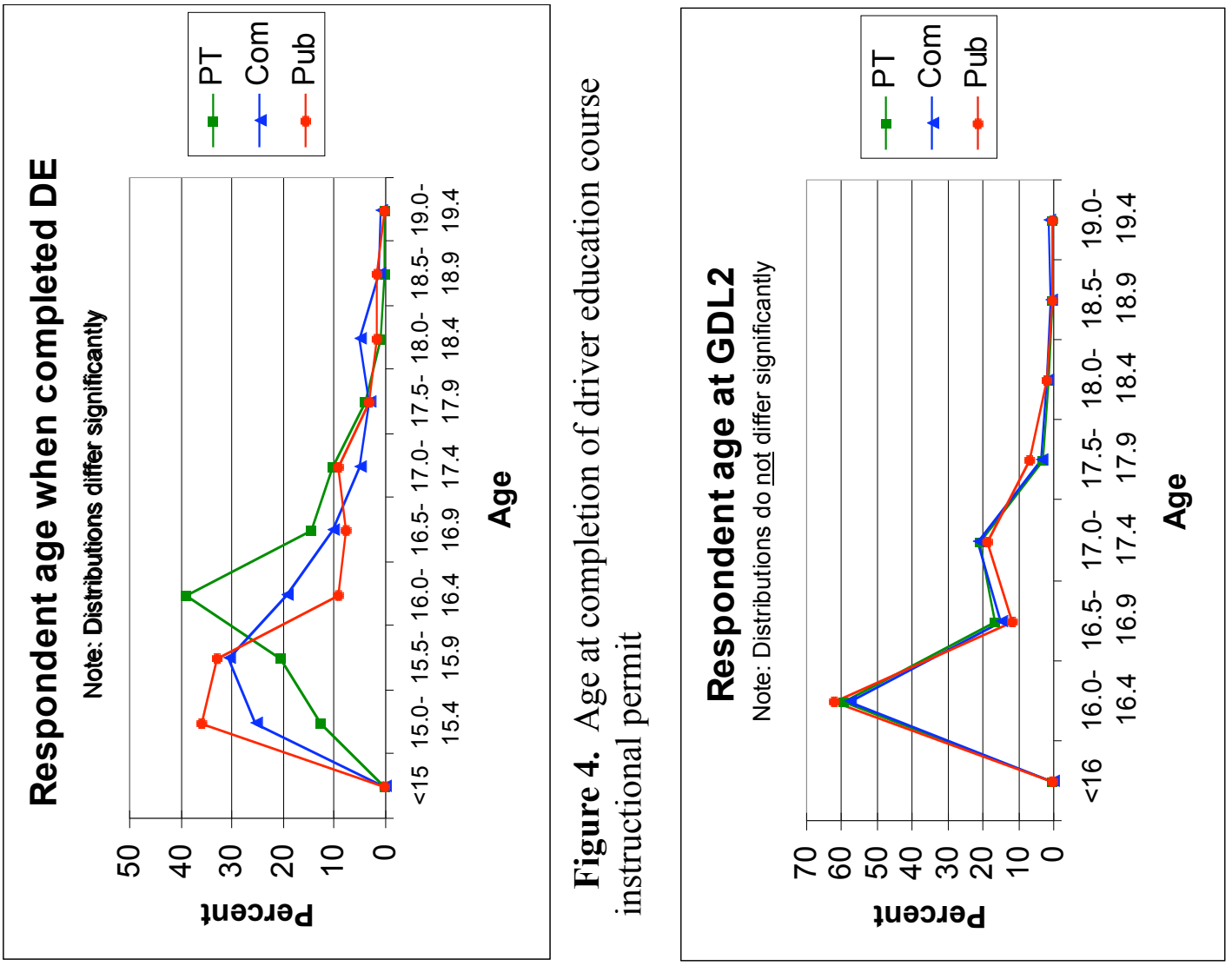

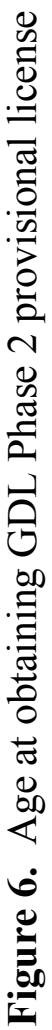




\section{$\underline{\text { Student Evaluations of Driver Education Experience }}$}

Respondents were asked to indicate the extent to which they agreed with 22 general and coursespecific driver education evaluative statements. Responses to each statement were on a 5-point scale anchored by "completely agree" on one extreme and "completely disagree" on the other. For analysis, these anchors were assigned numerical scores of +2 and -2 , respectively. A score of 0 was assigned to the neutral response "neither agree nor disagree." One-way classification analyses of variance (3 levels of the independent variable DE type) were conducted for each of the 22 evaluation items. All F-ratios indicating a significant difference in mean responses $(\mathrm{p}<$ .05) were subjected to Duncan's Multiple Range tests to ascertain the source of the differences in evaluation scores among the DE types.

Table 25 lists each of the evaluation statements, the mean response score by survey respondents in each of the three DE mode groups, and a summary of the ANOVA results. Ten of the 22 statements, denoted by bold type, produced significantly different mean scores $(p<.05)$. Results of the Duncan tests applied to the ratings with significant F-ratios are indicated by underscores of means that are not significantly different from each other.

Table 25. Extent of agreement with course evaluation statements

\begin{tabular}{|l|c|c|c|c|c|c|}
\multirow{2}{*}{ Q14 x Q10 } & \multicolumn{3}{|c|}{ Means } & \multicolumn{3}{c|}{ ANOVA } \\
\cline { 2 - 6 } & $\mathrm{PT}$ & $\mathrm{Com}$ & $\mathrm{Pub}$ & $\mathrm{F}$ & $\mathrm{df}$ & $\mathrm{p}$ \\
\hline $\begin{array}{l}\text { 1. If I had not taken any driver education, I think I would have } \\
\text { had more accidents. }\end{array}$ & 0.35 & 0.28 & 0.18 & 00.82 & 2 & .442 \\
\hline $\begin{array}{l}\text { 2. I would be as good a driver as I am, even if I had not taken any } \\
\text { driver education. }\end{array}$ & -0.42 & -0.44 & -0.39 & 0.05 & 2 & .956 \\
\hline 3. Driver education helped me be a more cautious driver. & 0.62 & 0.61 & 0.57 & 0.14 & 2 & .866 \\
\hline 4. Driver education increased my driving confidence. & 0.60 & 0.68 & 0.55 & 1.05 & 2 & .350 \\
\hline $\begin{array}{l}\text { 5. I think the driver education program I took is valuable for } \\
\text { training new drivers. }\end{array}$ & 0.71 & 0.81 & 0.80 & 1.49 & 2 & .226 \\
\hline $\begin{array}{l}\text { 6. Compared to what I knew about driving before I took the } \\
\text { course, I know a lot more now. }\end{array}$ & 0.66 & 0.75 & 0.57 & 2.12 & 2 & .122 \\
\hline $\begin{array}{l}\text { 7. I think that young drivers who take the driver education } \\
\text { course I did are more skilled than other young drivers who } \\
\text { did not. }\end{array}$ & $\mathbf{0 . 2 6}$ & $\underline{0.52}$ & $\underline{0.46}$ & 6.89 & 2 & .001 \\
\hline 8. The course I took prepared me very well to begin driving. & 0.78 & 0.69 & 0.68 & 1.23 & 2 & .292 \\
\hline $\begin{array}{l}\text { 9. If I knew someone who was planning to get a driver's license } \\
\text { soon, I would recommend the same kind of driver education I } \\
\text { took. }\end{array}$ & 0.71 & 0.74 & 0.64 & 0.72 & 2 & .489 \\
\hline $\begin{array}{l}\text { 10. The classroom teacher seemed to care about whether the } \\
\text { students learned the material. }\end{array}$ & 0.60 & 0.45 & 0.53 & 1.49 & 2 & .226 \\
\hline 11. I enjoyed going to driver education. & 0.10 & 0.06 & 0.30 & 1.77 & 2 & .171 \\
\hline 12. The classroom teacher knew the subject matter. & $\mathbf{0 . 7 0}$ & $\underline{0.87}$ & $\underline{0.92}$ & 10.31 & 2 & $<.001$ \\
\hline 13. The teacher was prepared for class. & $\mathbf{0 . 6 1}$ & $\underline{0.84}$ & $\underline{0.87}$ & 11.40 & 2 & $<.001$ \\
\hline 14. The classroom teacher satisfactorily answered questions. & $\underline{0.65}$ & $\underline{0.77}$ & 0.87 & 4.74 & 2 & .009 \\
\hline $\begin{array}{l}\text { 15. The classroom teacher seemed to think the classroom part } \\
\text { of driver education is more important than the driving part. }\end{array}$ & $\mathbf{- 0 . 2 1}$ & $\underline{0.06}$ & $\underline{0.13}$ & 7.00 & 2 & .001 \\
\hline 16. The classroom teacher was a better than average teacher. & $\mathbf{0 . 6 1}$ & $\underline{0.33}$ & $\underline{0.36}$ & 7.69 & 2 & $<.001$ \\
\hline $\begin{array}{l}\text { 17. The instructor provided a good combination of lecture and } \\
\text { discussion. }\end{array}$ & $\underline{0.36}$ & $\mathbf{0 . 1 6}$ & $\underline{0.37}$ & 3.04 & 2 & .050 \\
\hline
\end{tabular}


Table 25. Extent of agreement with course evaluation statements

\begin{tabular}{|c|c|c|c|c|c|c|}
\hline \multirow{2}{*}{ Q14 x Q10 } & \multicolumn{3}{|c|}{ Means } & \multicolumn{3}{|c|}{ ANOVA } \\
\hline & PT & Com & Pub & $\mathrm{F}$ & $\mathrm{df}$ & $\mathrm{p}$ \\
\hline $\begin{array}{l}\text { 18. The behind-the-wheel part of the driver education class was the } \\
\text { most enjoyable. }\end{array}$ & 0.78 & 0.64 & 0.70 & 2.74 & 2 & .065 \\
\hline $\begin{array}{l}\text { 19. The behind-the-wheel instructor was a better than average } \\
\text { teacher. }\end{array}$ & $\underline{0.70}$ & 0.35 & $\underline{0.57}$ & 13.29 & 2 & $<.001$ \\
\hline $\begin{array}{l}\text { 20. The behind-the-wheel instructor was genuinely interested in } \\
\text { having me learn to drive. }\end{array}$ & $\underline{0.82}$ & 0.61 & $\underline{0.68}$ & 5.18 & 2 & .006 \\
\hline $\begin{array}{l}\text { 21. The behind-the-wheel instructor asked me to do things in the } \\
\text { car before I was ready to do them or before they were } \\
\text { explained. }\end{array}$ & -0.57 & -0.43 & -0.63 & 1.16 & 2 & .314 \\
\hline $\begin{array}{l}\text { 22. The behind-the-wheel instructor often made me nervous or } \\
\text { anxious while I was driving. }\end{array}$ & -0.42 & -0.48 & -0.82 & 3.30 & 2 & .037 \\
\hline \multicolumn{7}{|c|}{$\begin{array}{l}\text { Range: }+2 \text { to }-2 \\
\text { where: }+2=\text { Completely agree, }+1=\text { Generally agree, } 0=\text { Neither agree nor disagree, }-1=\text { Generally disagree, }-2=\text { Completely } \\
\text { disagree } \\
\text { A } 5 \text { percent level of significance }(\dot{\alpha}=0.05) \text { is employed for all tests, } p<.05 \\
\text { For those items, shown in bold type, for which there is a significant difference in mean rating associated with DE type }(p<.05) \text {, } \\
\text { common underscores indicate means that are NOT different. }\end{array}$} \\
\hline
\end{tabular}

The distribution of responses was examined for each of the items, and analysis of variance (ANOVA) indicated significant differences among the mean scores of the three DE types. They are discussed below.

7: I think that young drivers who take the driver education course I did are more skilled than other young drivers who did not. Although, on average, students from all of the DE modes indicated they believed that students who took the same type of DE they did were more skilled drivers than those who did not, both commercial and public school students gave significantly higher ratings to their course than did parent-taught students. Examination of the distribution of those ratings revealed that 61 percent and 62 percent of commercial and public school DE students, respectively, indicated that they generally or completely agreed with the item statement compared to only 39 percent of parent-taught students.

Eleven of the 22 evaluation items were directed at assessing students' perceptions about their DE instructors. Except for Item 7 discussed above, all of the statements that reveal significantly different evaluation opinions among the DE types are from this group.

Items 12 - 17 addressed various aspects of the classroom teacher's quality and style.

12: The classroom teacher knew the subject matter. Overall, all DE students gave their classroom instructor positive ratings. Both commercial and public school students gave significantly higher ratings to their teacher than did parent-taught students. Inspection of the distribution of those ratings showed that 72.9 percent of parent-taught drivers indicated that they generally or completely agreed with the item statement. This highly favorable response, however, was exceeded by both commercial and public school DE students at 89.4 percent and 93.4 percent respectively. 
13. The teacher was prepared for class. Again, DE students in all modes gave their classroom instructor positive ratings overall, but both commercial and public school students conferred significantly higher ratings to their teacher than did parent-taught students. Distributions of those ratings reveal that 86.5 percent and 92.1 percent of commercial and public school DE students, respectively, generally or completely agreed with the item statement compared to 65.4 percent of parent-taught students.

14. The classroom teacher satisfactorily answered questions. Mean ratings by public school DE students were the highest on this item. They were significantly higher than the ratings bestowed by parent-taught students but did not differ from those of commercial students. Commercial and parent-taught ratings did not differ significantly on this item. As is the case with several of the previously noted items, average ratings were positive (i.e., tend toward agreement with the item statement) for all DE types. Also consistent with responses to some of the other items, ratings that are statistically different are nonetheless relatively small. Examination of the distribution of responses for this item indicated that 90.8 percent of the public-school students either generally or completely agreed that their teacher satisfactorily answered their questions, compared to 82 percent and 70 percent of commercial and parenttaught students.

\section{The classroom teacher seemed to think the classroom part of driver education is more} important than the driving part. Public and commercial school respondents agreed with this statement significantly more than did parent-taught students. General or complete agreement was registered by 38.2, 29.1 and 19.3 percent of public, commercial and parenttaught DE students, respectively. Conversely, 29.3 percent of parent-taught respondents disagreed, compared to 21.4and 19.7 percent of commercial and public school students.

16. The classroom teacher was a better than average teacher. Average ratings by students in all DE modes leaned toward agreement with this statement. Significantly higher rankings, however, were given by the parent-taught students. More than 64 percent of parent-taught respondents generally or completely agreed that their teacher was better than average compared to 53.9 and 51.5 percent of public and commercial school DE participants.

17. The instructor provided a good combination of lecture and discussion. On this item, commercial school teachers received lower average marks from their students than did public school or parent-taught teachers. Public and commercial school DE students expressed stronger opinions - both in agreement and disagreement - on this item than did parent-taught students. Forty-one percent of parent-taught respondents indicated neither agreement nor disagreement.

Items 19, 20 and 22 refer to evaluation of the behind-the-wheel driving instructor. The same teacher may or may not serve as both the classroom and in-vehicle instructor. Multiple instructors are most frequently encountered in commercial school DE settings and are least common in parent-taught courses.

19. The behind-the-wheel instructor was a better than average teacher. Significantly less agreement with this statement was expressed by commercial school students. Although 
nearly 53 percent of commercial school students generally or completely agreed that their behind-the-wheel teacher was "better than average," 64.5 and 71.2 percent of public school and parent-taught students so rated their in-vehicle instructor.

20. The behind-the-wheel instructor was genuinely interested in having me learn to drive. As evidenced in the responses to most of the instructor evaluation items, average responses to this item tended toward agreement with the statement by students in all DE modes. In this case, parent-taught students expressed significantly more agreement than did students in the other two modes. Nearly 83 percent of parent-taught respondents generally or completely agreed that their instructor was genuinely interested in having them learn to drive compared to 76 and 75 percent of public and commercial school students. Just over 10 percent of commercial students disagreed (4\% completely disagree) with the statement, suggesting that 10 percent of commercial school students believed their in-vehicle instructor was not interested in having students learn to drive. For parent-taught and public school students this opinion is expressed by 5 and 1 percent of the respondents, respectively.

22. The behind-the-wheel instructor often made me nervous or anxious while I was driving. A majority of DE students in all DE modes did not agree that their instructors made them nervous or anxious while driving. Among those respondents who did agree with the statement, however, were proportionally fewer public school students than either parenttaught or commercial school students. Twenty-five and 31 percent of parent-taught and commercial DE students generally or completely agreed that their instructor made them nervous or anxious while driving, compared to only 17 percent of public school students.

\section{$\underline{\text { Recent Driving Experience }}$}

\section{Frequency of Driving in Different Environments}

In an effort to ascertain if young drivers with different DE experiences also differ in the conditions under which they drive or the environments in which they drive, respondents were asked to express how frequently they drove during the past year under eight conditions.

Responses were made on a five-point scale where $1=$ never or almost never, $2=$ less than once a month, $3=$ once a month to a few times a month, $4=$ once a week to a few times week, and $5=$ nearly every day. One-way classification ANOVAs with three levels of the variable DE type were conducted for each of the evaluation items. As previously, F-ratios indicating a significant difference in mean responses $(\mathrm{p}<.05)$ were subjected to Duncan's Multiple Range tests to ascertain the source of the differences in evaluation scores among the DE types.

Table 26 lists each of the driving frequency statements, the mean response score assigned by survey respondents in each of the three DE mode groups and the probability of the differences in means. Significant differences in mean response were observed for four of the conditions rated. Young drivers who completed a commercial driver education course report significantly more frequent driving in a big city and less frequent driving in a small town and on two-lane roads in rural areas than do parent-taught or public school trained drivers. These differences may simply reflect the greater availability of commercial driving schools in larger population areas. Parenttaught drivers report more frequent driving at night after dark than either commercial or public school taught drivers. 
Table 26. Self-reported frequency of driving in selected environments during past year

\begin{tabular}{|c|c|c|c|c|c|c|}
\hline \multirow[b]{2}{*}{ Q15x Q10 } & \multicolumn{3}{|c|}{ Means } & \multicolumn{3}{|c|}{ ANOVA } \\
\hline & $\begin{array}{l}\text { Parent- } \\
\text { taught }\end{array}$ & Commercial & $\begin{array}{l}\text { Public } \\
\text { School }\end{array}$ & $\mathrm{F}$ & $\mathrm{df}$ & $\mathrm{p}$ \\
\hline 1. During rush hours & 3.31 & 3.50 & 3.21 & 2.04 & 2 & .132 \\
\hline 2. In a small town & 4.10 & 3.35 & $\underline{3.79}$ & 12.38 & 2 & $<.001$ \\
\hline 3. In a big city & 3.51 & $\underline{3.61}$ & 3.01 & 5.42 & 2 & $<.005$ \\
\hline 4. On 2-lane roads in rural areas & $\underline{4.09}$ & $\overline{3.42}$ & $\underline{3.88}$ & 13.34 & 2 & $<.001$ \\
\hline 5. On major divided highways & $\overline{4.01}$ & 3.86 & $\overline{3.70}$ & 2.07 & 2 & .127 \\
\hline 6. $\quad$ At night after dark & 4.47 & $\underline{4.20}$ & $\underline{4.09}$ & 5.62 & 2 & .004 \\
\hline 7. At night after midnight & 2.93 & 2.72 & 2.86 & 1.14 & 2 & .319 \\
\hline 8. With passengers in your vehicle & 4.21 & 4.14 & 4.45 & 2.94 & 2 & .054 \\
\hline \multicolumn{7}{|c|}{$\begin{array}{l}\text { Range: } 1 \text { to } 5 \\
\text { where: }+1=\text { Never or almost never, }+2=\text { Less than once a month, }+3=\text { Once a month to a few times a month, }+4=\text { Once a } \\
\text { week to a few times week, }+5=\text { Nearly every day } \\
\text { A } 5 \text { percent level of significance }(\dot{\alpha}=0.05) \text { is employed for all tests, } p<.05 \\
\text { For those items, shown in bold type, for which there is a significant difference in mean rating associated with DE type }(\mathrm{p}< \\
.05) \text {, common underscores indicate means that are NOT different. }\end{array}$} \\
\hline
\end{tabular}

Self-ratings of driving knowledge, skills and attitudes

How do young drivers see themselves in terms of driving knowledge and skill both in comparison with others and in an absolute sense? A series of multi-part items again using 5point verbal scales scored on a numerical scale from -2 through +2 were used to asses any differences in young driver self-ratings as a function of type of DE experienced. On a scale in which $+2=$ well above average, $+1=$ above average, $0=$ average, $-1=$ below average, and $-2=$ well below average, respondents were asked to judge their own overall driving skill and driving safety (see Table 27). In neither case was there any statistically significant difference in their ratings by type of $\mathrm{DE}$. As is common in ratings of this type, the average rating both for driving skill and driving safety is above average. Overall, without regard to DE experience, only 1.5 percent of all respondents rated themselves either below average or well below average in driving skill. Similarly, only 5.1 percent gave themselves such ratings with regard to driving safety. Although the differences among the DE types are not significant, it is interesting to note that parent-taught students rate themselves slightly higher than both commercial and public school DE students in both driving skill and safety.

Table 27. Self-reported rating of overall driving skill and safety

\begin{tabular}{|c|c|c|c|c|c|c|}
\hline \multirow[b]{2}{*}{ Q16 x Q10 } & \multicolumn{3}{|c|}{ Means } & \multicolumn{3}{|c|}{ ANOVA } \\
\hline & PT & Com & Pub & $\mathrm{F}$ & df & $\mathrm{p}$ \\
\hline 1. Overall, with regard to driving skill, I consider myself: & 0.67 & 0.61 & 0.51 & 2.58 & 2 & .077 \\
\hline 2. Overall, with regard to driving safety, I consider myself: & 0.61 & 0.53 & 0.53 & 0.80 & 2 & .449 \\
\hline
\end{tabular}


In addition to rating themselves on overall driving skill and safety, respondents were asked to provide self-ratings on 19 specific driving skills, attitudes and behaviors in comparison with other drivers. As indicated in Table 28, mean ratings on a five-point scale where: $+2=$ well above average, $+1=$ above average, $0=$ average, $-1=$ below average and $-2=$ well below average, differ significantly as a function of type of DE on only two of the items.

Table 28. Self-reported comparison of driving knowledge, skills and attitudes with others

\begin{tabular}{|c|c|c|c|c|c|c|}
\hline \multirow[b]{3}{*}{ Q17 x Q10 } & \multirow{2}{*}{\multicolumn{3}{|c|}{ Means }} & \multirow{2}{*}{\multicolumn{3}{|c|}{ ANOVA }} \\
\hline & & & & & & \\
\hline & \multirow{2}{*}{$\begin{array}{c}\text { PT } \\
\underline{0.60}\end{array}$} & \multirow{2}{*}{$\begin{array}{c}\text { Com } \\
0.49 \\
\end{array}$} & \multirow{2}{*}{$\begin{array}{c}\text { Pub } \\
0.41 \\
\end{array}$} & \multirow{2}{*}{$\frac{F}{3.53}$} & \multirow{2}{*}{$\frac{\mathrm{df}}{2}$} & \multirow{2}{*}{$\begin{array}{c}\mathrm{p} \\
.030\end{array}$} \\
\hline 1. Anticipating hazards & & & & & & \\
\hline 2. Driving in an unfamiliar area & 0.28 & 0.24 & 0.21 & 0.30 & 2 & .739 \\
\hline 3. Obeying the traffic rules & 0.54 & 0.55 & 0.38 & 2.03 & 2 & .132 \\
\hline 4. Preventing a skid & 0.49 & 0.37 & 0.48 & 1.73 & 2 & .179 \\
\hline 5. Predicting traffic situations ahead & 0.62 & 0.54 & 0.45 & 2.71 & 2 & .068 \\
\hline 6. Driving cautiously & 0.62 & 0.57 & 0.45 & 2.15 & 2 & .117 \\
\hline 7. Smooth lane-changing in heavy traffic & 0.59 & 0.49 & 0.43 & 1.94 & 2 & .146 \\
\hline 8. Fast reactions & 0.68 & 0.56 & 0.51 & 2.77 & 2 & .063 \\
\hline 9. Paying attention to other road users & $\underline{0.73}$ & 0.61 & 0.58 & 3.52 & & .030 \\
\hline 10. Driving fast, if necessary & 0.58 & 0.61 & 0.57 & 0.25 & 2 & .777 \\
\hline 11. Driving in the dark & 0.68 & 0.63 & 0.60 & 0.65 & 2 & .522 \\
\hline 12. Controlling the vehicle in a skid & 0.29 & 0.17 & 0.19 & 1.53 & 2 & .218 \\
\hline 13. Avoiding tailgating other vehicles & 0.43 & 0.37 & 0.47 & 0.53 & 2 & .591 \\
\hline 14. Adjusting speed to the conditions & 0.62 & 0.51 & 0.65 & 2.26 & 2 & .106 \\
\hline 15. Passing on a two-lane road & 0.47 & 0.40 & 0.48 & 0.82 & 2 & .443 \\
\hline 16. Giving other drivers the right-of-way & 0.58 & 0.51 & 0.53 & 0.53 & 2 & .589 \\
\hline 17. Obeying the speed limits & 0.10 & 0.00 & 0.11 & 0.73 & 2 & .481 \\
\hline 18. Avoiding unnecessary risks & 0.49 & 0.40 & 0.44 & 1.06 & 2 & .346 \\
\hline 19. Tolerating other drivers' mistakes calmly & 0.03 & -0.07 & -0.09 & 0.63 & 2 & .533 \\
\hline \multicolumn{7}{|c|}{$\begin{array}{l}\text { Range: }+2 \text { to }-2 \\
\text { where: }+2=\text { Well above average, }+1=\text { Above average, } 0=\text { Average, }-1=\text { Below average, }-2=\text { Well below average } \\
\text { A } 5 \text { percent level of significance }(\alpha=0.05) \text { is employed for all tests, } p<.05 \\
\text { For those items, shown in bold type, for which there is a significant difference in mean rating associated with DE type }(\mathrm{p}< \\
.05) \text {, common underscores indicate means that are NOT different. }\end{array}$} \\
\hline
\end{tabular}

The only two items on which respondents differed significantly were: 1. Anticipating hazards and 9. Paying attention to other road users. On both of these items, parent-taught students' mean ratings were significantly higher than public school DE students, but did not differ from commercial school respondents. Commercial and public school respondents did not differ significantly from each other. Among parent-taught students, 64 percent rated themselves well above or above average on anticipating hazards compared to 52 and 47 percent for commercial and public school groups, respectively. Similarly, with regard to paying attention to other road users, 76 percent of parent-taught, 64 percent of commercial and 47 percent of public school students believe themselves to be either well above or above average.

Survey respondents were asked to indicate how much they agree or disagree with a series of 32 statements related to driving knowledge and skills and attitudes where: $-2=$ completely disagree, 
$-1=$ generally disagree, $0=$ neither agree nor disagree, $+1=$ generally agree,$+2=$ completely agree. Responses are summarized in Table 29.

Table 29. Self-reported driving knowledge, skills and attitudes

\begin{tabular}{|c|c|c|c|c|c|c|}
\hline \multirow{2}{*}{ Q18 x Q10 } & \multicolumn{3}{|c|}{ Means } & \multicolumn{3}{|c|}{ ANOVA } \\
\hline & PT & Com & Pub & $\mathrm{F}$ & $\mathrm{df}$ & $\mathrm{p}$ \\
\hline 1. I am confident that I know the rules of the road. & 0.96 & 0.94 & 0.99 & 1.24 & 2 & .291 \\
\hline $\begin{array}{l}\text { 2. Lots of drivers are careless and I can't do anything about it } \\
\text { if they crash into me. }\end{array}$ & 0.13 & 0.23 & 0.25 & 0.58 & 2 & .562 \\
\hline $\begin{array}{l}\text { 3. Today's cars are built safe and most have airbags, so going } \\
\text { faster or cornering fast is OK. }\end{array}$ & 1.28 & 1.13 & 1.37 & 2.88 & 2 & .057 \\
\hline $\begin{array}{l}\text { 4. If my parents have been involved in a lot of traffic } \\
\text { accidents, chances are I will be too. }\end{array}$ & -1.26 & -1.26 & -1.16 & 0.35 & 2 & .704 \\
\hline 5. Exceeding the posted speed limit is always dangerous. & 0.05 & -0.14 & 0.11 & 2.59 & 2 & .076 \\
\hline $\begin{array}{l}\text { 6. I feel like the one place where I am totally in control is in } \\
\text { my car. }\end{array}$ & -0.30 & -0.15 & -0.21 & 0.95 & 2 & .386 \\
\hline $\begin{array}{l}\text { 7. I live my life for today rather than worrying about the } \\
\text { future. }\end{array}$ & 0.46 & 0.45 & 0.47 & 0.01 & 2 & .994 \\
\hline $\begin{array}{l}\text { 8. No matter how carefully people drive, eventually they will } \\
\text { be involved in an accident. }\end{array}$ & 0.09 & 0.02 & -0.07 & 0.50 & 2 & .607 \\
\hline 9. Avoiding traffic tickets is largely a matter of luck. & 0.57 & 0.39 & 0.52 & 1.11 & 2 & .332 \\
\hline 10. Accidents are the result of mistakes made by drivers. & 0.62 & 0.64 & 0.64 & 0.06 & 2 & .946 \\
\hline $\begin{array}{l}\text { 11. Road rage is usually caused by another driver being } \\
\text { inconsiderate or careless. }\end{array}$ & -0.77 & -0.81 & -0.65 & 0.73 & 2 & .482 \\
\hline 12. If friends told me to drive faster, I probably would. & .59 & 0.47 & 0.68 & 1.20 & 2 & .302 \\
\hline $\begin{array}{l}\text { 13. Accidents happen when drivers } d \\
\text { consideration the possible actions }\end{array}$ & $\underline{0.80}$ & 0.87 & $\underline{0.71}$ & 3.59 & 2 & .028 \\
\hline $\begin{array}{l}\text { 14. It doesn't really matter if I drive recklessly, because I'm still } \\
\text { better than most drivers. }\end{array}$ & 1.15 & 1.04 & 1.31 & 2.25 & 2 & .106 \\
\hline $\begin{array}{l}\text { cautious driver, some of my friends would } \\
\text { I drive. }\end{array}$ & 0.70 & 0.62 & 0.84 & 1.14 & 2 & .321 \\
\hline $\begin{array}{l}\text { 16. Accidents are } u \\
\text { beyond the dris }\end{array}$ & 0.73 & 0.71 & 0.73 & 0.02 & 2 & .977 \\
\hline $\begin{array}{l}\text { 17. Sometimes, when I am upset, I rev the engine higher than } \\
\text { normal. }\end{array}$ & 0.75 & 0.47 & 0.68 & 2.43 & 2 & .089 \\
\hline $\begin{array}{l}\text { 18. I have found out how my car performs at speeds well above } \\
\text { the speed limit. }\end{array}$ & 0.01 & -0.03 & 0.08 & 0.19 & 2 & .831 \\
\hline $\begin{array}{l}\text { 19. Accidents occur because drivers don't drive as safely as } \\
\text { they should. }\end{array}$ & 0.76 & 0.77 & 0.73 & 0.10 & 2 & .908 \\
\hline 20. I take more driving risks when I am with my friends. & 0.67 & 0.48 & 0.57 & 1.44 & 2 & .239 \\
\hline 21. Fast cars are fun to drive. & -0.53 & -0.59 & -0.36 & 0.89 & 2 & .411 \\
\hline $\begin{array}{l}\text { 22. Your state of mind while driv } \\
\text { of you being involved in an a }\end{array}$ & 1.24 & 1.12 & 1.09 & 1.02 & 2 & .361 \\
\hline 23. Drag racing on an abandoned road can be fun to watch. & 0.32 & 0.15 & 0.40 & 1.28 & 2 & .279 \\
\hline $\begin{array}{l}\text { 24. It is possible to avoid accidents even under the most } \\
\text { difficult driving conditions, such as bad weather or heavy } \\
\text { traffic. }\end{array}$ & 0.66 & 0.69 & 0.60 & 0.44 & 2 & .642 \\
\hline 25. I like the feeling of accelerating. & -0.38 & 0.42 & 0.24 & 68 & 2 & .507 \\
\hline $\begin{array}{l}\text { 26. It is nice to get ahead of a line of cars all traveling the same } \\
\text { speed. }\end{array}$ & -0.34 & -0.35 & -0.05 & 2.00 & 2 & .136 \\
\hline $\begin{array}{l}\text { 27. Just following the flow of traffic justifies driving at high } \\
\text { speeds. }\end{array}$ & -0.04 & -0.13 & -0.12 & 0.41 & 2 & .665 \\
\hline
\end{tabular}


Table 29. Self-reported driving knowledge, skills and attitudes

\begin{tabular}{|c|c|c|c|c|c|c|}
\hline \multirow{2}{*}{ Q18 x Q10 } & \multicolumn{3}{|c|}{ Means } & \multicolumn{3}{|c|}{ ANOVA } \\
\hline & PT & Com & Pub & $\mathrm{F}$ & $\mathrm{df}$ & $\mathrm{p}$ \\
\hline $\begin{array}{l}\text { 28. Driving tricks, such as "four wheel skids" and "laying } \\
\text { rubber" are fun. }\end{array}$ & 0.92 & 0.72 & 0.84 & 1.60 & 2 & .203 \\
\hline $\begin{array}{l}\text { 29. If all drivers were attentive and careful, there would be } \\
\text { many fewer accidents. }\end{array}$ & 0.86 & 0.91 & 0.80 & 2.08 & 2 & .127 \\
\hline 30. After an argument, I might drive faster than I should. & 0.12 & -0.11 & -0.03 & 1.96 & 2 & .142 \\
\hline $\begin{array}{l}\text { 31. On a four-lane highway with a traffic jam, I try to get into } \\
\text { the lane that is moving the fastest. }\end{array}$ & -0.67 & -0.62 & -0.49 & 0.67 & 2 & .511 \\
\hline $\begin{array}{l}\text { 32. Even with all the thousands of cars on the roads, there is a } \\
\text { lot I can do myself to avoid an accident. }\end{array}$ & 0.93 & 0.85 & 0.89 & 1.63 & 2 & .198 \\
\hline \multicolumn{7}{|c|}{$\begin{array}{l}\text { Range: }-2 \text { to }+2 \\
\text { where: }-2=\text { Completely disagree, }-1=\text { Generally disagree, } 0=\text { Neither agree nor disagree, }+1=\text { Generally agree, }+2= \\
\text { Completely agree }\end{array}$} \\
\hline
\end{tabular}

A significant difference in mean response associated with type of DE was found for only one of the 32 items: 13 Accidents happen when drivers don't take into consideration the possible actions of other drivers. Very few DE students disagreed with this statement. Commercial DE students slightly, but significantly, agreed more strongly than public school students. Neither parent-taught and public school nor parent-taught and commercial school students differed significantly in their responses. More than 80 percent of all respondents in each of the DE modes generally or completely agreed with the statement.

\section{Driving Errors or Misjudgments}

\section{Driver error and violations}

Survey respondents were asked to report how often (on scale where: $1=$ never, $2=$ hardly ever, 3 = sometimes, $4=$ frequently, $5=$ nearly all the time) in the past year they thought they had committed each of 21 driving errors or misjudgments without regard to whether or not they were associated with a traffic offense or crash. No distinction is made between inadvertent and deliberate errors.

Analysis of variance conducted on responses to each item revealed no significant differences in the average frequencies associated with type of driver education. Mean responses are shown in Table 30.

The driving behaviors with the highest frequency of self-reported occurrence for all DE group respondents are:

Drive through a yellow traffic signal.

Drive 10 miles per hour or more above the speed limit.

Leave too late, and speed to get to destination in time.

Put the "pedal-to-the-metal" on a deserted road.

Tailgate the car in front to make its driver speed up or get out of your way. 
These five behaviors, in descending order, are the most frequently cited by students in all three DE modes, with the exception that last two listed are reversed in order for commercial DE students.

Table 30. Self-reported frequency of driving errors in past year

\begin{tabular}{|c|c|c|c|c|c|c|}
\hline \multirow{2}{*}{ Q19 x Q10 } & \multicolumn{3}{|c|}{ Mean } & \multicolumn{3}{|c|}{ ANOVA } \\
\hline & PT & Com & Pub & $\mathrm{F}$ & $\mathrm{df}$ & $\mathrm{p}$ \\
\hline 1. In the wrong lane approaching an intersection. & 1.83 & 1.93 & 1.82 & 0.80 & 2 & .449 \\
\hline 2. Drive through a yellow traffic signal. & 3.42 & 3.40 & 3.33 & 0.23 & 2 & .793 \\
\hline 3. Miss a traffic control, such as a stop sign. & 1.81 & 1.79 & 1.74 & 0.21 & 2 & .811 \\
\hline 4. Fail to notice pedestrians when turning. & 1.43 & 1.53 & 1.36 & 2.30 & 2 & .101 \\
\hline $\begin{array}{l}\text { 5. Tailgate the car in front to make its driver speed up or get } \\
\text { out of your way. }\end{array}$ & 2.05 & 2.11 & 1.92 & 0.76 & 2 & .469 \\
\hline 6. Drive 10 miles per hour or more above the speed limit. & 2.79 & 2.96 & 2.61 & 2.68 & 2 & .069 \\
\hline 7. Accidentally hit something when backing. & 1.29 & 1.37 & 1.42 & 1.33 & 2 & .266 \\
\hline 8. Cross an intersection knowing that the light has turned red. & 1.41 & 1.46 & 1.37 & 0.63 & 2 & .533 \\
\hline 9. Forget to cancel turn signals after changing lanes. & 1.72 & 1.74 & 1.63 & 0.54 & 2 & .582 \\
\hline 10. Fail to check mirrors before changing lanes. & 1.60 & 1.64 & 1.57 & 0.31 & 2 & .736 \\
\hline $\begin{array}{l}\text { 11. Dislike a particular type of driver and do something to show } \\
\text { your hostility. }\end{array}$ & 1.56 & 1.74 & 1.57 & 2.12 & 2 & .121 \\
\hline $\begin{array}{l}\text { 12. Underestimate the speed of an oncoming vehicle when } \\
\text { turning or passing. }\end{array}$ & 1.84 & 1.97 & 1.83 & 1.80 & 2 & .169 \\
\hline $\begin{array}{l}\text { 13. Accidentally turn on the wrong thing (like the windshield } \\
\text { wipers instead of the headlights). }\end{array}$ & 1.92 & 1.83 & 1.78 & 0.92 & 2 & .400 \\
\hline 14. Drive when over the blood-alcohol limit. & 1.13 & 1.08 & 1.14 & 0.84 & 2 & .431 \\
\hline 15. Get involved in unofficial "races." & 1.32 & 1.30 & 1.36 & 0.14 & 2 & .867 \\
\hline 16. Chase after another driver to show anger. & 1.19 & 1.18 & 1.12 & 0.53 & 2 & .586 \\
\hline 17. Drive too fast for conditions. & 1.90 & 1.89 & 1.72 & 1.19 & 2 & .305 \\
\hline 18. Drive without wearing your seat belt. & 1.37 & 1.29 & 1.36 & 0.53 & 2 & .589 \\
\hline 19. Leave too late, and speed to get to destination in time. & 2.56 & 2.67 & 2.39 & 1.54 & 2 & .216 \\
\hline 20. Made a "U" turn where it was not allowed & 1.71 & 1.66 & 1.72 & 0.21 & 2 & .813 \\
\hline 21. Put the "pedal-to-the-metal" on a deserted road. & 2.07 & 2.09 & 2.03 & 0.07 & 2 & .933 \\
\hline \multicolumn{7}{|c|}{$\begin{array}{l}\text { Range: } 1 \text { to } 5 \\
\text { where: } 1=\text { Never, } 2=\text { Hardly ever, } 3=\text { Sometimes, } 4=\text { Frequently, } 5=\text { Nearly all the time. } \\
\text { A } 5 \text { percent level of significance }(\dot{\alpha}=0.05) \text { is employed for all tests, } p<.05\end{array}$} \\
\hline
\end{tabular}

\section{$\underline{\text { Self-Reported Traffic Violations and Crashes }}$}

The final questions in the survey provide the most direct comparison with the results of the analysis of Texas driver records. Respondents were asked to indicate violations for which they were stopped by the police and to respond to a series of questions addressing their crash involvement history.

\section{Traffic violations}

Respondents were asked if they have ever been stopped for any of a list of traffic violations, whether or not they received a ticket, and if they had, how many times. Table 31 shows the number and percent of students in each of the three DE types who reported that they had been 
stopped at least once for each of the offenses. The offenses in Table 31 are ordered in descending order of the percentage of all respondents who reported at least one infraction.

Table 31. Self-reported traffic violations by DE type

\begin{tabular}{|c|c|c|c|c|c|c|c|c|}
\hline \multirow{3}{*}{ Q20 x Q10 } & \multirow{2}{*}{\multicolumn{8}{|c|}{ Stopped by police at least once for violation }} \\
\hline & & & & & & & & \\
\hline & \multicolumn{4}{|c|}{ Number } & \multicolumn{4}{|c|}{ Percent } \\
\hline Violation & $\mathrm{PT}$ & Com & Pub & Total & $\mathrm{PT}$ & Com & Pub & Total \\
\hline Speeding/other speed related violation & 59 & 62 & 14 & 135 & 30.7 & 30.5 & 18.4 & 28.7 \\
\hline Stop sign or traffic signal violation & 11 & 14 & 3 & 28 & 5.8 & 6.9 & 3.9 & 6.0 \\
\hline Disobey sign/signal other than "stop" & 5 & 9 & 3 & 17 & 2.6 & 4.3 & 3.9 & 3.6 \\
\hline Failure to signal & 9 & 6 & 1 & 16 & 4.8 & 2.9 & 1.3 & 1.9 \\
\hline Reckless, careless or negligent driving & 1 & 6 & 5 & 12 & 0.5 & 2.9 & 6.6 & 1.5 \\
\hline Seat belt violation & 5 & 5 & 2 & 12 & 2.6 & 2.4 & 2.7 & 3.4 \\
\hline Violation of a driver license provision & 6 & 5 & 1 & 12 & 3.1 & 2.4 & 1.3 & 2.5 \\
\hline $\begin{array}{l}\text { Failed to yield or other right-of-way } \\
\text { violation }\end{array}$ & 5 & 4 & 0 & 9 & 2.6 & 1.9 & 0.0 & 2.5 \\
\hline Unsafe or illegal passing & 1 & 5 & 1 & 7 & 0.5 & 2.4 & 1.3 & 2.5 \\
\hline Alcohol or drug-related violation & 2 & 0 & 0 & 2 & 1.0 & 0.0 & 0.0 & 0.4 \\
\hline All others that don't fit in above & 20 & 23 & 10 & 53 & 10.5 & 11.2 & 13.2 & 11.2 \\
\hline
\end{tabular}

Not surprisingly, speeding or other speed-related violations is both the most frequently reported offense and the violation with the most multiple offenses by single individuals. Table 32 shows the number of respondents in each DE type that were stopped for speeding by the number of times they were stopped. No significant association between the number of times individuals were stopped for speeding and the type of DE course they completed is evident from $\chi^{2}$ analysis.

Table 32. Number of drivers stopped for speeding by DE type

\begin{tabular}{|l|c|c|c|c|}
\cline { 2 - 5 } \multicolumn{1}{c|}{ Q20-1 x Q10 } & \multicolumn{4}{c|}{ Number of times stopped } \\
\cline { 2 - 5 } \multicolumn{1}{c|}{} & None & Once & Twice & 3 or more \\
\hline Parent-taught & 133 & 40 & 14 & 5 \\
\hline Pummercial & 141 & 43 & 11 & 8 \\
\hline \multicolumn{5}{|c|}{$\chi^{2}=6.29, \mathrm{df}=6, \mathrm{p}>.05$} \\
\hline
\end{tabular}

The same result, that is, no significant association between the number of violations and DE type, was found for all of the offenses.

\section{Crash involvement}

The final section of the survey asked young drivers to report if they have been involved in any crashes while they were driving, and if so, how many. All crash types are included without regard to who was at fault, how serious it was or whether or not the event was reported to the police or anyone else. For those who reported one or more crashes, follow-up questions were asked about respondents' first crash and their most recent crash. The follow-up items inquired about: 
- the respondent's license status at the time of the crash,

- how many vehicles were involved (single- versus multiple-vehicle crash),

- respondent's assessment of fault, and

- $\quad$ severity of crash (property damage only, injury, fatality)

All self-reported crashes

The number and percent of respondents in each DE group reporting crash involvement are summarized in Table 33. Overall, 43 percent of all respondents reported involvement in one or more crashes while they were driving; more than 40 percent of the drivers in each of the DE groups reported crash involvement.

Table 33. Self-reported crash involvement while driving by DE type

\begin{tabular}{|l|r|r|r|r|r|r|c|c|c|c|c|c|}
\cline { 2 - 17 } \multicolumn{1}{c|}{ Q21 x Q10 } & \multicolumn{1}{|c|}{ Number } & \multicolumn{1}{c|}{ Percent } \\
\cline { 2 - 16 } & None & $1+$ & 1 & 2 & 3 & $4+$ & None & $1+$ & 1 & 2 & 3 & $4+$ \\
\hline Parent-taught & 107 & 82 & 53 & 27 & 2 & 0 & 56.6 & 43.4 & 28.0 & 14.3 & 1.1 & 0.0 \\
\hline Commercial & 122 & 87 & 62 & 18 & 3 & 4 & 58.4 & 41.6 & 29.7 & 8.6 & 1.4 & 1.9 \\
\hline Public school & 43 & 33 & 23 & 7 & 3 & 0 & 56.6 & 43.4 & 30.3 & 9.2 & 3.9 & 0.0 \\
\hline Total & 272 & 202 & 138 & 52 & 8 & 4 & 57.4 & 42.6 & 29.1 & 11.0 & 1.7 & 0.8 \\
\hline
\end{tabular}

Examination of Table 33 suggests a very similar self-reported incidence of crashes for all three DE type groups. Analysis of involvement by DE group required combining the 3 and 4+ frequency of crash categories as shown in Table 34

Table 34. Self-reported crash involvement while driving by DE type - categories combined

\begin{tabular}{|l|c|c|c|c|c|c|c|c|c|c|}
\cline { 2 - 12 } \multicolumn{1}{c|}{ Q21 x Q10 } & \multicolumn{1}{c|}{ Number } & \multicolumn{1}{c|}{ Percent } \\
\cline { 2 - 12 } & None & 1 & 2 & $3+$ & Total & None & 1 & 2 & $3+$ & Total \\
\hline Parent-taught & 107 & 53 & 27 & 2 & 189 & 56.6 & 28.0 & 14.3 & 1.1 & 100 \\
\hline Commercial & 122 & 62 & 18 & 7 & 209 & 58.4 & 29.7 & 8.6 & 3.3 & 100 \\
\hline Public school & 43 & 23 & 7 & 3 & 76 & 56.6 & 30.3 & 9.2 & 3.9 & 100 \\
\hline Total & 272 & 138 & 52 & 12 & 474 & 57.4 & 29.1 & 11.0 & 2.5 & 100 \\
\hline
\end{tabular}

Chi-squared analysis of the frequency of crashes by DE type indicates no significant differences among the three distributions.

\section{First crash reported - License status}

The licensure status of young drivers at the time of their first reported crash experience is shown in Table 35. Analysis of these data again required grouping two categories, in this case the crashes reported before respondents had obtained an instructional permit ('Before GDL1') were combined with those that occurred during the period the driver held an instructional permit ('While had GDL1'). Differences associated with DE type in the distributions of the crash frequencies by license status did not reach significance. 
Table 35. Licensure status at time of first self-reported crash by DE type

\begin{tabular}{|c|c|c|c|c|c|c|c|c|c|c|}
\hline \multirow[b]{2}{*}{$\begin{array}{c}\text { Q22 x } \\
\text { Q10 }\end{array}$} & \multicolumn{5}{|c|}{ Number } & \multicolumn{5}{|c|}{ Percent } \\
\hline & $\begin{array}{l}\text { Before } \\
\text { GDL1 }\end{array}$ & $\begin{array}{l}\text { While } \\
\text { had } \\
\text { GDL1 }\end{array}$ & $\begin{array}{c}\text { While } \\
\text { had } \\
\text { GDL2 }\end{array}$ & $\begin{array}{l}\text { After } \\
\text { full } \\
\text { license }\end{array}$ & $\begin{array}{l}\text { All } 1^{\text {st }} \\
\text { crashes }\end{array}$ & $\begin{array}{l}\text { Before } \\
\text { GDL1 }\end{array}$ & $\begin{array}{l}\text { While } \\
\text { had } \\
\text { GDL1 }\end{array}$ & $\begin{array}{l}\text { While } \\
\text { had } \\
\text { GDL2 }\end{array}$ & $\begin{array}{l}\text { After } \\
\text { full } \\
\text { license }\end{array}$ & $\begin{array}{l}\text { All 1st } \\
\text { crashes }\end{array}$ \\
\hline $\mathrm{PT}$ & 2 & 10 & 42 & 28 & 82 & 2.4 & 12.2 & 51.2 & 34.1 & 100.0 \\
\hline Com & 2 & 10 & 33 & 42 & 87 & 2.3 & 11.5 & 37.9 & 48.3 & 100.0 \\
\hline Public & 2 & 3 & 17 & 11 & 33 & 6.1 & 9.1 & 51.5 & 33.3 & 100.0 \\
\hline Total & 6 & 23 & 82 & 81 & 192 & 3.1 & 12.0 & 42.7 & 42.2 & 100.0 \\
\hline
\end{tabular}

First crash reported - Vehicles involved

The number of first crashes that were single-vehicle and multiple-vehicle crashes are shown in Table 36. Again, no significant differences were found associated with type of DE.

Table 36. Number of vehicles involved in first crash

\begin{tabular}{|l|c|c|c|c|c|c|}
\cline { 2 - 7 } \multicolumn{1}{c|}{ Q10 x Q23 } & \multicolumn{3}{c|}{ Number } & \multicolumn{3}{c|}{ Percent } \\
\cline { 2 - 7 } & $\begin{array}{c}\text { Single } \\
\text { Vehicle }\end{array}$ & $\begin{array}{c}\text { Multiple } \\
\text { Vehicles }\end{array}$ & Total & $\begin{array}{c}\text { Single } \\
\text { Vehicle }\end{array}$ & $\begin{array}{c}\text { Multiple } \\
\text { Vehicles }\end{array}$ & Total \\
\hline Parent-taught & 24 & 59 & 83 & 28.9 & 71.1 & 100.0 \\
\hline Commercial & 19 & 68 & 87 & 21.8 & 78.2 & 100.0 \\
\hline Public school & 12 & 21 & 33 & 36.4 & 63.6 & 100.0 \\
\hline Total & 55 & 148 & 203 & 27.1 & 72.9 & 100.0 \\
\hline \multicolumn{7}{|c|}{$\chi^{2}=2.79, \mathrm{df}=2, \mathrm{p}>.05$} \\
\hline
\end{tabular}

First crash reported - Fault

Respondents were asked to assess fault for the first crash they experienced as a driver in one of six categories as shown in Tables 37 (number) and 38 (percent).

Table 37. Assignment of fault for first crash - Number

\begin{tabular}{|c|c|c|c|c|c|c|c|}
\hline \multirow[b]{2}{*}{ Q24 x Q10 } & \multicolumn{7}{|c|}{ Number } \\
\hline & $\begin{array}{l}\text { Mostly } \\
\text { your } \\
\text { fault }\end{array}$ & $\begin{array}{l}\text { Mostly an- } \\
\text { other driver's } \\
\text { fault }\end{array}$ & $\begin{array}{l}\text { About } \\
50 / 50\end{array}$ & $\begin{array}{l}\text { All the other } \\
\text { driver's fault }\end{array}$ & $\begin{array}{c}\text { Pedestrian, } \\
\text { animal, roadway } \\
\text { condition }\end{array}$ & $\begin{array}{l}\text { No } \\
\text { one's } \\
\text { fault }\end{array}$ & Total \\
\hline Parent-taught & 40 & 3 & 11 & 23 & 5 & 1 & 83 \\
\hline Commercial & 33 & 9 & 14 & 26 & 2 & 3 & 87 \\
\hline Public school & 18 & 1 & 7 & 5 & 1 & 1 & 33 \\
\hline Total & 91 & 13 & 32 & 54 & 8 & 5 & 203 \\
\hline
\end{tabular}


Table 38. Assignment of fault for first crash - Percent

\begin{tabular}{|l|r|r|r|r|r|r|r|}
\cline { 2 - 8 } \multicolumn{1}{c|}{} & \multicolumn{9}{c|}{ Q24 x Q10 } & $\begin{array}{c}\text { Mostly } \\
\text { your } \\
\text { fault }\end{array}$ & $\begin{array}{c}\text { Mostly an- } \\
\text { other driver's } \\
\text { fault }\end{array}$ & $\begin{array}{c}\text { About } \\
50 / 50\end{array}$ & $\begin{array}{c}\text { All the other } \\
\text { driver's fault }\end{array}$ & $\begin{array}{c}\text { Pedestrian, } \\
\text { animal, roadway } \\
\text { condition }\end{array}$ & $\begin{array}{c}\text { No one's } \\
\text { fault }\end{array}$ & Total \\
\hline Parent-taught & 48.2 & 3.6 & 13.3 & 27.7 & 6.0 & 1.2 & 100 \\
\hline Commercial & 37.9 & 10.3 & 16.1 & 29.9 & 2.3 & 3.4 & 100 \\
\hline Public school & 54.5 & 3.0 & 21.2 & 15.2 & 3.0 & 3.0 & 100 \\
\hline Total & 44.7 & 6.3 & 15.4 & 26.4 & 4.3 & 2.9 & 100 \\
\hline \multicolumn{9}{|c|}{} \\
\hline
\end{tabular}

For analysis, several different approaches to combining categories to eliminate low cell frequencies were examined. In no case did any of the combination schemes result in significant differences in the distributions attributable to DE type. Table 39 shows the results of combining all categories into two categories where: (1) the respondent reports accepting at least 50 percent of the fault for the crash and (2) the responding driver does not accept as much as half the blame for the crash. In addition to inclusion of the "other driver's fault" categories, this new category includes those crashes for which attribution of fault was assigned to pedestrians, animals in the roadway and roadway conditions and crashes the respondent believes were "no one's fault."

Table 39. Assignment of fault for first crash - Combined fault categories

\begin{tabular}{|c|c|c|c|c|c|c|}
\hline \multirow[b]{2}{*}{ Q24 x Q10 } & \multicolumn{3}{|c|}{ Number } & \multicolumn{3}{|c|}{ Percent } \\
\hline & $\begin{array}{c}\text { Respondent at } \\
\text { least } 50 \% \text { at } \\
\text { fault }\end{array}$ & $\begin{array}{l}\text { Respondent } \\
\text { less than } 50 \% \\
\text { at fault }\end{array}$ & Total & $\begin{array}{l}\text { Respondent at } \\
\text { least } 50 \% \text { at } \\
\text { fault }\end{array}$ & $\begin{array}{l}\text { Respondent } \\
\text { less than } 50 \% \\
\text { at fault }\end{array}$ & Total \\
\hline Parent-taught & 51 & 32 & 83 & 61.4 & 38.6 & 100.0 \\
\hline Commercial & 47 & 40 & 87 & 54.0 & 46.0 & 100.0 \\
\hline Public school & 25 & 8 & 33 & 75.8 & 24.2 & 100.0 \\
\hline Total & 123 & 80 & 203 & 60.6 & 39.4 & 100.0 \\
\hline
\end{tabular}

First crash reported - Severity

Self-reports of the severity of first crashes provide the only instance for which significant crashrelated differences associated with DE type are apparent. Respondents were asked to indicate the severity of their first crash by assigning it to one or more of the five severity categories:

- No injury to any person and no damage to any vehicles or property;

- Damage to a vehicle or other property;

- At least one person had a minor injury but it did not require medical attention;

- At least one person had an injury requiring medical attention; and

- One or more persons died because of the crash.

When responses were coded each crash was assigned to only the most severe category indicated by the reporting driver. None of the self-reports indicated a fatality. Tables 40 (number) and 41 (percent) summarize the reported severity information provided by respondents. Analysis of the frequencies of crash severities using all of the four categories for which responses were given 
revealed no significant difference in the severity of first crashes as a function of DE type $\left(\chi^{2}=\right.$ $11.34, \mathrm{df}=6, \mathrm{p}=.08$ ). If, however, the two "injury" categories are combined, i.e., the distinction between injuries that did and did not require medical attention is removed, some evidence for a DE mode-associated difference among the distributions is provided $\left(\chi^{2}=10.98\right.$, df $=2, p=.03)$. Additional pair-wise $\chi^{2}$ tests indicate the observed difference lies in the comparison of commercial school with public school DE students $\left(\chi^{2}=10.61, \mathrm{df}=2, \mathrm{p}=.004\right)$ and is evidenced by the much larger proportion of public school DE drivers reporting injury crashes. Differences between parent-taught and public school students' reports approach, but do not reach significance $\left(\chi^{2}=4.98, \mathrm{df}=2, \mathrm{p}=.08\right)$. No difference is indicated in the parent-taught /commercial school comparison $\left(\chi^{2}=1.47, \mathrm{df}=2, \mathrm{p}=.48\right)$.

Table 40. Severity of first self-reported crash by DE type - Number

\begin{tabular}{|c|c|c|c|c|c|}
\hline \multirow[b]{2}{*}{ Q25 x Q10 } & \multicolumn{5}{|c|}{ Number } \\
\hline & $\begin{array}{l}\text { No injury or } \\
\text { property } \\
\text { damage }\end{array}$ & $\begin{array}{c}\text { Property } \\
\text { damage } \\
\text { only }\end{array}$ & $\begin{array}{c}\text { At least one injury, } \\
\text { no medical attention } \\
\text { required }\end{array}$ & $\begin{array}{l}\text { At least one injury } \\
\text { requiring medical } \\
\text { attention }\end{array}$ & All 1st crashes \\
\hline Parent-taught & 13 & 61 & 4 & 5 & 83 \\
\hline Commercial & 15 & 67 & 3 & 2 & 87 \\
\hline Public school & 6 & 19 & 5 & 4 & 34 \\
\hline Total & 34 & 147 & 12 & 11 & 204 \\
\hline
\end{tabular}

Table 41. Severity of first self-reported crash by DE type - Percent

\begin{tabular}{|c|c|c|c|c|c|}
\hline \multirow[b]{2}{*}{ Q25 x Q10 } & \multicolumn{5}{|c|}{ Percent } \\
\hline & $\begin{array}{l}\text { No injury or } \\
\text { property } \\
\text { damage }\end{array}$ & $\begin{array}{c}\text { Property } \\
\text { damage } \\
\text { only }\end{array}$ & $\begin{array}{l}\text { At least one injury, } \\
\text { no medical attention } \\
\text { required }\end{array}$ & $\begin{array}{l}\text { At least one injury } \\
\text { requiring medical } \\
\text { attention }\end{array}$ & All 1st crashes \\
\hline Parent-taught & 15.7 & 73.5 & 4.8 & 6.0 & 100.0 \\
\hline Commercial & 17.2 & 77.0 & 3.4 & 2.3 & 100.0 \\
\hline Public school & 17.6 & 55.9 & 14.7 & 11.8 & 100.0 \\
\hline Total & 16.7 & 72.1 & 5.9 & 5.4 & 100.0 \\
\hline
\end{tabular}

\section{Most recent crash reported}

Respondents who report involvement in more than one crash were asked to respond to the same set of questions regarding their most recent crash. No significant differences in the distributions of responses to any of these inquiries were observed as a function of DE type.

\section{Summary of Survey Results}

As indicated previously, the survey was conducted for dual purposes. It was administered to provide a broader sample of opinion than could be obtained from the focus groups conducted with recent driver education students and it served as the primary means to obtain data that might differentiate young drivers who completed driver education in public school settings from those 
completing commercial driving school courses. Unlike the data culled from Texas Driver Records, which does not distinguish between commercial and public school DE courses, responses to the survey allow direct comparisons among all three of the primary DE modes of instruction in Texas; commercial, public school and parent-taught.

Taken as a whole, the survey results reveal many more similarities than differences among the three DE modes as reflected in opinions and attitudes about driving and driver education, recent driving experience and novice drivers' self-reported history of traffic violations and crashes. The most important similarities and differences among the three groups are summarized here.

Demographic characteristics as a function of DE type

As a gross measure of socioeconomic status, respondents were asked to indicate the highest academic level achieved by their parents. The responses of the young drivers indicate that parents of commercial DE students generally attained higher levels of educational achievement than either parent-taught or public school DE parents, particularly as indicated by the proportion of parents with baccalaureate and advanced college degrees. Public school DE parents exhibit the lowest overall educational attainment as evidenced by the smaller proportion whose highest level is less than graduation from high school and a smaller proportion of those who graduated with any type of post-secondary degree.

With one exception, the survey did not indicate significant age differences as a function of DE type at important licensure milestones. Average ages did not differ among the three DE types at completion of a DE course or the age at which respondents obtained their instructional permit, provisional license or unrestricted full license. Although the proportion of parent-taught respondents completing their DE course in the youngest age groups (less than 16 year old) was substantially smaller than that for either commercial or public school respondents, this appears to be an artifact related to how DE students define "course completion."

Home schooling for general academic subjects was reported by 6.4 percent of all survey respondents. Among the home-schooled respondents, 57 percent participated in the parenttaught DE program, compared to the 40 percent of all respondents who took a PT course.

No measures of driving exposure were available to the evaluation. However, in an effort to ascertain if young drivers with different DE experiences also differ in the conditions under which they drive or the environments in which they drive, respondents were asked to express how frequently they drove during the past year under eight conditions. Significant differences in mean response were observed for four of the conditions rated. Young drivers who completed a commercial driver education course reported significantly more frequent driving in a big city and less frequent driving in a small town and on two-lane roads in rural areas than did parent-taught or public school trained drivers. These differences may simply reflect the greater availability of commercial driving schools in larger population areas. Parent-taught drivers report more frequent driving at night after dark than either commercial or public school taught drivers.

Reasons for selecting mode of driver education

When respondents were asked why they chose the DE mode they participated in, they selected different reasons from the predetermined list provided. Overall, the single most often student- 
cited reason for selecting a particular DE course was that their parents made the decision. This was especially the case among commercial school students, 37 percent of whom provided that response. The most striking difference among DE modes was seen in the high proportion of parent-taught students who cited "Cost" as a reason for selecting this option. Nearly 30 percent of parent-taught respondents cited cost, compared to only about 6 and 10 percent of commercial and public school DE students, respectively. Second only to cost among reasons given by parent-taught students was "Schedule" $(28.8 \%)$. While comparable to the 24.4 percent of public school students selecting this option, it was offered twice as often by PT students than by young drivers taking commercial DE courses. Interestingly, the proportion of parent-taught students who identified the course they selected as the "best course available" is only half that of either commercial or public school DE students.

\section{Performance on tests}

Overall, 90 percent of survey respondents passed the "rules" test and "signs" tests, required before issuance of an instructional permit, on the first attempt. Only 82 percent of parent-taught students, however, reported passing on the first try compared to 97 and 93 percent of commercial and public school students. Stated differently, slightly more than 18 percent of parent-taught respondents report taking the test at least twice before passing while only about 3 percent of commercial DE students and 7 percent of public school trained respondents required more than one attempt.

Although students who successfully complete an approved course of driver education are not required to take an in-vehicle driving test, a parent of any DE student may request that the DPS administer an on-road test. When asked whether they opted to take the in-vehicle driving test, PT students were much less likely to have reported taking the DPS test than either commercial or public school DE students. Only 9.4 percent of PT students indicated they took the DPS test, compared to approximately 30 percent of both commercial and public school DE students. Similar to tests required for an instructional permit, a large majority of all DE students, nearly 90 percent, who did take the DPS in-vehicle test, passed on the first try. Again, however, significantly more parent-taught students reported requiring more than one try to pass the test. Only 71 percent of these students report passing on the first attempt, compared to about 96 and 86 percent of commercial and public school DE respondents, respectively.

\section{Driver Education Experience: Student Evaluations of DE Course and Instructors}

Survey respondents were asked to indicate the extent to which they agreed with 22 evaluative statements about their DE course. Half of these referred to opinions about their overall DE experience and half were statements directly assessing their DE instructors. Recall, of course, that for PT students, DE instructors are their parents.

Among the items directed toward the DE course in general, respondents differed significantly on only one of the 11 statements as a function of DE mode (I think that young drivers who take the driver education course I did are more skilled than other young drivers who did not). Although, on average, students of all of the DE modes indicated they believed that students who take the same type of DE they did are more skilled drivers than those who took other courses, both commercial and public school students gave significantly higher ratings than did parent-taught students. 
On the statements rating DE instructors, opinions expressed by students participating in the three DE modes differed significantly on nine of the eleven items. Again, students in all of DE modes generally gave their classroom instructor positive ratings overall. Differences in degree were evident, however, on the nine items summarized below.

The classroom teacher knew the subject matter. Average agreement ratings of both commercial and public school students were significantly higher than those of parent-taught students. Inspection of the distribution of those ratings reveals that 73 percent of parent-taught drivers indicate that they generally or completely agree with the item statement. This highly favorable response, however, is exceeded by both commercial and public school DE students at 89.4 and 93.4 percent, respectively.

The teacher was prepared for class. Again, DE students in all modes gave their classroom instructor positive ratings overall, but both commercial and public school students conferred significantly higher agreement ratings than parent-taught students.

The classroom teacher satisfactorily answered questions. Mean ratings by public school DE students are the highest on this item. They were significantly higher than the ratings bestowed by parent-taught students but did not differ from those of commercial students. Commercial and parent-taught ratings did not differ significantly from each other. Consistent with responses to most of these items, differences in ratings that were statistically significant are nonetheless relatively small.

The classroom teacher seemed to think the classroom part of driver education is more important than the driving part. Public and commercial school respondents agreed with this statement significantly more than did parent-taught students.

The classroom teacher was a better than average teacher. Average ratings by students in all DE modes tended toward agreement with this statement. Significantly higher rankings, however, were given by the parent-taught students.

The instructor provided a good combination of lecture and discussion. On this item, commercial school teachers received lower average marks from their students than did public school or parent-taught teachers. Public and commercial school DE students expressed stronger opinions both in agreement and disagreement - on this item than did parent-taught students. Forty-one percent of parent-taught respondents indicated neither agreement nor disagreement.

The behind-the-wheel instructor was a better than average teacher. Significantly less agreement with this statement was expressed by commercial school students. Although nearly 53 percent of commercial school students generally or completely agree that their behind-the-wheel teacher was "better than average," 64.5 and 71.2 percent of public school and parent-taught students so rated their in-vehicle instructor.

The behind-the-wheel instructor was genuinely interested in having me learn to drive. On this item, parent-taught students expressed significantly more agreement than did students in the other two modes. Nearly 83 percent of parent-taught respondents generally or completely agreed 
that their instructor was genuinely interested in having them learn to drive compared to 76 and 75 percent of public and commercial school students. Just over 10 percent of commercial students disagreed (4 percent of which "completely" disagreed) with the statement, suggesting that 10 percent of commercial school students believe their in-vehicle instructor was not interested in having students learn to drive. For parent-taught and public school students this opinion was expressed by 5 and 1 percent of the respondents, respectively.

The behind-the-wheel instructor often made me nervous or anxious while I was driving. A majority of DE students in all DE modes did not agree that their instructors made them nervous or anxious while driving. Among those respondents who did agree with the statement, however, were proportionally fewer public school students than either parent-taught or commercial school students. Twenty-five and 31 percent of parent-taught and commercial DE students generally or completely agreed that their instructor made them nervous or anxious while driving compared to only 17 percent of public school respondents.

\section{Recent Driving Experience}

Survey respondents were asked to rate themselves, relative to other drivers, on 19 specific driving skills, attitudes and behaviors. Responses differed significantly by type of DE on only two items: Anticipating hazards and Paying attention to other road users. On both of these items, parent-taught students' mean ratings were significantly higher than public school DE students, but did not differ from commercial school respondents. Commercial and public school respondents did not differ significantly from each other. Sixty-four percent of PT students rated themselves well above or above average on anticipating hazards compared to 52 and 47 percent of commercial and public school DE participants, respectively. Similarly, with regard to paying attention to other road users, 76 percent of parent-taught, 64 percent of commercial and 47 percent of public school students believe themselves to be either well above or above average.

Asked to indicate how much they agree or disagree with a series of 32 statements related to driving knowledge, skills and attitudes, a significant difference in mean response associated with type of DE was found for only one of the items: Accidents happen when drivers don't take into consideration the possible actions of other drivers. Very few DE students disagreed with this statement. Commercial DE students slightly, but significantly, agreed more strongly than public school students. Neither parent-taught and public school nor parent-taught and commercial school students differed significantly in their responses. More than 80 percent of all respondents in each of the DE modes generally or completely agreed with the statement.

Driving Errors or Misjudgments and Self-Reported Traffic Violations and Crashes Survey respondents were asked to report how often they thought they had committed each of 21 driving errors or misjudgments in the past year, without regard to whether or not they were associated with a traffic offense or crash. No significant differences in the average frequencies associated with type of driver education were found. The driving behaviors with the highest frequency of self-reported occurrence for all DE group respondents are, in descending order:

Drive through a yellow traffic signal.

Drive 10 miles per hour or more above the speed limit.

Leave too late, and speed to get to destination in time. 
Put the "pedal-to-the-metal" on a deserted road.

Tailgate the car in front to make its driver speed up or get out of your way.

\section{Traffic violations}

Respondents were asked if they have ever been stopped for any of a list of traffic violations, whether or not they received a ticket, and if they had, how many times. Not surprisingly, speeding, including other speed-related violations, was both the most frequently reported offense and the violation with the most multiple offenses by single individuals. No significant association between the number of times individuals were stopped for speeding and the type of DE course they completed was detected. The same result, that is, no significant association between the number of violations and DE type, was found for each of the offenses.

\section{All self-reported crashes}

The final section of the survey asked young drivers to report if they have been involved in any crashes while they were driving, and if so, how many. All crash types were included without regard to who was at fault, how serious it was or whether or not the event was reported to the police or anyone else. For those who reported one or more crashes, follow-up questions were asked about their first crash and their most recent crash. Follow-up items inquired about:

- the respondent's license status at the time of the crash,

- how many vehicles were involved (single- versus multiple-vehicle crash),

- $\quad$ respondent's assessment of fault, and

- $\quad$ severity of crash (property damage only, injury, fatality).

Very similar patterns of crashes were self-reported by all three DE mode groups. Overall, 43 percent of all respondents reported involvement in one or more crashes while they were driving. The difference among DE types was small and not statistically significant. More than 40 percent of the drivers in each of the DE groups report crash involvement.

Self-reports of the severity of first crashes provide the only instance for which significant crashrelated differences associated with DE type are apparent. Respondents were asked to indicate the severity of their first crash by assigning it to one or more of five severity categories:

- $\quad$ No injury to any person and no damage to any vehicles or property;

- Damage to a vehicle or other property;

- At least one person had a minor injury but it did not require medical attention;

- At least one person had an injury requiring medical attention; and

- One or more persons died because of the crash.

When responses were coded each crash was assigned to only the most severe category indicated by the reporting driver. Analysis of the frequencies of crash severities using all of the four categories for which responses were given ${ }^{19}$ revealed no significant difference in the severity of first crashes as a function of DE type. When the two "injury" categories are combined, i.e., the distinction between injuries that did and did not require medical attention is removed, some evidence for a DE mode-associated difference among the distributions is provided. Pair-wise

\footnotetext{
${ }^{19}$ Note that none of the self-reports indicated involvement in a fatal crash.
} 
comparisons indicate the observed significant difference among the combined severity categories lies in the comparison of commercial school with public school DE students. It is evidenced by the much larger proportion of public school DE drivers reporting injury crashes $(26.5 \%)$ compared to commercial school DE students (5.7\%). Differences between parent-taught (10.8\%) and public school students' reports on this measure approach, but do not reach significance. No difference is indicated in the parent-taught/commercial school comparison.

Most recent crash reported

Respondents who reported involvement in more than one crash were asked to respond to the same set of questions regarding their most recent crash and their first crash. No significant differences in the distributions of responses to any of these inquiries were observed as a function of DE type.

As with first crashes, the pattern of crashes by all three DE mode groups was very similar for subsequent crashes. Overall, 13.5 percent of all respondents reported involvement in at least two crashes while they were driving. The difference among drivers having taken each of the DE types was, again, small and not statistically significant. Just over 15 percent of PT respondents reported two or more crashes (15.4\%) compared to 11.9 and 13.1 percent of commercial and public school-trained novice drivers. 


\subsection{Driver Record Data}

\subsubsection{Detailed Evaluation and Analysis Approach Source Data for Analysis}

The basic data used for analyses of novice driver crashes and traffic offenses as a function of mode of driver education are derived from Texas Driver Records originated and maintained by the Texas DPS. A driver record is established for all Texas license holders. For novice drivers, they typically originate upon application for and receipt of an Instruction Permit (a Phase 1 License under the current Graduated Driver License Program). The minimum age for an Instruction Permit is 15. The DPS License Issuance Bureau provided computerized files of the driver records for all people in Texas with birth dates between October 1, 1979, and June 15, 1989, inclusive. This range encompasses virtually all drivers who, as of June 2004, held some form of Texas driver's license and who would have been eligible for the Parent-Taught Driver Education Program. The rationale for selecting these dates is as follows:

The Parent-Taught Driver Education Program officially started April 1, 1997. Because courses taken under the program must be completed before a student reaches 18 years of age, we estimated that few, if any, of the initial program participants would have been older than $17 \frac{1}{2}$ years of age when a parent-taught course was initiated, i.e., were born earlier than October 1, 1979. We further assumed that we could obtain driver records current as of June 15, 2004. The youngest people who could both have a driver record and have started a driver education course would necessarily be at least 15 years old on that date and, therefore, could not have been born more recently than June 15, 1989.

Driver Records for 2,303,439 Texas licensees meeting the age requirements set forth above were received from DPS in the form of two ASCII files, referred to as the Base File and the History File.

The Base File is comprised of 21 fields. ${ }^{20}$ For our purposes, the most important fields are those that identify the licensees' date of birth, the date of original application for a driver license (ORI_DATE) and the Driver Education Type (DE). In addition to ORI_DATE, there are other date fields in the driver records, e.g., DLI_DATE (Driver License Issue Date) and GDI_DATE (Graduated Driver License Issuance Date), among others. Based on consultation with DPS and our understanding of the driver record files, we selected ORI_DATE rather than any of the other date fields as the primary base-date for analysis to determine time from initial licensing to occurrence of crash and traffic offense events. It appears to be the most accurate, stable and least susceptible to error of the date fields. Driver License Issue Date, for example, captures the most recent transaction update of a license, which is not necessarily the same as the actual date of issuance of a license. Thus, for example, if a duplicate license is issued, the License Issuance Date will reflect the date the duplicate was issued, not the original issuance date. Although the exact frequency is unknown, a significant number of duplicate licenses are processed by DPS, especially for the youngest drivers. Date fields associated with the Texas graduated license were not used in the analysis because although the GDL provisions became effective as of January 1,

\footnotetext{
${ }^{20}$ Notably missing from among the Base File fields received DPS is driver gender. Therefore, analyses of gender differences in DE education type, crash or citation experience were not possible with this data set.
} 
2002, reprogramming of the driver record files required to accommodate the new GDL-related fields was not implemented by DPS until December 2002.

For novice drivers under 18 years old, the ORI_DATE, on which an individual's driver record is established, is typically the date when a teen obtains an instruction permit. However, there can be driver history elements that predate the issuance of an instruction permit/driver license. This could occur, for example, if an unlicensed 14-year-old is cited for a traffic offense, a 12-year-old driver is involved in a police-reported crash, or a driver of any age is cited for driving without a license. In these cases, DPS enters that element in its "unlicensed files" and transfers it to the driver record if and when an applicant is issued an instruction permit or other driver license. Although it is recognized that ORI_DATE is not without exception identical to the date of issuance of an instructional permit for novice drivers, it provides the best estimate available for that date. There is no reason to believe that any differences that may exist between ORI_DATE and the date of instructional permit issuance are distributed differentially among the records of young drivers as a function of the type of driver education they received. As will be seen, the analyses refer to time (months) after original driver record. Most results are provided in relation to multiple six-month periods ${ }^{21}$ following driver record origination, based on ORI_DATE.

The Driver Education Type (DE) field can take any of 11 codes that indicate the type of driver education course completed as of the date of the driver record obtained. Included are combinations of driver education types (for example, commercial school classroom phase combined with parent-taught in-vehicle phase) and no driver education. Approximately 28 percent of the driver records received indicate that the individual did not take a driver education course of any type. In these cases, the driver may have held a Minor's Restricted Driver License or the person was more than 18 years old and driver education was not required. If an individual who is required to complete driver education does not successfully complete an approved course, and DPS is notified, the record will be alarmed as "incomplete driver education." There is no information in the driver record identifying the specific driving school attended nor, for parenttaught students, the specific course (currently there are eight approved parent-taught courses) taken. Less than 1 percent $(0.82 \%)$ of all driver records indicates that some combination of commercial and parent-taught driver education was undertaken. Driver records for those students identified as completing driver education through a combination of DE modes are not included in the analysis of crash and citation involvement. The only records included in the present analysis are those for which the DE code indicates the individual completed a novice driver course that is specified as comprising only "parent-taught" or only "commercial" for both the required classroom and laboratory (in-vehicle) portions of driver education.

Thus, DE codes F (completed both commercial classroom \& laboratory) and J (completed commercial classroom, laboratory \& motorcycle training) constitute the Commercial and Public School category in the analysis. Of these 1,169,155 individuals, only 1,234 completed motorcycle training in addition to a basic DE novice course. Similarly, the parent-taught classification in the analysis includes only those drivers with DE codes P (completed both parent-taught classroom and laboratory phases of driver education) and code $\mathrm{N}$ (completed parent-taught classroom and laboratory (behind-the-wheel) phases and, in addition, completed

\footnotetext{
${ }^{21}$ Each nominal six-month period actually comprises 180 days or slightly less than six calendar months.
} 
motorcycle training). This group comprises 288,528 drivers of which only half of 1 percent have had motorcycle training in addition to the parent-taught course of study.

Limiting the driver records eligible for inclusion in the analyses as described above, reduced the sample size from 2,303,439 (total driver records received from DPS) to 1,457,683, or slightly more than 63 percent of the total records received. The great majority of records eliminated from consideration are associated with people who did not take a driver education course (more than 640,000 records). Of these, more than 98 percent did not complete a driver education course because they were older than 18 when their driver records were established and, therefore, were not required to take driver education prior to licensing.

The initial set of records eligible for analysis was further reduced by limiting included records to those with ORI_DATES between October 1, 1997 and January 1, 2004. People with ORI_DATES prior to October 1997 would not have been eligible for the parent-taught program. The January 2004 end date for inclusion was selected to insure that all drivers included had a minimum of 6 months of driver history after their records were established. Finally, an extensive data cleansing process was undertaken to eliminate records that were unusable due to errors or other corruptions in the data as received. Among the records excluded in this process are, for example, records with missing ORI_DATEs and records that indicate driver licensing actions that predate the licensees' dates of birth.

The History File is linked to the Base File by the REC_KEY (record key) field common to both. This key is a unique identifier for each individual included in the driver records. It is, essentially, a surrogate for an individual's driver license number, which number was not included in the files received from DPS for privacy and security reasons. Twelve fields, as indicated and defined in Table 42, are included in the history file.

The TRAN_TYPE (Transaction type) field is used to indicate if there is a driver history element (transaction) included in an individual's driver record and the type of transactions recorded. All entries take values of N/A, Accident, Conviction, or Misc. N/A simply indicates that no other transactions are recorded on an individual's driver record. All of the "Misc" entries in the current data have the transaction code: "Reported Deceased." This code does not necessarily refer to a death resulting from a traffic crash. "Reported deceased" is used for administrative purposes to note the death of a licensee from any cause.

Transaction types "Accident" and "Conviction" are of key importance to the analysis of the driver record data. They incorporate many more options than "N/A" and "Misc." These options are delineated in the "TRANSACTION" field. Six codes are included under the "Crash" transaction type. They correspond to the commonly employed crash categories based on the most severe injury sustained in a crash, that is "Fatal accident" $(\mathrm{K})$, "Accident with incapacitating injury" (A), "Accident with non-incapacitating injury" (B), "Accident with possible injury" (C), and "Non-injury accident" (PDO). A final code "Unknown injury accident" is used for all crashes for which injury status is unknown.

Two hundred fifty-six individual codes are included in the present data under transaction type "Conviction." The codes vary widely in specificity of the offense. The most prevalent 
conviction is for "Speeding," but offenses are also reported as, for example, "Speeding $15 \mathrm{mph}$ or more above the limit" and "Speeding 31 to $40 \mathrm{mph}$ or more above the limit." Similarly, a large number of convictions are for the offense "Failed to yield right-of-way," while other offenses are more specific, as for example, "Failed to yield right-of-way leaving private drive" and "Failed to yield right-of-way -- turning left." For purposes of the analysis, the 256 individual conviction transactions have been grouped into the 14 conviction groups listed in Table 43. Though most of the conviction groups are self-explanatory, some amplification is provided in the "Notes" column in the table. The specific offenses included in each conviction group are identified in Table 44.

Table 42. Driver record history file fields (variables)

\begin{tabular}{|c|c|}
\hline Field Name & Expanded field name: Comments/explanation \\
\hline REC_KEY & $\begin{array}{l}\text { Record Key: Unique Identifier for each individual (surrogate for DL \#, same as } \\
\text { REC_KEY in Base File) }\end{array}$ \\
\hline - I & $\begin{array}{l}\text { Incremental count of transactions: Incremental count for each individual, i.e., for } \\
\text { each REC_KEY }\end{array}$ \\
\hline $\mathrm{N}$ & Number of transactions: Total for each individual, i.e., for each REC_KEY \\
\hline SOURCE & $\begin{array}{l}\text { Source of transaction data: (No History Found, In-State History, Out-of-State } \\
\text { History) }\end{array}$ \\
\hline ST & State where transaction occurred \\
\hline TRAN_TYPE & $\begin{array}{l}\text { Transaction Type: All entries take values: N/A, Accident, Conviction, or Misc. } \\
\text { Used to identify if there is a driver history placed on the driver record and the type } \\
\text { of transactions recorded. All of the "Misc" entries in the current data have the } \\
\text { transaction code: "Reported Deceased." This code does not always refer to a fatal } \\
\text { traffic crash incident. "Reported deceased" is used to report the death of a licensee } \\
\text { from any cause }\end{array}$ \\
\hline ACT_DATE & $\begin{array}{l}\text { Action Date: Date of a transaction: the date a crash or traffic offense occurred. For } \\
\text { accident transactions, this field is used to indicate the date of a crash. For traffic } \\
\text { offenses, this field is used to indicate the date the offense occurred (CON_DATE } \\
\text { indicates the date of final disposition). }\end{array}$ \\
\hline TRANSACTION & $\begin{array}{l}\text { Description of Transaction: Used to capture the driver history offense, crash } \\
\text { incidents, education courses and or administrative history. Note, courses reported } \\
\text { taken/completed do not always remove or replace traffic or alcohol-related } \\
\text { conviction. There are instances when a court may impose the required DWI } \\
\text { education course without a related offense. Courses taken to obtain insurance } \\
\text { discounts are not reported on the driver history. }\end{array}$ \\
\hline LOCATION & City or County where transaction occurred \\
\hline CON_DATE & $\begin{array}{l}\text { Conviction Date: the conviction date field for a traffic offense is used to indicate the } \\
\text { final disposition and disposition date for the offense }\end{array}$ \\
\hline CMV & $\begin{array}{l}\text { Commercial Vehicle Violation: All entries take values: N/A, Non-CMV, Unk-CMV, } \\
\text { or CMV. Indicates the type of vehicle used. As traffic citations are reported, the } \\
\text { officer will indicate the type of vehicle in use. If this field is incomplete the UNK } \\
\text { transaction will be entered }\end{array}$ \\
\hline HAZ_MAT & Hazardous Material Involved: All entries take values: N/A, Non-Haz, or Haz \\
\hline
\end{tabular}


Table 43. Conviction groups for analysis

\begin{tabular}{|c|c|}
\hline Conviction Group* & Notes \\
\hline \multicolumn{2}{|l|}{ 1. Speeding over the limit } \\
\hline \multicolumn{2}{|l|}{ 2. Racing/excessive acceleration } \\
\hline 3. Other speed-related violations & Including unsafe speed, speed under minimum, etc. \\
\hline \multicolumn{2}{|l|}{ 4. Red light/stop sign violation } \\
\hline $\begin{array}{l}\text { 5. Disregard other traffic signs, signals, } \\
\text { markings }\end{array}$ & All types except: red lights, stop signs, yield signs \\
\hline \multicolumn{2}{|l|}{ 6. Failure to yield right-of-way } \\
\hline \multicolumn{2}{|l|}{ 7. Improper signal/fail to signal } \\
\hline 8. Other moving violations & $\begin{array}{l}\text { Moving violations not included in other more specific } \\
\text { conviction groups }\end{array}$ \\
\hline 9. Alcohol and drug violations & $\begin{array}{l}\text { Includes education courses/programs. Courses completed do } \\
\text { not always remove or replace an alcohol-related conviction and } \\
\text { a court may in some instances impose a required DWI } \\
\text { education course without a related offense. }\end{array}$ \\
\hline 10. Negligent/antisocial violations & $\begin{array}{l}\text { Broad range: from failing to dim headlights to negligent } \\
\text { homicide. Offenses included in other groups could also be } \\
\text { considered to be the result of negligent and/or antisocial } \\
\text { behavior. }\end{array}$ \\
\hline \multicolumn{2}{|l|}{ 11. Driver license violations/No license } \\
\hline \multicolumn{2}{|l|}{ 12. Other DL violations (commercial) } \\
\hline $\begin{array}{l}\text { 13. Mandated driving safety } \\
\text { course/program (excludes alcohol- } \\
\text { related courses that are included in } \\
\text { conviction group 9) }\end{array}$ & $\begin{array}{l}\text { Some of these courses may not have been ordered by the court, } \\
\text { but offered as an alternative to fines/jail-time. Completion may } \\
\text { or may not expunge conviction for original offense from record. } \\
\text { Courses taken to obtain insurance discounts are not reported in } \\
\text { the driver history. }\end{array}$ \\
\hline 14. Miscellaneous violations & All other convictions not grouped elsewhere. \\
\hline
\end{tabular}

Table 44. Offenses included in conviction groups for analysis

\begin{tabular}{|c|c|}
\hline Conviction Group & Transactions Included \\
\hline \multirow{15}{*}{ 1. Speeding over the limit } & Speeding \\
\hline & Speeding 01-10 mph over speed limit \\
\hline & Speeding $06-10 \mathrm{mph}$ over speed limit \\
\hline & Speeding 11-15 mph over speed limit \\
\hline & Speeding 11-20 mph over speed limit \\
\hline & Speed $15 \mathrm{mph}$ or more over posted limit \\
\hline & Speeding 16-20 mph over speed limit \\
\hline & Speeding 21-25 mph over speed limit \\
\hline & Speeding 21-30 mph over speed limit \\
\hline & Speeding 26-30 mph over speed limit \\
\hline & Speeding 31-35 mph over speed limit \\
\hline & Speeding 31-40 mph over speed limit \\
\hline & Speeding 36-40 mph over speed limit \\
\hline & Speeding $41 \mathrm{mph}$ or more above speed limit \\
\hline & Speeding in a school zone \\
\hline
\end{tabular}


Table 44. Offenses included in conviction groups for analysis (cont'd)

\begin{tabular}{|c|c|}
\hline Conviction Group & Transactions Included \\
\hline \multirow{4}{*}{$\begin{array}{l}\text { 2. Racing/excessive } \\
\text { acceleration }\end{array}$} & Excessive acceleration \\
\hline & Racing \\
\hline & Speed contest on road open to traffic \\
\hline & Increased speed while being overtaken \\
\hline \multirow{5}{*}{$\begin{array}{l}\text { 3. Other speed-related } \\
\text { violations }\end{array}$} & Fail to control speed \\
\hline & Unsafe speed \\
\hline & Speed under minimum \\
\hline & Speed less than minimum \\
\hline & Operating at erratic/suddenly changing speeds \\
\hline \multirow{4}{*}{$\begin{array}{l}\text { 4. Red light/stop sign } \\
\text { violation }\end{array}$} & Disregarded flashing red signal \\
\hline & Ran stop sign \\
\hline & Ran red light \\
\hline & Failure to obey stop sign \\
\hline \multirow{20}{*}{$\begin{array}{l}\text { 5. Disregard other traffic } \\
\text { signs, signals, markings }\end{array}$} & Disregarded turn marks at intersection \\
\hline & Disregarded traffic control device \\
\hline & Fail to obey sign/traffic control device \\
\hline & Failure to obey traffic sign \\
\hline & Disregarded signal at RR crossing \\
\hline & Fail stop proper place-flash red signal \\
\hline & Fail to stop-designated point-yield sign \\
\hline & Disregarded flashing yellow signal \\
\hline & Failure to obey yield sign \\
\hline & Fail to obey railroad gates/sign/signal \\
\hline & Disregarded warning sign at construction \\
\hline & Disregarded lane control signal \\
\hline & Disregarded RR crossing gate or flagman \\
\hline & Failed to stop at marked RR crossing \\
\hline & Failure to obey lane markings or signal \\
\hline & Fail to obey RR crossing restriction \\
\hline & Failure to obey traffic signal or light \\
\hline & Fail to stop - designated point/stop sign \\
\hline & Disregarded no lane change sign \\
\hline & Failure to obey warning light/flasher \\
\hline \multirow{12}{*}{$\begin{array}{l}\text { 6. Failure to yield right-of- } \\
\text { way }\end{array}$} & Failed to yield at stop intersection \\
\hline & Failed to yield right-of-way (FYROW) \\
\hline & FYROW - turn left \\
\hline & FYROW leaving private drive, alley, etc. \\
\hline & FYROW to emergency vehicle \\
\hline & Failed to yield row at open intersection \\
\hline & Failure to yield right-of-way \\
\hline & FYROW to pedestrian in crosswalk--no signals \\
\hline & Failed to yield when changing lanes \\
\hline & Failed to yield turn right on red signal \\
\hline & FYROW on green signal \\
\hline & FYROW when turning \\
\hline
\end{tabular}


Table 44. Offenses included in conviction groups for analysis (cont'd)

\begin{tabular}{|c|c|}
\hline Conviction Group & Transactions Included \\
\hline \multirow{13}{*}{$\begin{array}{l}\text { 6. Failure to yield right-of- } \\
\text { way (continued) }\end{array}$} & FYROW to pedestrian at signal intersect \\
\hline & FYROW at stop sign \\
\hline & FYROW at traffic sign \\
\hline & FYROW to other vehicle \\
\hline & FYROW to pedestrian on sidewalk \\
\hline & FYROW to emergency vehicle \\
\hline & FYROW at unsigned intersection \\
\hline & FYROW to pedestrian \\
\hline & FYROW at crosswalk \\
\hline & FYROW at traffic signal \\
\hline & Failed to yield at yield intersection \\
\hline & Fail to stop from alley driveway or bldg \\
\hline & Failed to stop for approaching train \\
\hline \multirow{8}{*}{$\begin{array}{l}\text { 7. Improper signal/fail to } \\
\text { signal }\end{array}$} & Improper turn or stop signal \\
\hline & Failed to signal distance before turn \\
\hline & Failed to signal - for stop \\
\hline & Failure to use lights as required \\
\hline & Failure to signal lane change or turn \\
\hline & Failure to use or improper signal \\
\hline & Giving wrong signal \\
\hline & Failed to sound horn - mountain road \\
\hline \multirow{25}{*}{ 8. Other moving violations } & Changed lane when unsafe \\
\hline & Following too closely \\
\hline & Failed to drive in single lane \\
\hline & Improper turn \\
\hline & Illegal backing \\
\hline & Drove wrong way on one-way roadway \\
\hline & Wrong side of road \\
\hline & Failed to signal lane change \\
\hline & Turned when unsafe \\
\hline & Turned left from wrong lane \\
\hline & Drove onto controlled access hwy where prohibited \\
\hline & Turned right from wrong lane \\
\hline & Turned right too wide \\
\hline & Crossing physical barrier \\
\hline & Illegal pass on right \\
\hline & Cut corner left turn \\
\hline & Fail to stop proper place-traffic light \\
\hline & Passed--insufficient clearance \\
\hline & Failed to give one-half of roadway \\
\hline & Wrong side road-not passing \\
\hline & Drove on wrong side--divided highway \\
\hline & Improper or erratic lane changes \\
\hline & Failure to keep in proper lane \\
\hline & Driving wrong way-one way street or road \\
\hline & Drove wrong way in designated lane \\
\hline
\end{tabular}


Table 44. Offenses included in conviction groups for analysis (cont'd)

\begin{tabular}{|c|c|}
\hline Conviction Group & Transactions Included \\
\hline \multirow{46}{*}{$\begin{array}{l}\text { 8. Other moving violations } \\
\text { (continued) }\end{array}$} & Improper backing \\
\hline & Driving on wrong side \\
\hline & Drove through safety zone \\
\hline & Driving wrong way \\
\hline & Making improper left turn \\
\hline & Passing where prohibited \\
\hline & Making improper U-turn \\
\hline & Drove to left of rotary traffic island \\
\hline & Improper lane/location - entrance/exit ramp/way \\
\hline & Driving on wrong side-undivided street/rd \\
\hline & Improper lane/location - straddling center line \\
\hline & Passed vehicle stopped for pedestrian \\
\hline & Passing authorized emergency vehicle \\
\hline & Passing on wrong side \\
\hline & Driving on wrong side - divided highway \\
\hline & Driving wrong way on divided highway \\
\hline & Following improperly \\
\hline & Failed to pass met vehicle to right \\
\hline & Making improper right turn \\
\hline & Making improper turn around \\
\hline & Pass with insufficient distance/visibility \\
\hline & Passing violation - opposite direction restrict \\
\hline & Ran off road \\
\hline & Violation resulting in accident \\
\hline & Failed to signal turn \\
\hline & Drove without lights when required \\
\hline & Impeding traffic \\
\hline & Did not use designated lane or direction \\
\hline & Drove center lane-not pass or left turn \\
\hline & Improper lane or location \\
\hline & Made U-turn on curve or hill \\
\hline & Turned across dividing section \\
\hline & Passing viol-posted sign/pavement mark \\
\hline & Improper position for turning \\
\hline & Hit and run - fail to stop and render aid - property damage accident \\
\hline & Improper lane/location - in occupied lane \\
\hline & Improper lane/location - limit access hwy \\
\hline & Improper lane/location - slower vehicle lane \\
\hline & Improper lane/location - oncoming traffic lane \\
\hline & Improper method of turning \\
\hline & Improper lane/location - median \\
\hline & Improper lane or location - crossover \\
\hline & Improper passing \\
\hline & Drove on sidewalk \\
\hline & Disregarded no passing zone \\
\hline & Cut across driveway to make turn \\
\hline
\end{tabular}


Table 44. Offenses included in conviction groups for analysis (cont'd)

\begin{tabular}{|c|c|}
\hline Conviction Group & Transactions Included \\
\hline \multirow{18}{*}{$\begin{array}{l}\text { 9. Alcohol \& drug } \\
\text { violations }\end{array}$} & Driving while intoxicated - under 21 \\
\hline & Driving under influence - minor \\
\hline & Open container - passenger \\
\hline & Driving while intoxicated \\
\hline & Consume alcohol while driving \\
\hline & Driving under the influence of alcohol or drugs \\
\hline & Driving under the influence of alcohol \\
\hline & Intoxication manslaughter \\
\hline & Intoxication assault \\
\hline & Driving under influence of drugs \\
\hline & DUI alcohol - BAC .10 or more \\
\hline & Driving Under Influence \\
\hline & Driving while impaired - ability def impaired \\
\hline & Administrative Per Se for $.10 \mathrm{BAC}$ \\
\hline & DWI education program completed \\
\hline & DWI education program required \\
\hline & DWI education program waived \\
\hline & Driving while intoxicated - probated \\
\hline \multirow{27}{*}{$\begin{array}{l}\text { 10. Negligent/antisocial } \\
\text { violations }\end{array}$} & Fail to stop and render aid \\
\hline & Leaving scene of accident \\
\hline & Failed to stop for school bus \\
\hline & Unsafe start \\
\hline & Reckless driving \\
\hline & Careless driving \\
\hline & Disregard police officer \\
\hline & Negligent collision \\
\hline & Cut in after passing \\
\hline & Reckless/careless/negligent driving \\
\hline & Inattentive driving \\
\hline & Negligent driving \\
\hline & Leaving accident scene before police arrive \\
\hline & Failed to use due care for pedestrian \\
\hline & Passing school bus displaying warning \\
\hline & Failure to obey police or peace officer \\
\hline & Leave accident scene before police arrive - prop damage \\
\hline & Fleeing from police officer \\
\hline & Criminal negligent homicide \\
\hline & Hit-and-run - fail to stop and render aid after accident \\
\hline & Involuntary manslaughter \\
\hline & Leave accident scene before police arrive - per injury \\
\hline & Aggravated assault with motor vehicle \\
\hline & Failure to obey safety zone \\
\hline & Failed to dim headlights - following \\
\hline & Failed to dim headlights - meeting \\
\hline & Fail to use headlight dimmer as required \\
\hline
\end{tabular}


Table 44. Offenses included in conviction groups for analysis (cont'd)

\begin{tabular}{|c|c|}
\hline Conviction Group & Transactions Included \\
\hline \multirow{13}{*}{$\begin{array}{l}\text { 11. Driver license } \\
\text { violations/No license }\end{array}$} & No drivers license \\
\hline & Violate DL restriction \\
\hline & Driving while license invalid \\
\hline & No motorcycle endorsement \\
\hline & Driving while license suspended/revoked \\
\hline & Operate vehicle more than one pass - minor \\
\hline & Violate operating hours - minor \\
\hline & Violate restrictions of driver license \\
\hline & Driving while license suspended \\
\hline & Driving while license withdrawn \\
\hline & Display fictitious driver license \\
\hline & Driving while license cancelled \\
\hline & Driving while license disqualified \\
\hline \multirow{6}{*}{$\begin{array}{l}\text { 12. Other DL violations } \\
\text { (commercial) }\end{array}$} & No commercial driver license \\
\hline & Restriction violation - CMV \\
\hline & No commercial operator license \\
\hline & Failed to report change address name - CDL \\
\hline & Violate DL restriction on occupational license \\
\hline & Endorsement violation - CMV \\
\hline \multirow{4}{*}{$\begin{array}{l}\text { 13. Mandated driving } \\
\text { safety course/program } \\
\text { (excludes alcohol-related) }\end{array}$} & Driving safety course \\
\hline & Completed teen court program \\
\hline & Repeat offender - education program completed \\
\hline & Repeat offender - education program required \\
\hline \multirow{20}{*}{$\begin{array}{l}\text { 14. Miscellaneous } \\
\text { violations }\end{array}$} & Fail to stop - unsigned intersection/entering roadway \\
\hline & Slower vehicle failed to keep to right \\
\hline & Improper lane/location - HOV/restricted lane \\
\hline & Bus failed to stop at RR crossing \\
\hline & Improper lane/location - road shoulder/ditch/sidewalk \\
\hline & Following fire equipment unlawfully \\
\hline & Carry passenger without helmet \\
\hline & Obstructed view through windshield \\
\hline & Operating vehicle where prohibited \\
\hline & Passenger/load obstruct view of driver \\
\hline & Obstructing traffic \\
\hline & Prohibited motor vehicle on control access hwy \\
\hline & Stop-stand-park/obstruct - impede traffic \\
\hline & Fail to stop proper place - not intersection \\
\hline & Operate w/o lights as required by law \\
\hline & Volatile chemical act offense \\
\hline & Stop-stand-park/prohibited or improper \\
\hline & Operate vehicle with child in open bed \\
\hline & Clinging to other vehicles \\
\hline & Red light on front \\
\hline
\end{tabular}




\subsubsection{Results of the Driver Record Analysis}

\section{Analysis of Driver Records - Age, Crash, and Traffic Conviction Data}

The analyses summarized in the tables and figures in this section address the age of young drivers upon obtaining their first licenses (instructional permits) and the two primary outcome measures on which parent-taught and commercial/public school driver education programs have been compared: crash and traffic citation experience. The basic approach was the same for both crash and citation data.

Because Texas adopted a Graduated Drivers License that became effective in January 2002, two distinct and independent analyses have been conducted. Novice drivers under 18 years old who were issued an instruction permit (and therefore had a driver record) prior to January 1, 2002, were not subject to the requirements and restrictions of the Texas GDL. Drivers issued their instruction permits on or after January 1, 2002, were subject to the provisions of the GDL. The tables and figures in which the results of the analyses are summarized are presented separately, either side-by-side or in adjacent presentations, for both pre- and post-GDL licensees.

Two metrics are used in the analyses of both crashes and convictions for comparisons of parenttaught drivers with drivers who received commercial or public school driver education and training: frequency of crashes, i.e., how many crashes were experienced by each group, and relative likelihood of crashes, i.e., the likelihood that a crash involved a parent-taught driver relative to a driver who took a commercial/public school course.

\section{Age at Origination of Driver Records}

It is commonly noted that the high incidence of crashes among the youngest drivers, attributable at least in part to a combination of inexperience, immaturity and developmental factors, is exacerbated by the availability of any type of driver education that has the effect of encouraging earlier licensure. In Texas, as elsewhere, licensure is permitted at an earlier age (16-18) only if an approved driver education course is successfully completed. The results of the survey discussed in the preceding sections suggest that students completing the three primary DE options in Texas do not differ in age at critical stages of the licensing process. Those results, while benefiting from the distinction between commercial and public school DE students that the driver records lack, are based on a relatively small sample of respondents and are subject to bias associated with the low survey response rate. The $1,457,683^{22}$ driver records analyzed for the evaluation, on the other hand, provide a near-census of young drivers who completed either a parent-taught or "commercial" DE course. As emphasized previously, both commercial and public school DE courses are coded as "commercial" in the driver records.

Figures 8 and 9 provide both the average age of novice drivers and the distribution of driver ages when their driver records were established, pre- and post-GDL respectively. As noted earlier, record origination is typically contemporaneous with obtaining an instructional driving permit. As indicated in the figures, small but statistically significant differences in the mean age at which drivers (nominally) obtained their first driving licenses (instructional permits) are observed as a function of DE type for both those young drivers who were subject to the Texas

\footnotetext{
${ }^{22}$ Less 12 records that were deleted because of a missing birth date or a known error in the birth date reported.
} 


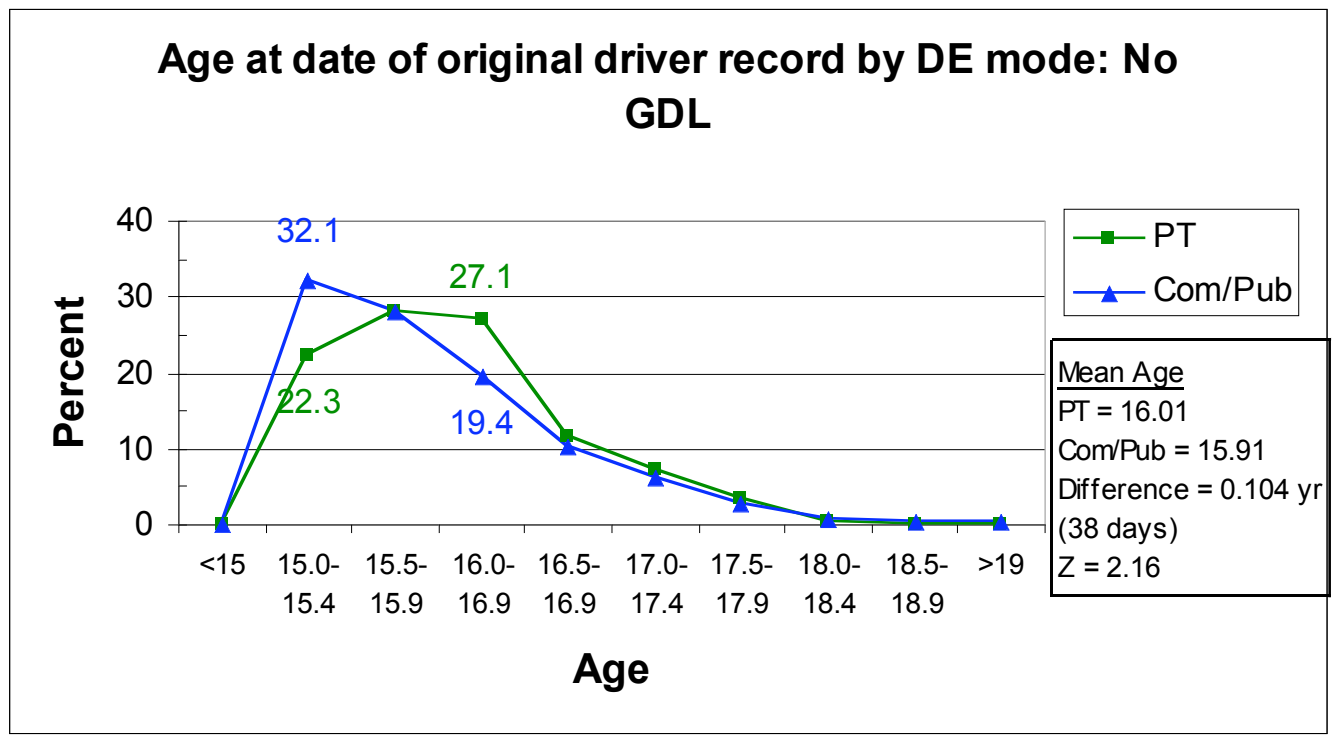

Figure 8. Pre-GDL distribution of driver ages at driver record origination

Graduated Driver License program and those who were not. Prior to the GDL, PT drivers were 0.104 years (38 days) older than Com/Pub-trained drivers when they obtained instructional permits. Among novices who were subject to the GDL, PT drivers were 0.160 years (58 days) younger than their Com/Pub peers were when they obtained instructional permits.

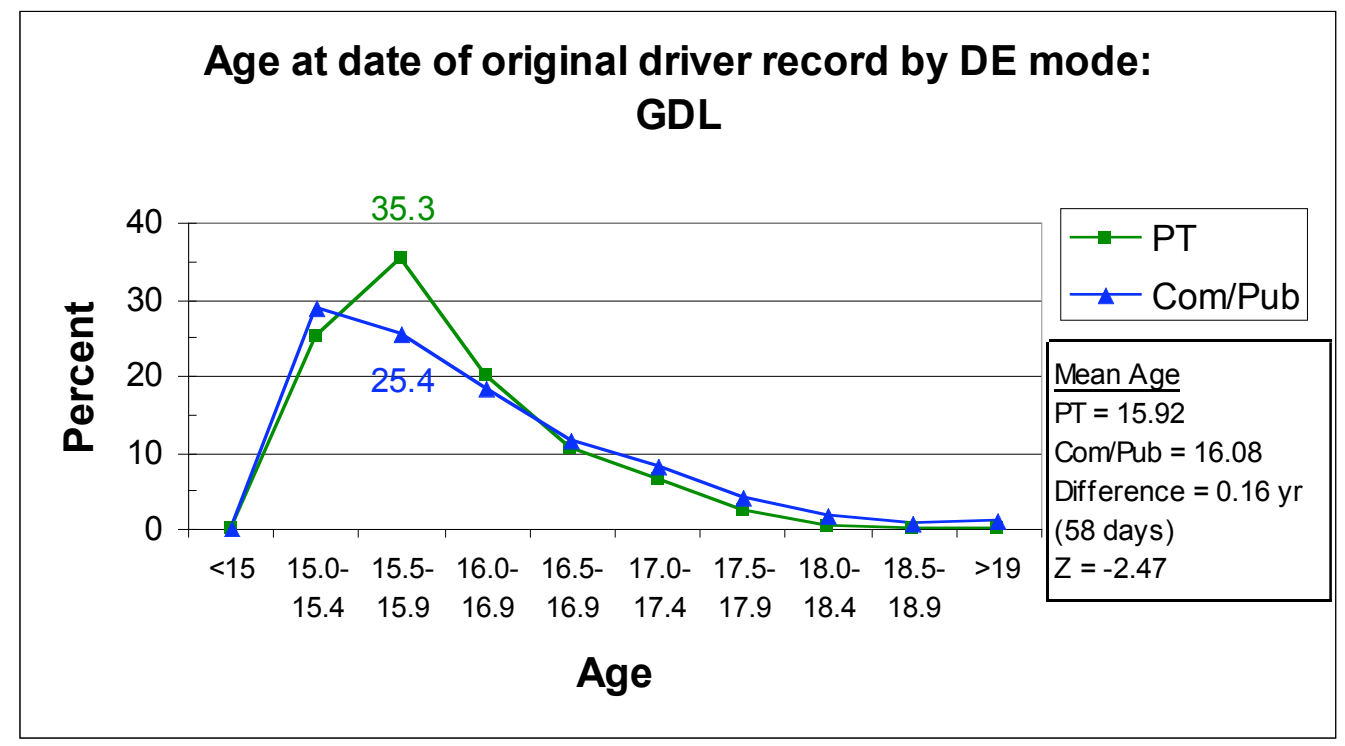

Figure 9. Post-GDL distribution of driver ages at driver record origination

Of greater interest than the mean ages at initial licensure are the distributions of those ages. Figures 8 and 9 illustrate the percent of drivers, pre- and post-GDL respectively who obtained instructional permits within half-year age groups. The distribution of these ages differ significantly for both the pre-GDL $\left(\chi^{2}=10,861, \mathrm{df}=8, \mathrm{p}<.01\right)$ and post-GDL groups $\left(\chi^{2}=\right.$ $6,972, \mathrm{df}=8, \mathrm{p}<.01)$ as a function of DE type. The distribution of ages at driver record 
origination for PT and Com/Pub-trained drivers before the GDL was in effect are very similar except at two points in the distributions. Proportionally, nearly 10 percent more Com/Pub drivers had driver records (typically indicating obtaining instructional permits) established as 15to 15.4-year-olds than did PT drivers. Driver records were established proportionally more frequently in the 16 to 16.4 age range for PT drivers than they were for Com/Pub drivers, suggesting that PT students delayed obtaining an instruction permit relative to students taking the traditional forms of DE.

Since the introduction of GDL, PT novice drivers established a driver record as 15.5- to 15.9year-olds proportionally more often than did Com/Pub drivers. About 10 percent more PT driver records originated in this age range (35.3\% compared to $25.4 \%)$. Because of the strong relationship between record origination and obtaining an instructional permit, it is apparent that since the inception of the GDL, a significant proportion of PT novices are getting instructional permits at an earlier age than their Com/Pub counterparts.

\section{Frequency of Crashes}

The total number of crashes experienced by each driver (classified by driver education type and severity of crash) was calculated for all drivers eligible for inclusion in the analysis in consecutive 180-day periods (nominally six-month periods) following the origination of the individual's driver record. As noted previously, a driver record is typically initiated coincident with obtaining an instructional permit. For drivers not subject to GDL, the number of six-month periods ranged from one (for the newest drivers) to six (for the oldest, most experienced drivers in the driver record data base), thus encompassing up to nearly three years of driving experience following issuance of an instructional permit. Because the GDL was not in effect until January 2002, the maximum number of six-month periods for drivers subject to the GDL provisions in the current data was four, or approximately two years of driving experience. Simple two-tailed Z-tests were applied to the mean number of crashes per driver in each nominal six-month period following origination of a driver record to test the significance of observed differences in the number of crashes experienced in each time period as function of type of driver education.

The results of these tests are summarized in Tables 45 and 46 for drivers not subject to GDL and post-GDL drivers, respectively. Because the actual mean number of crashes per individual is very small, especially as the severity of crashes increase, average crashes per driver have been transformed to the number of crashes per 10,000 drivers.

In the tables, lightly-shaded green cells indicate those time periods during which parent-taught drivers experienced significantly $(\mathrm{p}<.05)$ more crashes per 10,000 drivers than commercial/public-school-taught drivers. The darker-shaded blue cells indicate periods during which commercial/public-school-taught drivers experienced significantly more crashes per 10,000 drivers than parent-taught drivers. Unshaded cells in comparable time periods are not significantly different. The larger value in each significantly different PT versus Com/Pub pair is highlighted in bold type. 
Table 45. Crashes per 10,000 drivers not subject to GDL, by driver education mode

\begin{tabular}{|c|c|c|c|c|c|c|c|}
\hline \multirow{2}{*}{ Crash Severity } & \multirow{2}{*}{ DE Mode } & \multicolumn{6}{|c|}{ Months after date of original driver record } \\
\cline { 3 - 8 } & & $\mathbf{1 - 6}$ & $\mathbf{7 - 1 2}$ & $\mathbf{1 3 - 1 8}$ & $\mathbf{1 9 - 2 4}$ & $\mathbf{2 5 - 3 0}$ & $\mathbf{3 1 - 3 6}$ \\
\hline \multirow{2}{*}{ All Crashes } & $\mathrm{PT}$ & $\mathbf{3 6 9 . 9}$ & $\mathbf{5 8 4 . 3}$ & $\mathbf{6 5 3 . 6}$ & 604.5 & 532.3 & 493.7 \\
\cline { 2 - 8 } & $\mathrm{Com} / \mathrm{Pub}$ & 262.3 & 469.4 & 631.6 & $\mathbf{6 3 4 . 9}$ & $\mathbf{5 7 3 . 5}$ & $\mathbf{5 2 7 . 5}$ \\
\hline \multirow{2}{*}{ At Least One Fatality } & $\mathrm{PT}$ & $\mathbf{1 . 1}$ & $\mathbf{2 . 4}$ & 1.8 & 2.4 & $\mathbf{3 . 2}$ & 3.1 \\
\cline { 2 - 8 } & $\mathrm{Com} / \mathrm{Pub}$ & 0.6 & 1.2 & 1.5 & 1.9 & 1.9 & 2.6 \\
\hline \multirow{2}{*}{ Incapacitating Injury } & $\mathrm{PT}$ & $\mathbf{1 1 . 8}$ & $\mathbf{1 8 . 0}$ & $\mathbf{1 8 . 9}$ & 18.1 & 15.9 & 13.4 \\
\cline { 2 - 8 } & $\mathrm{Com} / \mathrm{Pub}$ & 6.7 & 11.8 & 16.4 & 16.6 & 14.6 & 13.8 \\
\hline \multirow{2}{*}{$\begin{array}{l}\text { Non-incapacitating } \\
\text { Injury }\end{array}$} & $\mathrm{PT}$ & $\mathbf{4 7 . 1}$ & $\mathbf{7 3 . 4}$ & $\mathbf{7 9 . 4}$ & 74.4 & 63.2 & 60.9 \\
\hline \multirow{2}{*}{ Possible Injury } & $\mathrm{Com} / \mathrm{Pub}$ & 30.9 & 53.4 & 74.6 & 73.3 & 65.9 & 61.1 \\
\cline { 2 - 8 } & $\mathrm{PT}$ & $\mathbf{8 4 . 5}$ & $\mathbf{1 3 9 . 8}$ & 157.5 & 146.8 & 128.0 & 118.0 \\
\cline { 2 - 8 } & $\mathrm{Com} / \mathrm{Pub}$ & 70.3 & 128.1 & $\mathbf{1 6 8 . 5}$ & $\mathbf{1 6 7 . 9}$ & $\mathbf{1 5 1 . 7}$ & $\mathbf{1 4 0 . 2}$ \\
\hline \multirow{2}{*}{ Non-Injury } & $\mathrm{PT}$ & $\mathbf{2 2 5 . 4}$ & $\mathbf{3 5 0 . 8}$ & $\mathbf{3 9 6 . 1}$ & 362.9 & 322.1 & 298.4 \\
\cline { 2 - 7 } & $\mathrm{Com} / \mathrm{Pub}$ & $\mathbf{1 5 3 . 9}$ & 274.9 & 370.6 & $\mathbf{3 7 5 . 2}$ & $\mathbf{3 3 9 . 5}$ & $\mathbf{3 0 9 . 8}$ \\
\hline
\end{tabular}

Lightly-shaded green cells indicate parent-taught drivers experienced significantly more crashes per $10 \mathrm{~K}$ drivers than commercial/public-school-taught drivers during comparable time periods $(\mathrm{p}<.05)$.

Darker-shaded blue cells indicate commercial/public-school-taught drivers experienced significantly more crashes per $10 \mathrm{~K}$ drivers than parent-taught drivers during comparable time periods $(\mathrm{p}<.05)$.

Unshaded cells are not significantly different in comparable time periods

Table 46. Crashes per 10,000 drivers subject to GDL, by driver education mode

\begin{tabular}{|c|c|c|c|c|c|}
\hline \multirow{2}{*}{ Crash Severity } & \multirow{2}{*}{ DE Mode } & \multicolumn{4}{|c|}{ Months after date of original driver record } \\
\hline & & $1-6$ & $7-12$ & $13-18$ & $19-24$ \\
\hline \multirow{2}{*}{ All Crashes } & PT & 92.7 & 512.0 & 533.0 & 405.1 \\
\hline & Com/Pub & 122.5 & 457.7 & 527.8 & 390.5 \\
\hline \multirow{2}{*}{$\begin{array}{l}\text { At Least One } \\
\text { Fatality }\end{array}$} & PT & 0.4 & 2.8 & 4.2 & 3.2 \\
\hline & Com/Pub & 0.3 & 1.9 & 1.5 & 3.0 \\
\hline \multirow{2}{*}{$\begin{array}{l}\text { Incapacitating } \\
\text { Injury }\end{array}$} & PT & 3.2 & 15.4 & 14.9 & 9.2 \\
\hline & Com/Pub & 3.1 & 9.8 & 12.2 & 9.3 \\
\hline \multirow{2}{*}{$\begin{array}{l}\text { Non-incapacitating } \\
\text { Injury }\end{array}$} & PT & 13.9 & 63.5 & 60.4 & 41.1 \\
\hline & Com/Pub & 15.3 & 50.6 & 57.2 & 44.3 \\
\hline \multirow{2}{*}{ Possible Injury } & $\mathrm{PT}$ & 23.0 & 116.1 & 121.7 & 95.3 \\
\hline & Com/Pub & 32.8 & 117.2 & 138.1 & 92.9 \\
\hline \multirow{2}{*}{ Non-Injury } & PT & 52.2 & 314.2 & 331.9 & 256.2 \\
\hline & Com/Pub & 70.9 & 278.2 & 318.8 & 240.9 \\
\hline \multicolumn{6}{|c|}{$\begin{array}{l}\text { Lightly-shaded green cells indicate parent-taught drivers experienced significantly more crashes per } 10 \mathrm{~K} \\
\text { drivers than commercial/public-school-taught drivers during comparable time periods }(\mathrm{p}<.05) \text {. } \\
\text { Darker-shaded blue cells indicate commercial/public-school-taught drivers experienced significantly more } \\
\text { crashes per } 10 \mathrm{~K} \text { drivers than parent-taught drivers during comparable time periods }(\mathrm{p}<.05) \text {. } \\
\text { Unshaded cells are not significantly different in comparable time periods }\end{array}$} \\
\hline
\end{tabular}

\section{Relative Likelihood of Crashes}

The "frequency of crashes" analysis provides a comparison of the crash experience of parenttaught and commercial/public-school-taught novice drivers in terms of the number of crashes, but it does not offer a convenient assessment of the relative occurrence of crashes as a function 
of mode of driver education. Therefore, an analysis of the relative likelihood of crashes (by severity) is presented; both to provide such comparisons and to indicate how confident we can be that the observed differences represent true differences. The likelihood analysis casts the crash data in terms of the likelihood that a parent-taught driver will be involved in a crash relative to a driver who has taken a more traditional commercial or public school driver education course. Relative likelihood is nothing more than the ratio of two proportions, i.e., the proportion of crashes in which parent-taught drivers were involved, divided by the proportion of crashes in which commercial/public-school-taught drivers were involved. Computationally, relative likelihood (RL) is defined as:

$$
R L=\frac{a /(a+b)}{c /(c+d)}
$$

where:

$\mathrm{a}=$ the number of parent-taught drivers in crashes of a given severity.

$\mathrm{b}=$ the number of parent-taught drivers not in crashes of the given severity.

$\mathrm{c}=$ the number of commercial/public-school-taught drivers in crashes of the same severity.

$\mathrm{d}=$ the number of commercial/public-school-taught drivers not involved in such crashes.

To illustrate, using the number of fatal crashes during the first six months of driving experience among drivers not subject to GDL, the likelihood of a parent-taught driver being in such a crash relative to the likelihood of a commercial/public-school-taught driver being in a fatal crash is calculated as:

$$
R L=\frac{19 /(19+171,612)}{35 /(35+617,058)}=1.95
$$

The RL of 1.95 indicates that among novice drivers not subject to the GDL, fatal crashes in which the drivers were parent-taught were 1.95 times more likely to have occurred during the first six months of driving than were fatal crashes in which commercial/public-school-taught drivers with the same duration of driving experience were involved.

The example above illustrates a specific instance of the general interpretation of Relative Likelihood: If RL equals 1, the two groups being compared (PT versus Com/Pub) can be said to be equally likely to have been involved in a crash of the given severity. Values of RL ranging from 0 to 1 indicate that PT drivers are less likely than Com/Pub drivers to have been involved. Values of RL greater than 1 (ranging from 1 to $\infty$ ) correspond to situations in which PT drivers are more likely to be involved in a crash of the given severity than are Com/Pub drivers.

The relative likelihood statistic as illustrated above pertains to the specific data set examined. As such, it is useful in describing and characterizing the crashes of parent-taught and commercial/public-school-taught drivers that occurred among the particular drivers for whom driver records were available for analysis. They do not, however, allow us to consider in any quantitative way how confident we should be that the same results would be observed in another data set; for example comparable data from future years with different drivers. Therefore, in order to provide a measure of generalization to the present results, a Z-test and related 95-percent 
confidence intervals $(95 \% \mathrm{CI})$ have been constructed around each RL reported to test its statistical significance. For a detailed explanation of the calculations used to construct the CIs and additional discussion on the use and computation of relative likelihoods, see Griffin and DeLaZerda (2000) and Sahai and Khurshi (1996).

The lower and upper bound of the 95 percent CI for the RL calculated in the example above are 1.12 and 3.41, respectively. In practical terms, this means that we can be 95-percent certain that the true value for $\mathrm{RL}=1.95$ lies between 1.12 and 3.41 and is, therefore, statistically significantly greater than 1 at $p<.05$. When the $\mathrm{CI}$ for any RL includes 1 , we cannot be confident that the true value is different from 1 and therefore the RL cannot be said to be statistically significant. This holds without regard to the numerical size of the RL.

The results of all of the calculations of the relative likelihood of crashes, classified by severity, and their associated 95 percent CI and Z, are shown in Table 47, both for drivers not subject to the Texas GDL (left half of table) and drivers who were subject to the GDL (right half of table) . 


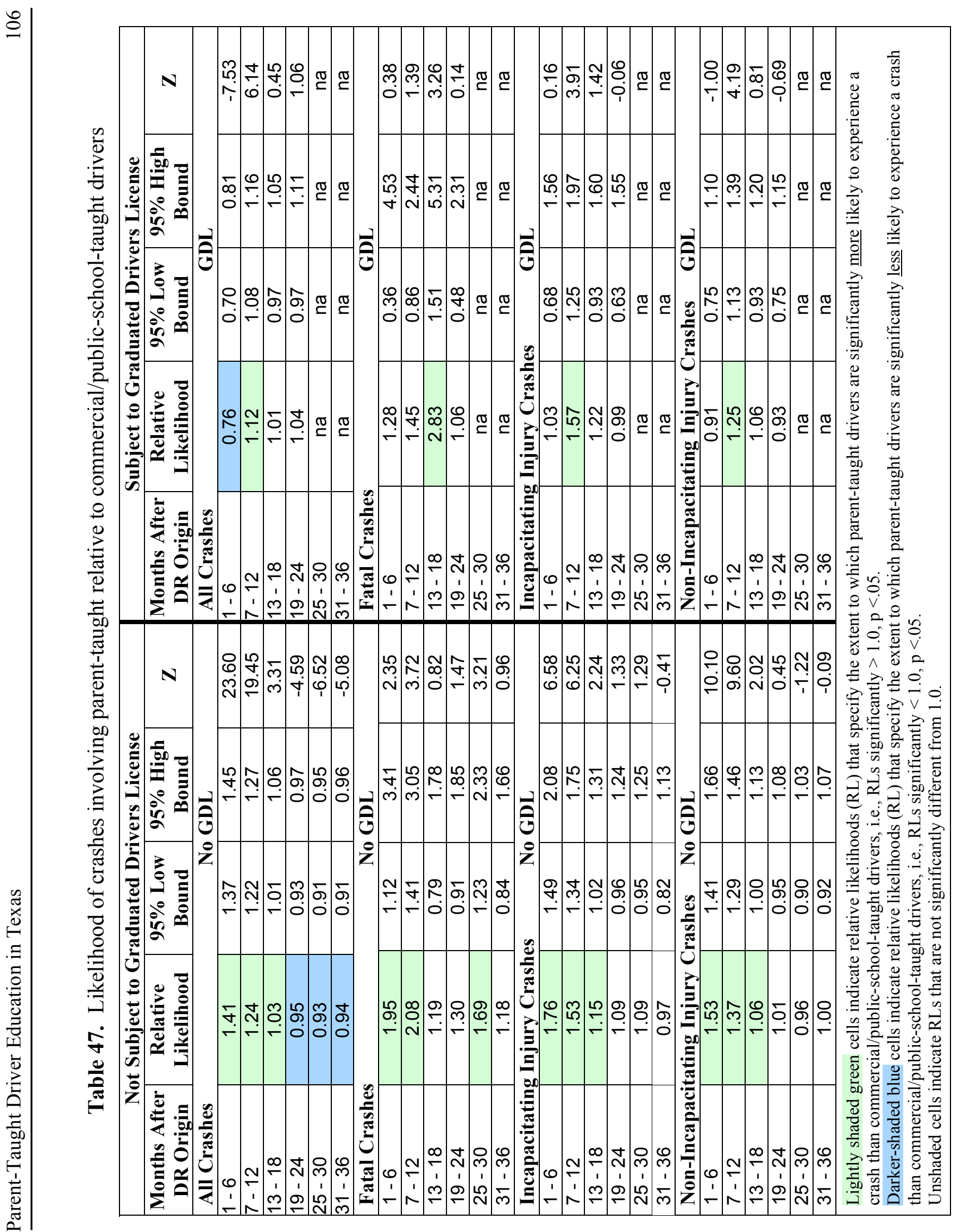




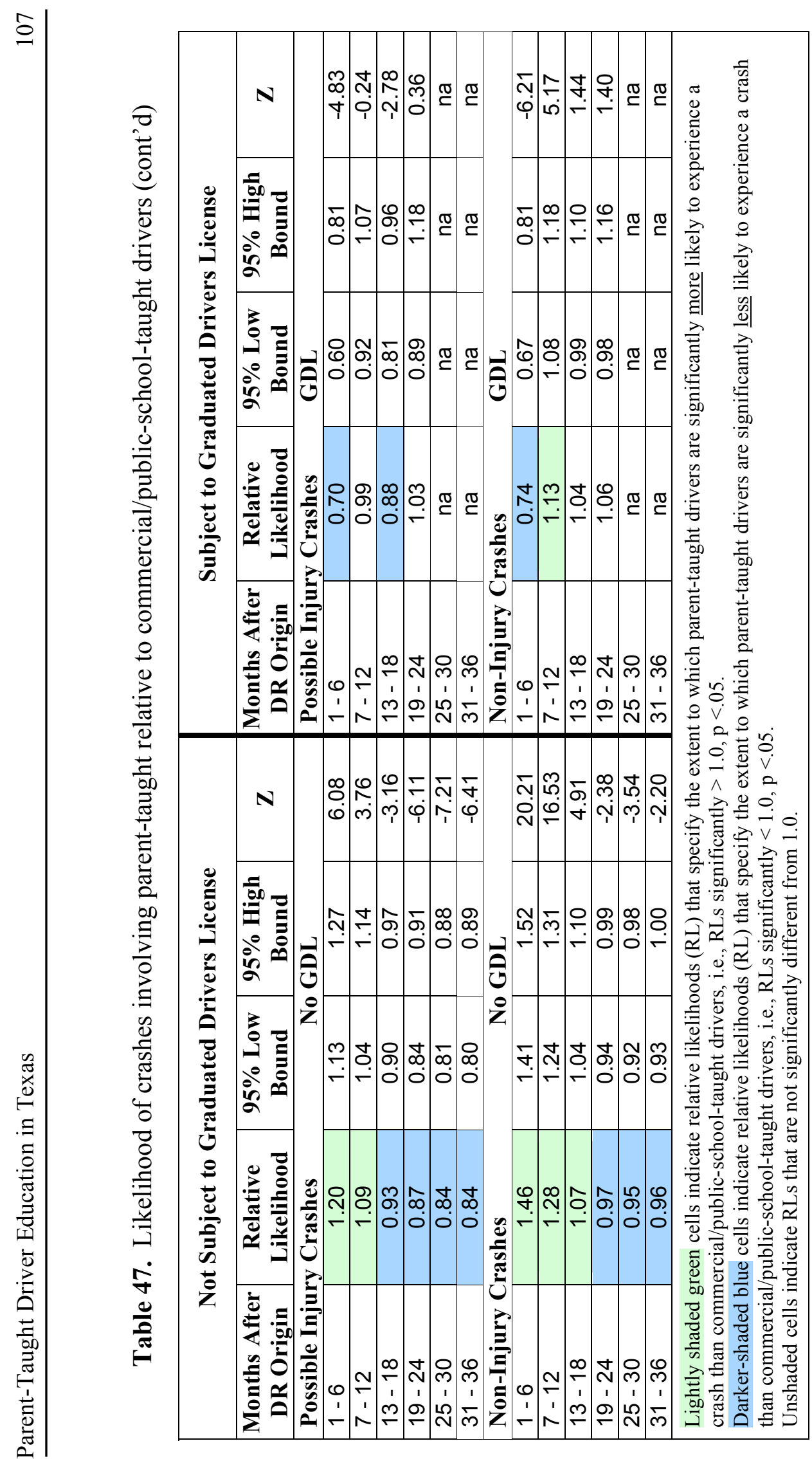




\section{Graphical Presentation of Crash Analysis Results}

Graphical representations of the analysis results for crashes, presented in Figures 10-15, provide a way to observe differences between parent-taught and commercial/public-school-taught drivers' crash experiences for each crash severity level in terms of crash frequency and the relative likelihood of crashes for both pre- and post-GDL drivers on a single page.

Each figure is comprised of four sub-figures. The left-hand figures apply to drivers who were not subject to the provisions of the graduated driver license and the right-hand figures refer to drivers who were subject to GDL. The top row of figures illustrates the frequency of crashes as provided in Tables 45 and 46. The bottom figures on each page show the relative likelihood of crashes as reported in Table 47.

The crash frequency figures are straightforward bar charts showing the number of crashes per 10,000 drivers experienced in each nominal 6-month period following establishment of an individual's driver record. The error bars represent the standard error of the mean about the mean, translated to frequency of crashes per 10,000 drivers.

The results of all of the calculations of relative likelihoods and the associated 95-percent confidence intervals are shown graphically in the lower part of each figure. The example RL calculation from page 104 is used in the sample figure below. Shown in this example is the likelihood of a parent-taught driver being involved in a fatal crash relative to that of a commercial/public-school-taught driver, pre-GDL. The RLs designated by the square symbol in each six-month period indicates that, for example, in the first time period parent-taught drivers were nearly twice (1.95) as likely as commercial/public-school-taught drivers to have been involved in a fatal crash. The 95 percent confidence interval, shown by the vertical line $(\mid)$ through each RL symbol, indicates if the value is significantly different from the likelihood of Com/Pub drivers' involvement in fatal crashes. If the confidence interval line does not cross the "equally likely" balance point of 1.0, the likelihood of crash involvement is significantly different for parent-taught relative to commercial/public-school-taught drivers. Note that the Relative Likelihood Index is presented in the figures on a log scale, centered on the "equally likely" balance point of 1 . Also, some of the RL figures appear to have no confidence intervals represented. This is occurs in those instance in which the CI is smaller than the extent of the symbol used to represent RL.

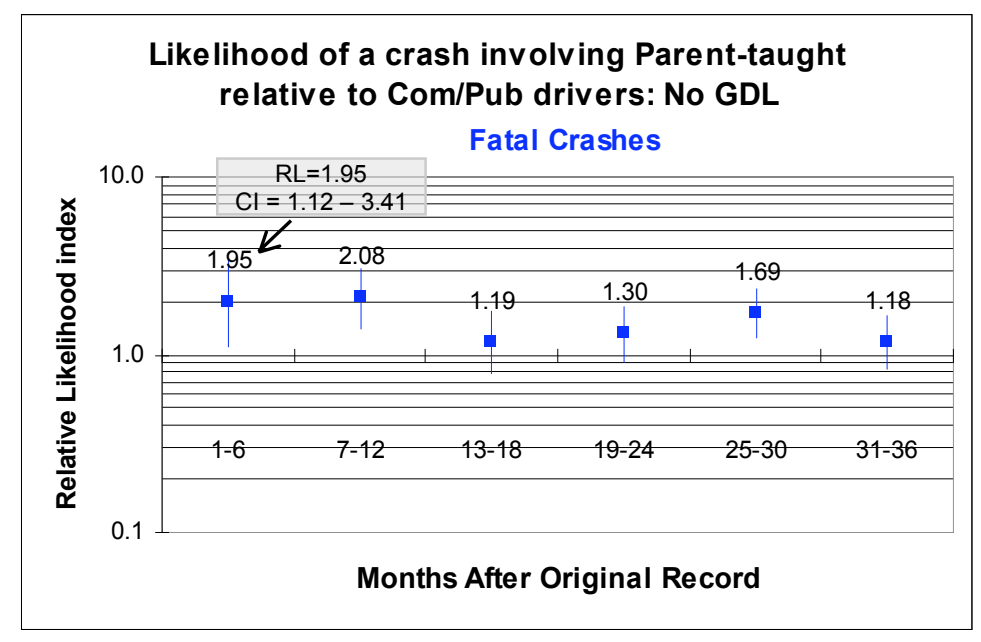



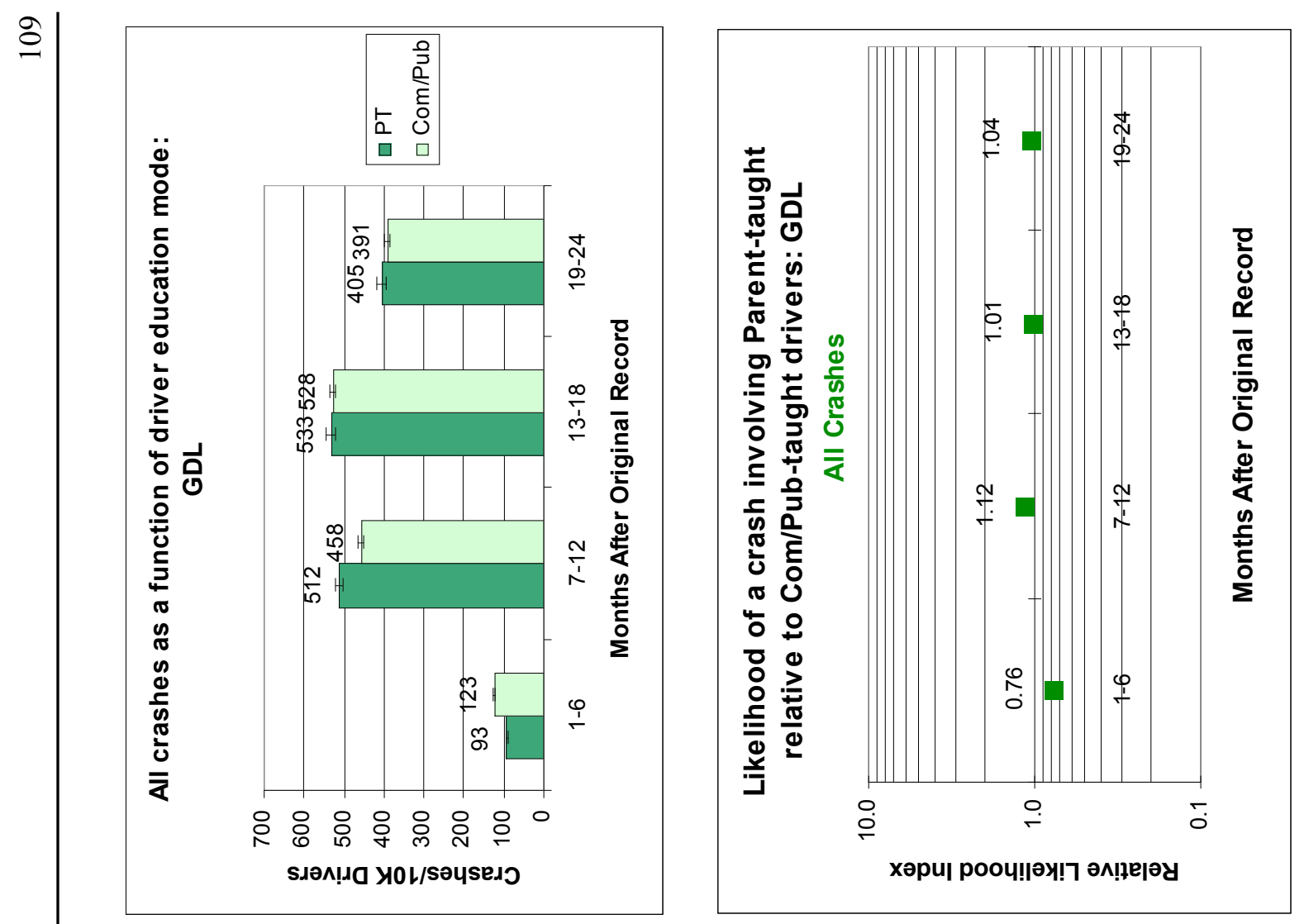

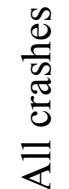
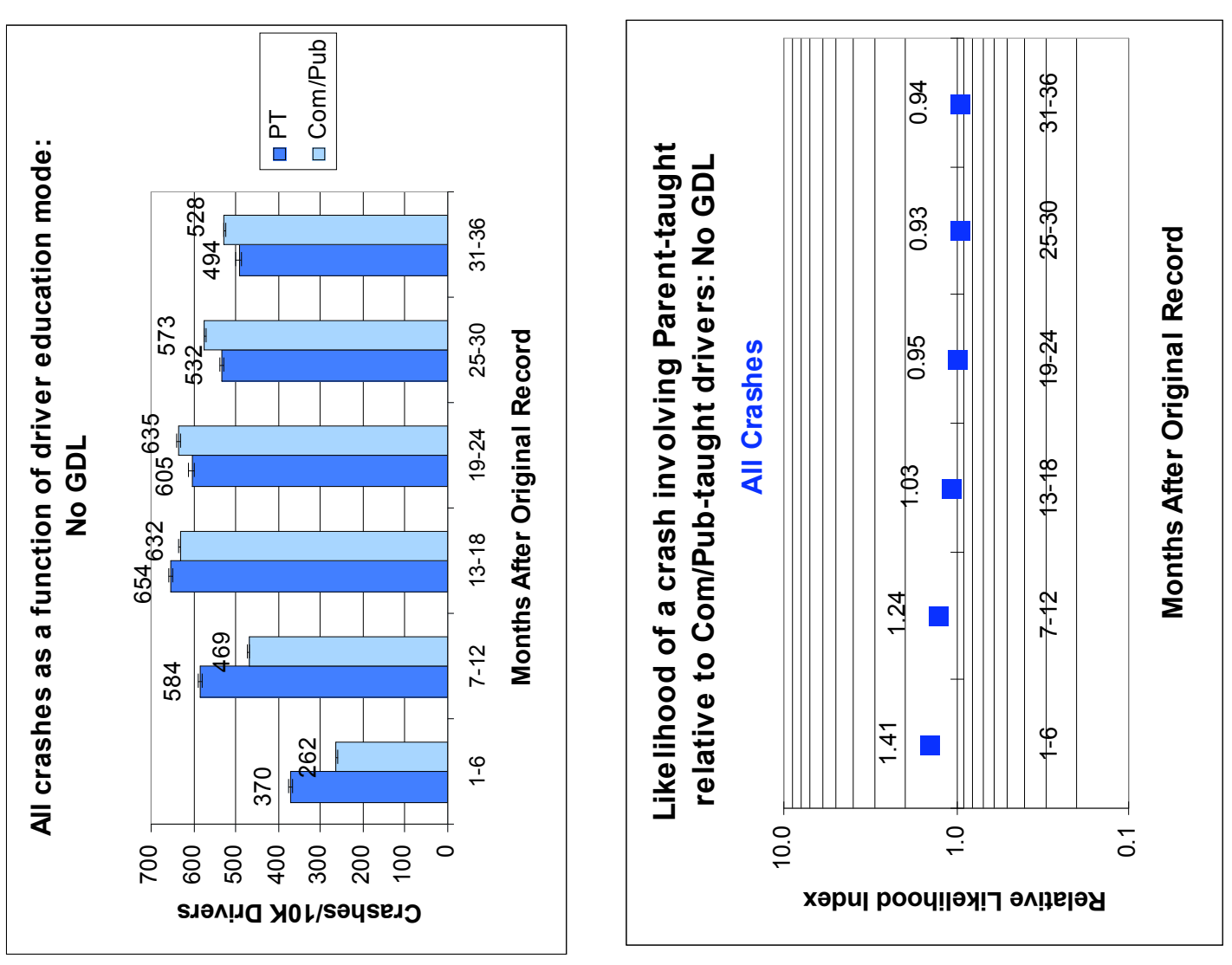

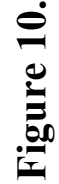



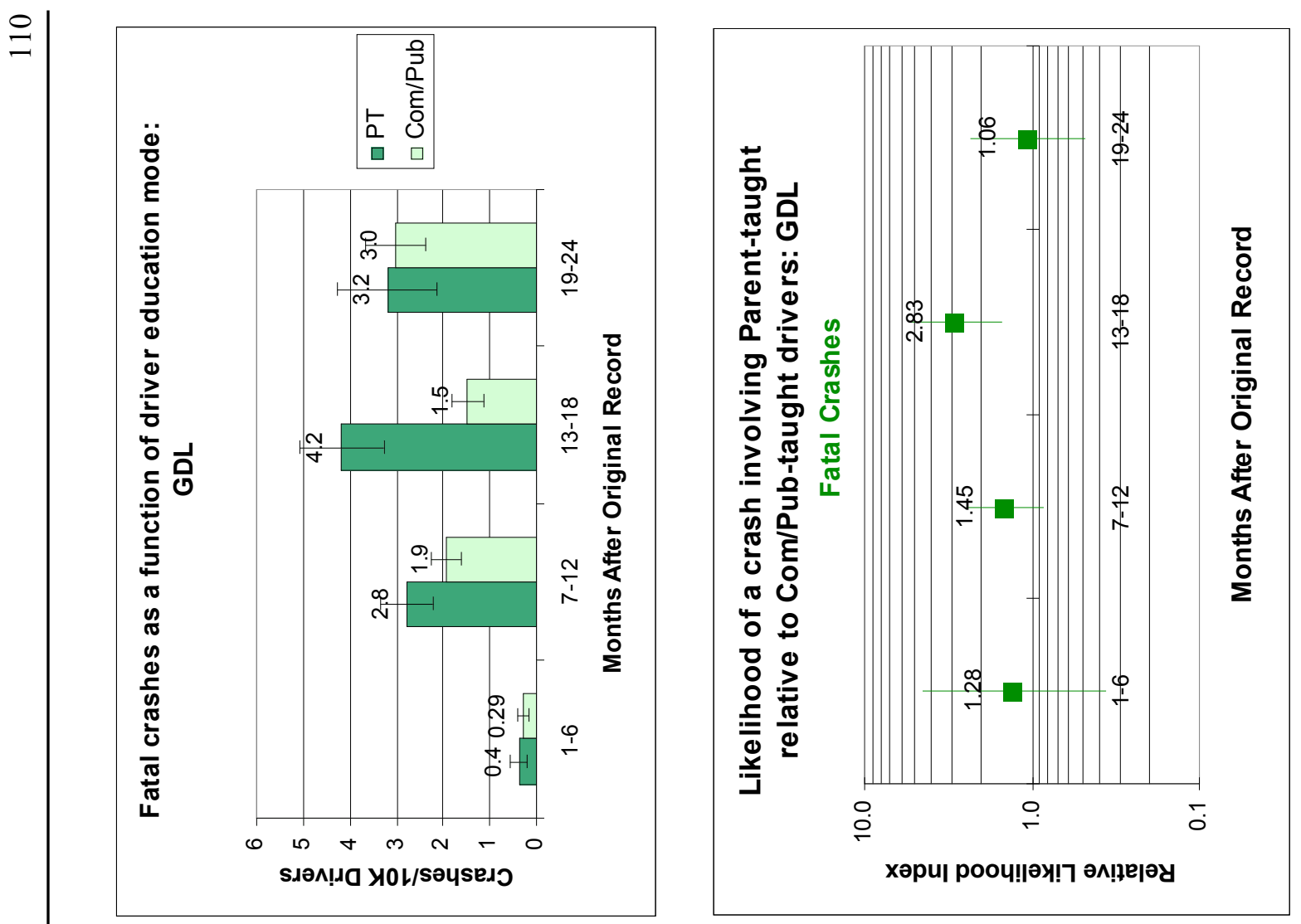

范
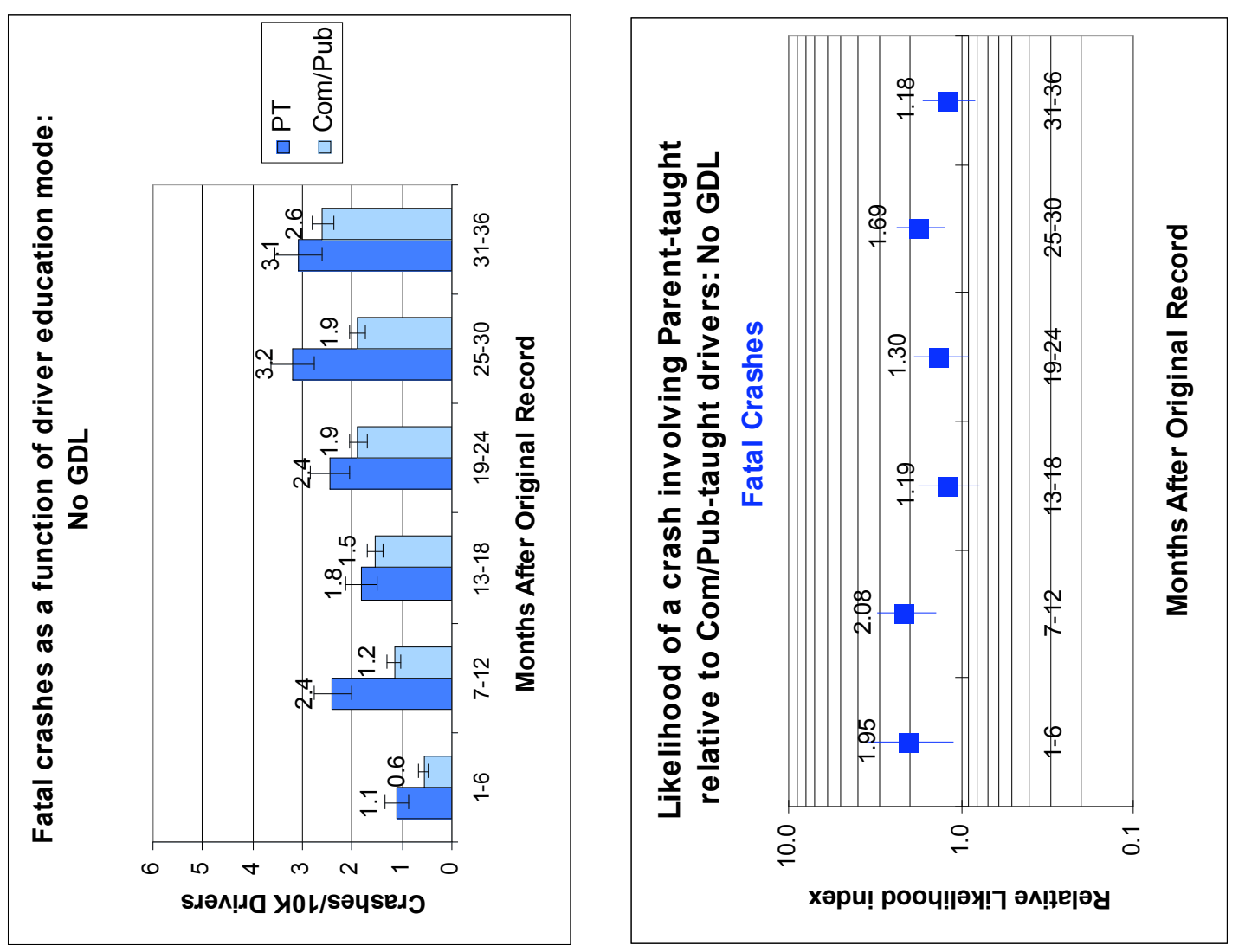

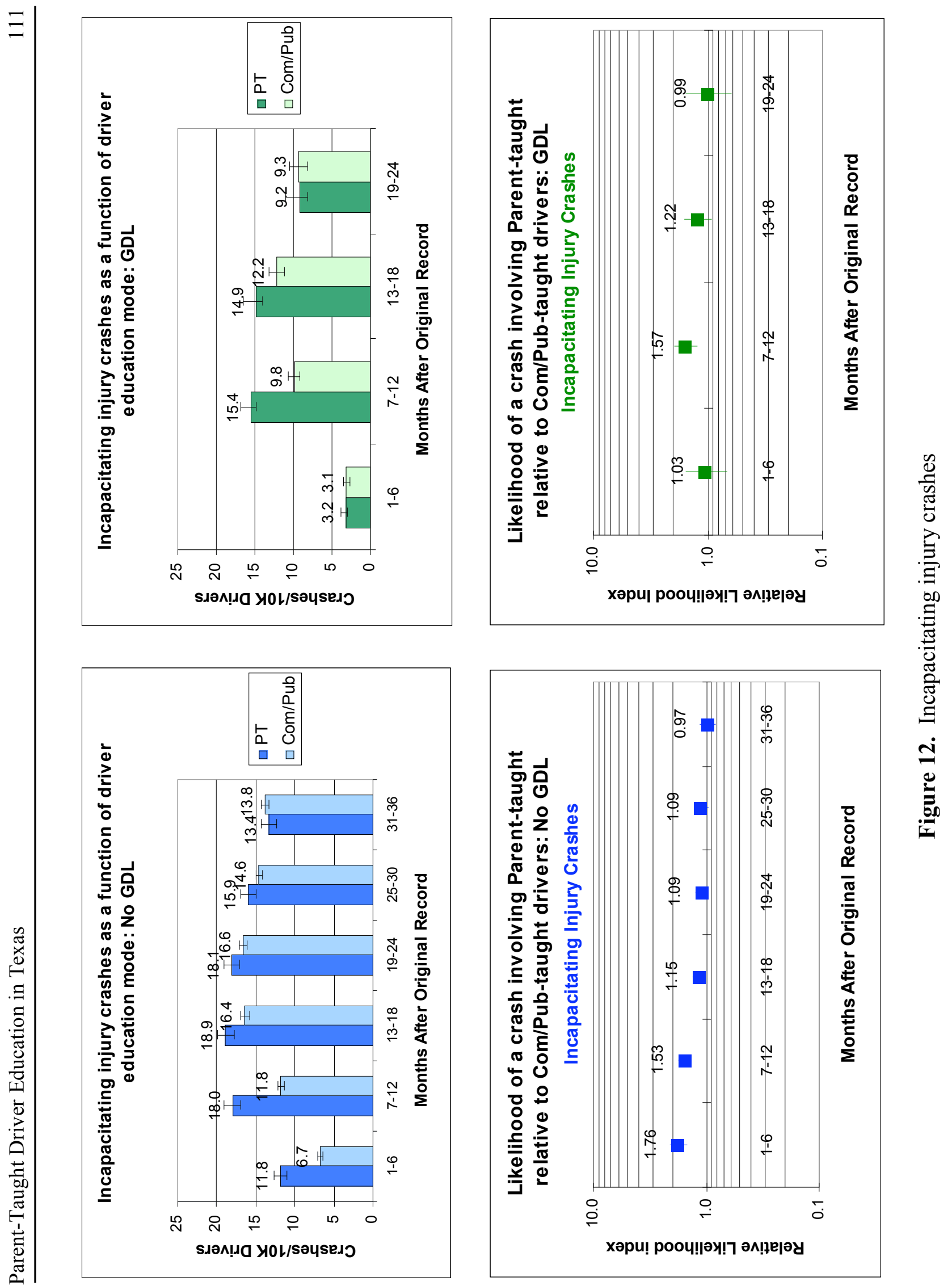

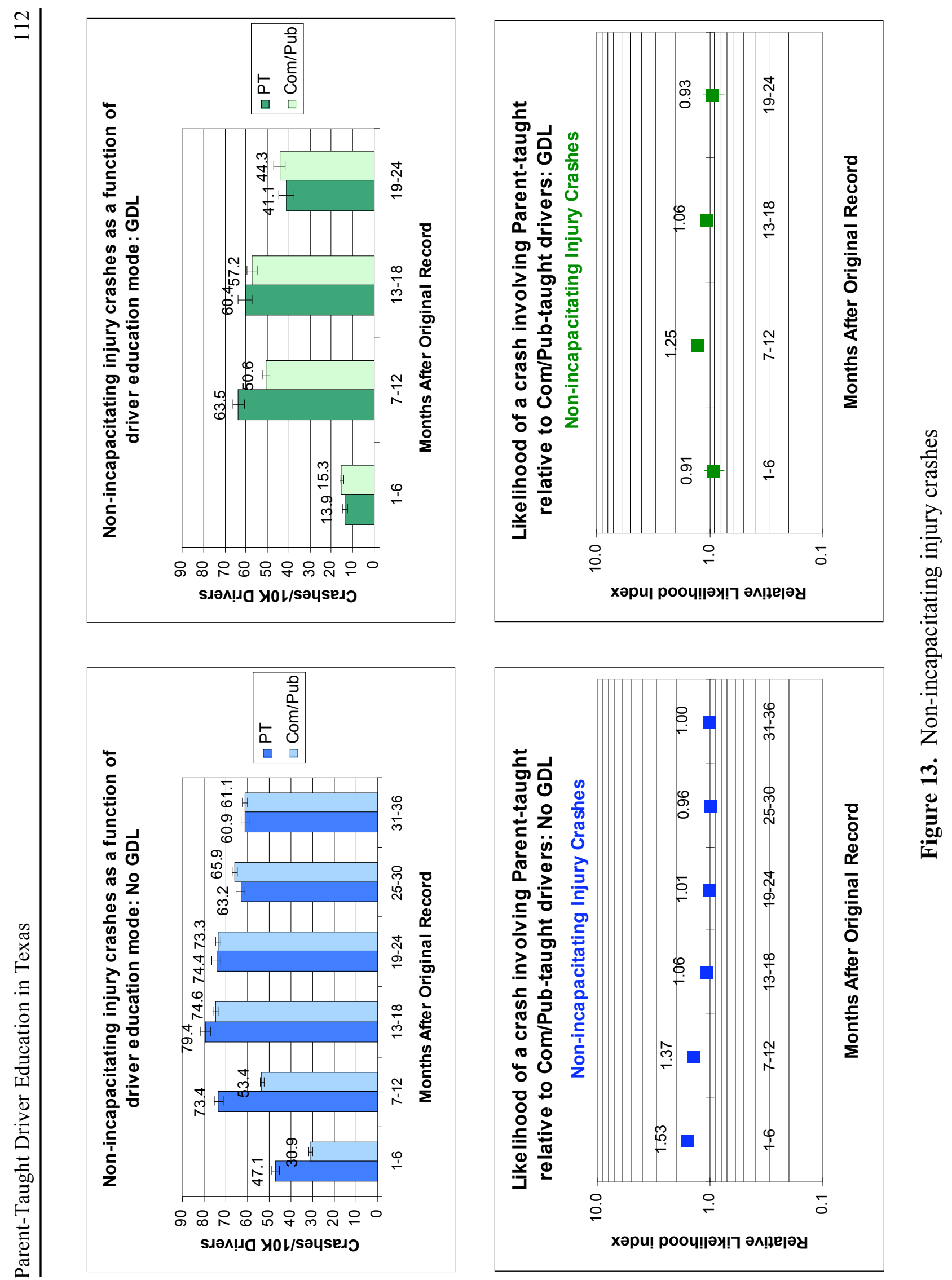

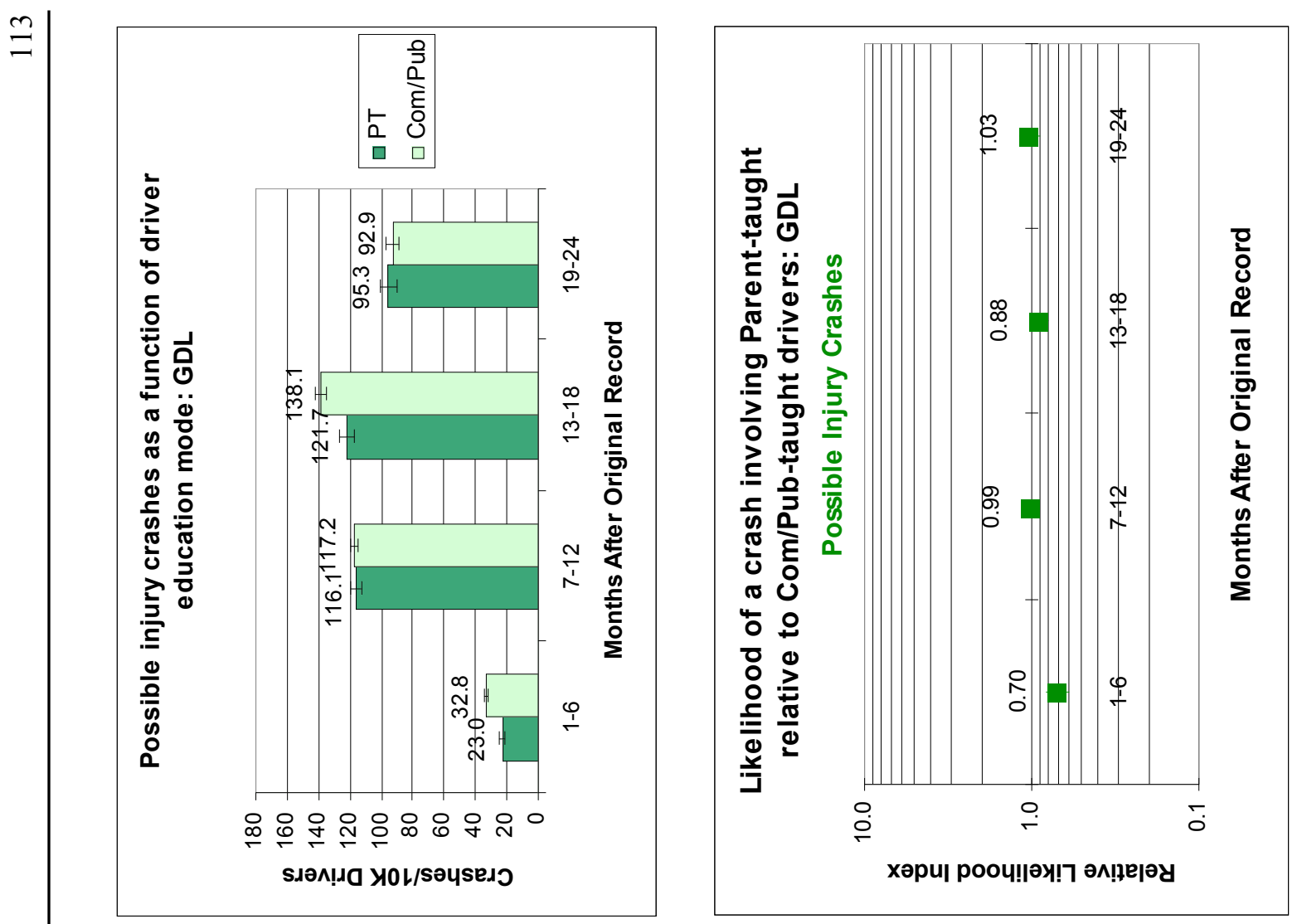

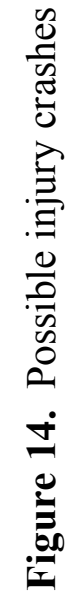
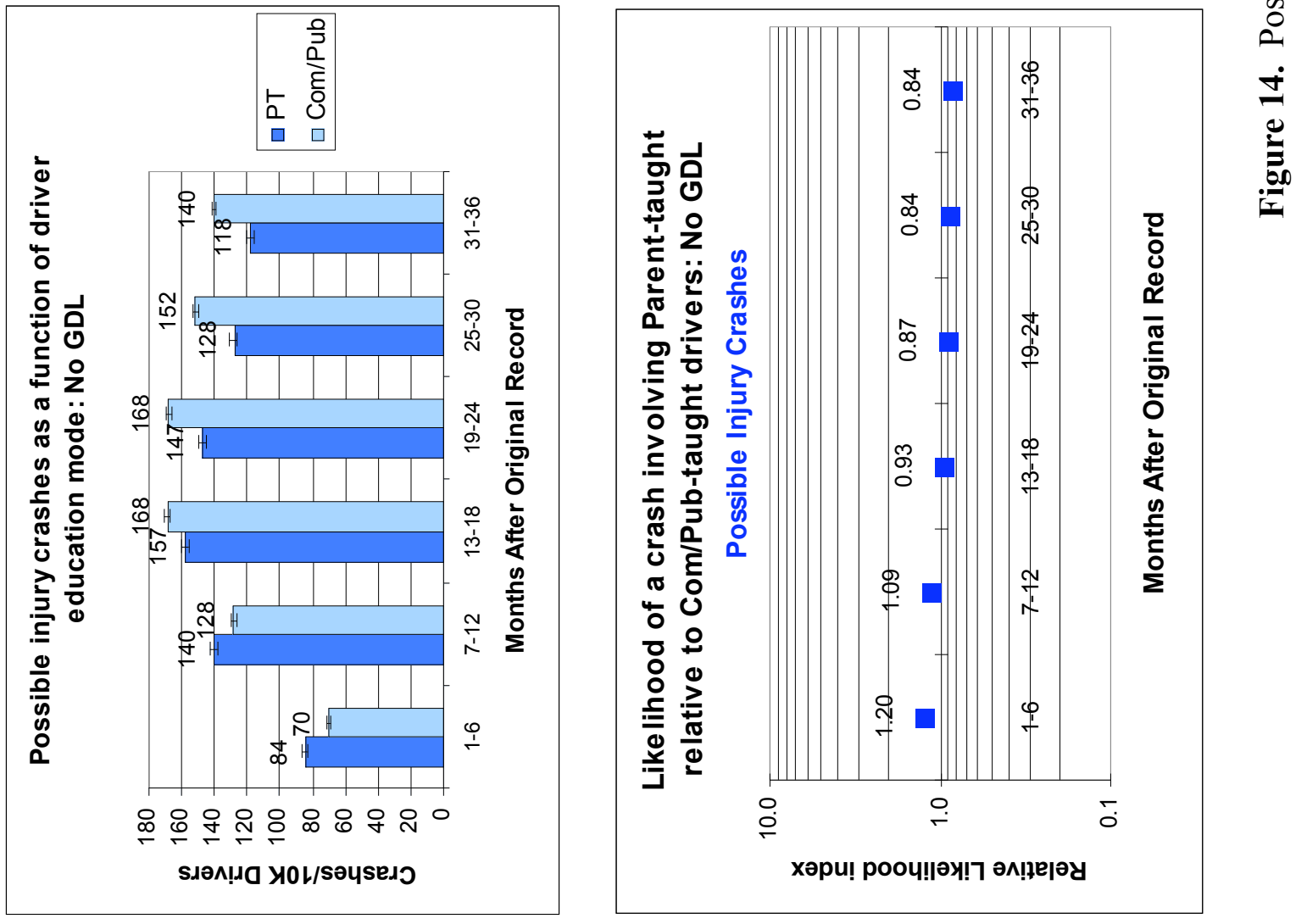

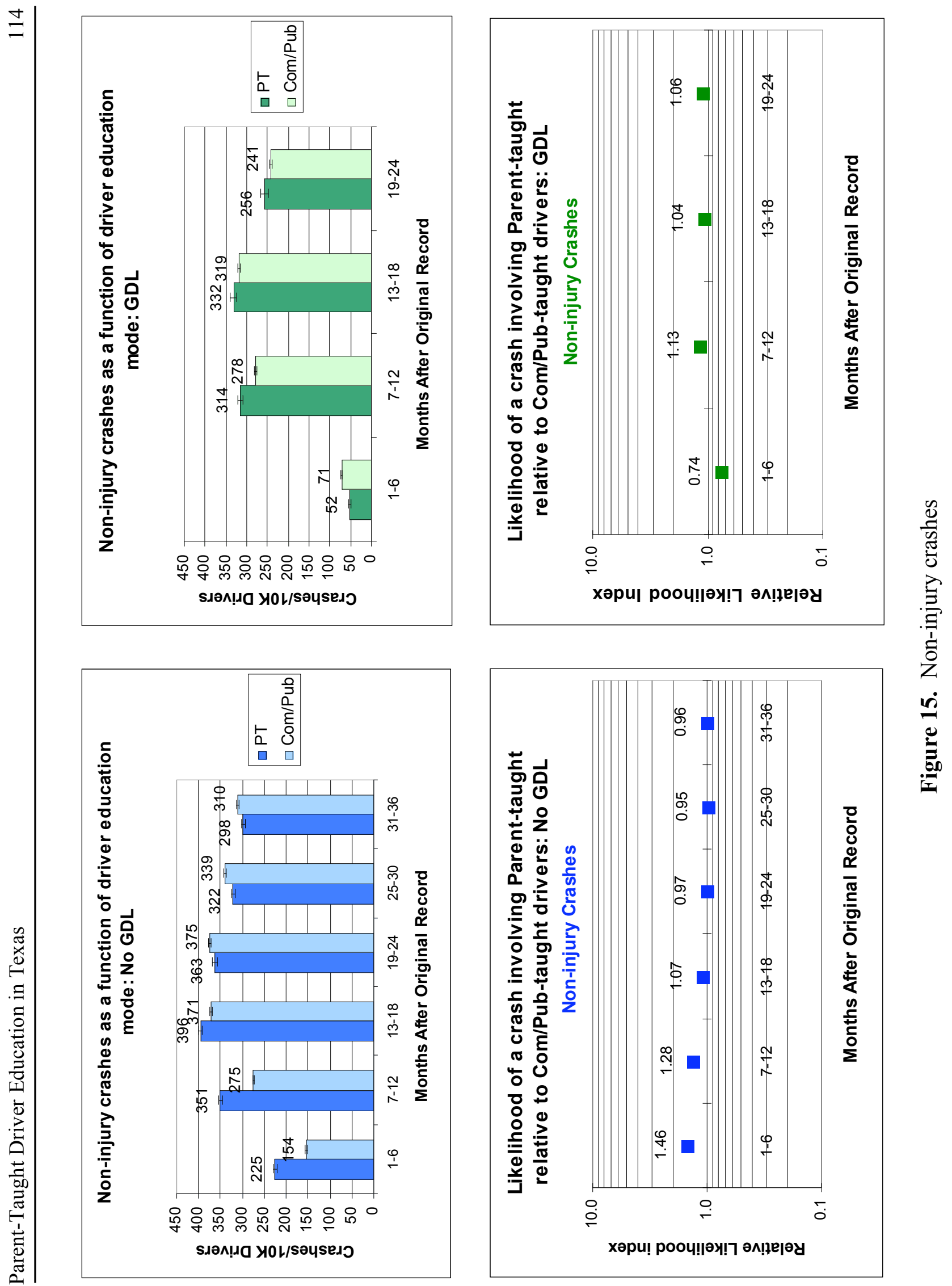


\section{Summary of Driver Record Crash Analysis}

Analyses were conducted of the driver records of more than 1.4 million drivers who completed either a TEA-certified commercial or public school novice driver education course or completed a driver education course under the Texas Parent-Taught Driver Education Program administered by the Texas DPS. The analyses include virtually all novice drivers in Texas who were less than 18 years old and for whom a Texas driver record was originated between October 1997 and January 2004. All of these drivers were eligible for the Parent-Taught program implemented in April, 1997. Because the Texas Graduated Drivers License Program, instituted January 1, 2002, modified the rules and regulations for young driver licensing - notably by adding certain driving restrictions -- the analyses were conducted separately for those novice drivers subject to the GDL and those who were not. By definition, drivers under 18 who received an instructional permit prior to January 1, 2002, were not subject to GDL.

Table 48 provides a summary of the results of comparisons between parent-taught and commercial or public-school-taught novice drivers in terms of the frequency and likelihood of crashes, by severity, as a function of type of driver education completed. Only statistically significant differences between PT and Com/Pub-trained drivers are shown in this table.

Results are provided for consecutive, nominally six-month, periods commencing with the establishment of each individual's driver record. With some exceptions, driver records are established coincident with issuance of an instructional permit. Six periods encompassing the first three years of driving experience are analyzed for drivers NOT subject to the GDL. Four periods (two years) of driving experience were available for drivers who started their driving experience under the GDL program.

The data and analyses summarized in Table 64 permit the following general conclusions:

1. The relationship between crashes and type of driver education experienced is different for those young drivers who were and were not subject to the Graduated Driver License Program.

2. Crash Involvement - Non-GDL Over the first year of driving experience, parent-taught drivers NOT subject to GDL experienced more crashes per 10,000 drivers and were more likely to have been in a crash than their counterparts who completed a commercial or public school DE course. This relationship holds for all crash severities. For example, PT drivers are 1.20 and 1.09 times more likely to be in a possible injury crash than Com/Pub drivers in each of the first two sixmonth periods of driving experience, respectively. The observed differences in crash frequency and likelihood of occurrence increase with crash severity. In the first year of driving experience, a PT driver not subject to GDL is about twice as likely to be involved in a fatal crash relative to a Com/Pub driver.

In the third six-month period of driving experience, significant differences related to DE type in both the frequency of crashes and the likelihood of crash involvement become smaller or, as in the case of fatal crashes no longer differ significantly. Nonetheless, PT drivers still 


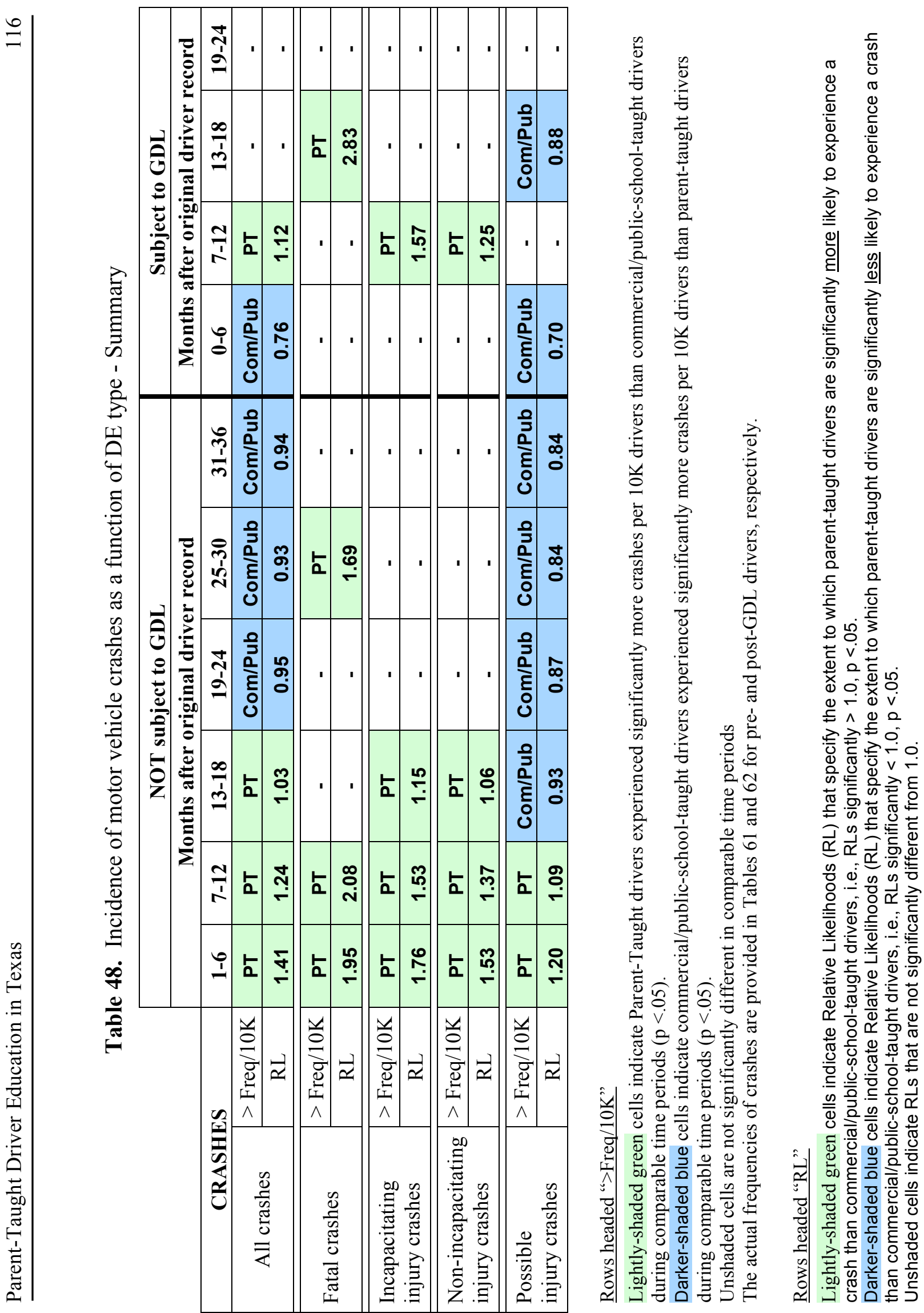


exhibit a 15 percent greater likelihood of experiencing an incapacitating injury crash and a 6 percent greater likelihood of having a non-incapacitating crash than do Com/Pub-trained drivers. In the least severe of crashes in which at least one injury was sustained (possible injury crashes), Com/Pub drivers were involved almost 8 percent ${ }^{23}$ more often than PT drivers during this period.

With two exceptions, significant differences in crash involvement as a function of DE type disappear in the fourth through sixth six month periods after a driver record was established. Throughout these periods, Com/Pub drivers continue to experience significantly more possible injury crashes than PT young drivers; 15 to 19 percent more, depending on period. More importantly, the likelihood of involvement in fatal crashes during the first six months of drivers' third year of experience is substantially greater for PT than for Com/Pub drivers. In the $25^{\text {th }}$ through $30^{\text {th }}$ month period after receiving an instruction permit, former PTDE students exhibit a nearly 70 percent greater likelihood of being in a fatal crash $(\mathrm{RL}=1.69)$.

3. Crash Involvement - GDL

While of historical interest and relevant to the impact of the Texas GDL requirements, the analysis of crash involvement of drivers trained before implementation of the GDL does not directly apply to more recent, current or future novice drivers' DE experience. Since January, 2002, all new drivers less than 18 years old have been subject to the Texas GDL Program. The crash involvement analyses summarized on the right side of Table 64 pertains specifically to young drivers who are, or until recently were, subject to the GDL provisions.

During the first six months of driving experience following establishment of a Texas driver record, parent-taught novice drivers experienced significantly fewer total crashes and the likelihood of a PT driver being involved in a crash was significantly less than commercial or public-school-taught novice drivers. For all crashes, without regard to severity, Com/Pubtrained drivers had 32 percent more crash involvement than PT drivers. This large difference, however, is seen only in the incidence of possible injury crashes. More serious crashes, including non-incapacitating and incapacitating injury crashes and crashes in which at least one person was killed, do not differ significantly among the three DE modes. Recall that the first six months of driving experience approximates the time coincident with novices holding a GDL Phase 1 instructional permit.

Crash involvement as a function of type of DE changes dramatically during the second sixmonth period of experience, roughly equivalent to the GDL Phase 2 period when novices can legally drive independently but are subject to restrictions. PT novices are about 12 percent more likely to be involved in a crash of any severity level than are Com/Pub-taught drivers. More importantly, the differences between PT and Com/Pub, while not significant for fatal crash involvement, otherwise increase as crash severity increases. Post-GDL parent-taught drivers were 25 percent more likely to be involved in a non-incapacitating injury crash and 57 percent more likely to be involved in an incapacitating injury crash than were their commercial or public school peers.

\footnotetext{
${ }^{23}$ For Relative Likelihoods $(\mathrm{RL})<1.00$, percentage differences are calculated from the reciprocal of the RL.
} 
By the third six-month period of driving experience, approximately coincident with restriction-free full licensure, only two significant differences in crash experience related to DE type remain. First, Com/Pub drivers are about 14 percent more likely to be involved in possible injury crashes than PT drivers. Second, and much more striking, the relative likelihood of PT drivers being involved in fatal crashes is 2.83 , that is, PT drivers are considerably more than twice as likely - approaching three times -- to be in fatal crashes.

\section{Frequency and Relative Likelihood of Traffic Offense Convictions}

Analyses of the frequency and relative likelihood of convictions for traffic offenses as a function of mode of driver education paralleled the results of the crash analyses. The only difference is that instead of comparing PT to Com/Pub drivers in terms of crashes of various severities, the novice driver education delivery modes are compared in terms of convictions in 14 conviction categories, ${ }^{24}$ again during nominal six-month periods beginning with issuance of an instructional permit.

Tables 49 and 50 provide the "frequency of convictions" results for Non-GDL and GDL drivers, respectively (analogous to Tables 45 and 46, for crashes). Relative likelihood of conviction results are shown in Table 51 for both non-GDL and GDL drivers.

\section{Graphical Presentation of Conviction Analysis Results}

As with crashes, graphical representations of the analysis results for traffic convictions are presented in Figures 16-28, providing a means to observe, on a single page, differences between parent-taught and commercial/public-school-taught drivers' conviction experience for all convictions combined and for each of the 14 conviction categories analyzed in terms of conviction frequency and the relative likelihood of a conviction for both pre- and post-GDL drivers that exhibit significant differences between DE types. ${ }^{25}$

Each figure, again like those for the crash analysis, is comprised of four sub-figures. The lefthand figures apply to drivers who were not subject to the provisions of the graduated driver license and the right-hand figures refer to drivers who were subject to GDL. The top row of figures illustrates the frequency of convictions as provided in Tables 65 and 66. The bottom figures on each page show the relative likelihood of conviction as reported in Table 67.

\footnotetext{
${ }^{24}$ See Table 44 for a complete listing of all offenses included in each conviction group.

${ }^{25}$ Figures are not provided for two conviction categories (Commercial DL violations and Miscellaneous violations). No significant differences as a function of DE type during any time period tested were determined for these categories for either pre- or post-GDL novice drivers.
} 
Table 49. Convictions per 10,000 drivers not subject to GDL, by driver education mode

\begin{tabular}{|c|c|c|c|c|c|c|c|}
\hline \multirow{2}{*}{ Conviction Group } & \multirow[b]{2}{*}{ DE Mode } & \multicolumn{6}{|c|}{ Months after date of original driver record } \\
\hline & & $1-6$ & $7-12$ & 13-18 & $19-24$ & $25-30$ & $31-36$ \\
\hline \multirow{2}{*}{ All convictions } & PT & 470.5 & 935.6 & 1344.2 & 1238.0 & 1319.9 & 1345.4 \\
\hline & Com/Pub & 309.2 & 690.0 & 1297.3 & 1095.9 & 1354.4 & 1349.5 \\
\hline \multirow{2}{*}{$\begin{array}{l}\text { Speeding over the } \\
\text { limit }\end{array}$} & $\mathrm{PT}$ & 121.8 & 285.2 & 435.1 & 537.2 & 569.7 & 613.9 \\
\hline & Com/Pub & 82.7 & 214.9 & 381.0 & 517.9 & 590.0 & 621.3 \\
\hline \multirow{2}{*}{$\begin{array}{l}\text { Racing/excessive } \\
\text { acceleration }\end{array}$} & PT & 5.8 & 13.3 & 19.1 & 19.1 & 19.4 & 17.2 \\
\hline & Com/Pub & 4.1 & 9.8 & 19.8 & 15.1 & 20.1 & 18.3 \\
\hline \multirow{2}{*}{$\begin{array}{l}\text { Other speed-related } \\
\text { violations }\end{array}$} & PT & 16.3 & 28.6 & 36.7 & 36.8 & 36.2 & 32.2 \\
\hline & $\mathrm{Com} / \mathrm{Pub}$ & 11.5 & 21.1 & 35.6 & 30.2 & 35.4 & 35.0 \\
\hline \multirow{2}{*}{$\begin{array}{l}\text { Red light/stop sign } \\
\text { violation }\end{array}$} & PT & 23.5 & 45.9 & 73.9 & 66.4 & 76.8 & 75.5 \\
\hline & Com/Pub & 17.1 & 40.4 & 86.2 & 66.2 & 89.9 & 87.8 \\
\hline \multirow{2}{*}{$\begin{array}{l}\text { Disregard/fail to obey } \\
\text { other traffic signals, } \\
\text { signs, or markings }\end{array}$} & $\mathrm{PT}$ & 3.4 & 7.0 & 13.2 & 12.1 & 13.2 & 13.9 \\
\hline & $\mathrm{Com} / \mathrm{Pub}$ & 3.3 & 8.4 & 17.5 & 13.4 & 18.5 & 17.6 \\
\hline \multirow{2}{*}{$\begin{array}{l}\text { Failure to yield right- } \\
\text { of-way }\end{array}$} & PT & 250.0 & 487.1 & 553.8 & 574.8 & 494.1 & 476.7 \\
\hline & Com/Pub & 149.7 & 330.1 & 496.7 & 490.0 & 465.4 & 432.0 \\
\hline \multirow{2}{*}{$\begin{array}{l}\text { Improper } \\
\text { signal/failure to signal }\end{array}$} & PT & 0.5 & 0.8 & 2.1 & 1.0 & 1.5 & 2.2 \\
\hline & Com/Pub & 0.3 & 1.3 & 2.2 & 1.9 & 3.1 & 2.8 \\
\hline \multirow{2}{*}{$\begin{array}{l}\text { Other moving } \\
\text { violations }\end{array}$} & $\mathrm{PT}$ & 19.3 & 36.6 & 55.2 & 49.5 & 54.0 & 50.8 \\
\hline & Com/Pub & 15.9 & 33.3 & 62.0 & 52.0 & 65.0 & 64.4 \\
\hline \multirow{2}{*}{$\begin{array}{l}\text { Alcohol and drug } \\
\text { violations }\end{array}$} & PT & 1.9 & 3.7 & 14.2 & 10.3 & 19.1 & 25.7 \\
\hline & $\mathrm{Com} / \mathrm{Pub}$ & 1.5 & 3.8 & 13.0 & 7.8 & 17.0 & 23.0 \\
\hline \multirow{2}{*}{$\begin{array}{l}\text { Negligent/antisocial } \\
\text { violations }\end{array}$} & PT & 2.6 & 4.5 & 7.1 & 5.8 & 5.7 & 6.4 \\
\hline & Com/Pub & 2.4 & 4.9 & 6.1 & 5.8 & 6.7 & 7.2 \\
\hline \multirow{2}{*}{$\begin{array}{l}\text { Driver license } \\
\text { violations/No license }\end{array}$} & PT & 24.7 & 21.8 & 29.6 & 25.8 & 27.9 & 27.8 \\
\hline & Com/Pub & 19.8 & 20.8 & 38.2 & 31.0 & 40.7 & 37.4 \\
\hline \multirow{2}{*}{$\begin{array}{l}\text { Other DL violations } \\
\text { (commercial) }\end{array}$} & PT & 0.5 & 0.2 & 0.3 & 0.1 & 0.2 & 0.4 \\
\hline & $\mathrm{Com} / \mathrm{Pub}$ & 0.4 & 0.3 & 0.2 & 0.2 & 0.4 & 0.3 \\
\hline \multirow{2}{*}{$\begin{array}{l}\text { Mandated driving } \\
\text { safety course/program }\end{array}$} & PT & 235.7 & 467.6 & 531.1 & 549.8 & 472.6 & 457.2 \\
\hline & Com/Pub & 138.4 & 312.6 & 472.3 & 467.0 & 441.4 & 410.8 \\
\hline \multirow{2}{*}{$\begin{array}{l}\text { Miscellaneous } \\
\text { Violations }\end{array}$} & PT & 0.4 & 1.0 & 1.8 & 1.3 & 2.2 & 2.6 \\
\hline & Com/Pub & 0.4 & 0.8 & 1.9 & 1.4 & 2.3 & 2.6 \\
\hline \multicolumn{8}{|c|}{$\begin{array}{l}\text { Lightly-shaded green cells indicate parent-taught drivers experienced significantly more convictions per } 10 \mathrm{~K} \\
\text { drivers than commercial/public-school-taught drivers during comparable time periods }(\mathrm{p}<.05) \text {. } \\
\text { Darker-shaded blue cells indicate commercial/public-school-taught drivers experienced significantly more } \\
\text { convictions per } 10 \mathrm{~K} \text { drivers than parent-taught drivers during comparable time periods }(\mathrm{p}<.05) \text {. } \\
\text { Unshaded cells are not significantly different in comparable time periods. }\end{array}$} \\
\hline
\end{tabular}


Table 50. Convictions per 10,000 drivers subject to GDL, by driver education mode

\begin{tabular}{|c|c|c|c|c|c|}
\hline \multirow[b]{2}{*}{ Conviction Group } & \multirow[b]{2}{*}{ DE Mode } & \multicolumn{4}{|c|}{ Months after date of original driver record } \\
\hline & & $1-6$ & $7-12$ & 13-18 & 19-24 \\
\hline \multirow{2}{*}{ All convictions } & PT & 138.8 & 647.5 & 672.3 & 861.9 \\
\hline & Com/Pub & 182.1 & 560.2 & 562.4 & 815.2 \\
\hline \multirow{2}{*}{$\begin{array}{l}\text { Speeding over the } \\
\text { limit }\end{array}$} & PT & 21.9 & 141.4 & 253.8 & 245.6 \\
\hline & $\mathrm{Com} / \mathrm{Pub}$ & 38.7 & 135.1 & 252.8 & 203.8 \\
\hline \multirow{2}{*}{$\begin{array}{l}\text { Racing/excessive } \\
\text { acceleration }\end{array}$} & PT & 1.8 & 5.9 & 5.3 & 7.8 \\
\hline & $\mathrm{Com} / \mathrm{Pub}$ & 1.4 & 5.8 & 3.5 & 7.4 \\
\hline \multirow{2}{*}{$\begin{array}{l}\text { Other speed-related } \\
\text { violations }\end{array}$} & $\mathrm{PT}$ & 3.9 & 20.2 & 24.1 & 24.3 \\
\hline & $\mathrm{Com} / \mathrm{Pub}$ & 6.6 & 17.5 & 19.3 & 22.4 \\
\hline \multirow{2}{*}{$\begin{array}{l}\text { Red light/stop sign } \\
\text { violation }\end{array}$} & $\mathrm{PT}$ & 4.4 & 23.2 & 39.7 & 36.4 \\
\hline & Com/Pub & 9.0 & 23.4 & 37.3 & 40.3 \\
\hline \multirow{2}{*}{$\begin{array}{l}\text { Disregard/fail to obey } \\
\text { other traffic signals, } \\
\text { signs, or markings }\end{array}$} & $\mathrm{PT}$ & 0.9 & 3.7 & 5.0 & 6.0 \\
\hline & Com/Pub & 1.9 & 5.2 & 7.5 & 7.4 \\
\hline \multirow{2}{*}{$\begin{array}{l}\text { Failure to yield right- } \\
\text { of-way }\end{array}$} & PT & 42.9 & 378.5 & 294.2 & 465.9 \\
\hline & $\mathrm{Com} / \mathrm{Pub}$ & 54.7 & 296.5 & 227.6 & 413.6 \\
\hline \multirow{2}{*}{$\begin{array}{l}\text { Improper signal/failure } \\
\text { to signal }\end{array}$} & $\mathrm{PT}$ & 0.1 & 0.6 & 0.4 & 2.0 \\
\hline & Com/Pub & 0.1 & 1.0 & 1.6 & 1.5 \\
\hline \multirow{2}{*}{$\begin{array}{l}\text { Other moving } \\
\text { violations }\end{array}$} & PT & 5.3 & 24.4 & 26.9 & 33.0 \\
\hline & $\mathrm{Com} / \mathrm{Pub}$ & 9.1 & 26.3 & 31.2 & 33.8 \\
\hline \multirow{2}{*}{$\begin{array}{l}\text { Alcohol and drug } \\
\text { violations }\end{array}$} & $\mathrm{PT}$ & 0.6 & 2.0 & 8.9 & 6.7 \\
\hline & $\mathrm{Com} / \mathrm{Pub}$ & 0.6 & 1.9 & 5.8 & 4.1 \\
\hline \multirow{2}{*}{$\begin{array}{l}\text { Negligent/antisocial } \\
\text { violations }\end{array}$} & $\mathrm{PT}$ & 0.3 & 3.1 & 3.9 & 4.7 \\
\hline & $\mathrm{Com} / \mathrm{Pub}$ & 1.3 & 3.8 & 4.7 & 4.0 \\
\hline \multirow{2}{*}{$\begin{array}{l}\text { Driver license } \\
\text { violations/No license }\end{array}$} & $\mathrm{PT}$ & 55.8 & 43.7 & 16.7 & 19.6 \\
\hline & Com/Pub & 58.0 & 42.6 & 19.4 & 26.7 \\
\hline \multirow{2}{*}{$\begin{array}{l}\text { Other DL violations } \\
\text { (commercial) }\end{array}$} & PT & 0.6 & 0.3 & 0.0 & 0.3 \\
\hline & $\mathrm{Com} / \mathrm{Pub}$ & 0.5 & 0.4 & 0.0 & 0.3 \\
\hline \multirow{2}{*}{$\begin{array}{l}\text { Mandated driving } \\
\text { safety course/program }\end{array}$} & PT & 39.7 & 360.9 & 283.5 & 448.9 \\
\hline & $\mathrm{Com} / \mathrm{Pub}$ & 48.6 & 281.0 & 213.2 & 395.9 \\
\hline \multirow{2}{*}{$\begin{array}{l}\text { Miscellaneous } \\
\text { Violations }\end{array}$} & PT & 0.4 & 0.5 & 1.8 & 1.6 \\
\hline & Com/Pub & 0.2 & 0.6 & 0.9 & 1.0 \\
\hline \multicolumn{6}{|c|}{$\begin{array}{l}\text { Lightly-shaded green cells indicate parent-taught drivers experienced significantly more convictions per } \\
\text { 10K drivers than commercial/public-school-taught drivers during comparable time periods }(\mathrm{p}<.05) \text {. } \\
\text { Darker-shaded blue cells indicate commercial/public-school-taught drivers experienced significantly more } \\
\text { convictions per 10K drivers than parent-taught drivers during comparable time periods }(\mathrm{p}<.05) \text {. } \\
\text { Unshaded cells are not significantly different in comparable time periods. }\end{array}$} \\
\hline
\end{tabular}




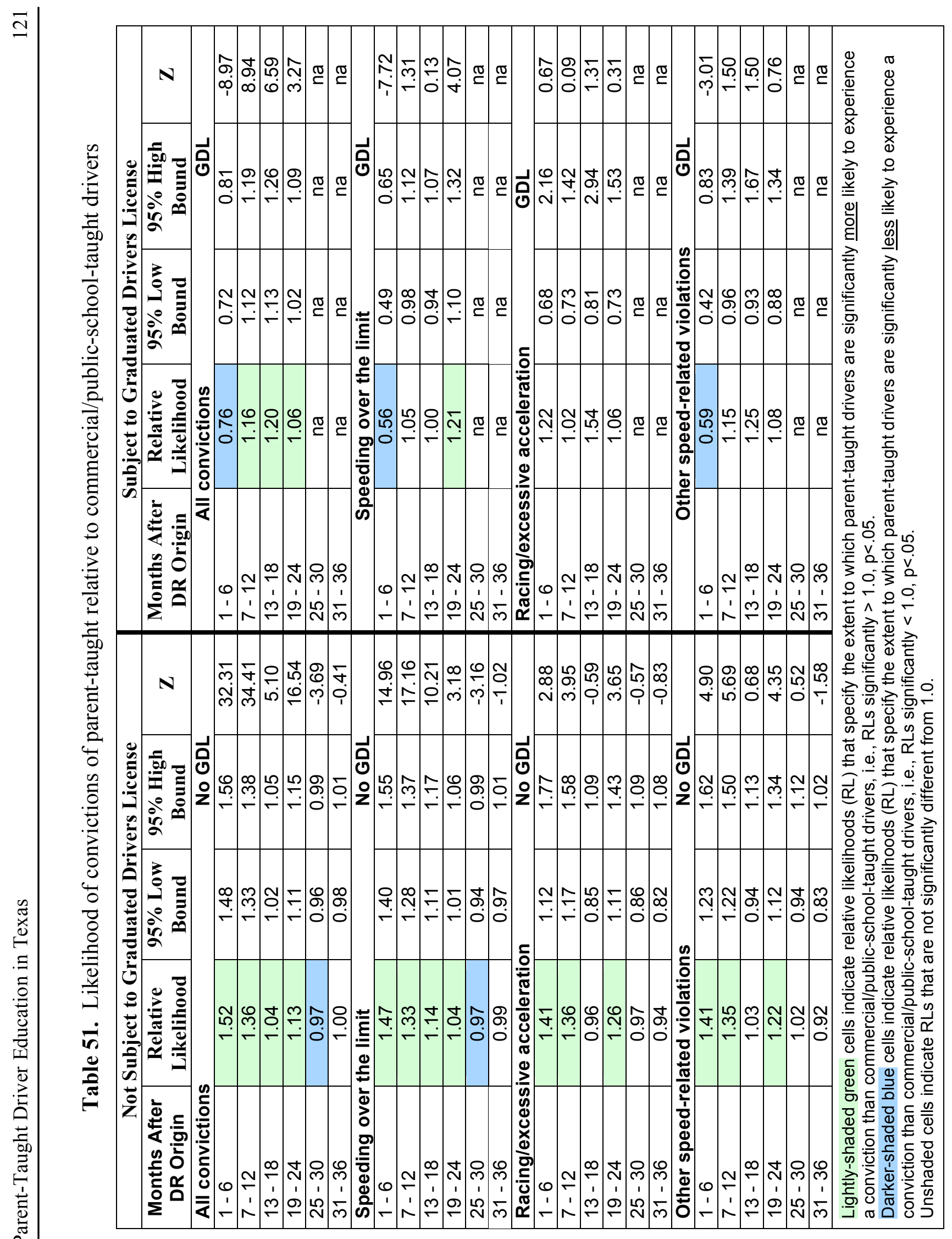




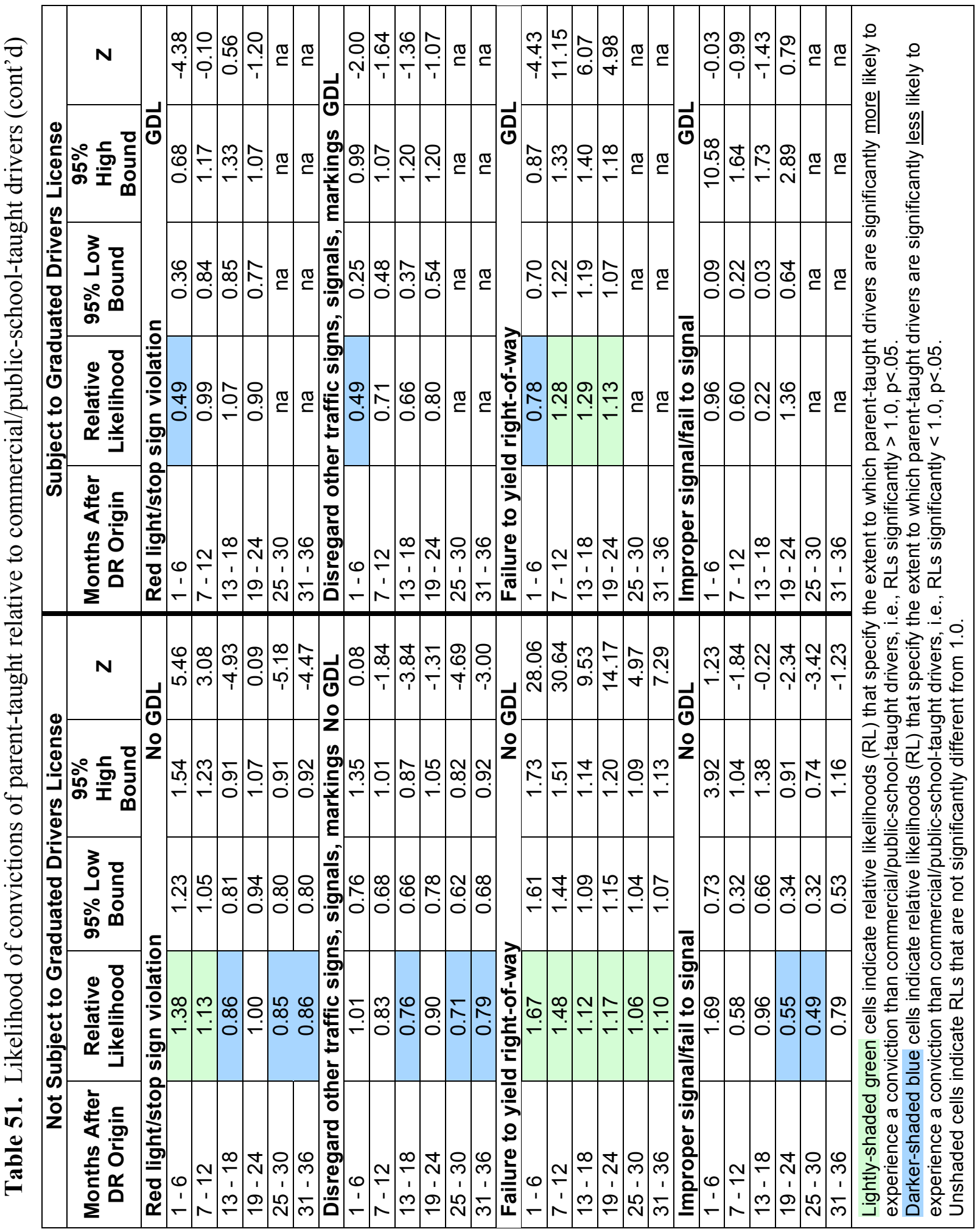




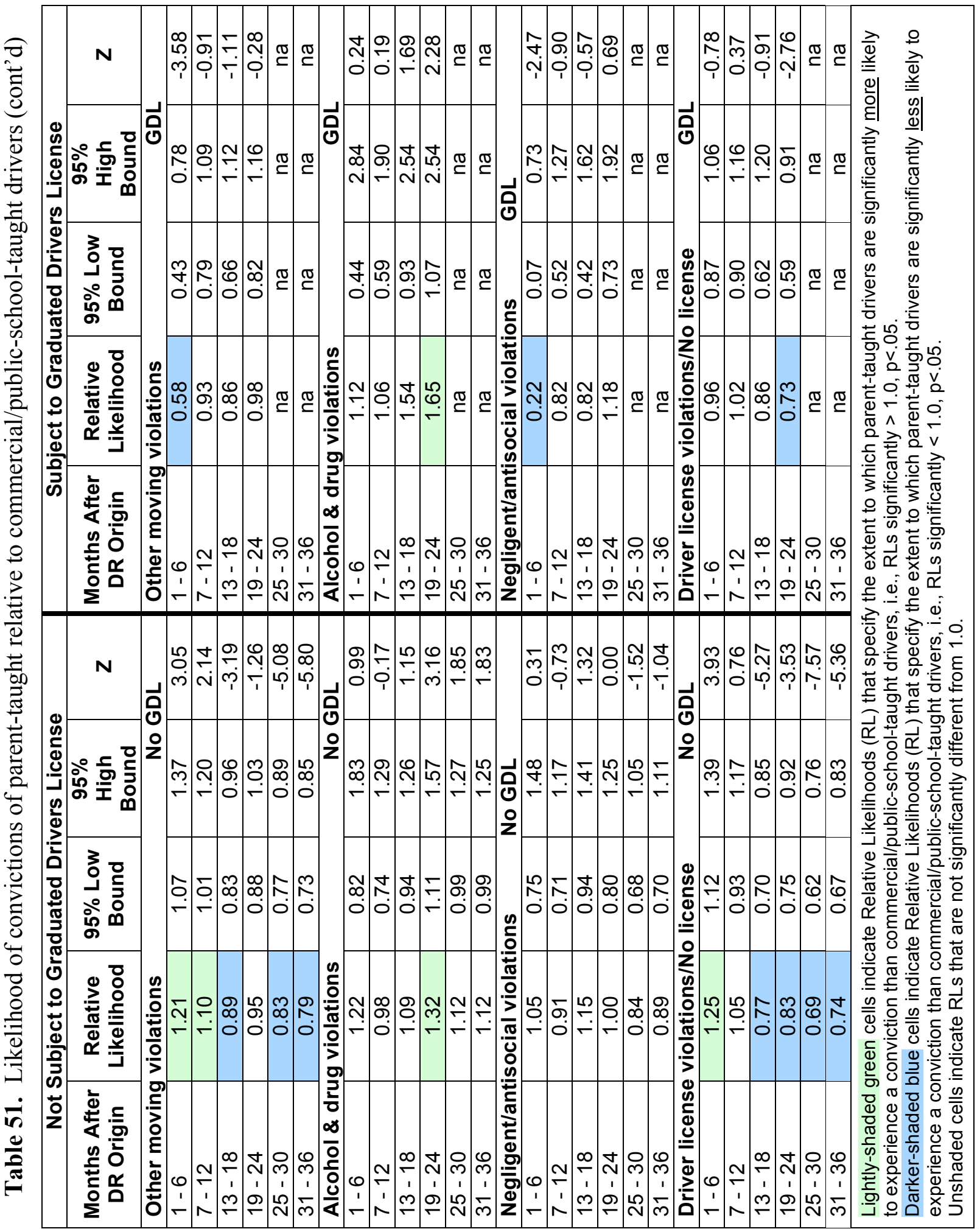




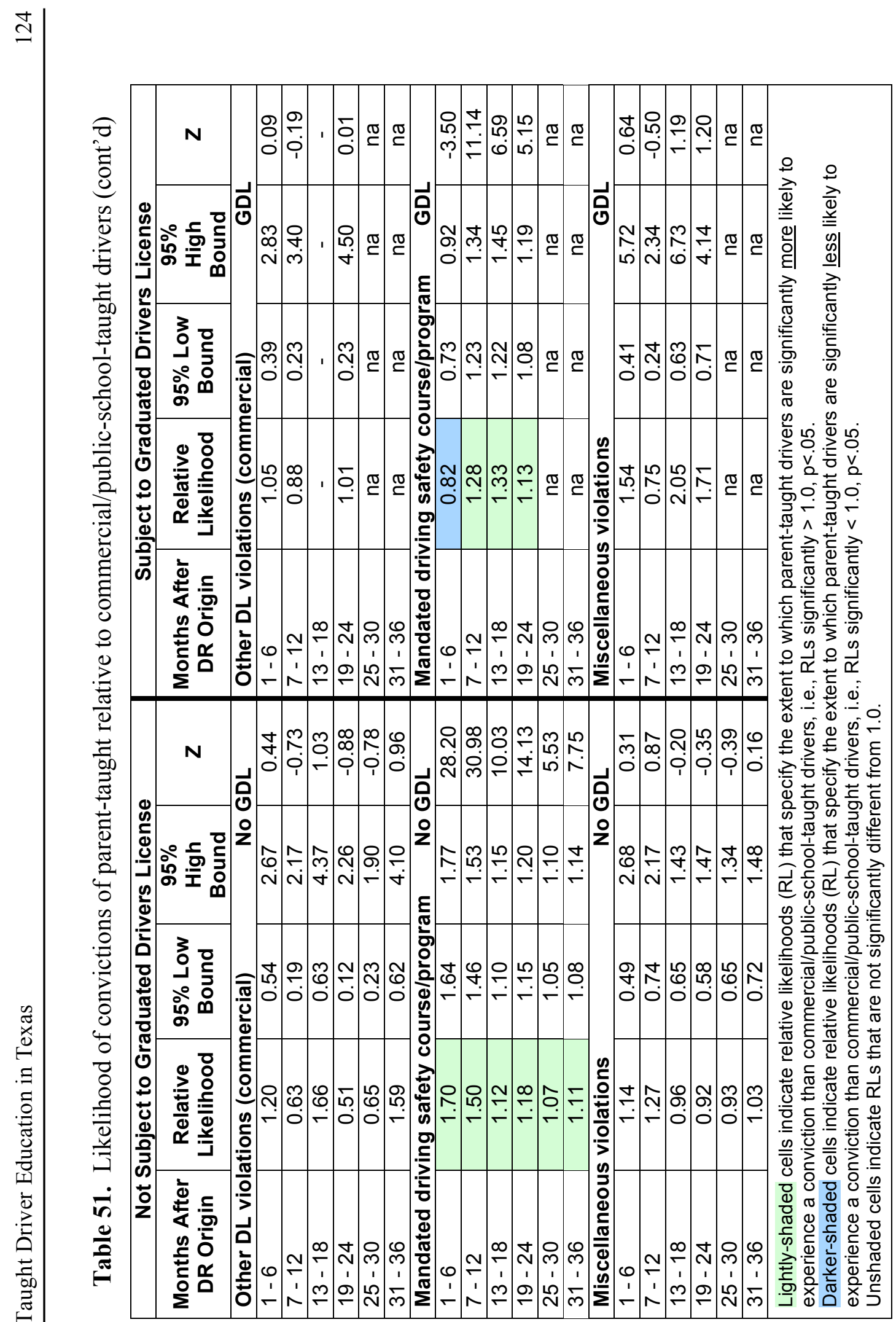



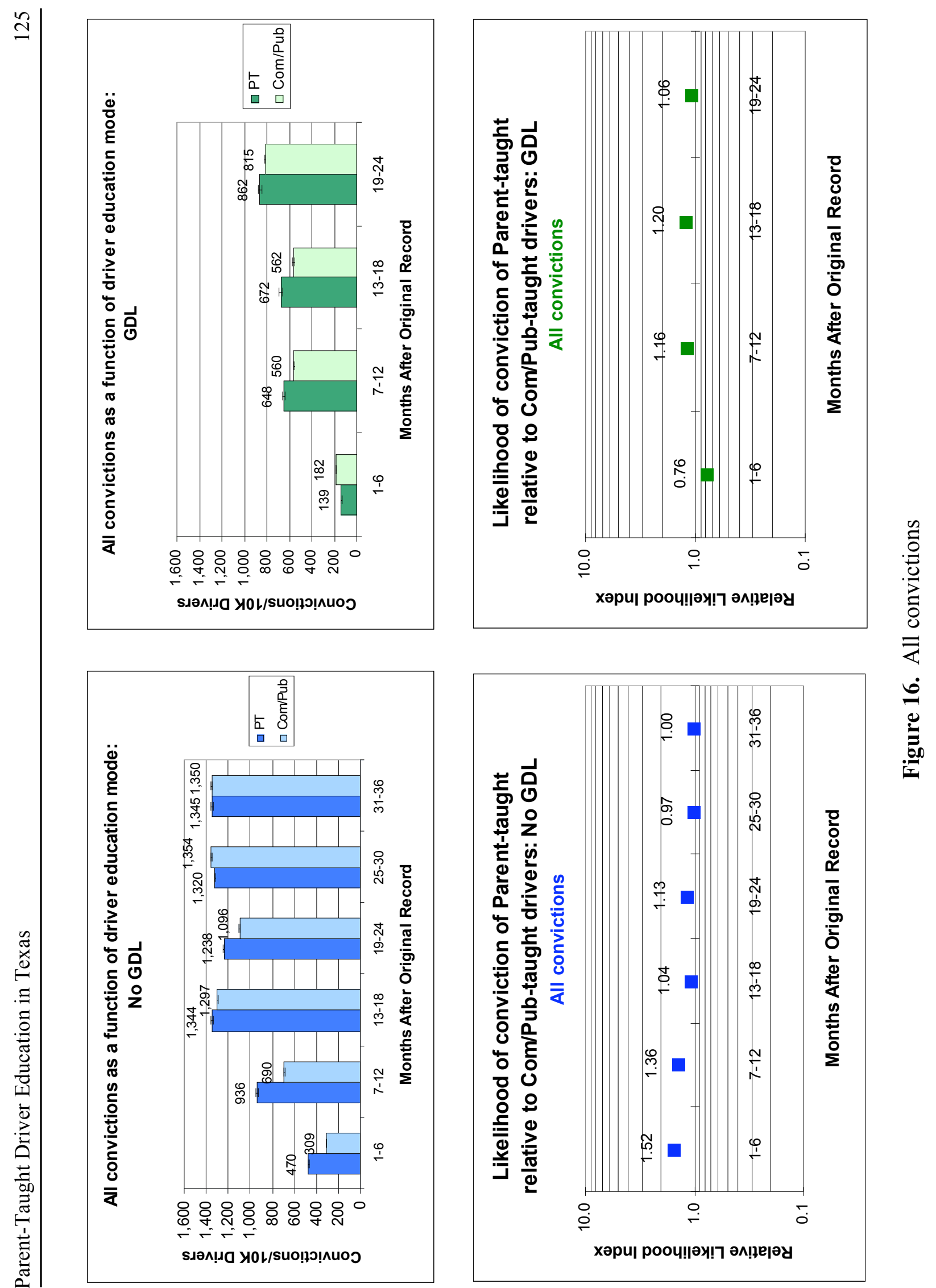

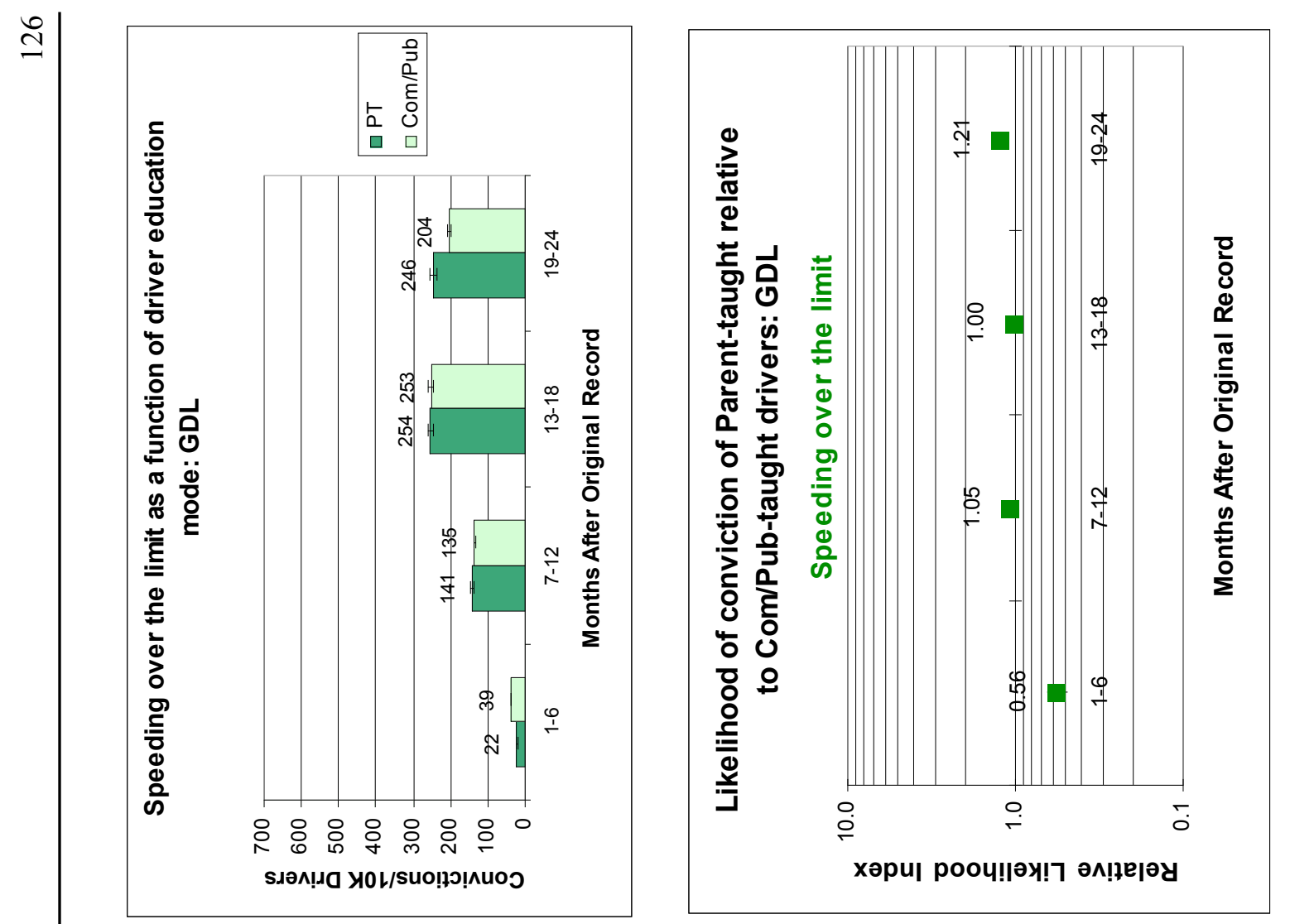

0
0
0
0
0
0
.$\Xi$
.$\Xi$
.0
0
0
0
0
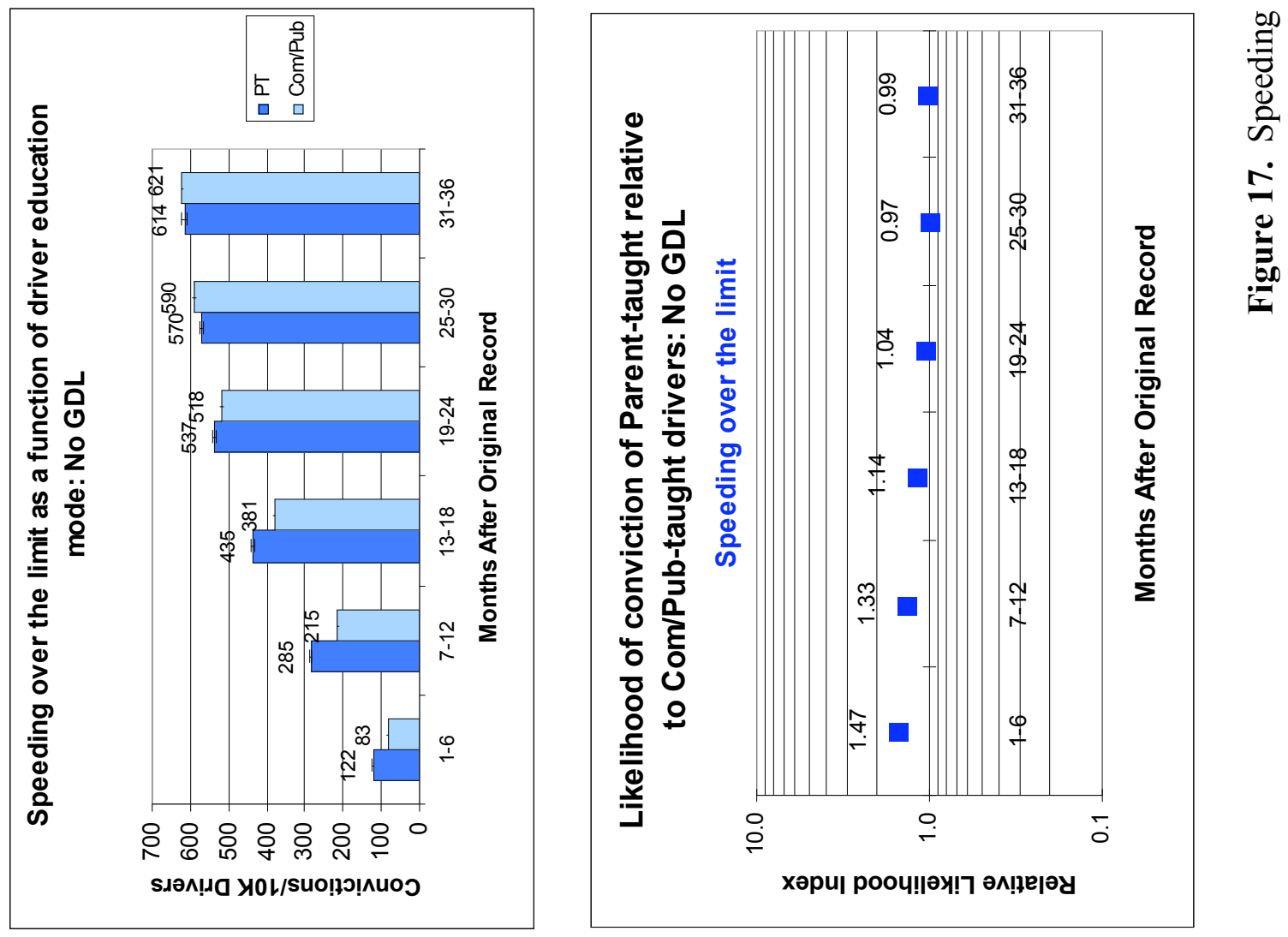

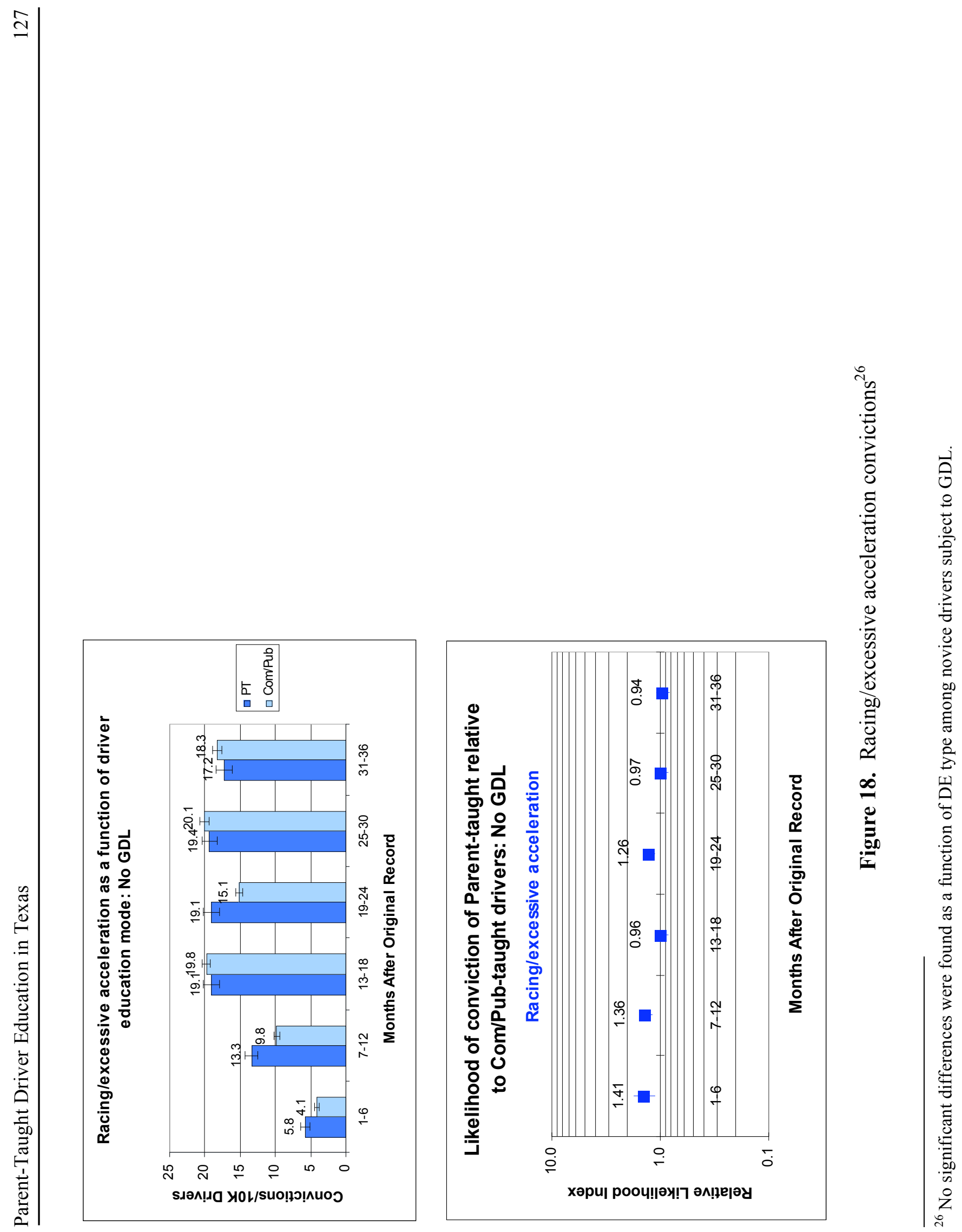

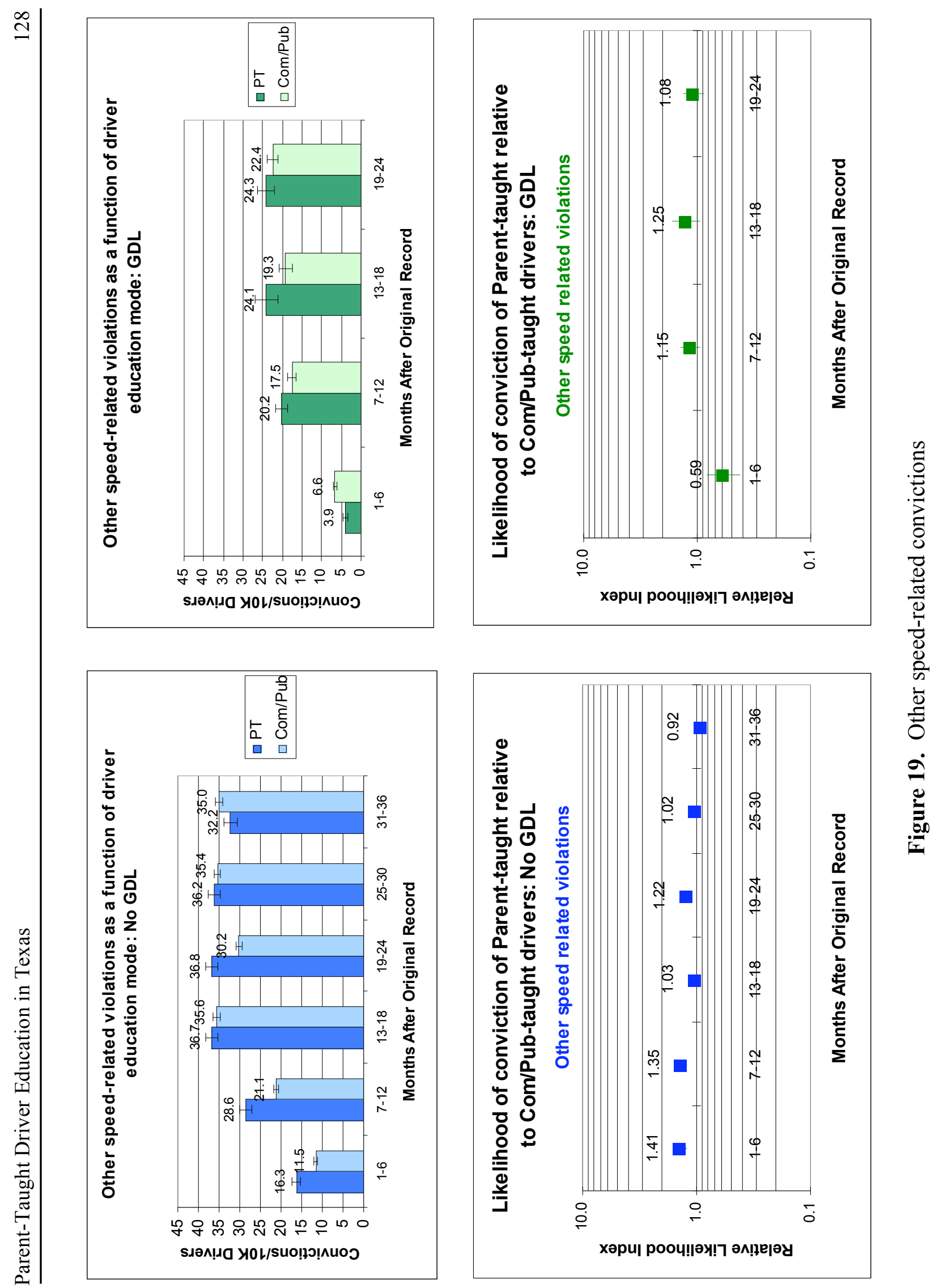

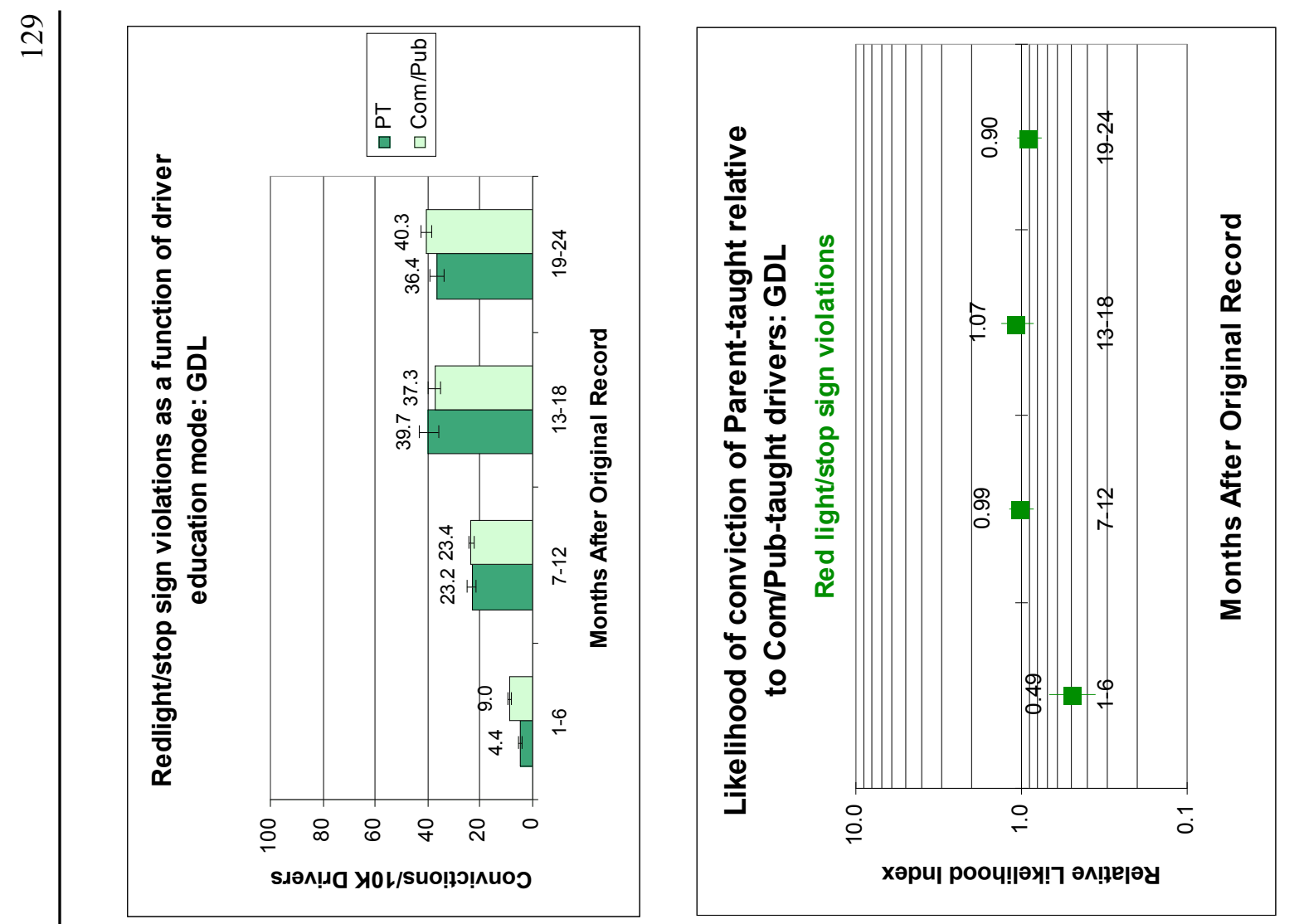

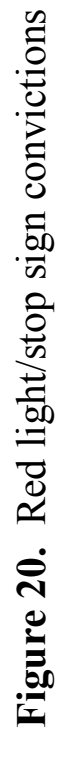
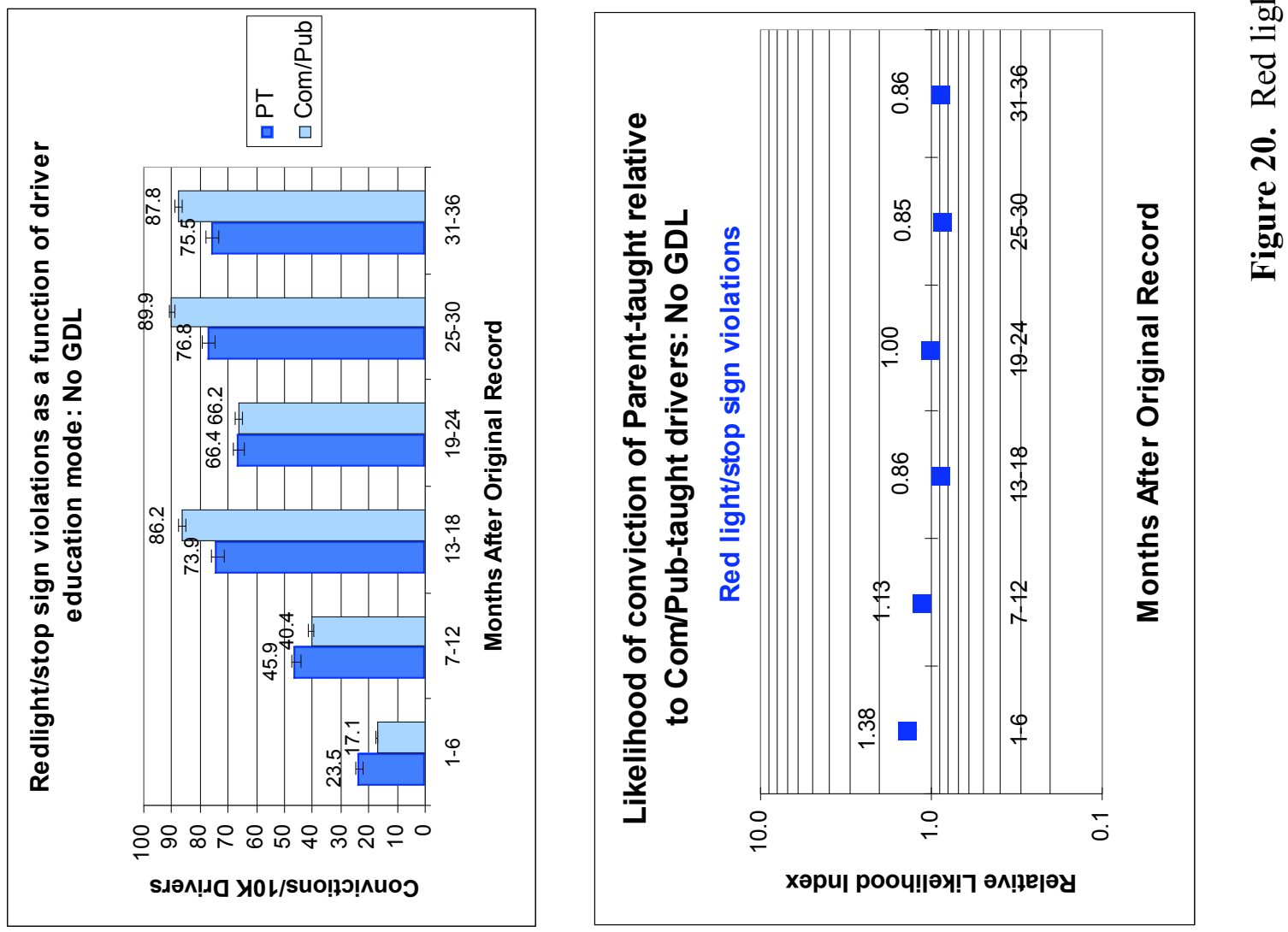

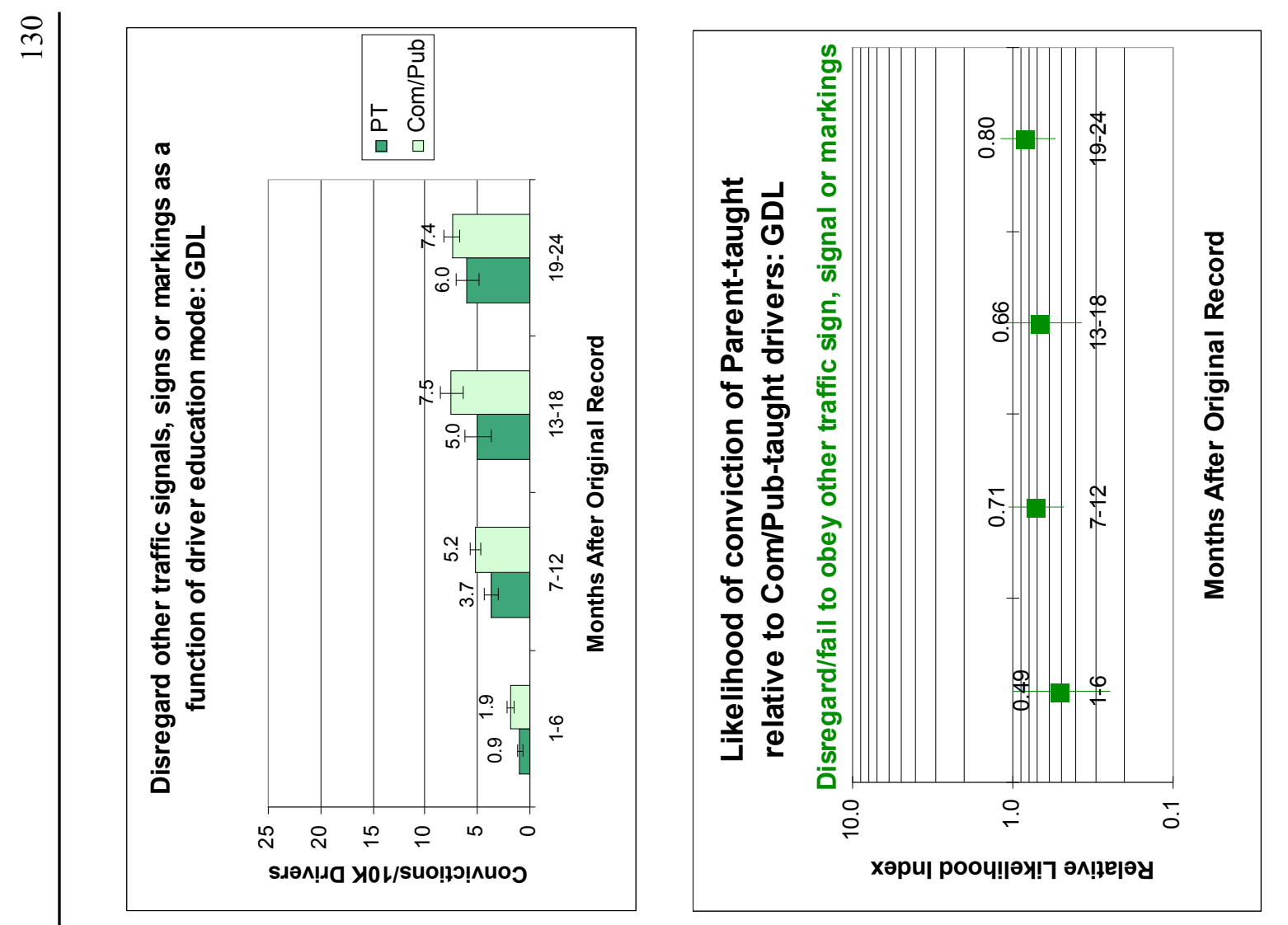

告
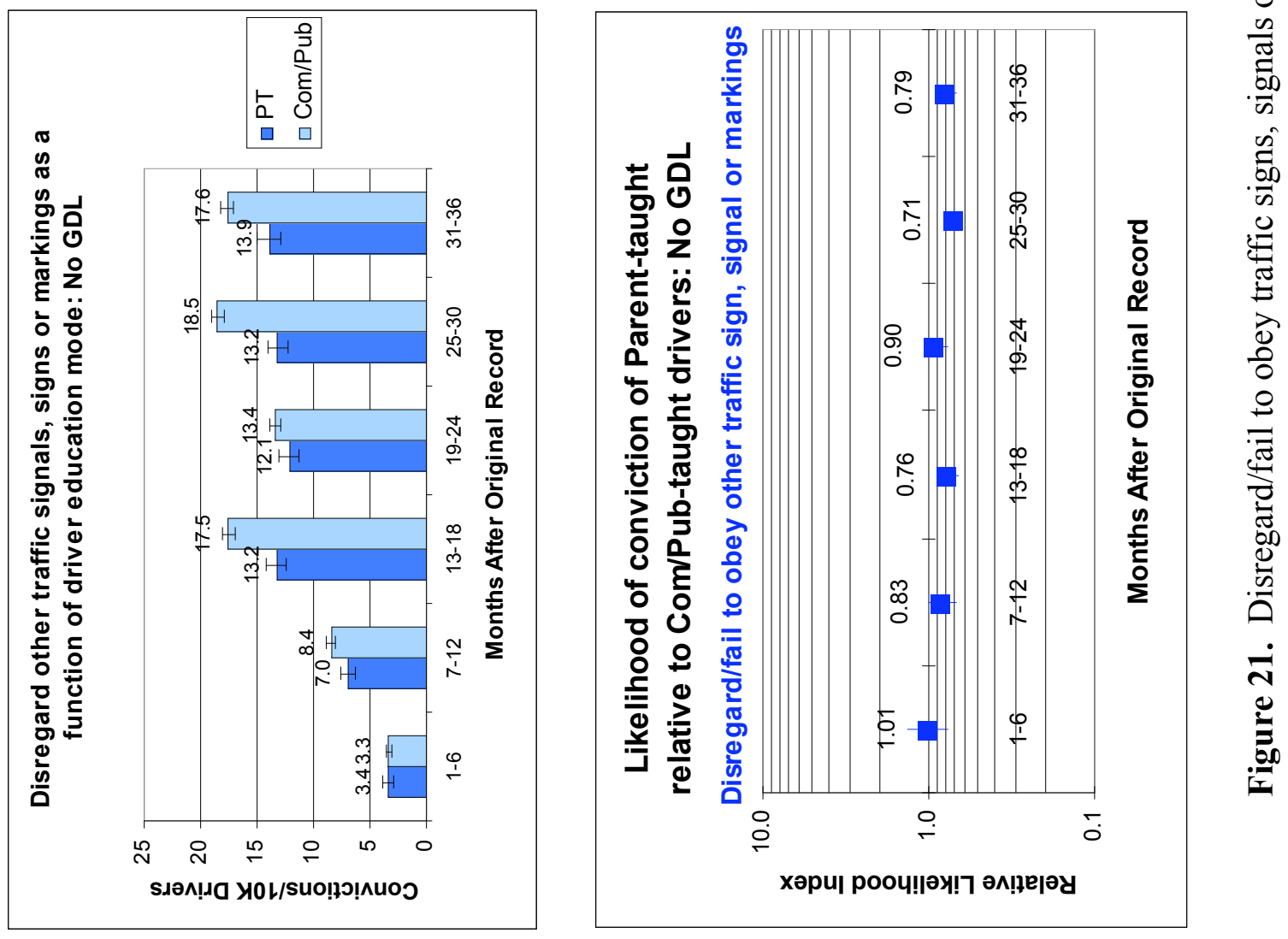

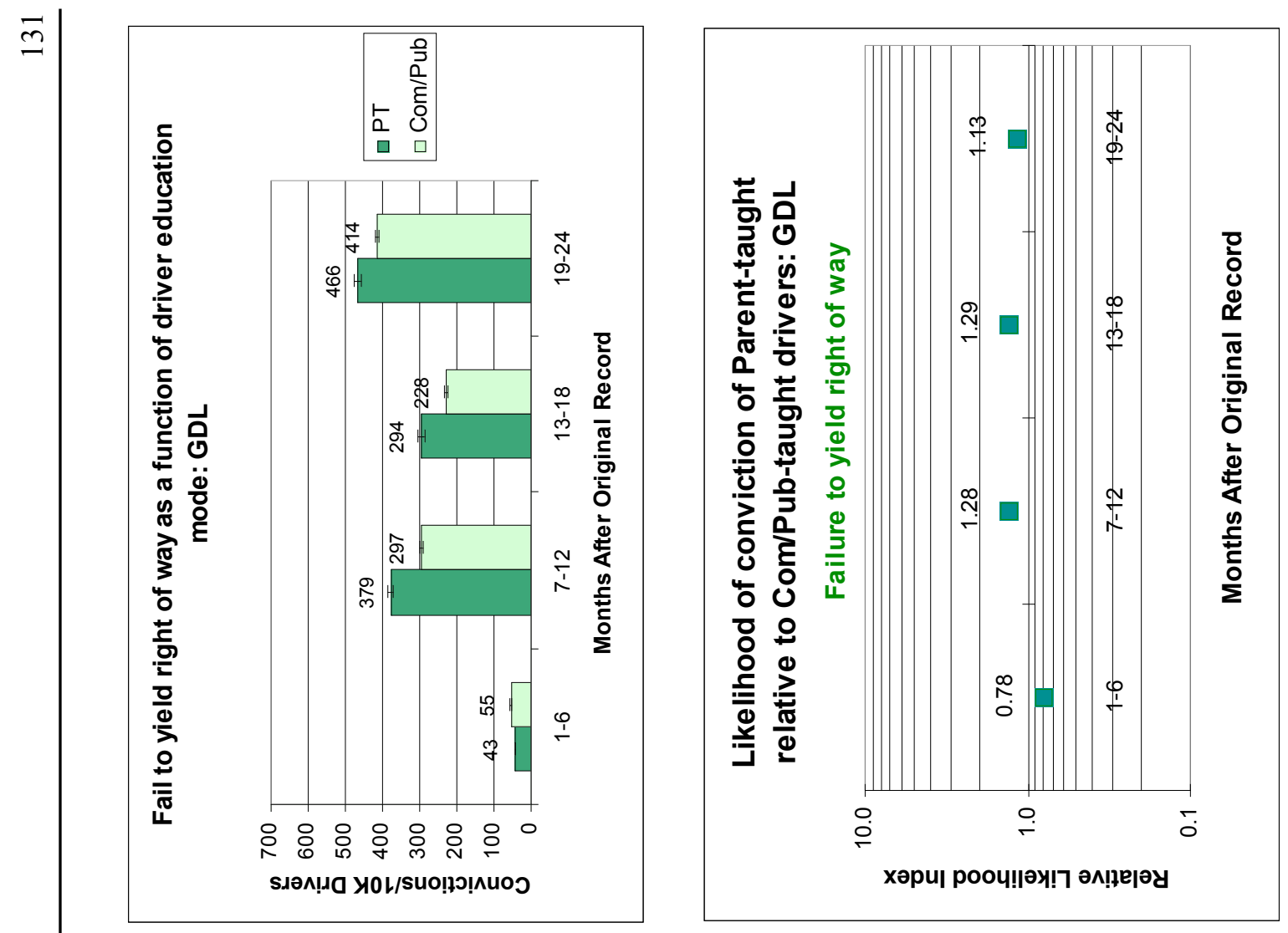

告
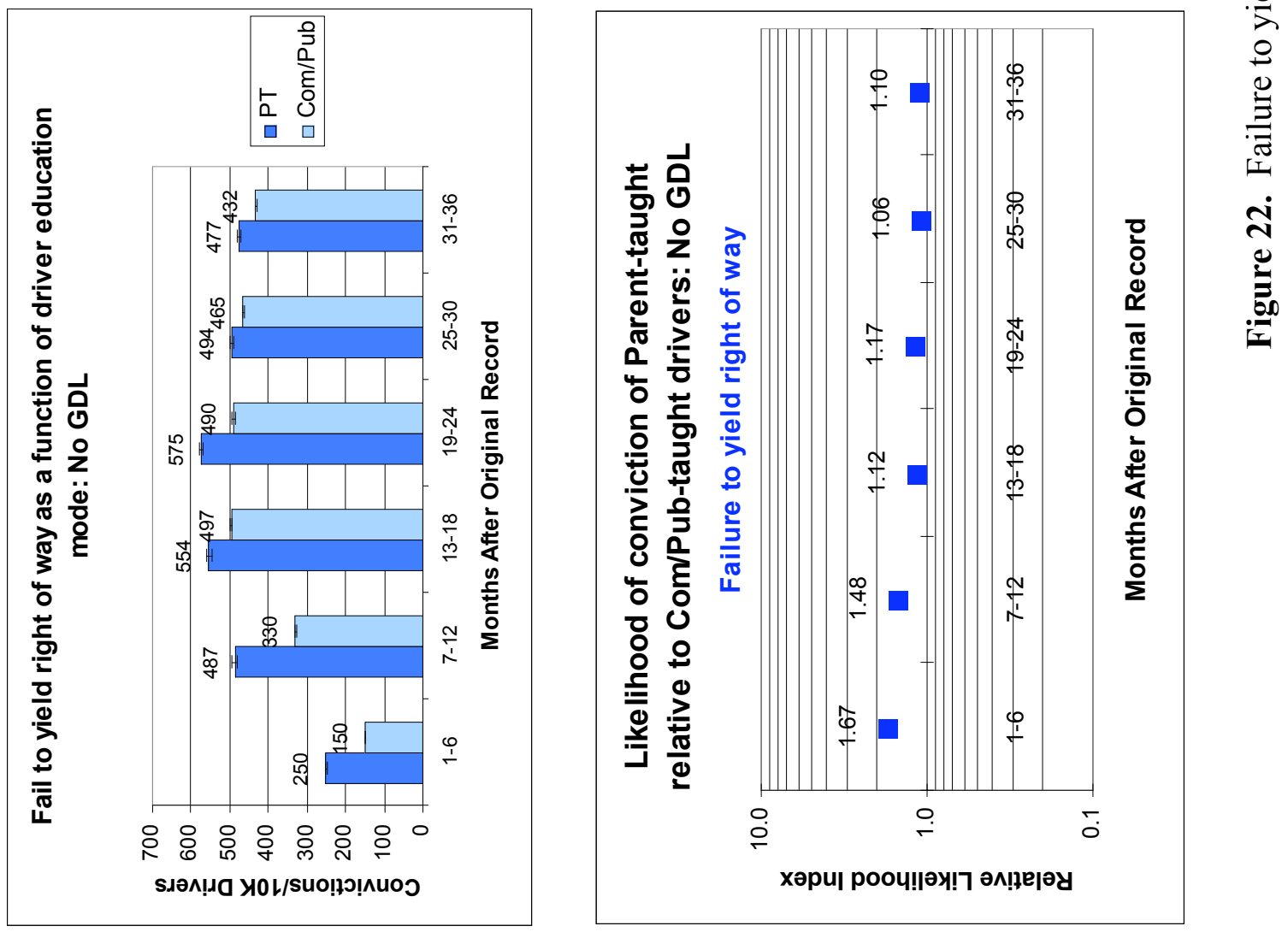

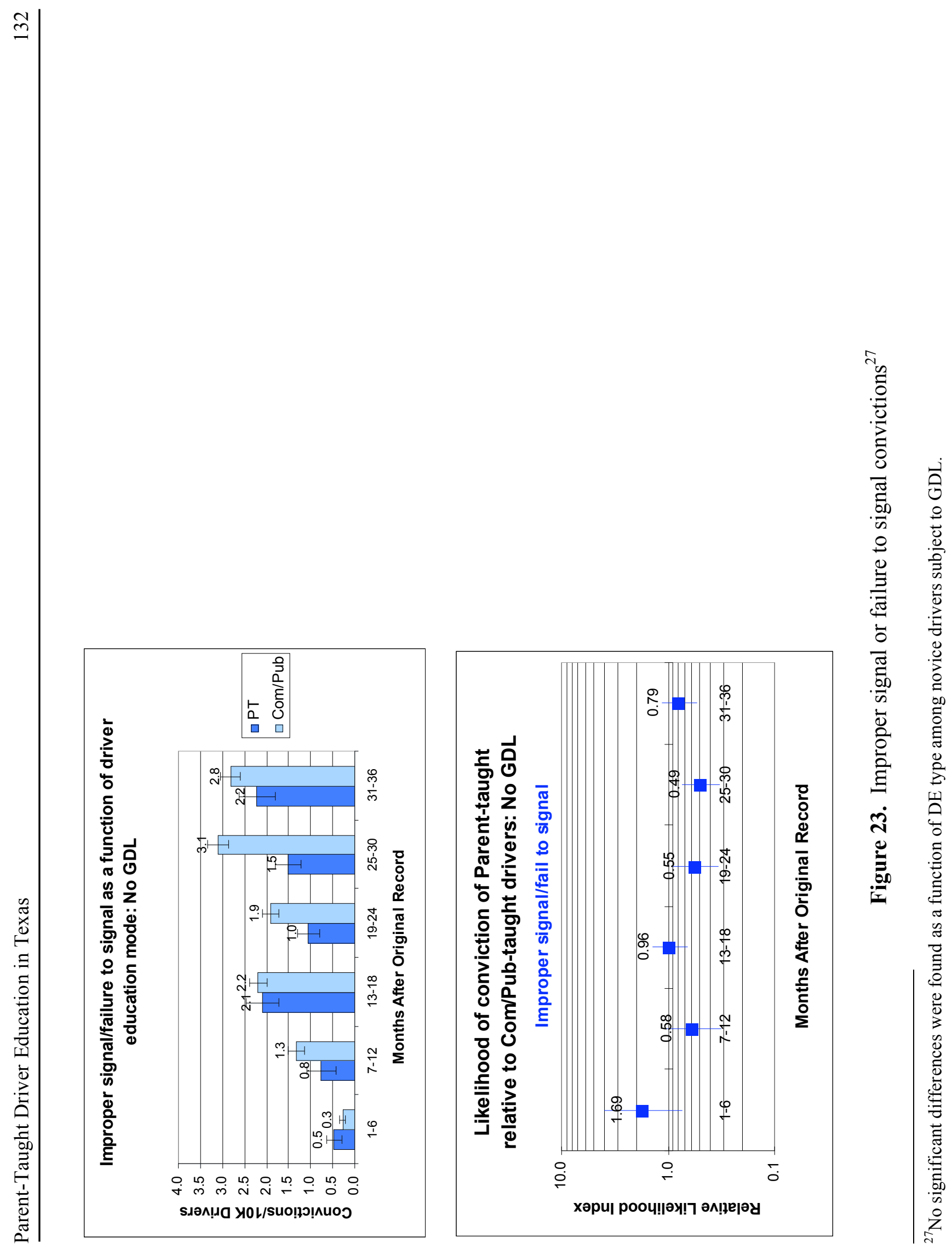

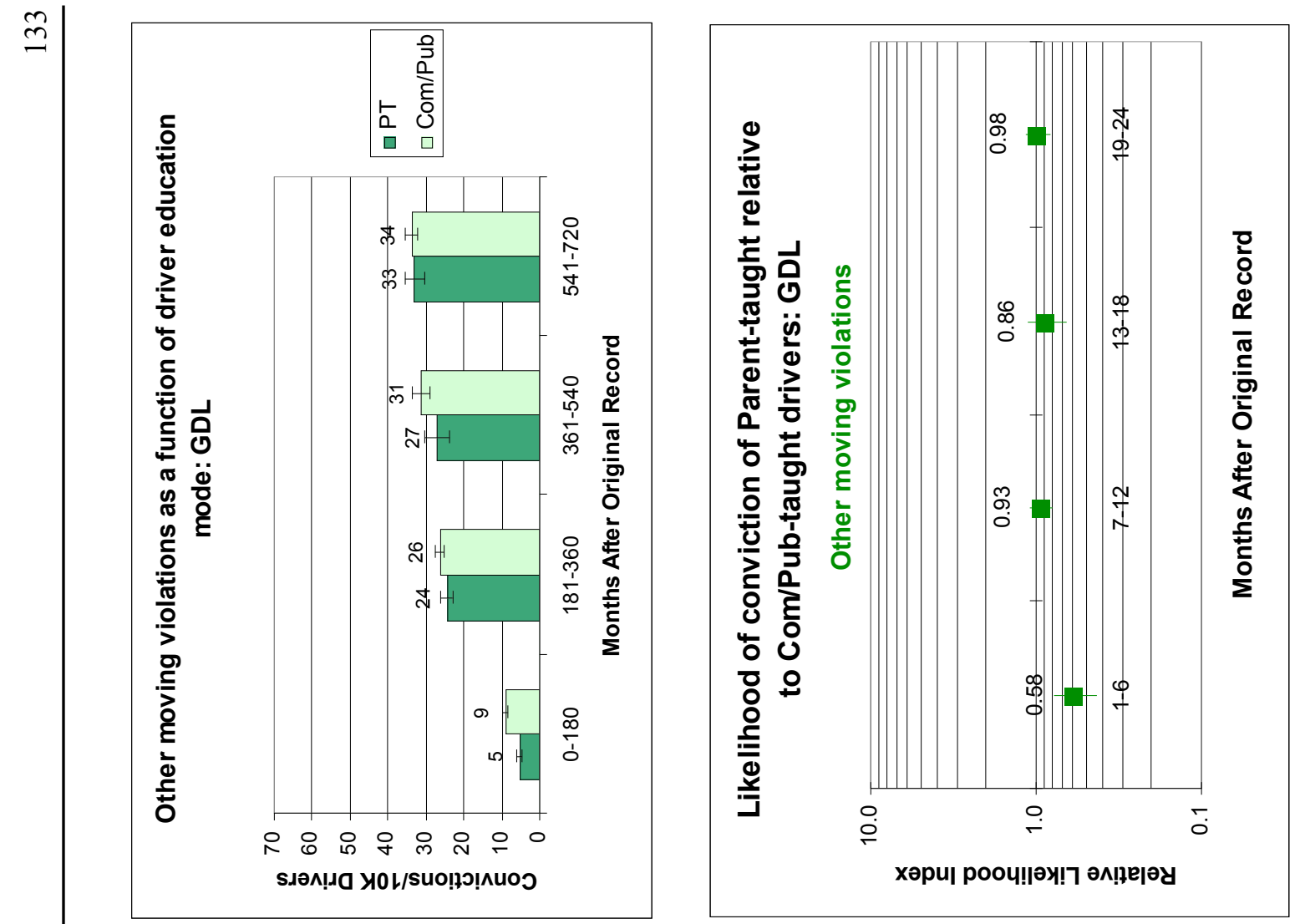

0
0
00
0
0
0
0
0
0
0
0
0
0
0
0
0
0
0
0
0
0
0
0
0
0
0
0
0
0
0
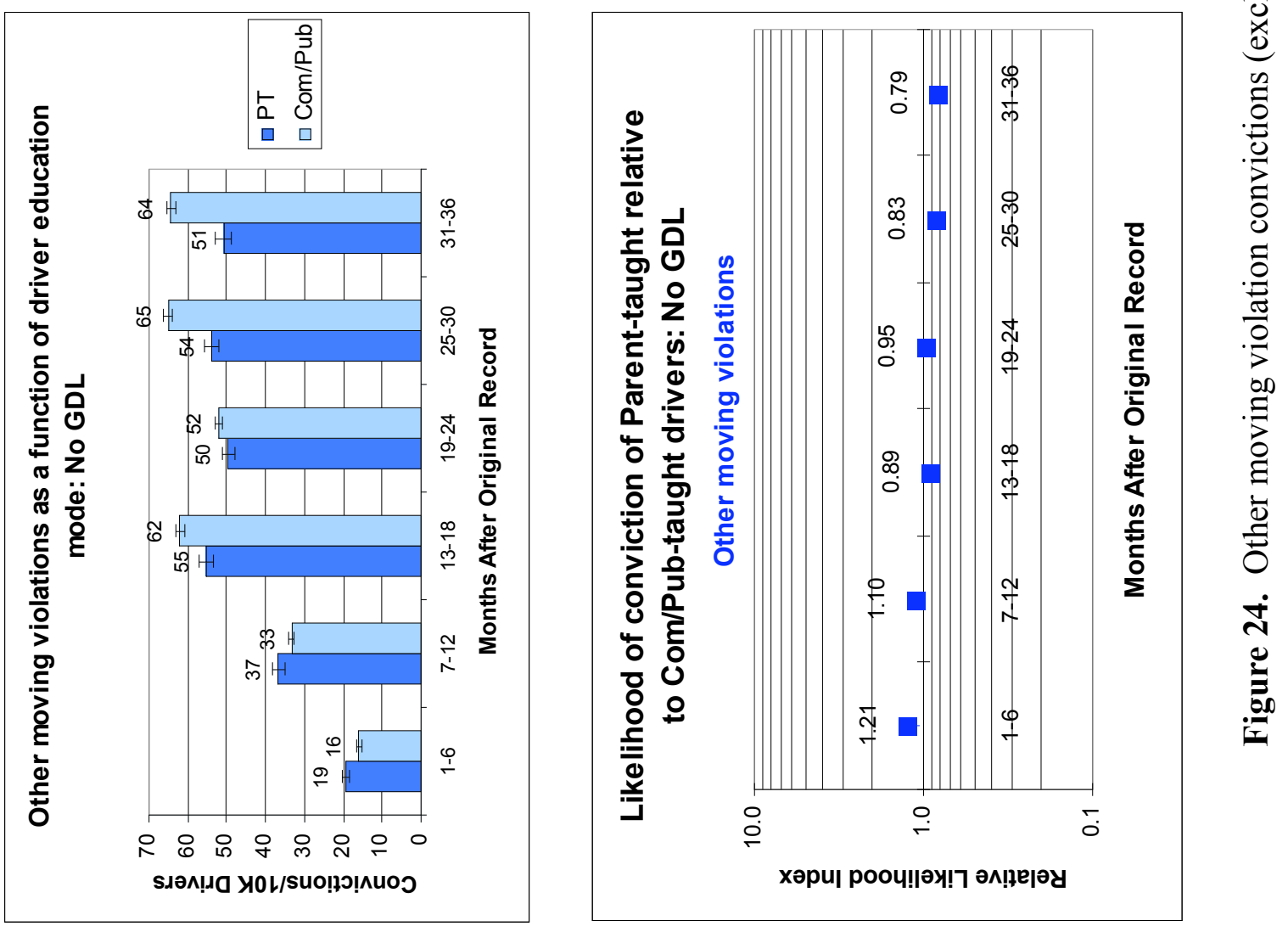

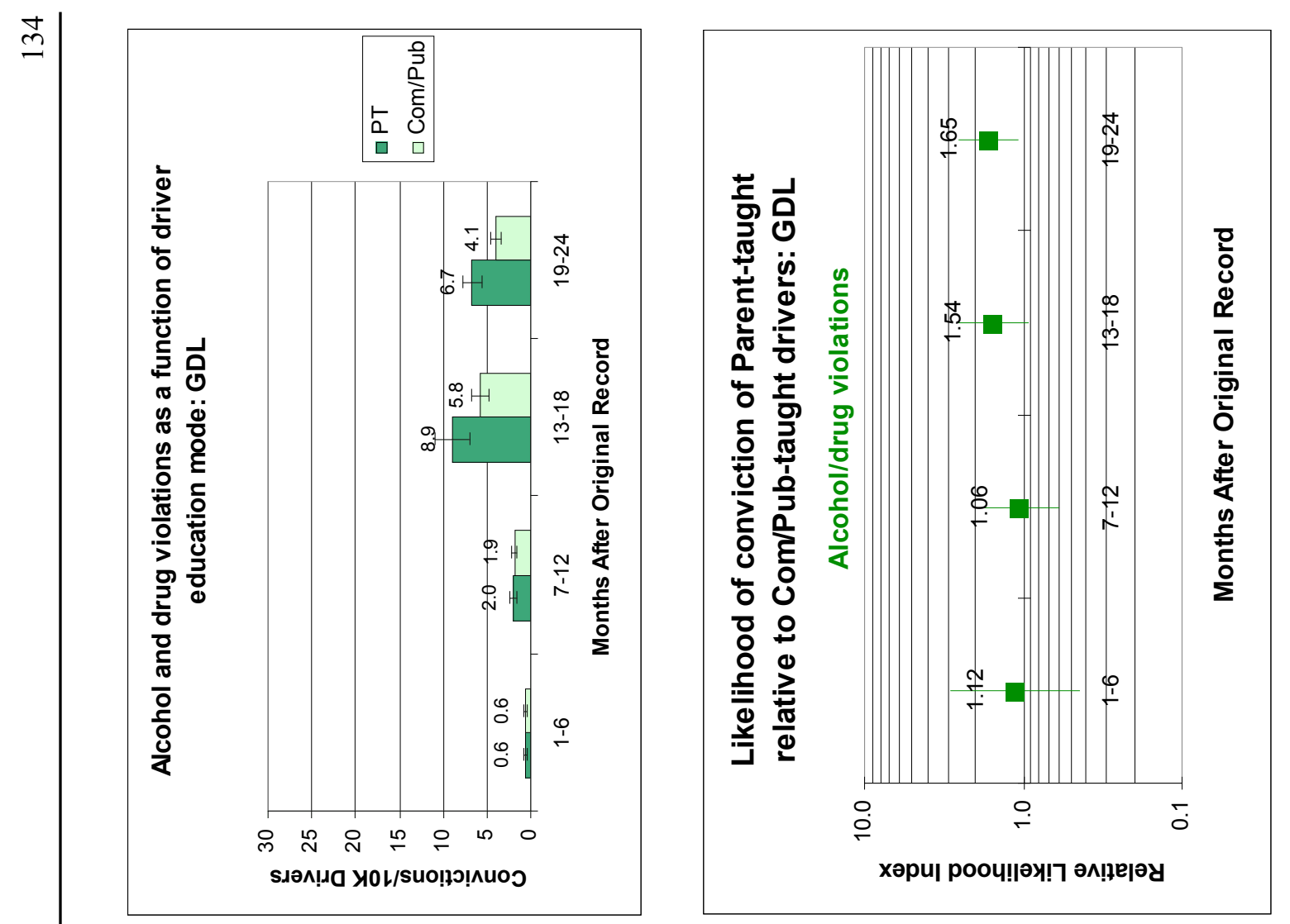

告
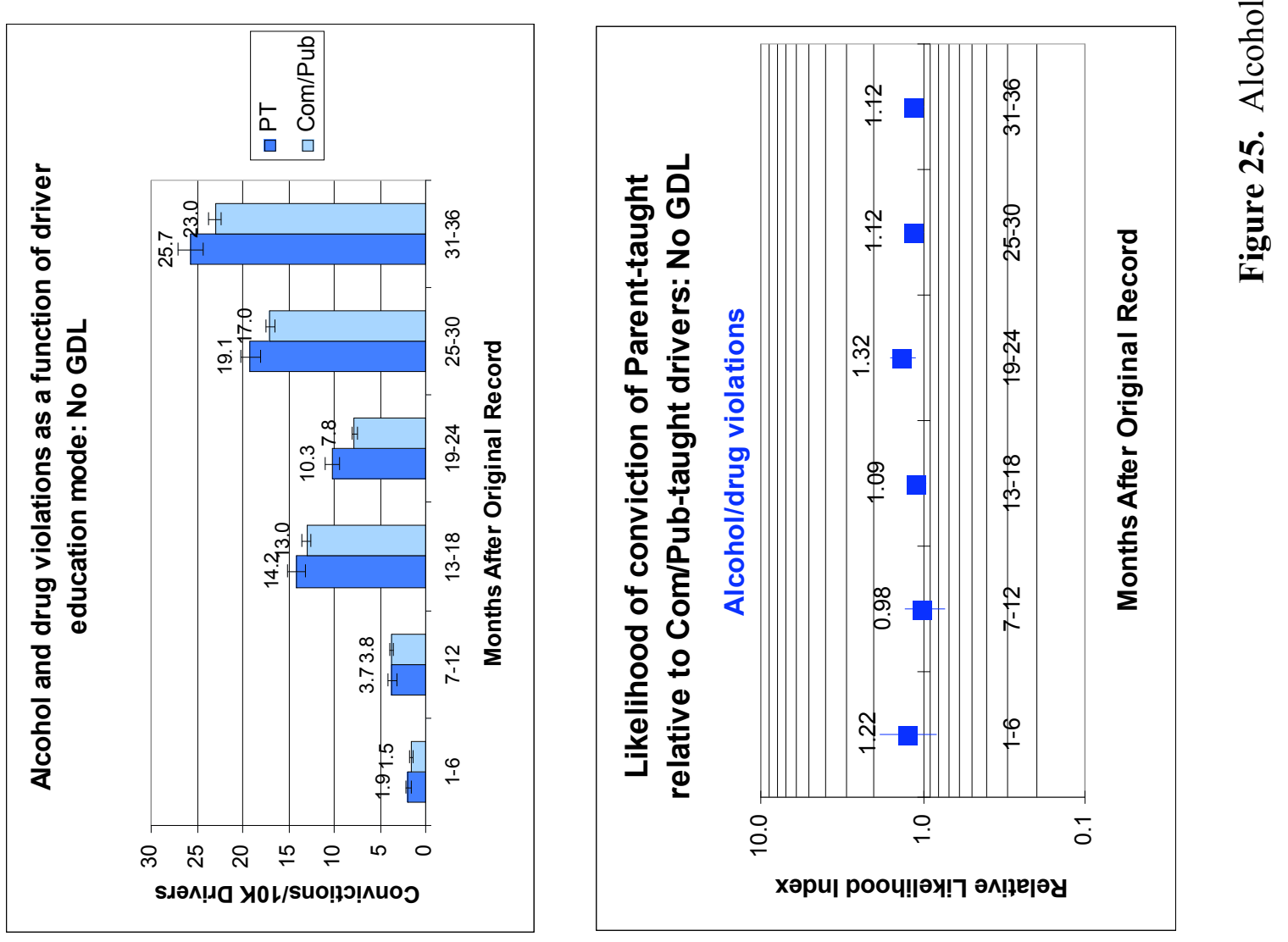

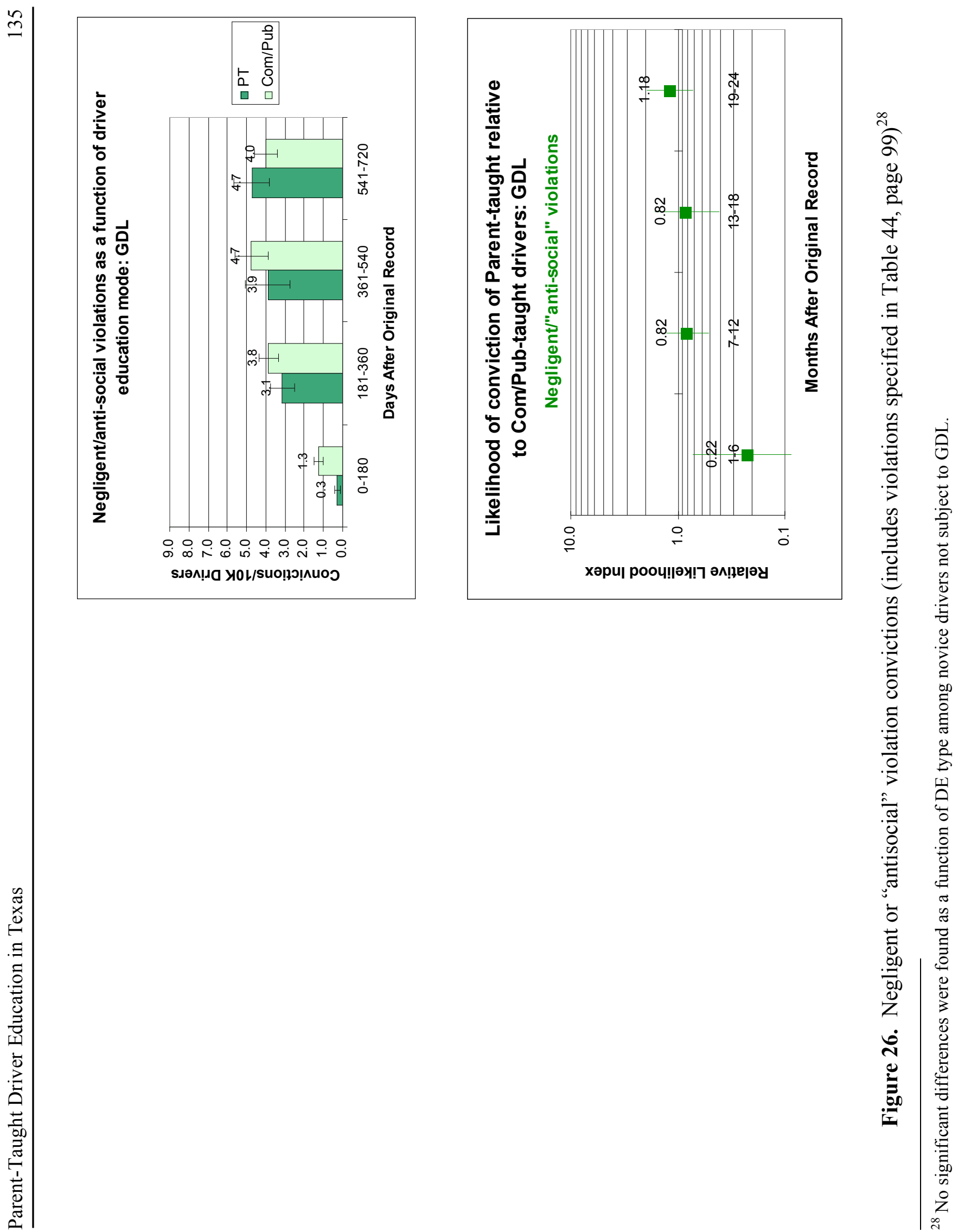

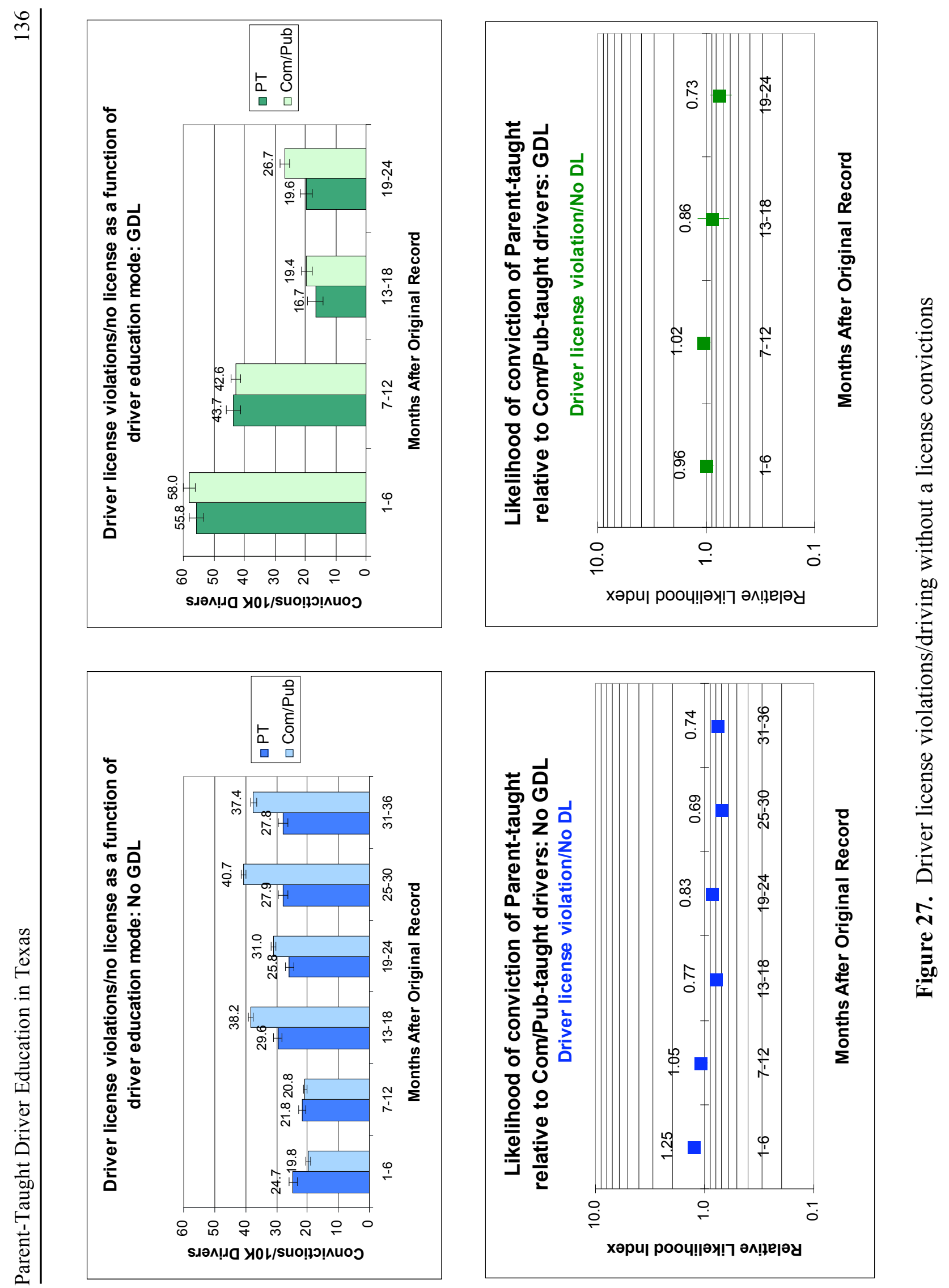

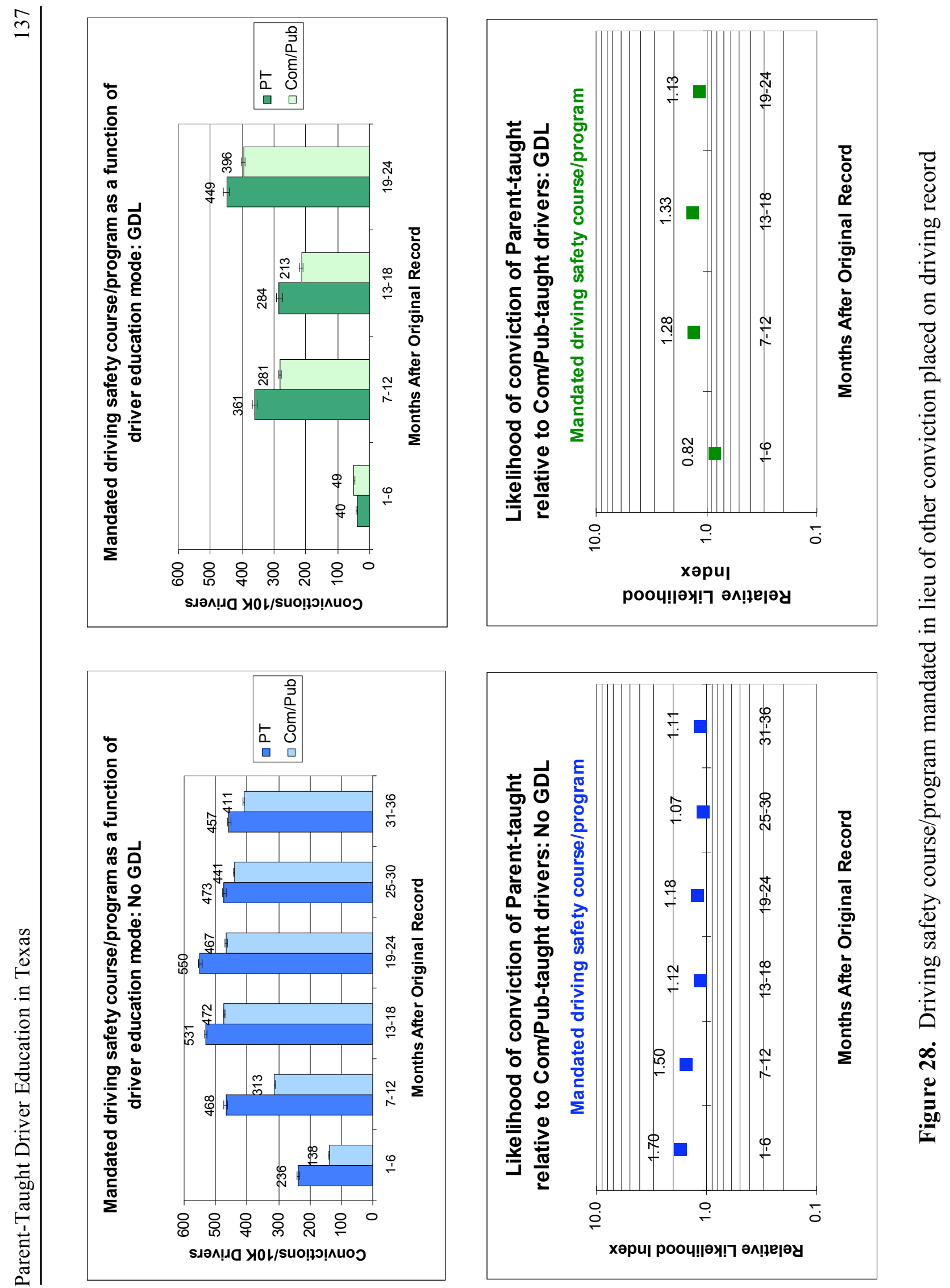


\section{Summary of Driver Record Conviction Analysis}

The driver records of the same set of 1.4 million drivers who completed either a TEA-certified Commercial or Public School novice driver education course or completed a driver education course under the Texas Parent-Taught Driver Education Program that were analyzed for crash involvement, were examined for traffic offense convictions.

Table 52 provides a summary of the results of comparisons between parent-taught and commercial or public-school-taught novice drivers in terms of the frequency and relative likelihood of convictions within the 14 conviction categories, as a function of type of driver education completed. Only statistically significant differences between PT and Com/Pub-trained drivers are shown in this table. Results, like those for crashes, are provided for consecutive, nominally six-month, periods commencing with the establishment of each individual's driver record. Also, results are again noted and discussed separately for young drivers subject to GDL and drivers whose licensing pre-dated the 2002 implementation of the Texas GDL.

The data and analyses summarized in Table 52 permit the following general conclusions:

1. The relationship between convictions and type of driver education experienced is different for those young drivers who were and were not subject to the Graduated Driver License Program.

2. Conviction History - Non-GDL

Prior to implementation of the GDL, parent-taught novice drivers experienced 52 percent more convictions for all offenses combined than commercial/public-school-taught drivers during the first six months of driving experience. During this period, PT drivers had significantly more convictions in eight of the 14 conviction groups. Differences in the remaining six conviction groups were small and not significantly different. The second sixmonth period presents a very similar picture. PT drivers experienced more convictions in seven of the same eight conviction groups as in the initial six months of driving. The differences evident in the first year included convictions in several important, i.e., potentially serious categories. For example, RLs summarized in Table 52 suggest that PT students (preGDL) were approximately 13 percent to nearly 70 percent more likely to have had convictions for speeding over the limit, racing, other speed-related offenses, red light/stop sign violations and failure to yield right-of-way depending on the specific offense and period. PT students were also markedly more likely to have taken court-mandated safety courses and, to a lesser extent, more likely to have convictions for other moving violations.

In the third six-month period of driving experience, the absolute frequency of convictions in most conviction groups increases without regard to type of DE, likely due to increased driving exposure. Differences related to DE type in both the frequency of convictions and the likelihood of convictions, however, become smaller, disappear completely or reverse direction. See, especially, the relative likelihood of convictions for red light violations, failure to obey other traffic signals, signs or markings and other moving violations in Table 52. In these categories, Pub/Com-trained drivers are 16, 32, and 12 percent more likely to have been convicted of offenses in these categories, respectively, during the $13^{\text {th }}-18^{\text {th }}$ month 


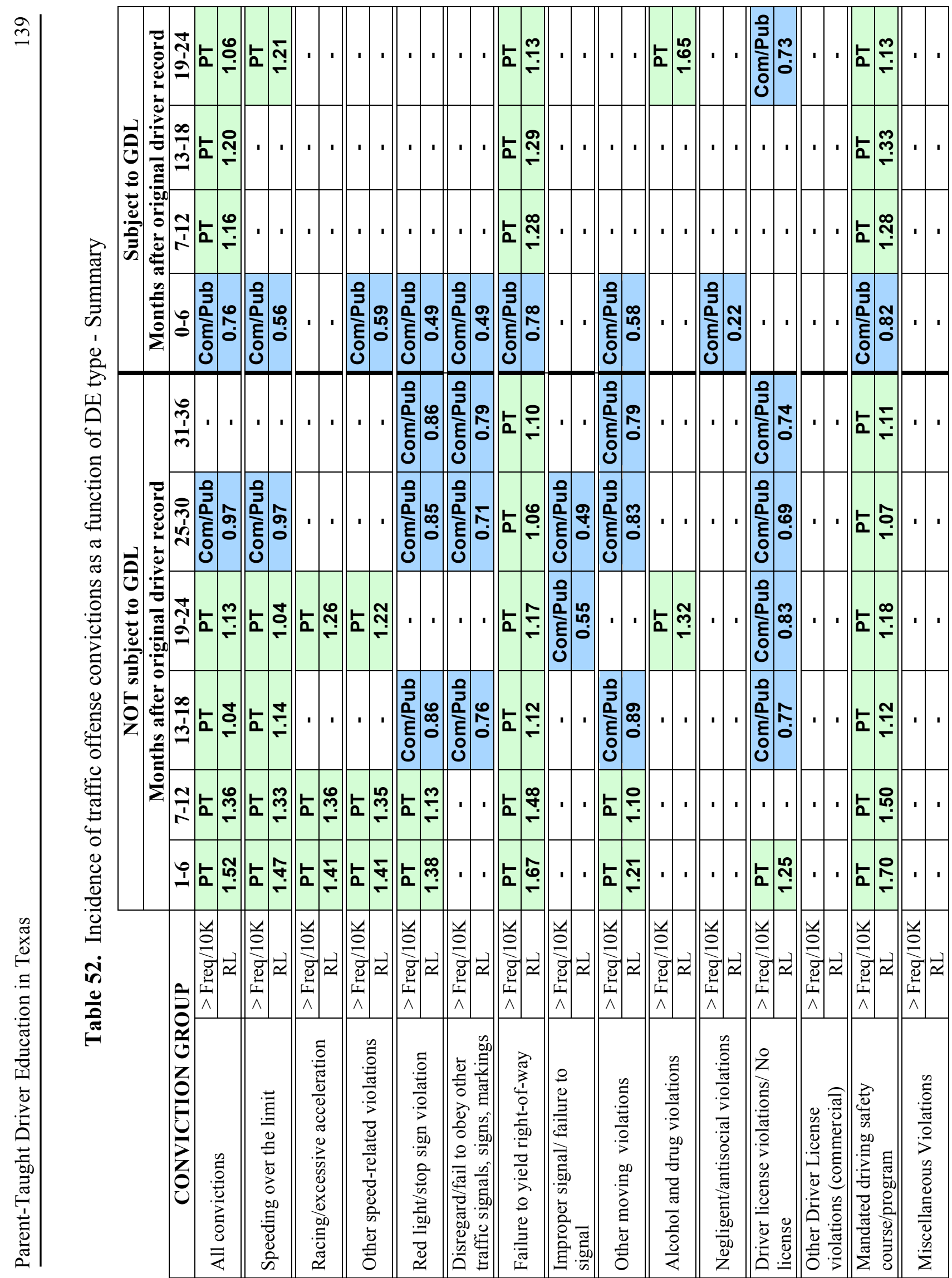


of driving experience. Speeding over the limit, racing, and failure to yield right-of-way convictions continue during this period to be significantly more likely among PT drivers, although the magnitude of the differences are smaller than during the first year of driving.

In six of the conviction categories, PT young drivers continue to experience more convictions per 10,000 drivers (and significantly greater likelihoods of having a conviction) during the fourth six-month period of driving (months 19-24 after establishment of a driver record), including convictions for speeding, racing, failure to yield right-of-way and, for the first time, alcohol and drug violations. In the last year for which data is available (months 25-30 and 31-36, differences in convictions as a function of DE type become less frequent and, with a few exceptions, smaller in magnitude.

3. Conviction History - GDL

Inspection of the right side of Table 52 reveals that, in many respects, the pattern of convictions among young drivers subject to the provisions of the Graduated Driver License program mirrors that for crashes discussed previously.

During the first six months of driving experience following establishment of a Texas driver record, parent-taught novice drivers experienced significantly fewer total convictions/10,000 drivers and the likelihood of a PT driver being convicted was significantly less than commercial or public-school-taught novice drivers in 8 of the 14 conviction groups. PT drivers did not exhibit more convictions during this first, supervised, six-months of driving experience in any of the conviction categories. It should be noted that absolute number of convictions in all categories was substantially lower in the first six months of driving under the GDL for both PT and Com/Pub drivers than it was prior to implementation of the GDL.

Following the first six-month period, there were few significant differences in convictions as a function of DE type. The most notable exceptions were seen in the greater likelihood for PT drivers to have convictions for failure to yield right-of-way and, like those drivers not subject to GDL, participation in mandated driving safety courses or programs. Somewhat perplexing, is the 65 percent greater likelihood for PT drivers to have received an alcohol or drug-related violation conviction in the fourth six-month period following origination of a driver record. Again in this case, the absolute number of convictions was substantially lower than in the comparable time period before GDL. 


\subsection{CONCLUSIONS AND RECOMMENDATIONS FROM THE EVALUATION}

The primary goal of the present evaluation was to determine the impact of the Texas parenttaught driver education program on the education and training of young novice drivers and on the safety of novice drivers on Texas streets and highways. Information and data pertinent to these issues have been developed through focus groups conducted with driver education instructors, students and parents of DE students; a statewide mail survey of young drivers; and examination of Texas driver records. Analysis of the information generated by this approach was directed toward answering two basic questions about the parent-taught program relative to commercial driving school and public school based DE:

- Are there discernible differences in the attitudes, knowledge and skills of novice drivers exposed to the three core driving instruction options available in Texas?

- Are teenage drivers exposed to the parent-taught driver education program in Texas demonstrably different from either those who complete school-based or commercial driving school training as measured by post-licensing crash involvement and traffic offense convictions?

The evaluation is comparative in nature and does not purport to assess in any absolute sense the value or benefit derived from any of the three modes of DE delivery in Texas. Nor does it attempt to evaluate specific DE courses, course providers or instructors/teachers. Rather, the evaluation was conducted at a more global, macro level to determine if the parent-taught program, as a State policy, has contributed in any negative way to the training and licensing of young, novice drivers in Texas. In short, is there evidence that the parent-taught DE program performs less well than either of the two more traditional DE delivery options?

Eleven conclusions drawn from the information generated in the evaluation and the rationale for each are discussed below.

\subsection{Conclusions from the Analyses}

\subsubsection{Differences in Age at Licensing}

Before discussing the extent to which the evaluation provides answers to the specific questions posed above, a discussion of the relationship between DE and driver age at licensure is in order. More than 25 years ago, Robertson (1980) concluded "driver education in high school is a major contributing factor to the early licensure of teenagers and, as a result of this earlier exposure, their increased involvement as drivers in serious crashes." It is of interest, then, to consider if any of the three DE approaches evaluated here lead to younger licensing and the increased driving exposure that accompanies licensing. Information to this point, while limited, is provided by the young driver survey and in the Texas driver records.

\section{Conclusion 1}

Taken as a whole, the data suggest that prior to the Texas GDL program, the parent-taught program does not appear to have encouraged earlier licensing and, indeed, may have delayed obtaining instructional permits for a portion of PT students. 


\section{Conclusion 2}

Since the implementation of the GDL, PT students are obtaining at least their first licenses, i.e., instructional permits, somewhat younger than commercial/public school DE students do, suggesting that parent-taught novice drivers are subject to the opportunity for increased exposure to the risks of driving, albeit during the period of most supervision. Confirmation of greater exposure would require data not available to the present evaluation, that is, differences in actual miles driven as a function of $D E$ type.

Based on self-reports from recent Texas DE students, no differences in the mean age at which four licensing milestones were attained were observed. Average ages at each of the three license stages under the GDL program, i.e., instructional permit, provisional license, and unrestricted license were numerically very similar for young drivers in all of the DE modes and do not differ significantly. Average age at completion of a DE course also does not differ among the three DE modes. Examination of the distributions of ages at each of these milestones reveals differences as a function of DE type only for age at completion of a driver education course. The proportion of parent-taught respondents completing their DE course before reaching age 16 is substantially smaller than that for either commercial or public school respondents and, conversely, considerably greater in the 16- to 16.4-year-old group. The cumulative percent of parent-taught, commercial and public school-trained drivers completing their DE course within the first six months after reaching age 16 is 71.2, 74.7, and 77.6 percent, respectively. This apparent delay in completion of DE courses by some PT novice drivers may simply be an artifact of how young drivers define "completion" of their course. In any event, since there are no differences among the distribution of ages at which licenses are obtained as a function of DE type, the differences in age distributions should not influence exposure to the risks of driving.

Unlike the self-report survey data, inspection of driver records does reveal small, but statistically significant, differences in the mean age at which drivers obtained their first driving license (an instructional permit) as a function of DE type for both those young drivers who were subject to the Texas Graduated Driver License program and those who were not. Prior to the GDL, PT drivers were 0.104 years (38 days) older than Com/Pub-trained drivers when they obtained instructional permits. Among novices who were subject to the GDL, PT drivers were 0.160 years (58 days) younger than their Com/Pub peers were when they obtained instructional permits.

The distribution of ages at origination of driver records, and, nominally, age at obtaining instruction permits, differ significantly for both the pre-GDL and post-GDL groups as a function of DE type. Before the GDL, nearly 10 percent more of the Com/Pub drivers had driver records established as 15- to 15.4-year-olds than did PT drivers. Driver records were established proportionally more frequently in the 16 to 16.4 age range for PT drivers than they were $\mathrm{Com} / \mathrm{Pub}$ drivers, suggesting that PT students delayed obtaining an instruction permit relative to students taking the traditional forms of DE.

Since the introduction of GDL, PT novice drivers established a driver record as 15.5- to 15.9year-olds proportionally more often than did Com/Pub drivers. About 10 percent more PT driver records originated in this age range (35.3 compared to $25.4 \%$ ). Because of the strong relationship between record origination and obtaining an instructional permit, it is apparent that 
since the inception of the GDL, a significant proportion of PT novices are getting instructional permits at an earlier age than their Com/Pub counterparts.

\subsubsection{Differences in Attitudes, Knowledge and Skills of Novice Drivers}

Both the focus groups and the survey of young drivers provide suggest some limited conclusions about differences in attitudes, knowledge and driving skills associated with the type of DE experienced by novice drivers. These conclusions must be considered tentative because generalizations from information developed from the focus groups is constrained by the nature of such groups ${ }^{29}$ and generalization of the survey results is hampered by the low response rate relative to the stratified random sample of novice drivers to whom the survey was sent.

\section{Conclusion 3}

Driver education students and their parents agree that the parent-taught DE program offers advantages over commercial and public school modes of DE delivery in terms of cost, comfort and individualized personal attention to the student. Professional DE instructors believe the negative aspects of the parent-taught program outweigh any perceived benefits, due largely to a lack of training, knowledge, and teaching skills on the part of parent-teachers.

\section{Conclusion 4}

No, or at most slight, differences in driving knowledge and skills among the three DE course delivery modes are discernible from self-reports of specific driving-related knowledge and skills.

\section{Conclusion 5}

As measured by State-administered tests, parent-taught students demonstrate poorer driving knowledge early in the training and licensing process and poorer driving skills at the end of formal driver education. Although only a small proportion of DE students fail to pass either the test required to obtain an instructional permit or the optional in-vehicle road test on the first attempt, significantly more PT drivers require multiple attempts to pass.

\section{Attitudes and Beliefs}

Parents who taught their teens in the PT program and young drivers themselves, whether or not they participated in the PT program, generally believed that PTDE provided: (1) a less stressful and more comfortable environment in which to learn to drive; (2) greater individual attention to the student; and (3) opportunity to both customize the teaching/learning experience to the individual student's needs and provide a means for transmitting the values and attitudes of the parents to young drivers. Focus group discussions with commercial and public school driver education teachers suggest that they generally did not disagree with the notion that the PT program aided parents in conveying values, attitudes, and, they would add, driving behaviors, of the parents to young drivers. However, unlike parents, DE instructors viewed this in a negative light. Despite the good intentions of many parents, they believe, parents often communicated less-than-optimal values and attitudes and, most importantly, passed on dangerous driving behaviors to their children when they served as the primary driving instructors.

\footnotetext{
${ }^{29}$ See page 17 for a discussion of some of these limitations.
} 
Self-ratings of novice drivers' attitudes, knowledge and skills, whether in the form of comparisons with other drivers or the extent of agreement with statements related to their attitudes, knowledge and skills revealed virtually no significant difference associated with the type of DE course taken. ${ }^{30}$ Ratings differed significantly on only 3 of 51 items, and these differences were limited to small disparities within a response category. Thus, it appears that while both parents and teens seemed to believe the parent-taught program provided a more effective means to transmit attitudes than did the traditional DE programs, this was not reflected in teens' assessments of their own specific attitudes and driving behaviors.

\section{Knowledge and Skills}

As implied above, young drivers' self-assessments of their driving-related attitudes, knowledge and skills did not differ as a function of the type of DE course in which they participated. On 13 of the 17 items dealing with specific driving skills and capabilities, PT young drivers rated themselves marginally higher than did commercial or public school taught drivers. The differences, however, were not statistically significant.

In contrast, self-reported success on the knowledge test required before being granted an instructional permit and on the optional in-vehicle on-road test, revealed differences among the three DE types. Specifically, although most novice drivers passed the "rules" and "signs" tests, required before issuance of an instructional permit, on the first attempt, significantly more PT students reported taking the test at least twice before passing. Only 82 percent of parent-taught students reported passing on the first try compared to 97 and 93 percent of commercial and public school students. No data were collected that specifically accounts for this discrepancy. Commercial and public school DE instructors, having more experience in preparing students for the test, undoubtedly being more familiar with the universe of items from which specific test questions are drawn, and likely knowing the parts of the test with which previous students have had trouble, may stress those areas in preparing their students during the typical six hours of classroom instruction that precedes application for an instructional permit. Without regard to the controlling mechanism, it is clear that at least a portion of PT students are less prepared to take the initial driving knowledge test required for an instructional permit.

Parent-Taught DE students also performed differently on the optional on-the-road driving test. Although students who successfully complete an approved course of driver education are not required to take an in-vehicle driving test, a parent of any DE student may request that the DPS administer an on-road test. PT students were much less likely to report they have taken the DPS test than either commercial or public school DE students. Only 9.4 percent of PT students indicated they took the DPS test, compared to approximately 30 percent of both commercial and public school DE students. Similar to tests required for an instructional permit, a large majority of all DE students, nearly 90 percent, who did take the DPS in-vehicle test, passed on the first try. Again, however, significantly more parent-taught students reported requiring more than one try to pass the test. Only 71 percent of PT students who opted to take the test reported passing on the first attempt, compared to about 96 and 86 percent of commercial and public school DE respondents, respectively.

\footnotetext{
${ }^{30}$ See Tables 28 and 29.
} 


\subsubsection{Differences in Driving Errors, Traffic Offenses and Crash Involvement}

The young driver survey and analysis of Texas driver records offer information relevant to these issues; the former provide self-reports from a sample of novice drivers and the latter afford

official records of driver crash and citation data.

\section{Conclusion 6}

Based on self-reports, the incidence of driving errors among young drivers subject to the GDL does not differ as a function of type of $D E$.

\section{Conclusion 7}

Based on driver records, PT novice drivers were convicted of more traffic offenses than commercial or public school-trained drivers before implementation of the GDL program, especially in the first year of driving.

\section{Conclusion 8}

Since implementation of the GDL, convictions for traffic offenses are substantially fewer for all novice drivers. Differences that do exist are generally smaller and favor PT drivers during the period of most supervision, i.e., the instructional permit phase of licensing. During the period when for most young drivers requirements for adult supervision are reduced (provisional license) and after supervisory and other GDL restrictions are removed (full licensure), PT drivers again experience proportionally more total traffic convictions than drivers trained under commercial/public school DE programs.

\section{Conclusion 9}

Based on self-reports of novice drivers subject to the GDL, the incidence of crashes involving parent-taught drivers is not greater than that reported by commercial or public school trained novice drivers.

\section{Conclusion 10}

Before implementation of the Texas GDL, based on crashes reported in Texas driver records, proportionally more and more-serious crashes were experienced by parent-taught novice drivers over the first 18 months of driving experience. Through the next 18 months of driving most differences disappear except for possible injury crashes which occurred with greater frequency among Com/Pub-trained drivers and fatal crashes, which occurred significantly more often among PT drivers in the first half of the third year of driving experience.

\section{Conclusion 11}

Since implementation of the GDL, crashes are substantially fewer for all novice drivers. Differences that do exist generally are small and favor PT drivers during the period of most supervision, i.e., the instructional permit phase of licensing. During the period when requirements for adult supervision are reduced (provisional license) and after supervisory and other GDL restrictions are removed (full licensure), PT drivers experience proportionally more crashes and more serious crashes than drivers trained under commercial/public school DE programs. 
Driving Errors

Self-reports of the frequency of each of 21 driving errors or misjudgments in the past year, whether or not these errors resulted in a traffic offense or crash, revealed no significant differences in the average frequencies associated with type of driver education. The five driving behaviors with the highest frequency of self-reported occurrence for all DE group respondents were:

Drive through a yellow traffic signal.

Drive 10 miles per hour or more above the speed limit.

Leave too late, and speed to get to destination in time.

Put the "pedal-to-the-metal" on a deserted road.

Tailgate the car in front to make its driver speed up or get out of your way.

All DE groups reported the top three in the same order of frequency.

\section{$\underline{\text { Traffic violations }}$}

Self-reports of traffic stops, whether or not a citation was issued, indicated that speeding is both the most frequently reported offense and the violation with the most multiple offenses by single individuals among novice drivers who completed each of the three DE modes. No significant differences between the number of times individuals were stopped for speeding and type of DE course completed were detected. Nor was a significant association between the number of violations and DE type found for any of the offenses. Based solely on these self-reports, there is no evidence suggesting that the incidence of driving offenses differs as a function of the type of DE received. Analysis of convictions for traffic offenses included in Texas driver records, however, led to a rather different conclusion.

Prior to implementation of the GDL, parent-taught novice drivers experienced 52 percent more convictions for all offenses combined than commercial/public-school-taught drivers during the first six months of driving experience. During this period, PT drivers had significantly more convictions in 8 of the 14 conviction groups. Differences in the remaining six conviction groups were small and not significantly different. The second six-month period presented a very similar picture. PT drivers experienced more convictions in 7 of the same 8 conviction groups as in the initial six months of driving. The differences evident in the first year included convictions in several important, i.e., potentially serious categories. For example, RLs summarized in Table 68 suggest that PT students (pre-GDL) were approximately 13 percent to nearly 70 percent more likely to have had a conviction for speeding over the limit, racing, other speed-related offenses, red light/stop sign violations and failure to yield right-of-way depending on the specific offense and period. PT students were also markedly more likely to have taken a court-mandated safety course and, to a lesser extent, more likely to have convictions for other moving violations.

In the third six-month period of driving experience, the absolute frequency of convictions in most conviction groups increased without regard to type of DE, likely due to increased driving exposure. Differences related to DE type in both the frequency of convictions and the likelihood of convictions, however, generally became smaller, disappeared completely or reversed direction over time. See, especially the relative likelihood of convictions for red light violations, failure to obey other traffic signals, signs or markings and other moving violations in Table 52. In these 
categories, Com/Pub-trained drivers were 16, 32, and 12 percent more likely to have been convicted of offenses in these categories, respectively, during the $13^{\text {th }}-18^{\text {th }}$ months of driving experience. Speeding over the limit, racing, and failure to yield right-of-way convictions continued during this period to be significantly more likely among PT drives, although the magnitude of the differences were smaller than during the first year of driving.

In six of the conviction categories, PT young drivers continued to experience more convictions per 10,000 drivers (and significantly greater likelihoods of having a conviction) during the fourth six-month period of driving (months 19-24 after establishment of a driver record), including convictions for speeding, racing, failure to yield right-of-way and, for the first time, alcohol and drug violations. In the last year for which data is available (months 25-30 and 31-36) differences in convictions as a function of DE type became less frequent and, with a few exceptions, smaller in magnitude.

After implementation of the GDL program, parent-taught novice drivers experienced significantly fewer total convictions/10,000 drivers than commercial or public-school-taught novice drivers. Additionally, the likelihood of a PT driver being convicted was significantly less than commercial or public-school-taught novice drivers in eight of the 14 conviction groups during the first six months of driving experience following establishment of a Texas driver record. PT drivers did not exhibit more convictions during this first, supervised, six-months of driving experience in any of the conviction categories. It should be noted that absolute number of convictions in all categories was substantially lower in the first six months of driving under the GDL for both PT and Com/Pub drivers than it was prior to implementation of the GDL.

Following the first six-month period, there were few significant differences in convictions as a function of DE type. The most notable exceptions were seen in the greater likelihood for PT drivers to have convictions for failure to yield right-of-way and, like those drivers not subject to GDL, participation in mandated driving safety courses or programs. Somewhat perplexing, was the 65 percent greater likelihood for PT drivers to have received an alcohol or drug-related violation conviction in the fourth six-month period following origination of a driver record. Again, in this case, the absolute number of convictions was substantially lower than in the comparable period before GDL.

\section{Crash Involvement}

Self-reports of crash involvement revealed very similar patterns among participants in all three DE delivery modes. Overall, 43 percent of all respondents reported involvement in one or more crashes while they were driving. Differences among DE types are small and not statistically significant. More than 40 percent of the drivers in each of the DE groups report crash involvement. There is some evidence of a DE mode-associated difference in the frequency of some crashes. When all crashes that resulted in at least one injury, whether or not medical attention was required, are combined, a significantly larger proportion of the total crashes reported by public school trained drivers resulted in an injury than did commercial school trained drivers (28 versus 6 percent). The proportion of all parent-taught drivers' crashes that were reported to have involved an injury (11\%), did not differ significantly from either of the other DE types. 
The analysis of Texas driver records provided more compelling evidence regarding crash involvement. Significant differences in the crash experience of parent-taught drivers and drivers who completed the traditional modes of novice driver education and training are apparent.

Over the first year of driving experience, parent-taught drivers not subject to GDL, ${ }^{31}$ experienced more crashes per 10,000 drivers and were more likely to have been in a crash than their counterparts who completed a commercial or public school DE course. The disparity between PT and Com/Pub drivers was progressively larger as crash severity increased. In the first year of driving experience, PT drivers not subject to GDL were about twice as likely to have been involved in fatal crashes relative to Com/Pub drivers.

In the third six-month period of driving experience, significant differences related to DE type in both the frequency of crashes and the likelihood of crash involvement became smaller or, as in the case of fatal crashes, no longer differed significantly. Nonetheless, PT drivers still exhibited a 15 percent greater likelihood of experiencing incapacitating injury crashes and a 6 percent greater likelihood of having non-incapacitating crashes than did Com/Pub-trained drivers. In the least severe of crashes in which at least one injury was sustained (possible injury crashes), $\mathrm{Com} / \mathrm{Pub}$ drivers were involved almost 8 percent more often than PT drivers were during this period.

With two exceptions, significant differences in crash involvement as a function of DE type disappeared in the fourth through sixth six-month periods (two plus years after licensure) after a driver record was established. Throughout these periods, Com/Pub drivers continued to experience significantly more possible injury crashes than PT young drivers; 15-19 percent more, depending on period. More importantly, the likelihood of involvement in fatal crashes during the first six months of drivers' third year of experience was substantially greater for PT than for Com/Pub drivers. In the $25^{\text {th }}$ through $30^{\text {th }}$ month period after receiving an instruction permit, former PTDE students exhibited a nearly 70 percent greater likelihood of being in a fatal crash.

Since January 2002, all new drivers less than 18 years old have been subject to the Texas GDL Program. Though considerably different from pre-GDL experience, differences in crash involvement as a function of type of driver education remain among novices who are, or until recently were, subject to the GDL provisions.

During the first six months of driving experience following establishment of a Texas driver record, parent-taught novice drivers experienced significantly fewer total crashes and the likelihood of a PT driver being involved in a crash was significantly less than commercial or public-school-taught novice drivers. For all crashes, without regard to severity, Com/Pub-trained drivers had 32 percent more crash involvement than PT drivers. This large difference, however, is seen only in the incidence of possible injury crashes. More serious crashes, including nonincapacitating and incapacitating injury crashes and crashes in which at least one person was killed, do not differ significantly. Recall that the first six months of driving experience approximates the time coincident with novices holding a GDL Phase 1 instructional permit.

\footnotetext{
${ }^{31}$ All novice drivers who obtained an instructional permit before January 1, 2002.
} 
Crash involvement as a function of type of DE changes dramatically during the second sixmonth period of experience, roughly equivalent to the GDL Phase 2 period when novices can legally drive independently but are subject to restrictions. PT novices are about 12 percent more likely to be involved in crashes of any severity level than are Com/Pub-taught drivers. More importantly, the differences between PT and Com/Pub, while not significant for fatal crash involvement, otherwise increase as crash severity increases. Post-GDL parent-taught drivers are 25 percent more likely to be involved in non-incapacitating injury crashes and 57 percent more likely to be involved in an incapacitating injury crashes than are their commercial or public school peers.

By the third six-month period of driving experience, approximately coincident with restrictionfree full licensure, only two significant differences in crash experience related to DE type remain. First, Com/Pub drivers are about 14 percent more likely to be involved in a possible injury crash than are PT drivers. Second, and much more striking, the relative likelihood of PT drivers being involved in a fatal crash is 2.83 , that is, a PT driver is considerably more than twice as likely - approaching three times -- to be in a fatal crash.

\subsection{Recommendations for Texas Driver Education}

Since its inception, the parent-taught driver education program has proven to be a very popular alternative to TEA-approved and licensed novice driver education and training among parents of teenagers and young prospective licensees who wish to be licensed before age 18. Its popularity can be attributed to a combination of factors including cost, perceived advantages in terms of the convenience, ease and reduced stress of getting a driver license, and, in some areas of the State, the limited availability of public and/or commercial driving school options.

Undoubtedly, many parents who serve as their teens' sole driving instructor under the program are highly motivated to do well and succeed in producing novice drivers who are at least as prepared to drive as many teens who take a traditional driver education course and who have a novice driving record at least the equal of graduates of commercial or public school DE courses. Many other parents are highly motivated to be their child's primary driving instructor, have the best interests of their children at heart, but simply are not equipped with the requisite aptitudes, attitudes and experience to do so successfully. Still other parents who opt to participate in the program are neither appropriately equipped nor motivated.

Although there is most certainly a large range of motivations and aptitudes among driver education instructors in TEA approved/certified DE program, State recognition of these instructors is predicated on a combination of at least minimal initial and continuing education, training, and experience requirements and State-imposed oversight. Currently, Texas grants identical status to driver education and training provided by parents as that provided by Stateregulated driver education programs and instructors. Given the differences, especially in crash experience, among novice drivers completing parent-taught and commercial or public school driver education courses in the present evaluation, modifications in the parent-taught program appear warranted if Texas is to continue the parent-taught program essentially in its current form. 
It would be unreasonable as well as economically, administratively and logistically impractical to require parents to meet standards of education, training and experience identical to those for licensed, certified driving instructors. Nonetheless, more rigorous requirements than currently imposed on parents and on the DPS however, may be feasible. Four general recommendations to this end are offered below.

\section{Recommendation 1}

Improve the criteria for parental participation in the parent-taught driver education program.

Currently, the only criteria a parent, stepparent, grandparent, step-grandparent, foster parent, or legal guardian needs to meet in order to teach in the program include:

- $\quad$ Possession of a valid Texas driver license for the preceding three years;

- No convictions (including probated sentences) for criminally negligent homicide or driving while intoxicated;

- No license suspensions, revocations, or forfeitures in the past three years for traffic-related violations; and

- No disability due to mental illness.

A more demanding parental driver record may be appropriate with regard to traffic convictions and crash involvement in order to qualify for the parent-teacher position. As a minimum, consideration should be given to disqualifying parents from participating in the PTDE program if sufficient points have been assessed and recorded on their driving record under the Texas Driver Responsibility Program ${ }^{32}$ to subject them to driver license surcharges. Under the Driver Responsibility Program, implemented in September 2003, surcharges are assessed on the license of a person who has accumulated six or more points during the preceding 36-month period. Two points are assigned for a moving violation and three points are assigned for a moving violation that resulted in an accident.

\section{Recommendation 2 \\ Require at least some minimum training and/or testing for parents who want to teach their children to drive under the program.}

The addition of a qualifying examination and/or a short training program developed specifically for the parent-taught program could help assure at least a minimum degree of mastery of the necessary subject matter for teaching teens to drive. Even a requirement for the parent-teacher to pass the current instructional permit test and successfully complete an approved defensive driving course could motivate parents to upgrade their knowledge of current laws, increase their awareness of traffic issues and raise their level of consciousness with regard to driving safety.

\section{Recommendation 3}

Improve DPS monitoring of and accountability for the activities of the PT program.

Currently, parents are required to complete a Parental Driver Education Affidavit (DL-90A) and may be required to present a Classroom Instruction Record (DL-91A) and a Behind the Wheel Record Log (DL-91B). While it is not obvious how improvements might be implemented, it is

\footnotetext{
${ }^{32}$ Article 10, Subtitle I, Title 7, Chapter 708, Texas Transportation Code.
} 
apparent that the current procedures for assuring that parents are in fact meeting their responsibilities under the parent-taught program are not sufficient.

\section{Recommendation 4 Reinstitute a requirement for an on-road driving assessment before granting a provisional and/or unrestricted license to novices under 18.}

Over the past several Texas legislative sessions, various bills have been introduced that would reinstitute the requirement for a road test for drivers licensed before they are 18 years old. Some would have required a road test only for young license applicants who completed a parent-taught driver education course, while others required all applicants to pass a road test without regard to the type of driver education completed. To date, all such bills have failed. While requiring all applicants to pass a road test has the obvious advantage of appearing to be more equitable, there is a rational counterargument to the proposition that requiring only parent-taught students to take a road test would be discriminatory. The original purpose of a road test as a prerequisite to licensure was to provide "a demonstration of the applicant's ability to exercise ordinary and reasonable control in the operation of a motor vehicle of the type that the applicant will be licensed to operate." 33 Driving instructors certified or licensed by the State by virtue of their education, training and experience clearly can be characterized as acting as agents of the State when they certify that their students have demonstrated the ability to exercise ordinary and reasonable control in the operation of a motor vehicle. It is reasonable to posit that among the knowledge and skills obtained through their training is the ability to determine an applicant's ability to control of a motor vehicle to a degree acceptable for licensing. Delegating this responsibility to parents without any training or other demonstration that they are capable of making that determination is neither reasonable nor prudent.

Neither the conclusions indicating a negative impact of the parent-taught program on young driver crash involvement nor the recommendations above diminish the desirability, indeed critical importance, of extensive and intensive parental involvement in the learning process for young novice drivers, especially in providing structured, supervised driving practice. The conclusions and recommendations here are directed specifically to the condition under which parents often become the only source of novice driver education and training.

\footnotetext{
${ }^{33}$ Chapter 521, Section 161 of the Texas Transportation Code
} 
This page intentionally left blank. 


\subsection{REFERENCES}

Griffin, L. I., and DeLaZerda, S. (June 2000) Unlicensed to kill. Report prepared for AAA Foundation for Traffic Safety, Washington, DC.

Lonero, L.P., Clinton, K.M., Persaud, B.N., Chipman, M.L., and Smiley, A.M.. (2005) A longitudinal analysis of Manitoba Public Insurance Driver Education Program. Winnipeg, Manitoba: Manitoba Public Insurance.

Malfetti, J. L., Rose, P. R., Dekorp, N. A., and Basch, C. E. (1989) Young Driver Attitude Scale: The development \& field testing of an instrument to measure young driver risk-taking attitudes and some exploratory interventions. New York: Safety Research \& Education Project - Teachers College Columbia University.

Masten, S. V., and Chapman, E. A. (2003, April). The effectiveness of home-study driver education compared to classroom instruction: The impact on student knowledge, skills, and attitudes. Report Number: CAL-DMV-RSS-03-203. Report to the Legislature of the State of California. Sacramento CA: California Department of Motor Vehicles

Mayhew, D. R., and Simpson, H. M. (1996). Effectiveness and role of driver education and training in a graduated licensing system. Prepared by the Traffic Injury Research Foundation, Ottawa, Canada K2P-0B4. Available on-line: http://www.drivers.com/article/305/. See also: Mayhew, Daniel R., Simpson, Herbert M., Williams, Allan F., and Ferguson, Susan A. (1998). Effectiveness and role of driver education and training in a graduated licensing system. Journal of Public Health Policy 19, 51-67.

McKnight, A. J. (1985). Driver education - when? In: Young driver accidents: In search of solutions, Proceedings of an International Symposium, D.R. Mayhew, H.M. Simpson, and A.C. Donelson (Eds.), 109-115. Ottawa, Ontario: Traffic Injury Research Foundation of Canada. Cited in Mayhew \& Simpson, 1996.

Oregon Traffic Safety Education Association (2002, October). Oregon driver education parent involvement resource guide: A guide for implementing a parent involvement program. Developed in cooperation with ODOT Transportation Safety Division Driver Education Program. Available on-line: http://www.oregon.gov/ODOT/TS/docs/DE/Oregon_DE_Parent_Inv_Res_Guide.pdf.

Parker, D., Reason, J.T., Manstead, A.S.R., and Stradling, S. (1995) Driving errors, driving violations and accident involvement. Ergonomics. 38, 1036-1048.

Robertson, L.S. (1980). Crash involvement of teenaged drivers when driver education is eliminated from high school. American Journal of Public Health 70(6): 599-603. Cited in Mayhew and Simpson, 1996.

Sahai, H., and Khurshi, A. (1996). Statistics in epidemiology: Methods, techniques, and applications. Boca Raton, FL: CRC Press. 
Smith, M. F. (1994, May). Research agenda for an improved novice driver education program. DOT-HS-808-161 National Highway Traffic Safety Administration, Washington, D.C.

Stock, J.R., Weaver, J.K., Ray, H.W., Brink, J.R., and Sadoff, M.G. (1983). Evaluation of Safe Performance Secondary School Driver Education Curriculum Demonstration Project. Report No. DOT HS 806 568. National Highway Traffic Safety Administration, Washington, DC.

Texas Administrative Code, Title 19 Education Part 2, Texas Education Agency, Chapter 176 Driver Training Schools. Available online at http://info.sos.state.tx.us/pls/pub/readtac\$ext.ViewTAC?tac view=4\&ti=19\&pt=2\&ch=176.

Texas Education Agency. (2006) Texas driver education certificates, Gross sales. Available online at http://www.tdtsea.com/Certificates.pdf.

Texas Statutes, Transportation Code, Title 7, Vehicles and Traffic, Chapter 521, Driver's Licenses and Certificates. Available online at http://www.capitol.state.tx.us/statutes/tn.toc.htm. 


\subsection{APPENDICES}

Appendix A: Guidance Provided by the Texas Department of Public Safety to Participants in the Parent-Taught Driver Education Program

Appendix B: Texas Education Agency Guidance for Model Course 101

Appendix C: Focus Group Discussion Guides

Appendix D: Mail Survey Forms 
This page intentionally left blank. 


\section{APPENDIX A \\ Guidance Provided by the Texas Department of Public Safety to Participants in the Parent- Taught Driver Education Program}

The text reproduced in this appendix is available at:

http://www.txdps.state.tx.us/administration/driver licensing control/parenttaught.htm

The text provided here was downloaded from the DPS Web site on March 24, 2006. It constitutes the initial Web page on the DPS and includes links to additional DPS-provided information and guidance regarding the parent-taught program. Any changes since March 24, 2006, can be accessed at the DPS site. 
This page intentionally left blank. 


\section{Parent Taught Driver Education \\ PLEASE READ THE FOLLOWING INFORMATION CAREFULLY BEFORE BEGINNING THE PROGRAM}

Texas implemented a Parent Taught Driver Education Program on April 1, 1997. The Parent Taught Driver Education Program requires students to acquire the essential knowledge, skills and experience to perform reduced-risk practices in the total traffic environment. To achieve this goal, students are required to master the following elements: applicable Texas traffic laws, rules and procedures for operating and owning an automobile; benefits of occupant protections, use of a space management systems; factors and behaviors that effect driver performance including alcohol and other drugs; and protection of Texas natural resources, including litter prevention.

The Parent Taught Driver Education Program is available to teenagers between the ages of 14 and 17. However, before the instructor (parent, stepparent, grandparent, step-grandparent, foster parent or legal guardian) begins teaching this course, the instructor must have a valid TEXAS driver license for the preceding three years. Active US military personnel and their spouse may participate as instructors if they hold a valid license from their State of permanent residence or last duty station for the preceding three years.

The instructor cannot have a conviction (including a probated sentence) of criminally negligent homicide or driving while intoxicated. The instructor's license may not be suspended, revoked, or forfeited in the past three years for traffic-related violations. Furthermore, the instructor may not be disabled due to mental illness. Questions as to mental stability will be forwarded to the Medical Advisory Board for determination.

It is the responsibility of the instructor to check both their criminal and driver records prior to requesting the packet. The Department will not check the instructor's record until issuance of the instruction permit or provisional driver license to the student. If at that time it is determined that the instructor has a prohibited conviction the instruction permit or provisional driver license will be denied and all prior classroom or behind the wheel/in car instruction credit is invalid.

In order to apply for a Parent Taught Driver Education Program, you must complete the DL-92 - Request Form and submit with a $\$ 20.00$ non-refundable fee (check or money order only) to: Texas Department of Public Safety, License Issuance Bureau, P.O. Box 149246, Austin, Texas 78714-9246. An additional Request Form and $\$ 20.00$ non-refundable fee are required for each student who will be participating in the Parent Taught Driver Education Program. Please allow 2 - 3 weeks for delivery.

The Request Form must be completely filled out with original signatures or the process will be delayed.

Upon receipt of your Request Form, a DE-964 Certificate will be assigned to the student and forwarded to the designated Driver License Office where the student will apply for the license and take the required tests. The DE-964 Certificate will be maintained and 
available at the designated Driver License office for the instructor to complete. The Parent Taught Driver Education packet will be mailed to the instructor's address.

\section{THE STATE ADOPTED TEXTBOOKS ARE NO LONGER REQUIRED}

\section{Frequently Asked Questions (FAQ'S)}

What is the difference between the Classroom methods, block and concurrent? The entire program consists of a minimum of 32 hours classroom instruction; 7 hours behind-the-wheel instruction and 7 hours in-car practice. The options for teaching all or portions of the program are detailed below:

Block Method:

The student completes all 32 hours of classroom instruction of the program as prescribed in Course 101 or as prescribed under one of the other Texas Department of Public Safety approved PTDE programs (Course 102, 103, 104, 105, 106, 107 or 108). The student is then eligible to test for a Texas Instruction Permit. Prior to advancing to the 14 hours of behind-the-wheel and in-car practice, the student must be at least 15 years of age and meet all other eligibility requirements to obtain a Texas Instruction Permit.

If a student selects the block method but wishes to transfer to or from the Parent Taught Program or a TEA approved driver training school, all 32 hours of classroom instruction must be completed prior to transferring to a TEA approved driver training school. No hours of instruction (classroom or behind -the- wheel) may be transferred between the Parent Taught Program and a TEA approved driver training school.

Concurrent Method: The student is required to complete a minimum of 6 hours of the classroom instructions, contained in Module One, "Texas Driver Responsibilities Knowing Texas Traffic Laws" as prescribed in Course 101 or as prescribed under one of the other Texas Department of Public Safety approved PTDE programs (Course 102, $103,104,105,106,107$ or 108). After completion of this portion of classroom instruction, the student must apply for a Texas Instruction Permit from the Texas Department of Public Safety provided the student is at least 15 years of age and meets all other eligibility requirements.

After completion of this portion of the classroom instruction, the remaining 26 hours of classroom instruction are completed simultaneously with the behind-the-wheel and incar practice.

If a student selects the concurrent method but wishes to transfer to or from the Parent Taught Program or a TEA approved driver training school, all 32 hours of classroom instruction must be completed prior to transferring to a TEA approved driver training school. No hours of instruction (classroom or behind-the-wheel) may be 


\section{transferred between the Parent Taught Program and a TEA approved driver training school.}

If an instructor elects to utilize the Concurrent Driver Education Program and the student is issued an instruction permit after completing the first six (6) hours of classroom instruction but then fails to complete the remainder of the 32 hours of classroom instruction, the instructor MUST notify the Department of Public Safety that the student has failed to complete the Concurrent Driver Education Program by submitting the Parent Taught Driver Education Cancellation Form (DL-93). Upon receipt of this form, the Department will cancel the Texas Instruction Permit that was issued to the student who failed to complete the CONCURRENT driver education program. The fees previously paid (both for the PTDE packet and the Texas Instruction Permit) will be forfeited. After cancellation, ALL previous driver education training hours (classroom instruction, behind-the-wheel instruction, and in-car instruction) are forfeited and must be repeated. After cancellation, the applicant will have to make a new application and pass all required exams again to obtain another Texas Instruction Permit or Texas Driver License.

\section{Why are there different course numbers? (Course 101, 102, 103, 104, 105, 106, 107 and 108)?}

Model Program Course - 101 The Model Program Course is the State approved curriculum for driver education programs in public and licensed schools developed by the Texas Education Agency (TEA). This program replaces the State-adopted driver education textbook, which is no longer required. The Model Program Course package entitled the Texas Driver and Traffic Safety Education Master Curriculum Guide, includes 10 modules with over 1,600 pages of sample classroom and behind the wheel lesson plans, support materials, worksheets, exams, instructor activities, fact sheets, student worksheets, transparency masters, in-car lessons, resources, evaluations, and parent involvement support. The Model Program Course is available FREE for use by schools, teachers, and parent taught instructors ONLINE or can be ordered in print or on a CD-ROM for a fee from the Texas Education Agency. For instructions on using or ordering the Model Program Course for Parent Taught Driver Education (course 101) open the internet and go to http://www.tea.state.tx.us/safedriver/parent101.html or contact TEA at 512/463-9322. If an instructor chooses to utilize this course they are responsible for developing the curriculum and lesson plan. This would include obtaining course materials. http://www.txdps.state.tx.us/ftp/forms/Curriculum2.pdf

Program Course - 102 is offered by National Driver Training Institute and has been approved by the Department. In order to instruct from this course, an application for the Texas Parent Taught Driver Education Program is required. Course - 102 has received approval from the Department for the use of an interactive CD ROM or their textbook "Help for the Teenager Who Wants to Drive." In addition, you must contact the National Driver Training Institute at 1-800-942-2050. There may be additional costs associated with this program. For additional information about this program go to http://www.GraduatedDriverLicensing.com 
Program Course - 103 is offered by Driver Ed in a Box $®$ and has been approved by the Department. In order to instruct from this course, an application for the Texas Parent Taught Driver Education Program is required. Course - 103 has received approval from the Department for the use of an interactive CD ROM or their textbook "Driver Ed in a Box, The Textbook." In addition, you must contact Driver Education Supplies and Training at 1-800-562-6405. There may be additional costs associated with this program. For additional information about this program go to http://www.driveredinabox.com

Program Course - 104 is offered by Curb Buster and has been approved by the Department. In order to instruct from this course, an application for the Texas Parent Taught Driver Education Program is required. Course - 104 has received approval from the Department for the use of an interactive CD ROM or their textbook "Drive Right." In addition, you must contact Curb Busters at 1-866-526-9484. There may be additional costs associated with this program. For additional information about this program go to http://curbbuster.com

Program Course - 105 is offered by Driver Ed at Home and has been approved by the Department. In order to instruct from this course, an application for the Texas Parent Taught Driver Education Program is required. Course - 105 has received approval from the Department for the use of their textbook "Responsible Driving." In addition, you must contact Driver Ed at Home at 1-713-227-4409. There may be additional costs associated with this program. For additional information about this program go to http://www.driverslicensetraining.com

Program Course - 106 is offered by Texas Driver and Traffic Safety Education Association and has been approved by the Department. In order to instruct from this course, an application for the Texas Parent Taught Driver Education Program is required. Course - 106 has received approval from the Department for the use of their textbook "Texas Traffic Safety Education Student Manual." In addition, you must contact Texas Driver and Traffic Safety Education Association at 1-936-435-8324. There may be additional costs associated with this program. For additional information about this program send an email to tgilbert@esc6.net

Program Course - 107 is offered by Virtual Drive of Texas and has been approved by the Department. In order to instruct from this course, an application for the Texas Parent Taught Driver Education Program is required. Course - 107 has received approval from the Department for the use of computer based training version provided on CD ROM "Virtual Drive of Texas." In addition, you must contact Virtual Drive of Texas at 1-806570-6423. There may be additional costs associated with this program. For additional information about this program go to http://www.virtualdriveoftexas.com

Program Course - 108 is offered by DriversEd.com and has been approved by the Department. In order to instruct from this course, an application for the Texas Parent Taught Driver Education Program is required. Course - 108 has received approval from the Department for the use of an online computer based training version, 
"DriversEd.com." In addition, you must contact DriversEd.com at 1-888-651-2886. There may be additional costs associated with this program. For additional information about this program go to http://www.driversed.com

If using the Parent Taught Driver Education Program, can I receive a discount from my automobile insurance company? Depending upon the insurance company, this program may or may not qualify for a discount for automobile insurance purposes as determined by the Texas Department of Insurance. Please consult with your insurance carrier concerning this matter.

Can I use film and or videos during my classroom instruction period? Yes, however, no more than 10 hours of video can be counted toward the 32 hours of classroom instruction.

How are the Classroom and Behind-the-Wheel Instruction Log Records utilized? Classroom and Behind-the-Wheel Instruction Log Records are for the instructor's use only. You will enter the date of completion after the required hours for each specified unit title and driving time. These record logs are for instructor use. You may be required to present this form as proof you have completed all objectives outlined in the Parent Taught Education Program.

Forms to take to the Driver License Office upon completion of the required classroom hours and to obtain an Instruction Permit:

1. Application for Texas Driver License, DL-14A

2. Parental Driver Education Affidavit, DL-90A

3. Classroom Instruction Record, DL-91A (You may be required to present this form as proof you have completed all objectives outlined in the Parent Taught Education Program)

4. Pay the required fee for Instruction Permit Issuance

5. Proof of Liability Insurance (If you own the vehicle)

6. Proof of identity

7. Proof of Social Security Number

8. Verification of Enrollment and Attendance Form in school

In order to obtain an unrestricted driver license, the following documents must be presented upon returning to the Driver License Office.

1. Valid Instruction Permit (minimum age 16 and held a VALID Instruction Permit for a 6 month period)

2. Verification of Enrollment and Attendance Form in school

3. Parental Driver Education Affidavit, DL-90B

4. Classroom Instruction and Behind the Wheel Record Log, DL-91A and DL-91B

(You may be required to present this form as proof you have completed all objectives outlined in the Parent Taught Education Program)

5. Pay the required fee for Provisional Driver License. 


\section{ADDITIONAL INFORMATION:}

- A legal guardian is defined as a guardian who has been legally appointed by a court of competent jurisdiction (Power of Attorney is not legally sufficient).

- Driving While Intoxicated (DWI) or Criminal Negligent Homicide convictions (including a probated sentence) are a permanent entry on the driver record. DWI's are indefinite and therefore, makes the instructor ineligible to teach the student the Parent Taught Driver Education Program.

- The instructor must be present for the issuance of the Texas Instruction Permit or the issuance of the Class $C$ Driver License. If there is more than one instructor teaching this course, the Classroom Instruction-Driver Education Affidavit or the Behind the Wheel-Driver Education Affidavits (DL-90A or DL-90B) are required for each instructor. At least one of the instructors must accompany the student when applying for the Texas Instruction Permit or Class C Driver License; the affidavit for the absent instructor will need to be notarized before coming to the Driver License Office.

- No classroom instruction is permitted prior to receipt of the Parent Taught Driver Education packet. Any instruction prior to that time will not be accepted toward the required instruction time.

- No behind-the-wheel instruction or in-car practice may be permitted until the child has been issued a Texas Instruction Permit. Driving without a license or permit on a public street or highway is a violation of State law. Any behind-the wheel instruction prior to issuance of the Instruction Permit will not be accepted toward the required instruction or practice time.

- The course must be completed prior to the student's eighteenth (18th) birthday to receive credit under this program.

- The student must take a written and vision examination prior to receiving the Texas Driver License Instruction permit. However, the skills (driving) test will be waived for teenagers who complete both classroom and behind-the-wheel portions of a Texas driver education course. The instructor participating in the Parent Taught Driver Education Program has the option to waive the skills (driving) test or require the student to pass the skills (driving) test administered by DPS prior to issuing a Class $\mathrm{C}$ driver license. 


\title{
APPENDIX B
}

\section{Guidance Provided by the Texas Education Agency to Parents Participating in the Parent- Taught Driver Education Program Who Are Using Course 101}

\author{
How to Teach Parent-Taught Course 101
}

The document reproduced in this Appendix is available at:

$$
\text { http://www.tea.state.tx.us/safedriver/parent101.html }
$$

The version provided here was downloaded from the TEA Web site on March 24, 2006. It includes links to Texas Education Agency and Department of Public Safety Web pages, many of which, in turn, provide links to other Web pages and to PowerPoint and PDF files relevant to the teaching of Course 101 and to other novice driver education, training and licensing information. All links in the document contained herein were unbroken and active as of March 24, 2006. 
This page intentionally left blank. 


\section{How to Teach Parent Taught Course 101}

Course 101 is divided into 10 Modules. Each Module contains many lessons. Do not get overwhelmed by the length of a Module. Each lesson is only two pages in length and most lessons take a short to medium time to teach depending on the subject being taught.

STEP ONE: Open Supplement and Worksheet File. The Parent Instructor begins by opening the Module 1-Supplement \& Worksheet file.

\section{$\underline{\text { CLICK HERE to view and open the Supplement and Worksheet File }}$}

\section{CLICK HERE if you are having trouble opening the CDrom or the online modules}

NOTE: To view and print the Modules you will need to have the latest version of Adobe Acrobat. You may obtain a free copy of Adobe Acrobat at http://www.adobe.com.

STEP TWO: Print Supplement \& Worksheet File. Parent Instructor prints the Supplement \& Worksheet File for Module One and arranges the printed materials beside them on the computer table next to the computer. Close the Supplement \& Worksheet File after printing is complete.

The supplement and worksheet file contains all the documents that the student will read or work on while being taught Module One. Note that there are 3 different types of materials in the Supplement \& Worksheet File-Fact Sheets, Worksheets, and Evaluation and Assessment Sheets.

STEP THREE: Open Transparency File. The Parent Instructor begins by opening the Module 1-Transparency File. You must have the PowerPoint program to open this file. If you do not have PowerPoint you can use the picture of the Transparency that is printed in the curriculum file to obtain the transparency information. Skip this step and Step 4 if you do not have PowerPoint.

\section{$\underline{\text { CLICK HERE to View and Open Transparencies. }}$}

STEP FOUR: Print Transparency File. Parent Instructor prints the Transparency File for Module One and arranges the printed materials beside them on the computer table next to the computer. Close the Transparency File after printing is complete. Skip this step if you do not have PowerPoint.

STEP FIVE: Open Curriculum File. The Parent Instructor opens the Module OneCurriculum file.

\section{CLICK HERE to View and Open Modules.}


STEP SIX: Save the Curriculum File. Parent Instructors who open the file from a webpage are encouraged to save the Curriculum file to their computer hard drive or burn it to a CD. If you are using a CD of Course 101, skip this step.

(There is no requirement to print the Curriculum File. The Parent instructor can read the entire course from the computer screen. However, the curriculum can be printed if the Parent Instructor prefers to work from printed materials or can be ordered on a CD or in print by submitting an order form with the required fees).

\section{CLICK HERE to open the Course 101 Order Form.}

STEP SEVEN: Prepare Parent Instructor Teaching Notes for Module. The Parent Instructor reads everything related to the lesson and writes notes to themselves on what they will say and do with their student to teach the information.

\section{Each Lesson includes the following:}

- KNOWLEDGE AND SKILLS: The lessons on the even numbered pages begin with a box. Inside the box are the student Knowledge and Skills. The Parent Instructor scrolls past the introduction pages to the first Knowledge and Skills box (Page 4, Module 1). The Knowledge and Skills tell the Parent Instructor what the student is supposed to know when they finish that page of instruction. The Parent Instructor must repeat the lesson until the student has mastered (learned) each the Knowledge and Skills for that lesson.

- TOPIC ACTIVITIES: The Topic Activities tell the Parent Instructor what to do or say to the student.

- LESSON PLANS: The even numbered pages are the lesson plans which contain the directions and information for the Parent instructor. It is where the Parent Instructor obtains information about the lesson before teaching the lesson to the student.

- TOPIC RESOURCES: The even numbered pages include a small picture or icon of the resource that goes with that particular lesson. Some of the resources listed such as videos and Textbooks are not required for the parent taught course.

- LESSON CONTENT: The odd numbered pages provide the ParentInstructor with additional information, content, and facts to help them teach the lesson.

STEP EIGHT: Prepare a Course 101 teaching Log on a sheet of paper or on the computer. The log is maintained by the instructor in addition to the forms required by DPS [Classroom Instruction-Driver Education Affidavit (DL-90A) and the Behind the Wheel Instruction-Driver Education Affidavit (DL-90B)]. DPS may not ask to see the teaching logs but they are important to the Parent Teacher because they 1) organize 
instruction, 2) provide information necessary to complete the required DPS forms, and 3) document instruction.

\section{CLASSROOM LOG (Modules 1-10)}

Column One: TOPIC/LESSON. Write the topic/lesson exactly as it is stated in the box on the odd number pages. A box may have 1 to 6 different topics.

Column Two: DATE. Post the date (or dates) the lesson was taught.

Column Three: LENGTH OF LESSON. State how many minutes the teacher spent teaching the topic/lesson.

Column Four: GRADES AND NOTES. Record grades student made on tests, worksheets, homework, reports, lessons, etc. and record notes on instructional activities.

Column Five: STUDENT SIGNATURE. Record Student Signature to verify instruction.

Column Six: INSTRUCTOR SIGNATURE. Record Instructor Signature to verify instruction.

\section{IN-CAR LOG (Modules 2-10)}

Column One: TOPIC/LESSON. Write the topic/lesson

Column Two: DATE. Post the date (or dates) the lesson was taught.

Column Three: LENGTH OF LESSON. State how many minutes the teacher spent teaching the topic/lesson. The lessons can be broken into any amount of time as long as the total meets the minimum requirements for the lesson.

Column Four: GRADES AND NOTES. Record grades student made on lessons, etc. and notes.

Column Five: STUDENT SIGNATURE. Record Student Signature to verify instruction.

Column Six: INSTRUCTOR SIGNATURE. Record Instructor Signature to verify instruction.

STEP NINE: Teach the lesson to the student. Use the instructor teaching notes, supplemental materials, and the transparencies to teach the lesson.

Keep teaching notes and all student work and tests in a three ring notebook or binder to prove to DPS that you used Course 101 to prepare and teach the Parent Taught Course. 
STEP TEN: Go to local DPS Driver License Station to obtain student's instruction permit.

\section{CLICK HERE to view Phase One licensing requirements for teen drivers.}

STEP ELEVEN: Repeat steps One through Nine until every lesson in Module $2-10$ is taught and recorded on the Teaching Log.

Module $2-10$ includes both classroom and In Car lessons. The In-car lesson is taught after finishing each Module 2- 10 classroom lesson. The State requires Parent instructors to complete 14 hours in In-Car lessons with a student driver. However, to ensure that a novice student driver has experience before they are allowed to drive alone, the National Highway Traffic Safety Administration recommends that Parent Instructors provide their child with a minimum of 50 supervised hours of in car instruction before licensing.

CLICK HERE to view Phase Two licensing requirements for teen drivers.

STEP TWELVE: When the student meets Phase Two Licensing requirements for teen drivers, go back to the local DPS Driver License Station to obtain Driver License. 


\section{APPENDIX C \\ Focus Group Discussion Guides}

1. Driver Education Instructors (Commercial \& Public Schools)

2. Parents Participating in Texas Parent-Taught Driver Education Program

3. Parents of Driver Education Students in Public and Commercial Driver Education Programs

4. Driver Education Students 
This page intentionally left blank. 


\section{DISCUSSION GUIDE 1}

\section{Focus Groups on Novice Driver Education Driver Education Instructors (Commercial \& Public Schools)}

I. INTRODUCTION-- 15 minutes

A. Welcome and opening comments

- "Thank you for being here. We have an important and, we hope, enjoyable task to undertake during the next $1 \frac{1}{2}$ hours or so."

B. Purpose of the focus group

- "We're here today to talk about novice drivers and driver education as delivered in Texas, specifically Drivers' Ed as delivered through the public schools, commercial driving schools, and the Texas Parent-Taught Program. We are working under contract with the National Highway Traffic Safety Administration who is interested in the views from various groups involved in teaching our kids to drive."

C. Guidelines/Rules for the group

- "Before we get into the discussion, I want to briefly mention a few logistics and guidelines for our discussion."

- Stress informal, comfortable, atmosphere for discussion, e.g., free to take a rest room break, availability of refreshments.

- Key is active participation. Be open and candid. No right or wrong or unimportant responses.

- Confidentiality - only use first names. Describe audio recording system for data reduction.

- One person talk at a time talk. Speak loudly.

D. Participant and moderator introductions

- Round table - First name, county or city where teach driver ed.

- During introductions, participants will be asked to give their teaching experience (number of years, other subjects taught, etc.) and describe their school.

- Warm-up discussion designed to allow an opportunity for each member of the group to feel comfortable talking in the group setting. For instance, participants may be asked to describe a most memorable moment in their DE teaching experience.

\section{GENERAL DISCUSSION OF NOVICE DRIVERS AND TEACHING DRIVER EDUCATION-- 20 minutes}

A. What are the primary problems encountered by novice drivers.

B. Does/can DE effectively address these problems?

C. What do you think the goal of DE should be? 
D. What do you think most people (not DE instructors) think the goal of DE is?

E. How well is each of these goals being met as a result of your DE program?

F. Do you believe the goals are met by other means of providing DE (i.e., public/commercial or parent-taught)?

G. Has the Texas Graduated Drivers License System affected the goals of DE? How?

III. THE DRIVER EDUCATION CURRICULUM AND TEACHING EXPERIENCE--15 minutes

A. What are the most important things that should be taught in DE?

B. What DE curriculum/methods do you use? What are its strengths?

C. What are the weaknesses of the curriculum/methods you use?

D. What are your strengths and weaknesses as a DE instructor?

IV. EXPECTATIONS -- 10 minutes

A. How do you think your students fare in the driving environment as licensed drivers after taking your DE course?

B. Do you have confidence in your students' abilities to drive upon completion of the course?

C. Are they ready to drive independently?

D. Do you have any advice for parents of beginning drivers?

V. COMPARISONS AND CONTRASTS AMONG THE MODES OF DRIVER EDUCATION -- 25 minutes

A. What do you believe are the primary differences between public and commercial driving school programs? Overall, do either produce better novice drivers?

B. Has the Graduated Drivers License System changed the content or methods you use in teaching novices?

C. What role do you think parents should play when their teenagers learn to drive?

D. How are parents involved in your work with students?

E. What do you think of the Parent taught DE Program?

F. Has the Parent-Taught Program influenced your teaching in any way? Changes in number or demographics of your students?

G. Do you have any experience with parent-taught students coming to you for part of their training?

H. Do you have any advice for parents serving as their teenagers' DE instructor?

VI. CLOSING REMARKS -- 5 minutes 


\section{DISCUSSION GUIDE 2}

\section{Focus Groups on Novice Driver Education Parents Participating in Texas Parent-Taught Driver Ed Program}

I. INTRODUCTION-- 15 minutes

A. Welcome and opening comments

- "Thank you for being here. We have an important and, we hope, enjoyable task to undertake during the next $1 \frac{1}{2}$ hours or so."

B. Purpose of the focus group

- "We're here today to talk about young novice drivers and driver education as delivered in Texas, specifically Drivers' Ed as delivered through the public schools, commercial driving schools, and the Texas Parent-Taught Program. We are working under contract with the National Highway Traffic Safety Administration who is interested in the views from various groups involved in teaching our kids to drive."

C. Guidelines/Rules for the group

- "Before we get into the discussion, I want to briefly mention a few logistics and guidelines for our discussion."

- Stress informal, comfortable, atmosphere for discussion, e.g., free to take a rest room break, availability of refreshments.

- Key is active participation. Be open and candid. No right or wrong or unimportant responses.

- Confidentiality - only use first names. Describe audio recording system for data reduction.

- One person talk at a time talk. Speak loudly.

D. Participant and moderator introductions

- Round table - First name, how long been driving, age and gender of teens now or recently taking some form of DE, County or city where teens taking DE, child's current license status (e.g., permit, provisional license, full license)

II. DRIVING SAFETY ATTITUDE EXERCISE-- 5 minutes

(see attached Questionnaire - to be completed by participants)

\section{GENERAL DISCUSSION OF NOVICE DRIVERS AND TEACHING DRIVER EDUCATION-- 25 minutes}

A. What do you think are the primary problems/issues teens face as new drivers?

B. What do you think the goals of DE should be? What should your child take with them after completing DE? 
C. How well do you think these goals have been (are being) met as a result of the DE program your child participated in?

D. Do you believe the goals are met (better, worse, about the same) by the other means of providing DE (i.e., public/commercial)?

E. What are the most important specific things that should be taught in DE? (Prompts: rules of the road; basic driving skills, e.g. vehicle control (steering, braking); attitudes, safety; decision making)

F. Did (is) your son/daughter learn(ing) them well enough?

IV. EXPECTATIONS -- 15 minutes

A. How do you think your children fare (or will fare) in the driving environment as licensed drivers after completing the DE course?

B. Do (did) you have confidence in your child's abilities to drive upon completion of the course?

C. Were they (will they be) ready to drive independently?

V. SPECIFIC EXPERIENCE WITH PARENT-TAUGHT PROGRAM -- 25 minutes

A. There are several ways teens can take drivers ed. Why did you choose to participate in the Parent-Taught Program?

B. Which option did you use for the course? (Course 101 - 107, see: DPS Approved Parent Taught Driver Ed Course Options) Did you use the Block or Concurrent Method? (see: Block vs. Concurrent Driver Ed Teaching Methods)

C. What materials did you use in teaching the course? Any parts of the total program of instruction that you didn't teach (e.g., used commercial driving school for in-vehicle instruction)?

D. What were (are) the best and worst parts of your experience teaching your child to drive? What are the programs main strengths and weaknesses? How do those positives \& negatives compare with commercial or public school drivers ed? Would you choose parent-taught again?

E. How would you evaluate your own strengths and weaknesses in teaching your child to drive?

F. Are you (will you) continuing your involvement with your teen's driving? How?

VI. CLOSING REMARKS -- 5 minutes 


\section{DISCUSSION GUIDE 3}

\section{Focus Groups on Novice Driver Education \\ Parents of Driver Education Students in Public and Commercial Driver Education Programs}

I. INTRODUCTION-- 15 minutes

A. Welcome and opening comments

- "Thank you for being here. We have an important and, we hope, enjoyable task to undertake during the next $1 \frac{1}{2}$ hours or so."

B. Purpose of the focus group

- "We're here today to talk about young novice drivers and driver education as delivered in Texas, specifically Drivers' Ed as delivered through the public schools, commercial driving schools, and the Texas Parent-Taught Program. We are working under contract with the National Highway Traffic Safety Administration who is interested in the views from various groups involved in teaching our kids to drive."

C. Guidelines/Rules for the group

- "Before we get into the discussion, I want to briefly mention a few logistics and guidelines for our discussion."

- Stress informal, comfortable, atmosphere for discussion, e.g., free to take a rest room break, availability of refreshments.

- Key is active participation. Be open and candid. No right or wrong or unimportant responses.

- Confidentiality - only use first names. Describe audio recording system for data reduction.

- One person talk at a time talk. Speak loudly.

D. Participant and moderator introductions

- Round table - First name, how long been driving, age and gender of teens now or recently taking some form of DE, County or city where teens taking DE, child's current license status (e.g., permit, provisional license, full license).

II. DRIVING SAFETY ATTITUDE EXERCISE-- 5 minutes

(see attached Questionnaire - to be completed by participants)

\section{GENERAL DISCUSSION OF NOVICE DRIVERS AND TEACHING DRIVER} EDUCATION-- 25 minutes

A. What do you think are the primary problems/issues teens face as new drivers?

B. What do you think the goals of DE should be? What should your child take with them after completing DE? 
C. How well do you think these goals have been (are being) met as a result of the DE program your child participated in?

D. Do you believe the goals are met (better, worse, about the same) by the other means of providing DE (i.e., public/commercial or parent-taught)?

E. What are the most important specific things that should be taught in DE? (Prompts: rules of the road; basic driving skills, e.g. vehicle control (steering, braking); attitudes, safety; decision making)

F. Did (is) your son/daughter learn(ing) them well enough?

IV. EXPECTATIONS -- 15 minutes

A. How do you think your children fare (or will fare) in the driving environment as licensed drivers after completing the DE course?

B. Do (did) you have confidence in your child's abilities to drive upon completion of the course?

C. Were they (will they be) ready to drive independently?

V. COMPARISONS AND CONTRASTS AMONG THE MODES OF DRIVER EDUCATION -- 25 minutes

A. There are several ways teens can take drivers ed. Why did you choose (as appropriate: public school DE, commercial driving school?

B. What do you believe are the primary differences between public and commercial driving school programs? Overall, do either produce better novice drivers?

C. Are you familiar with the parent-taught DE Program? Did you consider it as an option for your child?

D. What role do you think parents should play when their teenagers learn to drive?

E. How are/were you involved in your child's learning process? Is it (will it) continuing after licensing?

VI. CLOSING REMARKS -- 5 minutes 


\section{DISCUSSION GUIDE 4}

\section{Focus Groups on Novice Driver Education}

\section{Driver Education Students}

I. INTRODUCTION-- 15 minutes

A. Welcome and opening comments

- "Thank you for being here. We have an important and, we hope, enjoyable task to undertake during the next $1 \frac{1 / 2}{2}$ hours or so."

B. Purpose of the focus group

- "We're here today to talk about young novice drivers and driver education as delivered in Texas, specifically Drivers' Ed as delivered through the public schools, commercial driving schools, and the Texas Parent-Taught Program. We are working under contract with the National Highway Traffic Safety Administration who is interested in the views from various groups involved in teaching teens to drive."

C. Guidelines/Rules for the group

- Before we get into the discussion, I want to briefly mention a few logistics and guidelines for our discussion."

- Stress informal, comfortable, atmosphere for discussion, e.g., free to take a rest room break, availability of refreshments.

- Key is active participation. Be open and candid. No right or wrong or unimportant responses.

- Confidentiality - only use first names. Describe audio recording system for data reduction.

- One person talk at a time talk. Speak loudly.

D. Participant and moderator introductions

- Round table - First name, how long been driving, type of vehicle they drive, where they took DE, current license status (e.g., permit, provisional license, full license).

II. DRIVING SAFETY ATTITUDE EXERCISE-- 5 minutes

(see attached Questionnaire - to be completed by participants)

III. GENERAL DISCUSSION OF PARTICIPANTS’ DE EXPERIENCE-- 25 minutes

A. How would you describe the DE class you took?

B. Share your opinions about the instructor(s).

C. Share your opinions about the course material.

D. Share your opinions about the behind-the-wheel portion. 
E. Share your opinions about the test(s).

IV. CHOICES -- 15 minutes
A. Why did you choose to take (type of DE)?
B. Why do other students you know choose other types of DE?
C. Now that you are finished, what do you think of your choice?
D. What are the advantages of the course you took over others?
E. What are the disadvantages of the course you took over others?

\section{POST-COURSE THOUGHTS—20 minutes}
A. What do you think of your own driving and how well did DE prepare you to drive?
B. Are there any weak areas in your driving ability? If so, what are they?
C. How do you think your driving compares with other teens' driving?
D. What do you think of the licensing requirements?
E. How involved were your parents with your driver training?
F. What advice do you have for a 14- or 15-year-old considering taking DE today?

VI. WRAP-UP -- 10 minutes 


\section{APPENDIX D}

Mail Survey (page size reduced from original)

\section{Follow-Up Postcard}


This page intentionally left blank. 


\section{Texas
Transportation
Institute}

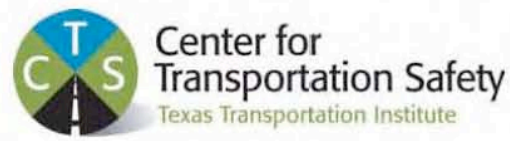

Dear Texas Driver,

You are invited to participate in a survey of your opinions about driver education and your driving experiences and attitudes. The Texas Transportation Institute at Texas A\&M University is conducting a survey of drivers who are taking or have completed a driver education course since 2003 . The information you share with us will be used to evaluate driver education in Texas and to identify both the good and bad driving experiences young people have had.

In Texas, there are three different ways to take driver education: at your school, at a commercial driving school, or from parents, grandparents or guardians under the Texas Parent Taught Driver Education Program. Surveys have been mailed to students who participated in all three types of driver education.

You are among 5,000 young drivers, randomly selected from almost 190,000 young people, invited to participate in this survey. We will give the Texas Department of Public Safety (DPS) a copy of the report that we will write about the survey, but the report will not include any information that could identify you. It is very important for you to know that the DPS is not conducting this survey, will not see anyone's individual survey responses, and will not even know whether you received a survey or if you completed it. The report will be made available to other organizations and individuals in Texas and across the United States who are interested in driver education and driving safety. However, we will not give anyone information that could identify you. The information we used to contact you will be destroyed as soon as the survey project is finished.

We hope you will fill out the survey as carefully and honestly as you can and mail it back to us in the enclosed envelope. The survey should only take you about 15 minutes. The information you and other young drivers provide will be used to help improve driver education in Texas.

Your participation in this survey is voluntary and we are not offering you any personal benefits for completing the survey. Additionally, there is no penalty if you choose not to participate.

Please help us by completing the survey now.

Thank you for your participation, and best wishes for good driving in Texas.

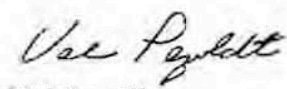

Val Pezoldt

Project Director

Texas Transportation Institute

The Texas A\&M University System

College Station, Texas 77843-3135

This research has been reviewed and approved by the Institutional Review Board - Human Subjects in Research, Texas A\&M University. For research-related problems or questions regarding subjects' rights, the Institutional Review Board may be contacted through Ms. Angelia Raines, Director of Research Compliance, Office of the Vice President for Research, at (979) 458-4067 (araines@vprmail.tamu.edu). 
2

For most of the survey questions, you only need to place an " $X$ " in the box next to the best answer. For most of these, please check only ONE box. A few items will indicate that more than one box can be marked.

Some items ask for dates. Please be as accurate as you can in providing the month, day and year, but if you are not sure, enter your best estimate.

Some other items provide space for a BRIEF written description. Please print clearly.

Depending on your answer to some questions, we will ask you to skip some items.

Remember:

NO ONE will know how you answered. Please answer as honestly as you can.

1. Are you: $\square$ Male $\square$ Female

2. Please tell us your birth date.

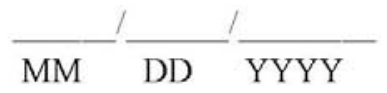

3. Are you now, or were you, a home-schooled student for high school? $\square$ Yes $\square$ No

4. What is the highest educational level completed by your parent (or guardian) who went farthest in school?

Did not graduate from high school

Graduated from high school

Took some college courses

Graduated from a community or junior college

$\square$ Graduated from a four year college or university

$\square$ Has a professional or advanced degree (for example, Masters degree, Ph.D, MD, etc.)

5. When did you get each of the three types of driver license below? Check "Not yet" for any of the licenses you have not yet gotten. Enter the Month and Year you received any of the licenses that have been issued to you.

Learner's or instruction permit (also called Graduated Drivers License Phase One)

Provisional License (Graduated Drivers License Phase Two)

Unrestricted License

Not yet MM YYYY

6. How many times did you take the traffic law and highway sign test (sometimes called the "rules of the road" test) for getting your learner's permit before you passed?

Have not taken the test yet

$\square$ Passed the test on the first try

$\square$ Took the test twice

Took the test three or more times 
7. If you now have a provisional or unrestricted license (any license after the instruction permit), did you take an in-vehicle driving test given by the Texas Department of Public Safety? Yes No Please skip - Do not count a DPS test for a motorcycle license to item 9

8. If Yes, how many times did you take the test before you passed?

Passed on the first try

Twice

Three or more times

9. Are you taking a driver education course now?

Yes (Please answer 9a)

No (Please answer 9b)

9a. Are you: (mark one or both choices, then skip to item \#10)

Taking the classroom part now

Taking the behind-the-wheel part now

9b. Have you completed a driver education course?

Yes, completed both classroom and behind-the-wheel.

When did you finish? Month Year (Please continue with item 10)

No, have not yet started either the classroom or behind the wheel parts of DE

(Thanks, you are done with the Survey, Please mail it back in the envelope provided)

10. What type of driver education course are you taking or did you take?

$\square$ A Parent-taught Driver Education Program course

(Continue to item 11)

From a commercial driving school (Skip to item 13)

At the high school you attend(ed) (Skip to item 13)

A combination of the above (Skip to item 13)

Please describe:

11. If you took a Parent-taught Driver Education Program course, who was your primary "parent" teacher?

Father

Mother

Grandparent

Guardian

Other: Who? 
12. Which Parent-taught course did you take?

Course 101: The Model Program Course, using the Texas Driver and Traffic Safety Education Master Curriculum Guide.

Course 102: National Driver Training Institute, using either the computer based training version provided on CD ROM or the textbook Help for the Teenager Who Wants to Drive. Course 103: Driver Ed in a Box, using either the computer based training version provided on CD ROM or the textbook Driver Ed in a Box.

Course 104: Curb Buster, using the textbook Drive Right.

$\square$ Course 105: Driver Ed at Home, using the textbook Responsible Driving.

Course 106: Texas Driver and Traffic Safety Education Association, using the textbook Texas Traffic Safety Education Student Manual.

Course 107: Virtual Drive of Texas, using the computer based training version provided on CD ROM, "Virtual Drive of Texas."

$\square$ I am not sure which course it is, but it used CDs and the computer.

$\square$ I am not sure which course it is, but the course did not use CDs and the computer.

13. What is the main reason you chose the type of driver ed course you are now taking or have completed? (Please mark at least one, but no more than 3 choices)

$\square$ Cost

$\square$ Scheduling

$\square$ Parent's decision

$\square$ Only option available

$\square$ Wanted to be with friends

$\square$ Best course available

Other, please state:

14. If you have completed or are now taking driver ed, indicate how much you agree or disagree with each of the statements below about the driver education course you took or are now taking. (Check one box in each row)

Answer questions about instructors for those who taught most often. If you were parent taught, answer questions about the parent who taught you most of the time.

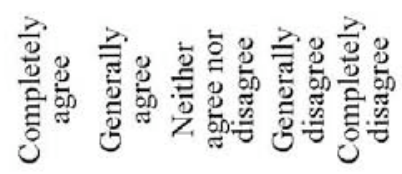

If I had not taken any driver education, I think I would have had more accidents.

I would be as good a driver as I am, even if I had not taken any driver education.

Driver education helped me be a more cautious driver. 
14. If you have completed or are now taking driver ed, indicate how much you agree or disagree with each of the statements below about the driver education course you took or are now taking. (Check one box in each row)

Answer questions about instructors for those who taught most often. If you were parent taught, answer questions about the parent who taught you most of the time.

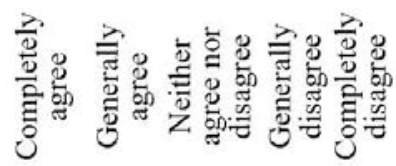

Driver education increased my driving confidence.

I think the driver education program I took is valuable for training new drivers.

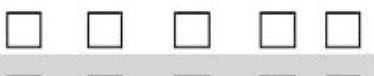

Compared to what I knew about driving before I took the course, I

know a lot more now.

I think that young drivers who take the driver education course I

did are more skilled than other young drivers who did not.

The course I took prepared me very well to begin driving.

If I knew someone who was planning to get a driver's license soon,

I would recommend the same kind of driver education I took.

The classroom teacher seemed to care about whether the students learned the material.

I enjoyed going to driver education.

The classroom teacher knew the subject matter.

The teacher was prepared for class.

The classroom teacher satisfactorily answered questions.

The classroom teacher seemed to think the classroom part of driver education is more important than the driving part.

The classroom teacher was a better-than-average teacher.

The instructor provided a good combination of lecture and

discussion.

The behind-the-wheel part of the driver education class was the most enjoyable.

The behind-the-wheel instructor was a better-than-average teacher.

The behind-the-wheel instructor was genuinely interested in having me learn to drive.

The behind-the-wheel instructor asked me to do things in the car before I was ready to do them or before they were explained.

The behind-the-wheel instructor often made me nervous or anxious

while I was driving. 
6

15. How often did you drive under the conditions below during the past year? (Please check one box in each row)

$\begin{gathered}\text { Never or } \\ \text { almost } \\ \text { never }\end{gathered}$
$\begin{aligned} & \text { Less than } \\ & \text { once a } \\ & \text { month }\end{aligned}$
In a small town
In a big city
On 2-lane roads in rural areas
On major divided highways
At night after dark
At night after midnight
With passengers in your
vehicle

16. With regard to skill and safety, how do you rate yourself as a driver compared to most other drivers? (Please check one box in each row)

$\begin{gathered}\text { Well } \\ \text { above } \\ \text { average }\end{gathered}$
$\begin{aligned} & \text { Overall, with regard to driving skill, } \\ & \text { consider myself: }\end{aligned}$
$\begin{aligned} & \text { Overall, in terms of driving safety, I'd rate } \\ & \text { myself: }\end{aligned}$

17. Compared to other drivers, how well do you think you usually perform each of the driving skills listed below? (Please check one box in each row)

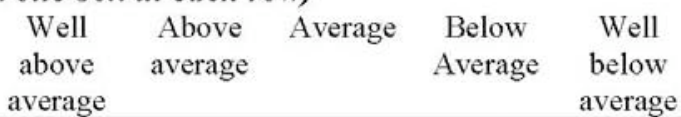

\section{Anticipating hazards}

Driving in an unfamiliar area

Obeying the traffic rules

Preventing a skid

Predicting traffic situations ahead

Driving cautiously

Smooth lane-changing in heavy traffic

Fast reactions

Paying attention to other road users

Driving fast, if necessary
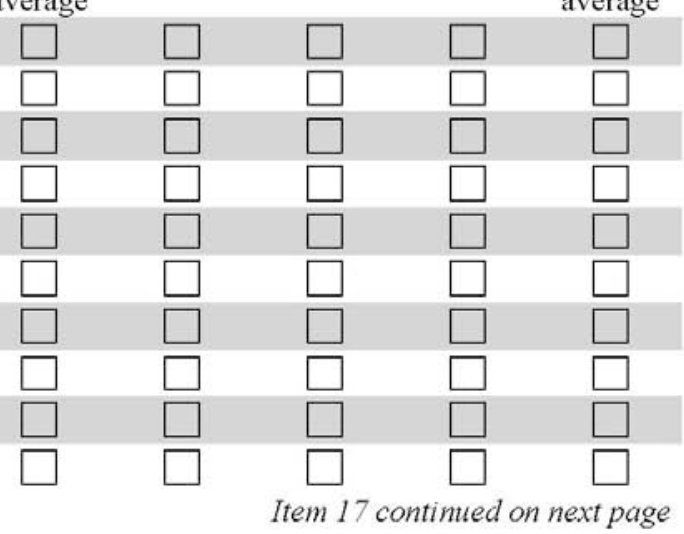
17. Compared to other drivers, how well do you think you usually perform each of the driving skills listed below? (Please check one box in each row)

\begin{tabular}{|c|c|c|c|}
\hline $\begin{array}{l}\text { Well } \\
\text { above } \\
\text { average }\end{array}$ & $\begin{array}{l}\text { Above } \\
\text { average }\end{array}$ & Average & $\begin{array}{c}\text { Below } \\
\text { Average }\end{array}$ \\
\hline
\end{tabular}

Driving in the dark

Controlling the vehicle in a skid

Avoiding tailgating other vehicles

Adjusting speed to the conditions

Passing on a two-lane road

Giving other drivers the right-of-way

Obeying the speed limits

Avoiding unnecessary risks

Tolerating other drivers' mistakes calmly

$\begin{array}{lll}\square & \square & \square \\ \square & \square & \square \\ \square & \square & \square \\ \square & \square & \square \\ \square & \square\end{array}$

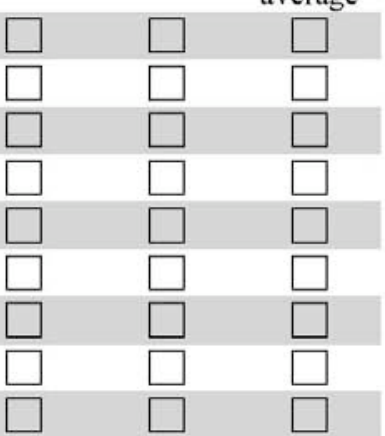

18. Indicate how much you agree or disagree with each of the following statements. (Check one box in each row)

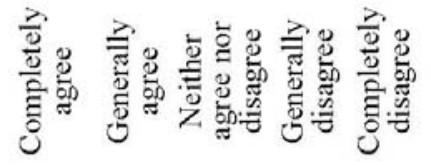

I am confident that I know the rules of the road.

Lots of drivers are careless and I can't do anything about it if they crash into me.

Today's cars are built safe and most have airbags, so going faster or cornering fast is $\mathrm{OK}$.

If my parents have been involved in a lot of traffic accidents, chances are I will be too.

Exceeding the posted speed limit is always dangerous.

I feel like the one place where I am totally in control is in my car.

I live my life for today rather than worrying about the future.

No matter how carefully people drive, eventually they will be involved in an accident.

Avoiding traffic tickets is largely a matter of luck.

Accidents are the result of mistakes made by drivers.

Road rage is usually caused by another driver being inconsiderate or careless.

If friends told me to drive faster, I probably would.

Accidents happen when drivers don't take into consideration the possible actions of other drivers.

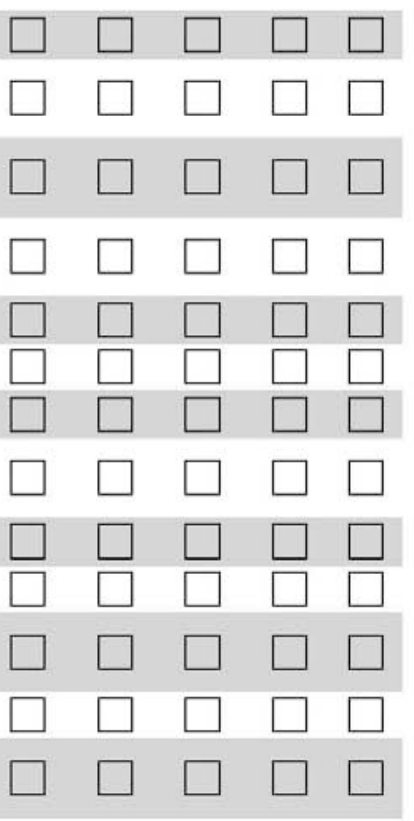

Item 18 continued on next page 
8

18. Indicate how much you agree or disagree with each of the following statements. (Check one box in each row)

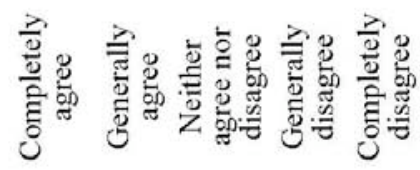

It doesn't really matter if I drive recklessly, because I'm still better than most drivers.

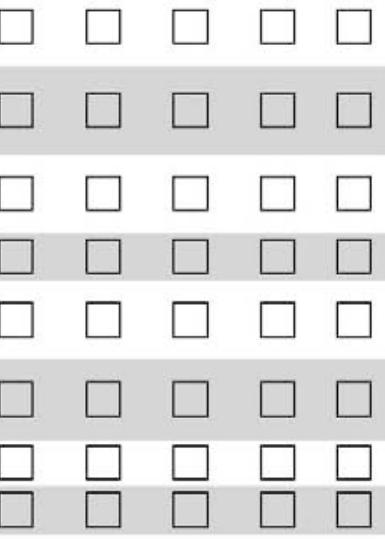

If I were a more cautious driver, some of my friends would laugh at the way I drive.

Accidents are usually due to bad luck or circumstances beyond the driver's control.

Sometimes, when I am upset, I rev the engine higher than normal.

I have found out how my car performs at speeds well above the speed limit.

Accidents occur because drivers don't drive as safely as they should.

I take more driving risks when I am with my friends.

Fast cars are fun to drive.

Your state of mind while driving will not affect the chances of you being involved in an accident.

Drag racing on an abandoned road can be fun to watch.

It is possible to avoid accidents even under the most difficult driving conditions, such as bad weather or heavy traffic.

I like the feeling of accelerating.

It is nice to get ahead of a line of cars all traveling the same speed.

Just following the flow of traffic justifies driving at high speeds.

Driving tricks, such as "four wheel skids" and "laying rubber" are

fun.

If all drivers were attentive and careful, there would be many

fewer accidents.

After an argument, I might drive faster than I should.

On a four-lane highway with a traffic jam, I try to get into the lane that is moving the fastest.

Even with all the thousands of cars on the roads, there is a lot I can do myself to avoid an accident. 
19. During the last year, about how often do you think you committed each of the driving errors or violations listed below - whether or not you were stopped by the police? (Check one box in each row)

In the wrong lane approaching an intersection.

Drive through a yellow traffic signal.

Miss a traffic control, such as a stop sign.

Fail to notice pedestrians when turning.

"Tailgate" the car in front to make its driver speed up or get out of your way.

Drive 10 miles per hour or more above the speed limit.

Accidentally hit something when backing.

Cross an intersection knowing that the light has turned red.

Forget to cancel turn signals after changing lanes.

Fail to check mirrors before changing lanes.

Dislike a particular type of driver and do something to show your hostility.

Underestimate the speed of an oncoming vehicle when turning or passing.

Accidentally turn on the wrong thing (like the windshield wipers instead of the headlights).

Drive when over the blood-alcohol limit.

Get involved in unofficial "races."

Chase after another driver to show anger.

Drive too fast for conditions.

Drive without wearing your seat belt.

Leave too late, and speed to get to destination in time.

Made a "U" turn where it was not allowed

Put the "pedal-to-the-metal" on a deserted road.

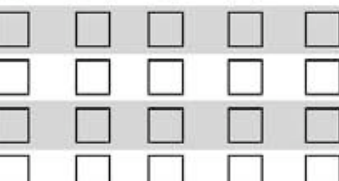


10

20. Have you ever been stopped by the police for any of the violations listed below regardless if you received a ticket or not? (Please check one box in each row)

Disregarded or didn't obey a sign or signal other than a stop sign or
traffic light
Failed to yield or other right of way violation
Unsafe or illegal passing
Failure to signal
Reckless, careless or negligent driving
Seat belt violation
Violation of a driver license provision
Alcohol or drug-related violation
All others that don't fit in above

21. Have you ever been involved in any accidents while you

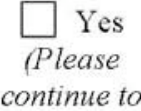

item 22)

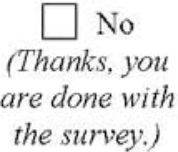

(Thanks, you the survey.)

\section{When did your first accident happen?}

Before you had an instruction permit

While you had an instruction permit

After being issued your provisional license

$\square$ After being issued your full, unrestricted license

$\square$ Other, please explain:

23. Was this a single vehicle accident, or were there other cars and drivers involved? Single vehicle - only your vehicle was in the accident.

One or more other vehicles and their drivers were in this accident.

\section{Who was at fault in your first accident?}

Mostly your fault

$\square$ Mostly an other driver's fault

$\square$ About $50 / 50$

$\square$ All the other driver's fault

$\square$ A pedestrian, animal, or roadway condition was to blame

No one's fault 
25. How serious was the accident for you or others involved? (Check all that apply to your first accident)

No injury to any people and no damage to any vehicles or property

$\square$ Damage to a vehicle or other property

$\square$ At least one person had a minor injury but it did not require medical attention

$\square$ At least one person had an injury requiring medical attention

$\square$ One or more persons died because of the accident.

26. Have you had any other accidents?

Yes: How many? (Please continue to item 27)

No (Thanks, you are done with the survey.)

27. When did your most recent accident happen?

$\square$ Before you had an instruction permit

$\square$ While you had an instruction permit

$\square$ After being issued your provisional license

$\square$ After being issued your full, unrestricted license

Other, please explain:

28. Was this a single vehicle accident, or were there other cars and drivers involved? Single vehicle - only your vehicle was in the accident.

One or more other vehicles and their drivers were in this accident.

\section{Who was at fault?}

Mostly your fault

Mostly an other driver's fault

$\square$ About $50 / 50$

$\square$ All the other driver's fault

$\square$ A pedestrian, animal, or roadway condition was to blame

No one's fault

30. How serious was your most recent accident for you or others involved? (Check all that apply to your most recent accident)

$\square$ No injury to any people and no damage to any vehicles or property

$\square$ Damage to a vehicle or other property

$\square$ At least one person had a minor injury but it did not require medical attention

$\square$ At least one person had an injury requiring medical attention

$\square$ One or more persons died because of the accident. 


\section{Thank you for completing the Survey}

Please fold the survey form in half, put it in the envelope we provided, and mail it back to us today

No Additional Postage is Necessary 


\section{Survey Follow-Up Postcard}

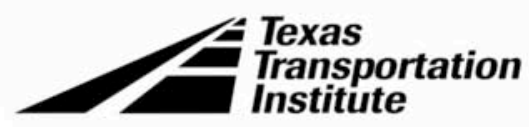

Center for

\section{It's Not Too Late...}

If you haven't already filled out the Driver Ed survey from the Texas Transportation Institute, there is still time. We need as many responses as possible and we would very much appreciate hearing back from you! It's anonymous, it takes about 15 minutes, and it's important.

If you have already sent the survey back, we thank you for participating. If you haven't completed the survey yet, please take a few minutes to fill it out and drop it in the mail.

\section{We Thank You!}


This page intentionally left blank. 

DOT HS 810760

April 2007 